University of Rhode Island

DigitalCommons@URI

Open Access Master's Theses

1997

\title{
Water Column Stratification and Mixing Events in Narragansett Bay During Winter and Spring
}

James Emery Andrews

University of Rhode Island

Follow this and additional works at: https://digitalcommons.uri.edu/theses

\section{Recommended Citation}

Andrews, James Emery, "Water Column Stratification and Mixing Events in Narragansett Bay During Winter and Spring" (1997). Open Access Master's Theses. Paper 1350.

https://digitalcommons.uri.edu/theses/1350

This Thesis is brought to you for free and open access by DigitalCommons@URI. It has been accepted for inclusion in Open Access Master's Theses by an authorized administrator of DigitalCommons@URI. For more information, please contact digitalcommons-group@uri.edu. 
WATER COLUMN STRATIFICATION AND MIXING EVENTS IN NARRAGANSETT BAY DURING WINTER AND SPRING

BY

JAMES EMERY ANDREWS

A THESIS SUBMITTED IN PARTIAL FULFILLMENT OF THE REQUIREMENTS FOR THE DEGREE OF

MASTER OF SCIENCE

IN

CHEMICAL OCEANOGRAPHY

UNIVERSITY OF RHODE ISLAND

1997 


\section{MASTER OF SCIENCE THESIS}

OF

\section{JAMES EMERY ANDREWS}

\section{APPROVED:}

Thesis Committee

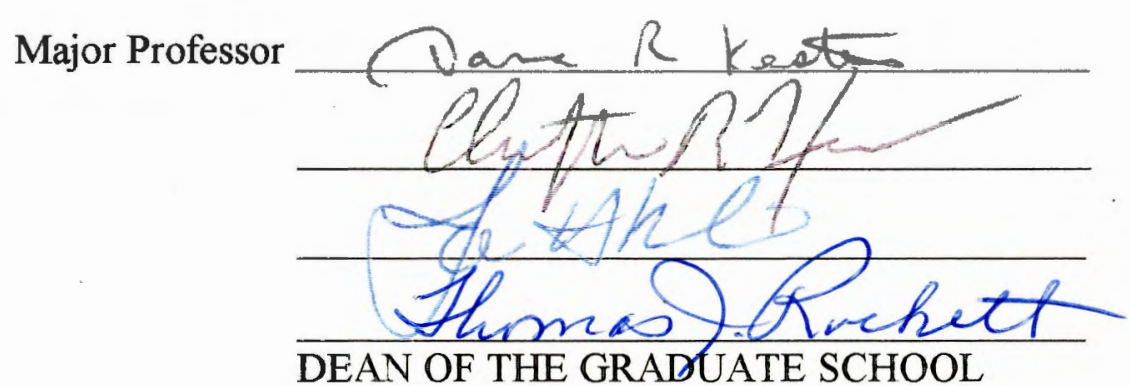

UNIVERSITY OF RHODE ISLAND 


\begin{abstract}
We deployed a buoy in the West Passage of Narragansett Bay, approximately one $\mathrm{km}$ east of Hope Island, within a bathymetric depression of approximately twice the surrounding water depth. The buoy contained an onboard logging computer and had three YSI-600 instruments, each capable of measuring temperature, salinity, dissolved oxygen, $\mathrm{pH}$ and pressure, logging at three different depths in the water column at a 20 minute sampling interval. The first deployment started on 6 January 1997 and lasted 18 days before problems required retrieving the buoy. Additionally, problems with the salinity sensors in this deployment made it impossible to use most of the salinity data. We fixed the salinity and electronic problems, modified the mooring system, and redeployed the buoy on 10 March 1997. We collected data for two months in this second deployment, until 8 May 1997.

Using the temperature, salinity (when available), dissolved oxygen and pressure data from these deployments, we investigated the relationship between physical stratification as determined by density, and oxygen variations. We also used the predicted tides, observed tides from the moored, bottom instrument, wind data from the GSO Pier and from T. F. Green Airport, USGS stream flow data and NOAA-NWS precipitation data from T.F. Green Airport to investigate forcing relationships for the physical stratification and destratification cycles.

Using the difference between the bottom and surface parameters as an index for stratification, we determined that the density related stratification results in increased vertical oxygen gradients, and that a $1 \mathrm{~kg} \mathrm{~m}^{-3}$ difference between surface and bottom in density is accompanied by approximately a $10 \%$ saturation difference over the same depth. The stratification cycles are related to the spring-neap tidal cycles for extended periods, and to strong wind forcing for shorter time scales. Large fresh water inputs can affect stratification as a result of estuarine entrainment whereby the vertical salinity gradient increases. This relationship suggests a linkage between the deep estuarine waters at the buoy station and the surface offshore waters, from Rhode Island Sound.
\end{abstract}




\title{
Acknowledgments
}

\author{
I stand as one upon a rock, \\ Environ'd with a wilderness of sea, \\ Who marks the waxing tide grow wave by wave. \\ -Shakespeare
}

I am greatly indebted to many for their assistance, support, patience, advice and tolerance over the past two years, and could never have accomplished the least fraction of this endeavor without them. First and foremost, I thank God for giving me the strength and ability to work on unraveling one of the many mysteries He has set before us. I thank Professor Dana Kester who got me started on the course and kept me on course, from my first visit to GSO and practically every day since then. No words are adequate to encompass my gratitude and respect. I thank the Coast Guard for allowing me this opportunity, and in particular, the command at the International Ice Patrol, for their flexibility and willingness to let me complete my thesis after my transfer. I'd also like to thank my parents for inspiration and support. In addition, I thank the members of my thesis committee, Professor Cindy Zoski, Professor Chris Kincaid, Professor James Miller and Professor Dana Kester for advice, guidance and suggestions, and for taking the time to help me complete my thesis and course of study. I would like to extend additional thanks to Professor Kincaid and Billy DeLeo, for providing me with the means to acquire $\mathrm{ADCP}$ current data, and their personal contributions of time and effort to help me get those data, and to Professor Kester for on-going support in the testing of the buoy. Thanks to Professor Emeritus John McNeill Sieburth for his personal contributions in time, ingenuity, and diesel fuel for the Melanitta... I like to think the sea-stories were on 
the house. Thanks to Mike Lizotte and Fred Barrieros, and all the staff at Endeco/YSI, Inc., for technical and product support, for being on call so often, for making many trips to GSO and for their support during our several trips to Marion.

Additional personal thanks are extended to Dr. Rob Pockalny for his Unix wizardry in generating output from the ADCP data, and for treating every miniscule request with importance; to the GSO Officer's Mess, Commanders Mike Alfultis and John Sifling, for postgraduate mentoring; to Captain Richard DeSalvo and his crew at Rhode Island Mooring Services for knowing what to do, what we really needed to do it, and helping us get it done safely and properly; to the staff at MERL for a seawater supply, and people at NMFS Narragansett for letting us use their Guildline Salinometer to establish our standards.

I am deeply indebted to my two fellow students, Andrea Magnuson Denny and Wendy Woods, for day-to-day advice, support and assistance. Also, I thank them for providing meteorological and YSI data from the GSO Time-series and from T.F. Green Airport. Others whose advice or opinions were important and helpful include Eric Klos and Dr. Mary Frances Fox, Dr. Nurit Kress, Professor Elijah Swift, Professor John King, and many others.

I am grateful to all the individuals whose steady contributions at GSO help keep projects like this one going, including but not limited to: David Butler and his staff at the Equipment Development Lab, Sylvia DeLuca and the individuals from Maintenance, who always managed to find us a vehicle somehow, Mark Gustafson for providing the boats and maintenance to get to the buoy and get back, John McCarthy and everyone in 
Purchasing for helping us get the bills paid properly, Bob Sand and the Computer Center folks, Christine Solitro and Professor John Merrill in the Student Office, and anyone I may have missed.

Finally, I thank the Lord for the unwavering love and support of my wife, Valerie. I could not have done any of this without her, and would not want to, anyway.

Much water goeth by the mill that the miller knoweth not of.

John Heywood 


\section{Preface}

This thesis is submitted in standard thesis format. Two appendices are included. In Appendix 1, performance specifications and operational data are provided for the YSI-600 and YSI-6000 Water Quality Measurement Instruments. In Appendix 2, all the ADCP transect data are included in five panel images, with a tabular reference for filename and image. 


\section{Table Of Contents}

INTRODUCTION

$\begin{array}{ll}\text { METHODS } & 10\end{array}$

$\begin{array}{lr}\text { Study Area } & 10\end{array}$

January Deployment 13

March Deployment 13

Buoy Description 14

Instrument Calibration $\quad 14$

Rigging and Mooring for First Deployment 15

Mooring Design for Second Deployment 18

$\begin{array}{ll}\text { Buoy Deployment } & 18\end{array}$

ADCP Instrument Data $\quad 21$

ADCP Sampling $\quad 22$

YSI Profiles $\quad 25$

Meteorological Time-Series $\quad 26$

$\begin{array}{lr}\text { RESULTS } & \mathbf{3 0}\end{array}$

January Deployment $\quad 30$

Discrete Profiles

GSO Pier Meteorological Time-Series

$\begin{array}{ll}\text { January Buoy Data } & 38\end{array}$

Temperature $\quad 38$

Salinity and Salinity Correction $\quad 38$

Dissolved Oxygen $\quad 48$

Depth or Pressure

March Buoy Data

Buoy Temperature Data

Raw Salinity Data and Development of Correction Factors $\quad 69$

Raw Dissolved Oxygen Data and Development of Correction Factors $\quad 81$

Buoy Pressure or Depth Data

Discrete Profiles at Buoy Station $\quad 105$

$\begin{array}{lr}\text { Meteorological Data } & 120\end{array}$

ADCP Images $\quad 129$

Morning (Falling) Tide $\quad 130$

Evening (Rising) Tide $\quad 132$

$\begin{array}{ll}\text { Vertical Velocities } & 133\end{array}$

DISCUSSION

January Deployment $\quad 135$

$\begin{array}{ll}\text { March Deployment } & 152\end{array}$

CONCLUSIONS 196 


\section{List of Tables}

Table 1

Table 2

Table 3

Table 4

Table 5

Table A-1
Estimated correction factors for oxygen sensors during January deployment

Calibration and profile-buoy offsets for salinity sensors during March deployment

Calibration and profile-buoy offsets for dissolved Page 87 oxygen sensors during March deployment

ADCP transects and profiles indexed by filename Page 131 and figure number

Stratification and destratification periods in the March deployment, and possible factors involved in causing stratification and destratification

Performance Data for YSI Instruments
Page 51

Page 74

Page 169 to 171

Page 200 


\section{List of Figures}

Figure 1

Figure 2

Figure 3

Figure 4

Figure 5

Figure 6

Figure 7

Figures $8 a$ and $b$

Figure 9

Figure 10

Figure 11

Figure 12

Figure 13

Figure 14

Figure 15

Figure 16

Figures $17 a$ and $b$

Figures $18 \mathrm{a}$ and $\mathrm{b}$

Figures $19 a$ and $b$

Figures $20 a$ and $b$

Figure 21

Figures 22a and $b$

Figure 23
Bathymetric chart of Narragansett Bay

Page 5

Chart depiction of study area centered on Hope Island

Zoomed view of bathymetry around Hope Island

Drawing of January deployment mooring system

Drawing of March deployment mooring system

Chart depiction of 5 April profiles and ADCP

transects

Comparison of wind data between Green Airport and GSO pier

Profiles from 24 January and 31 January at buoy station

January Meteorological Data from GSO Pier

Temperature data from buoy for January

deployment

Uncorrected data from salinity sensors for January

deployment

Salinity sensor response over range of temperatures

Corrected buoy salinity data

Uncorrected dissolved oxygen buoy data from

January deployment

Corrected buoy dissolved oxygen data for January

deployment

Pressure readings from the three buoy YSI-600's

during January deployment

Temperature from three buoy YSI's from 10 March to 8 May

Uncorrected salinity from buoy for March

deployment

Uncorrected dissolved oxygen from buoy for March deployment

Predicted tides for Newport, RI from 10 March to 8

May

Correction curves for salinity sensors during March deployment

Corrected salinity for three buoy YSI's for March deployment

Temperature, Salinity and Oxygen at three depths on 5 April 1997. Sampling is at once per five minutes from $06: 40$ to $18: 00$
Page 8

Page 12

Page 17

Page 20

Page 24

Page 29

Page 33 and 34

Page 37

Page 40

Page 42

Page 45

Page 47

Page 50

Page 55

Page 57

Page 61 and 62

Page 64 and 65

Page 66 and 67

Page 71 and 72

Page 77

Page 79 and 80

Page 83 
Figure 24

Figure 25

Figures 26a and b

Figure 27a and $b$

Figure 28

Figure 29

Figures $30 a$ and $b$

Figure 31

Figure 32

Figure 33

Figure 34

Figure 35

Figure 36

Figures $37 \mathrm{a}$ and $\mathrm{b}$

Figures 38a and $b$

Figure 39

Figure 40

Figure 41

Figure 42

Figure 43

Figure 44

Figure 45

Figure 46
Dissolved oxygen at surface, middle and bottom on 5 April showing drifted values and corrected values Correction curves for oxygen sensors during March deployment

Corrected dissolved oxygen data for three buoy

YSI's during March deployment

Uncorrected pressure data for three buoy YSI's during March deployment

Raw pressure from three buoy YSI's against $\Delta T$ in days

Corrected pressure data for three buoy YSI's during March deployment

Observed tidal signal, bottom pressure minus

surface pressure, and predicted tides for Newport,

RI from 10 March to 8 May.

Profile from 24 March at 13:40

Profile 2 from 5 April at noon

Profile 5 from 5 April at 14:15

Profile 7 from 5 April at 15:30

Profile from 22 April at 10:45

Profile from 8 May at 17:00

Wind speed and direction from time-series at GSO

Pier, with gaps filled by Green Airport data

Histograms of wind speed and wind direction for March deployment

USGS stream flow data for the Blackstone River

from Woonsocket, $\mathrm{RI}$ and precipitation data from

NOAA from Green Airport

Temperature from January 1997, showing wellstirred and isothermal periods

Thermal stratification and tide height versus time in January

Temperature, predicted tide and wind speed and direction, 16 to 17 January 1997

Bottom temperature and tide height between 6 January and 19 January

Oxygen gradient and tide height versus time in January

Stream flow for the Blackstone River and daily precipitation averages for T.F. Green Airport, January deployment

Surface and bottom salinity during an incremental destratification, plotted with tide height
Page 85

Page 89

Page 91

Page 95 and 96

Page 99

Page 101

Page 103 and

104

Page 108

Page 110

Page 112

Page 115

Page 117

Page 119

Page 122 and

123

Page 125

Page 128

Page 137

Page 139

Page 141

Page 144

Page 148

Page 151

Page 157 
Figures $47 \mathrm{a}$ and $\mathrm{b}$ Density and dissolved oxygen at three depths, March deployment

Figure 48 Bottom salinity and bottom oxygen, 9 April to 8 May, 1997

Figures $49 \mathrm{a}$ and $\mathrm{b}$ Density stratification and a scaled oxygen gradient versus time, March deployment. Plotted with predicted tide heights for Newport, RI

Figure 50

Figure 51

Figure 52

Figure 53

Figures 54a through $54 \mathrm{f}$

Figure 55

Figure 56

Figures A-1 through A-26
Salinity at three depths, observed tide height, and 24-hr moving average of tide height from 11 April to 20 April 1997

Wind speed and direction from 11 April to 20 April Page 177 1997

T-S Plots for surface, mid-depth and bottom instruments from 11 April to 20 April 1997

Dissolved Oxygen at three depths, and observed tide height from 11 April to 20 April 1997

Extracted ADCP sections based on hours after slack high water, zonally across the hole.

Predicted and observed tide height at the buoy station on 5 April 1997

Sketch of surface and bottom current structure in the vicinity of Hope Island approximately one to two hours before low water

Extracted images of ADCP flow magnitude and direction for transects across the Hope Is. Trough

Page 182
Page 179

Page 159 and

160

Page 164

Page 166 and 167

Page 174

Page 185 to

190

Page 192

Page 195

Page 204 to 228 


\section{Introduction}

In the water column, stratification due to a vertical density gradient may be established through modification of the surface salinity due to rainfall and riverine outflow (Hansen and Rattray 1966), or through modification of the surface temperature due to solar heating (Simpson and Bowers 1984). A result of this increased stratification is that vertical mixing is inhibited (Grasshoff 1975; Waldichuk 1984). Further, water trapped in bathymetric depressions may be likewise inhibited from horizontal mixing and advection (Kuo and Park 1992; Largier, et al. 1992). Such isolated water may be subject to notable changes in the concentration of dissolved gases such as oxygen and carbon dioxide due to respiration, the ongoing downward flux and decompositon of organic matter, and interaction with the sediments (Skirrow 1975). Water column stratification can also be a factor in primary productivity (Frenette, et al. 1994; Haas, et al. 1980; Peeters, et al. 1995; Rasmussen 1995) and it limits the amount of air-sea exchange (Downing and Truesdale 1955; Liss 1973; Waldichuk 1984). Three mechanisms which serve to reduce the level of stratification are tidal stirring (Haas 1977), wind-induced surface mixing (Blumberg and Goodrich 1990; Goodrich, et al. 1987), and convective overturning (Stanley and Nixon 1992; Lund-Hansen, et al. 1996; Simpson and Rippeth 1993; Simpson and Bowers 1984).

A great deal of effort has been devoted to studying chemical effects of stratification in large anoxic basins such as the Black Sea (Brewer, et al. 1970; Brewer and Murray 1973; Spencer and Brewer 1971), in fjord-type systems such as the Baltic Sea (Lund-Hansen, et al. 1996; Rasmussen 1995; Skyum, et al. 1994), at abyssal depths (Craig 1971; Fanning and Pilson 1972), within rivers and in estuaries dominated by 
freshwater-runoff (Anderson and Devol 1973; Peeters, et al. 1995; Prestidge and Taylor 1995; Simpson and Rippeth 1993), and in lakes (Frenette, et al. 1994). Most of these studies have been on seasonal time scales.

It is possible to sample temperature, salinity, dissolved oxygen, and $\mathrm{pH}$ at discrete depths within the water column in real-time, efficiently, rapidly and with excellent repeatability and confidence using commercially available Endeco/YSI, Inc. sensors. The maximum resolution for these instruments is a measurement every four seconds temporally, and vertically, a few centimeters. The character and quantity of measurable parameters allow a more thorough analysis and representation of water column features, and also allow an inference of the relevant dynamics. Temperature and salinity together provide the physical details of the vertical structure; dissolved oxygen and $\mathrm{pH}$ can indicate the in-situ balance between respiration and photosynthesis; and turbidity, when considered with the chemical parameters, may signify the level of productivity at a particular layer in the water column by showing the location of particulates and microbiota. Through a combination of sampling methods including fixed or floating arrays of sensors, sensors towed at a fixed depth, and vertical profiling at particular locations, a thorough analysis of the chemical character of a particular study site in a bay, estuary or river may be performed. The additional consideration of acoustic doppler current profiler (ADCP) data, meteorological data and tidal data can reveal relationships in the dynamics of a particular system, and may allow analysis of the conditions necessary for stratification.

Narragansett Bay has been studied extensively over the years by investigators at the University of Rhode Island's Graduate School of Oceanography (GSO) and other marine programs. Researchers have executed numerous investigations of its physical and 
chemical structure, initially to assess the broad scale structure and circulation (Wehe 1952; Hicks 1953), to investigate chemical and biological constituents (Martin 1965; Smayda 1957 and 1992), and to conduct synoptic and semi-synoptic characterizations of Narragansett Bay (Doering, et al. 1983). Successive studies have involved more fine scale examinations into current structure for modeling (Spaulding 1987; Swanson and Jayko 1987 ) and to assess fine scale variability related to seasonal and annual cycles (Pilson 1985). In many cases, however, it has been physically, financially and computationally difficult to accumulate time-series measurements on the temporal and spatial scales necessary to resolve the many dramatic changes in the Bay which can occur based on meteorological, tidal, and diel cycles, on the order of days to hours. With recentlydeveloped techniques, we now can measure short term changes in the water column on temporal and spatial scales of hours and meters, respectively.

Narragansett Bay is a shallow, flooded plain estuary, with a mean depth of approximately 8.5 meters (Pilson 1985). The bathymetry of the Bay shows that it is characterized by the broad flats and shallows associated with this type of estuary (Figure 1). Typical winter conditions within Narragansett Bay include decreased solar radiation, decreased surface heating, and increased air-sea exchange due to increased wind-stress. The paradigm for the physical structure of Narragansett Bay for winter conditions is that it is vertically well mixed (Pilson 1985). This results from observations that wind speeds and the frequency of storms increase in the winter, compared with summertime, and that Narragansett Bay's relatively shallow depth cause the participation of the entire water column in wind-induced, vertical mixing events (Weisberg 1974). Although Narragansett Bay is frequently generalized as a shallow flooded plain estuary, close inspection of the 
Figure 1. A bathymetric chart of Narragansett Bay, designed from $50 \mathrm{~m}$-grid soundings, formatted and plotted in GMT by Pockalny (1997). The mid- and up-Bay yellow linear sections are dredged shipping channels of about $12.2 \mathrm{~m}(40 \mathrm{ft})$ depth. The Graduate School of Oceanography is denoted by the gold star. 


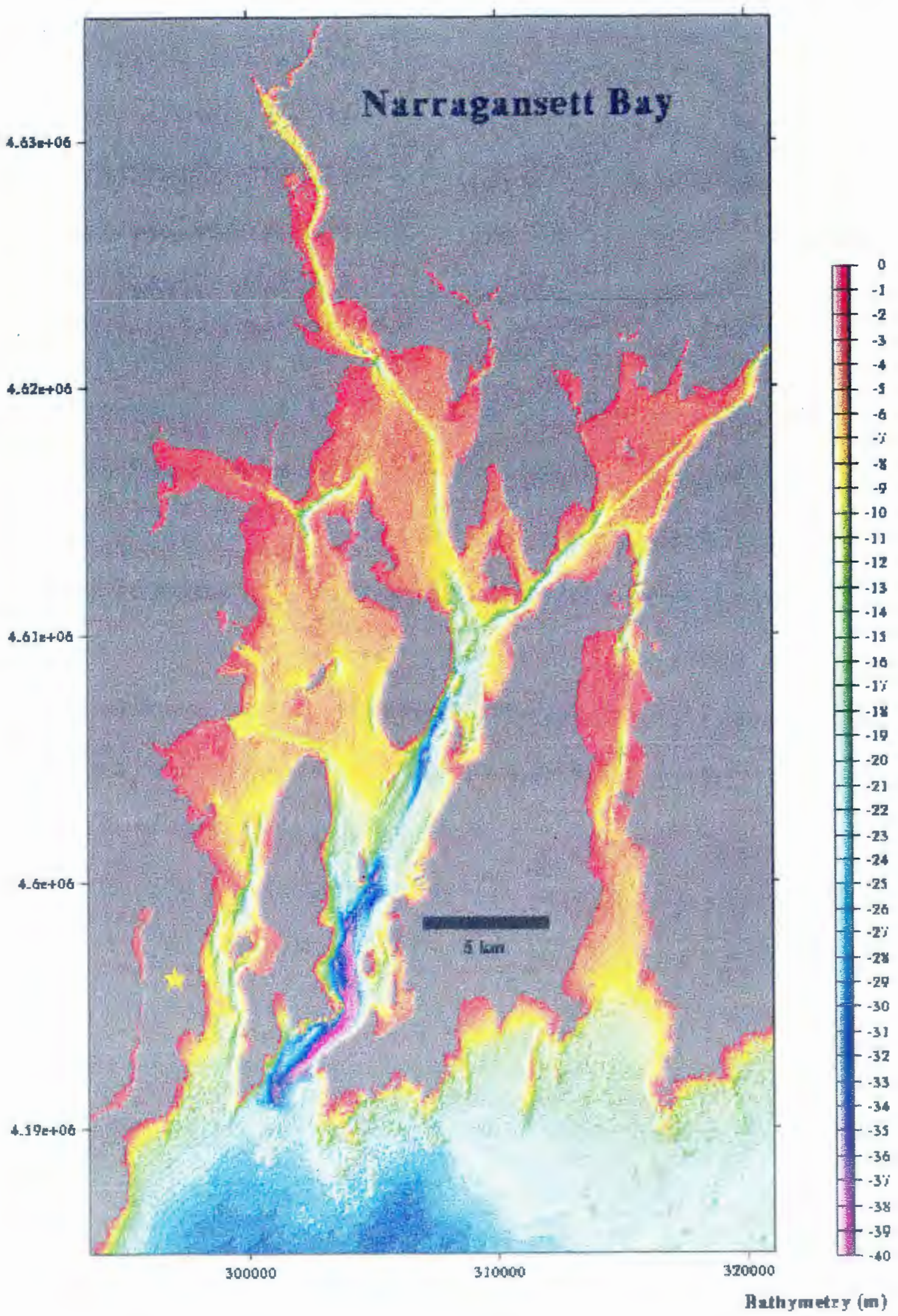


bathymetry of the Bay reveals the presence of deeper areas in both the East and West Passages (Figure 1). Some of these areas, produced during pauses in the most recent glacial retreat, are two to three times the depth of the surrounding water (McMaster, 1984). Considering the importance of the benthos in contributing to the remineralization of nutrients (Olsen, et al. 1981) and in overall carbon utilization (Frithsen 1989), these deeper depressions may play a special role in the ecology of Narragansett Bay, in the development and persistence of the stratified condition, and in the modification of dissolved chemical constituents such as oxygen, carbon dioxide, and redox potential of these waters. Do these deeper areas act as nutrient traps, where debris falling from above is accumulated and oxidized? Do the bottom features modify the currents and vertical mixing such that material from the bottom of the depression is brought to the surface? Does stratification in these areas produce a physical setting for the "seeding" of a phytoplankton bloom? Do the physical bounds of the depression prevent the circulation of the deep waters such that oxygen is removed and $\mathrm{CO}_{2}$ is continually added through the ongoing decomposition and respiration processes?

An analysis of waters in the vicinity of one of these depressions may indicate the importance of mixing, advection and diffusion processes, and may display short term changes between stratified layers as a result of physical, chemical and biological variability. The variability associated with these depressions may be seen to influence biological productivity, especially in colder and less productive winter conditions and in the transition to spring production. The area chosen for this investigation is in the mid-Bay region between Hope and Prudence Island (Figure 2). Though not the deepest of these Narragansett Bay depressions, the Hope Island feature was selected for a number of 
Figure 2. A chart depiction of the study area, centered on Hope Island. The blue-shaded depths are less than 2 meters, the white-shaded areas are from 2 to 7 meters depth, the gray shaded areas are from 7 to 15 meters depth, and the black shaded area is greater than 15 meters depth. The area of study is between Hope and Prudence Islands, and the position of the buoy is denoted by the filled circle. 


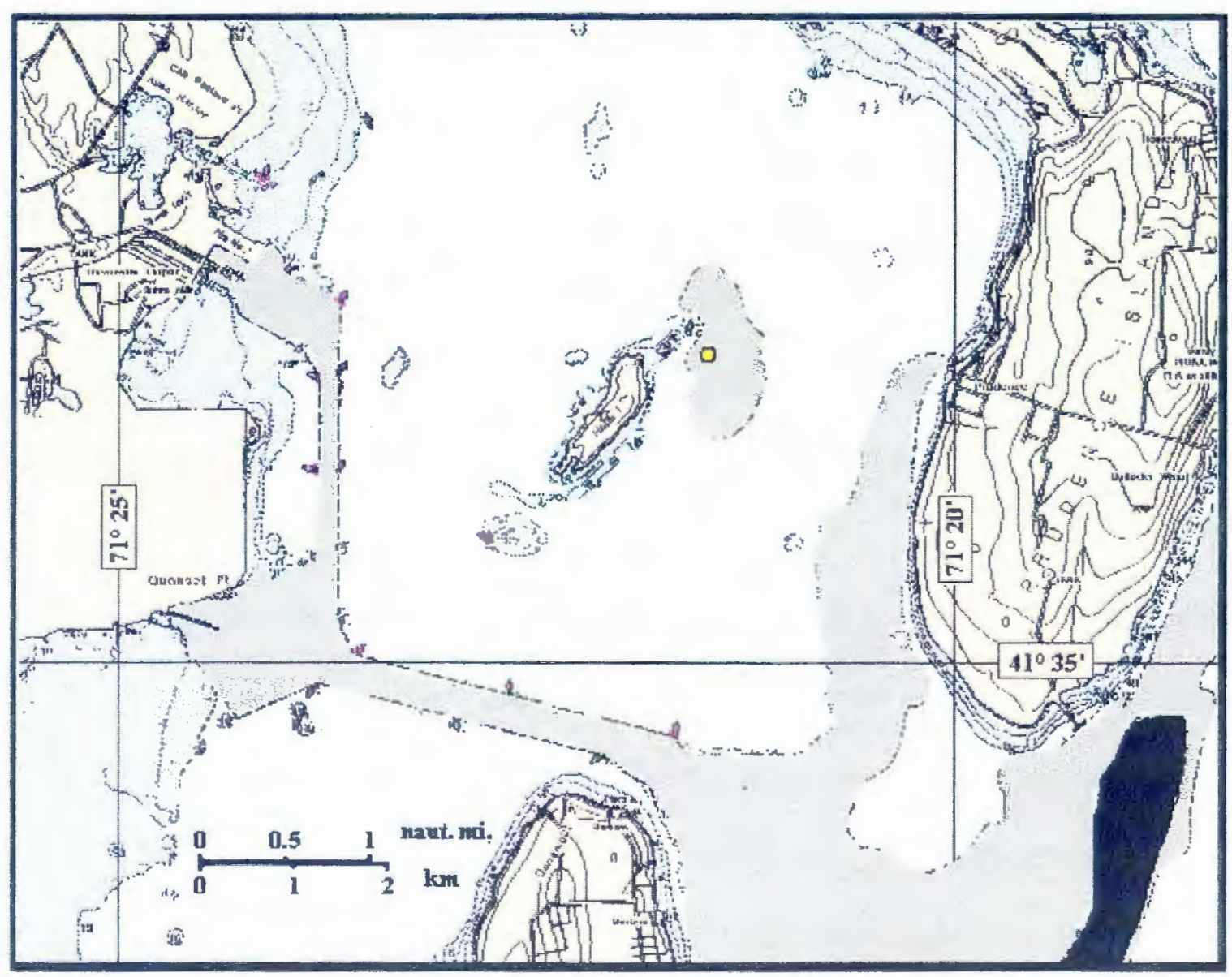


reasons. In a conversation about deep regions of the Bay with Mr. Eric Klos, a GSO scientist with considerable experience in sampling and scuba diving in the Bay, he mentioned that the deep areas of the Bay are of two types: erosional and depositional. The erosional deeps have strong tidal currents that prevent sediment accumulation, whereas the depositional deeps have fine-grain mud sediments (Klos, personal communication, 1995). The Hope Island trough is a depositional depression. It is readily accessible from our boat launch facilities, in Wickford and Allen's Harbor. It is not located in one of the maritime traffic areas within Narragansett Bay, so that deployment of a surface buoy would not pose a hazard to navigation, or to the scientific instruments. Also, it is situated at the juncture between the East and West Passage, and between the upper and lower Bay. Thus, its location in the transition zone between differing areas of the Bay may be important.

Using high resolution time series measurements at the surface, mid-depth, and near the bottom in the area of the Hope Island depression, a time-series of meteorological data from the GSO Dock and T.F. Green Airport, discrete vertical profiles over several days and ADCP data over a tidal cycle in and around this study area, we will determine the level and periodicity of stratification in the late winter/early spring, link these episodes of stratification to forcing mechanisms such as tides and winds, assess the current structure in the vicinity of the study area, and describe how these changes in the physical and current structure can affect the chemistry of Narragansett Bay. 


\section{Methods}

\section{Study Area}

A depression down to about $15.3 \mathrm{~m}(50 \mathrm{ft})$ depth is located $1 \mathrm{~km}$ east of Hope Island in the West Passage of Narragansett Bay (Figure 3). This hole is approximately twice the depth of the surrounding areas and is relatively limited in horizontal extent. Along a north-south axis, the hole is approximately $660-\mathrm{m}$ long, and from east-to-west, across the center of the feature, the hole is about $500-\mathrm{m}$. The south and west slopes, closest to Hope Island, are steeper than those on the north and east. The western slope drops about 7 meters over 160 meters laterally, while the eastern run is about 420 meters for the same drop. The southern slope drops 6 meters over 180 meters laterally, while the northern slope drops 7 meters over about 760 meters laterally. The absolute center of the hole, in the deepest area, is about $80-\mathrm{m}$ long by $50-\mathrm{m}$ wide, with a maximum depth of about 15 meters.

An oceanographic buoy, capable of simultaneously measuring temperature, salinity via conductivity, dissolved oxygen concentration, $\mathrm{pH}$, and in-situ pressure at three depths, was deployed to determine the chemical and physical characteristics of the water column, although we chose not to discuss $\mathrm{pH}$ due to calibration and processing complexities. We chose to deploy the buoy within the hole, close to the western slope of the feature. In the initial deployment, we regularly observed depths from the deepest instrument of up to 15 m (48 to 50 feet) at mean lower low water. However, due to the modification in the instrument mooring in the second deployment, the bottom instrument resided between 12 and $14 \mathrm{~m}$. A twenty-minute time interval was chosen for measurement as a compromise between resolving time-scales of less than one hour and providing a reasonable schedule 
Figure 3. A zoomed view of the bathymetric chart from Pockalny (1997), showing the depths and dimensions of the Hope Island Trough and surrounding seafloor. 


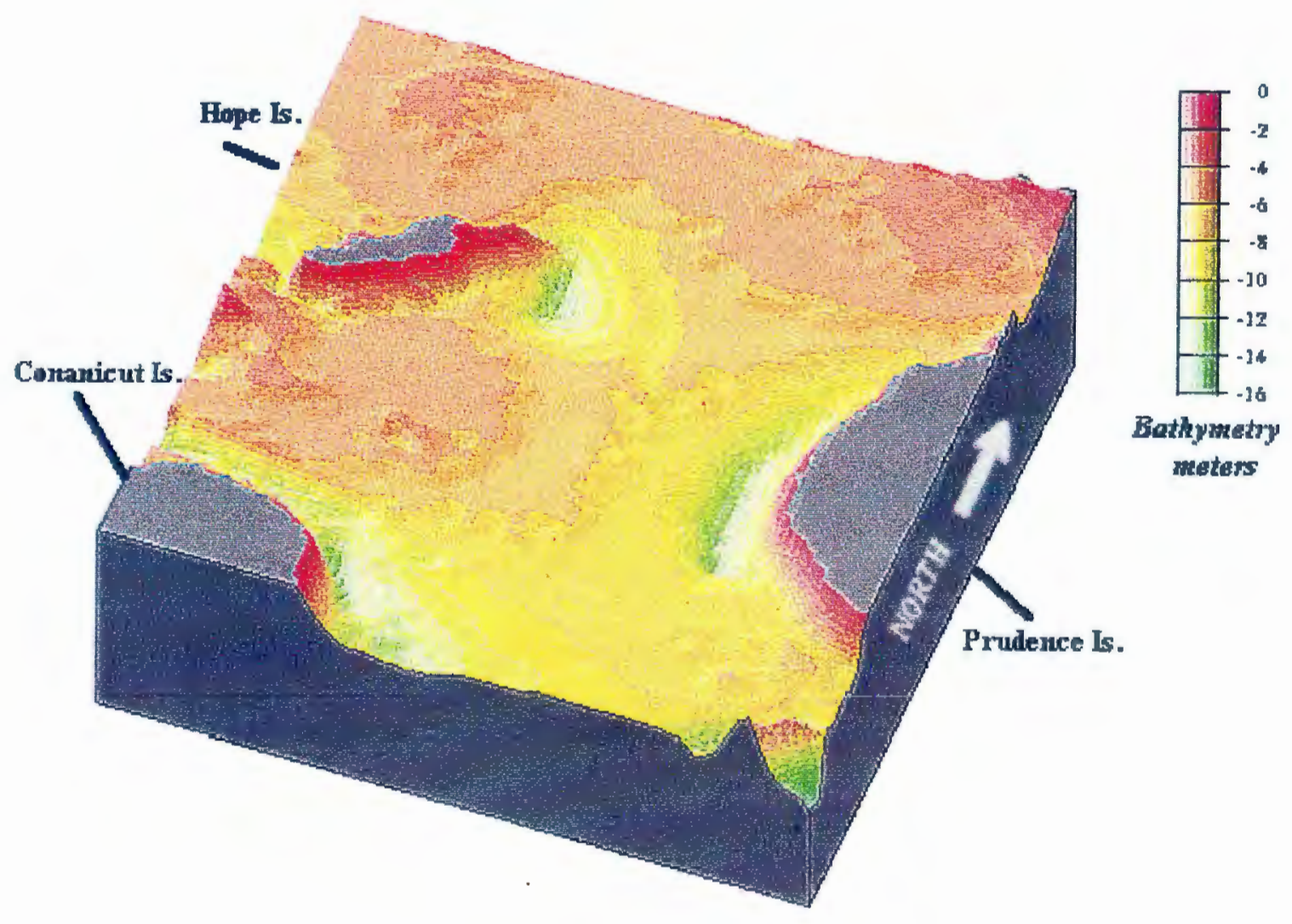


of two to three week intervals for servicing the sensors. The instrument-deployment depths of $0.5-\mathrm{m}, 4.3-\mathrm{m}$ and $12.3-\mathrm{m}$ were chosen to determine differences among the surface, the pycnocline, and the deep waters. The bottom instrument was positioned at a fixed distance above the seafloor, providing a measure of tidal water level variations, a feature not recorded by the floating instruments. Occasional vertical profiling in the vicinity, as well as predictions of tidal currents, and measurement of wind speed and wind direction were used to complement the buoy time-series measurements.

\section{January Deployment}

The initial deployment began 6 January 1997 and lasted for 25 days, but the data file spanned only 18 days. Problems with servicing the instruments and an electronic problem within the buoy's computer, coupled with errors in calibration, caused this first attempt to end sooner than originally planned. In addition, an apparent fouling of the bottom sensor's conductivity cell has made analysis of the data set problematic. The January data provide some useful information on winter-time processes in the Bay. Based on this initial deployment, modifications were made in the buoy computer electrical wiring and in the mooring configuration.

\section{March Deployment}

On 10 March 1997, we redeployed the buoy with a modified instrument mooring, so that we could more easily access and service the instruments on station. The instruments were all recalibrated, the electronic problem was fixed, and the buoy was reset to $\log$ at 20 minute intervals. At $06: 40$ on 5 April 1997, we downloaded the accumulated data in memory and set the logging interval to 5 minutes. Through the following tidal cycle we conducted ADCP transects and stationary time-series in the vicinity of the study 
area with GSO's 20' Maritime Skiff. At about 11:00, the H/Y Melanitta began taking discrete YSI- 6000 profiles within the study area and remained on scene conducting profiles and towed surface transects until approximately 16:00. At 18:00, the buoy's memory was accessed and data were once again downloaded. The buoy was then set to $\log$ at a 20 minute interval once again. On 22 April, we again visited the buoy, downloaded the data, conducted a profile and calibrated all three instruments. The final visit to the buoy for this study was on 8 May, and we again downloaded buoy data and conducted a profile.

\section{Buoy Description}

The buoy consists of a PVC-constructed spar which is foam-filled, and upon which is mounted a solar panel, a flashing beacon, and within which is housed a battery and datalogging computer. This buoy's computer records and stores the water-quality measurements of three SDI-12 compliant instruments. In this study, we outfitted the buoy with three YSI model $600 \mathrm{XL}$ instruments. Each YSI-600XL is capable of measuring temperature, conductivity (with which we determine salinity), dissolved oxygen, $\mathrm{pH}$ and depth. Each is essentially a mini-CTD, mounted in a serial array and capable of acquiring marine environmental data as rapidly as once every three minutes. For our study, we chose a 20 minute interval, to observe hourly-to-daily changes in the water column.

\section{Instrument Calibration}

Each $600 \mathrm{XL}$ required a pre-deployment calibration for all sensors except temperature. The salinity was calibrated using a secondary salinity standard which was determined relative to IAPSO Standard Seawater using a Guildline Salinometer. Dissolved oxygen and depth were calibrated in a moist atmosphere of known barometric 
pressure, and $\mathrm{pH}$ was calibrated using a three-buffer system, allowing independent determination of an empirical Nernst slope, from which we determined actual $\mathrm{pH}$ from a millivolt reading. After calibration the instrument was deployed immediately, to reduce sensor drift. More information regarding the YSI instruments and their calibration may be found in Appendix 1.

\section{Rigging and Mooring for First Deployment}

We used a two point mooring system (Figure 4), with legs of three-eighths inch galvanized steel chain, each 24 meters in length, and each moored by a $91 \mathrm{~kg}$ mushroom anchor. Each leg terminated at surface flotation which were then joined on each side by 4.6 meter lengths of three-eighths inch chain, with the buoy between them. The axis of the mooring was north-south, and an instrument mooring extended perpendicularly to the east. This leg was also 24 meters in length, with a YSI-600XL attached within 3.7 meters of the bottom mooring, a 34-kg grapnel anchor. This attachment location placed the YSI600 approximately $1 \mathrm{~m}$ from the seafloor, considering the chain's catenary when the mooring was deployed. Another YSI-600XL was attached within 3.7 meters of the top of this leg. With catenary, the middle instrument was situated at about 4 meters depth, and the deep instrument at about 14.8 meters. The deep instrument had a $9 \mathrm{~kg}$ flotation buoy tied into the chain at its location to provide buoyancy, and keep it from impacting the bottom. The problem associated with this arrangement was that the middle and deep instruments were difficult to retrieve and service from a small boat, due to the weight of the grapnel and chain. The surface YSI-600XL was mounted in a PVC pipe mounted on the side of the spar buoy with holes for water flow to the sensors. This instrument was about $0.5 \mathrm{~m}$ beneath the sea surface. 
Figure 4. A drawing of the mooring layout for the buoy deployment in January 1997. Flotation bodies are gray-filled, and the position of the YSI-600XL's are denoted by "Y" characters. The mooring leg, a $50 \mathrm{ft}, 3 / 8$ in chain mooring with the $75 \mathrm{lb}$ grapnel, is oriented such that this leg is coming out of the page, along a third axis. 


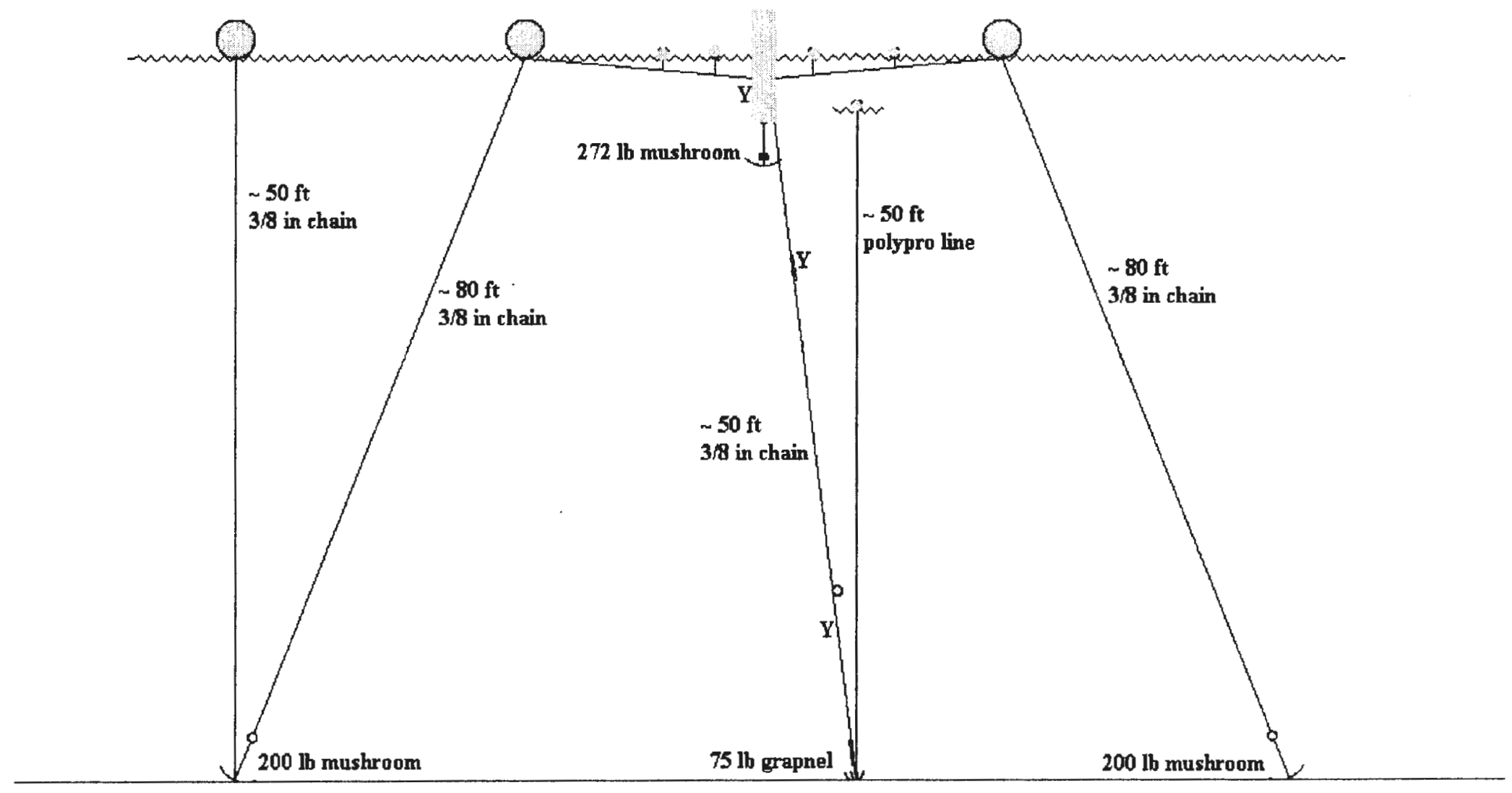

$Y$ indicates position of YSI-600 


\section{Mooring Design for the Second Deployment}

In the subsequent deployment, the chain instrument mooring perpendicular to the two-point buoy mooring was eliminated (Figure 5). Instead, the middle instrument was also fed through the PVC pipe on the side of the spar buoy and was freely suspended by its data cable and a light nylon line to hang at about $4.5 \mathrm{~m}$ depth. The instrument closest to the bottom was rigged away from the buoy itself. Its data cable ran from the buoy, and was affixed by cable ties along the length of the southward-running mooring chain to the southern surface float. The excess data cable was made up in a coil and secured to this surface float. A polypropylene line, with a $15-\mathrm{lb}$ diamond anchor, moored the instrument to the bottom. This instrument was made fast approximately 1 meter above the bottom and an 8-lb float was attached to the line just above the instrument to provide buoyancy, keeping the instrument away from the seafloor. As mentioned earlier, this arrangement allowed us to more easily access the middle and bottom instruments, without the use of heavy lifting equipment. The removal of the instrument leg, however, moved the positioning of the bottom instrument approximately 15 meters to the west, such that it was moored partway up the western slope of the depression at a depth of 11.5 to $14 \mathrm{~m}$ depending on the tide. This depth is still 4 to 5 meters greater than the seafloor that surrounds the depression.

\section{Buoy Deployment}

The initial buoy deployment was performed by Rhode Island Mooring Company (RIMS) on 6 January 1997. Downloading operations were undertaken on 15 January and 24 January, and the buoy was hauled for repairs on 31 January. The subsequent buoy deployment was performed by RIMS on 10 March 1997. Downloading operations were 
Figure 5. A drawing of the mooring layout for the buoy deployment in March 1997. Flotation bodies are gray-filled, and the position of the YSI-600XL's are denoted by "Y" characters. In this layout, the perpendicular mooring leg has been removed and the entire scheme is oriented in only two dimensions. 


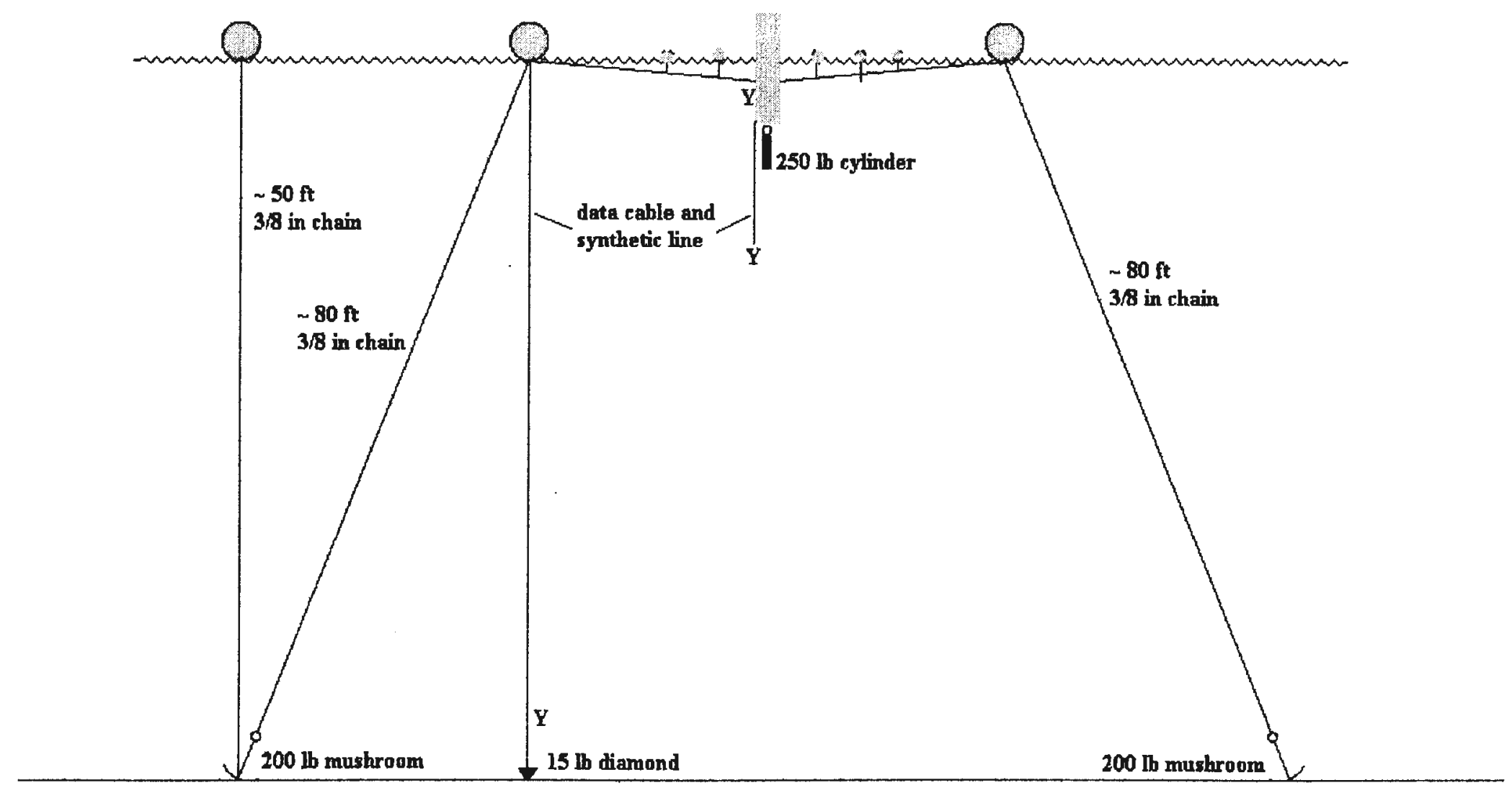

$Y$ indicates position of YSI-600 
undertaken on 24 March, on 5 April, prior to and just after the ADCP field day, on 22 April and on 8 May. The downloading operation required an on-site visitation to the buoy, attachment of a data-cable to the buoy and to a microcomputer, and, depending on the size of the data files, several minutes of connection time. A recent advancement, which has yet to be implemented, is the fitting of a telemetry system in which a cellular phone on the buoy is remotely called and the data is transferred by modem. Downloading operations have been performed primarily on board the Hydrographic Yacht Melanitta, through the generous assistance of Professor Emeritus John Sieburth. The Melanitta is a $7.3 \mathrm{~m}$ (24-ft) Surf Scoter operating from Wickford Cove, RI. It is an inboard diesel, minitrawler outfitted for performing oceanographic surveys in lakes, rivers, estuaries and in coastal waters. In winter, the Melanitta's cabin space and heated interior provided a necessary feature for work in the Bay. However, in the warmer and milder spring and summer months, the GSO 20-ft Maritime Skiff was used due to its higher speed.

\section{ADCP Instrument Data}

The ADCP was provided by Dr. Chris Kincaid and was operated by Mr. Billy DeLeo of the Kincaid Research Group at GSO. The instrument is a broad-band acoustic doppler current profiler produced by RD Instruments of San Diego, CA. The long term accuracy is $0.2 \%$ of the measured velocity, or $0.2 \mathrm{~cm} / \mathrm{s}$. The water-current velocity precision is represented by the statistical uncertainty of the horizontal velocities for a single ping when operating in the normal mode. The precision will increase proportional to the square root of the number of pings averaged together. For our study, we averaged over ensembles of eight pings, and attempted to keep the boat speed below about $3 \mathrm{kts}$.

RD Instruments gives other specification and performance data in its Technical Manual 
(RD Instruments, 1995). It should be noted that the times in the ADCP data files were one hour and two minutes greater than those from the buoy for the 5 April data. The $\mathrm{ADCP}$ data were all gathered with this offset and corrected during extraction and analysis to the correct buoy time.

\section{ADCP Sampling}

In order to evaluate the circulation at all depths entering the study area, we conducted three transects in a single circuit (Figure 6). Transect 1 was followed from west-to-east, south of the depression, for about 0.75 nautical miles (nm). Transect 2 was followed from east-to-west, across the center of the hole, for about $0.5 \mathrm{~nm}$. Transect 3 extended from southwest-to-northeast, at the north end of the hole and was followed for about $0.75 \mathrm{~nm}$. The first circuit was begun at approximately 07:00 and ended just after 08:00. We attempted to conduct all circuits within an hour, and when extra time was available, we conducted time-series measurements of over 50 to 100 ensembles at the buoy site. We conducted six circuits between 07:00 and 12:50, three of which included time-series data, and we continued this sampling regime until the southerly winds began to increase and waves increased to about $0.5 \mathrm{~m}$ wave heights. Between 13:23 and 13:32, we conducted a transect from the south end of the hole to the north end of the hole, however, data quality during our final circuit and in this north-south transect was lower than the earlier circuits due to increased sea-state. We conducted time series measurements at the buoy location from 14:00 until 18:00, for the remainder of our sampling day. For this entire period, the buoy was logging temperature, salinity, dissolved oxygen, $\mathrm{pH}$ and pressure at the three instrument depths at a five-minute sampling interval. Problems with the ADCP data extraction were encountered with one of the files, Transect 
Figure 6. A chart depiction of the transects, profiles and time-series operations undertaken on 5 April. The ADCP transects were performed roughly along the three transect lines, marked by the underscored 1, 2 and 3 characters. The time-series were all performed within 50 meters of the buoy, marked by the yellow-filled circle. The seven YSI-6000 profiles, conducted by the crew on H/Y Melanitta, were performed at the locations of the red, one through seven characters. 


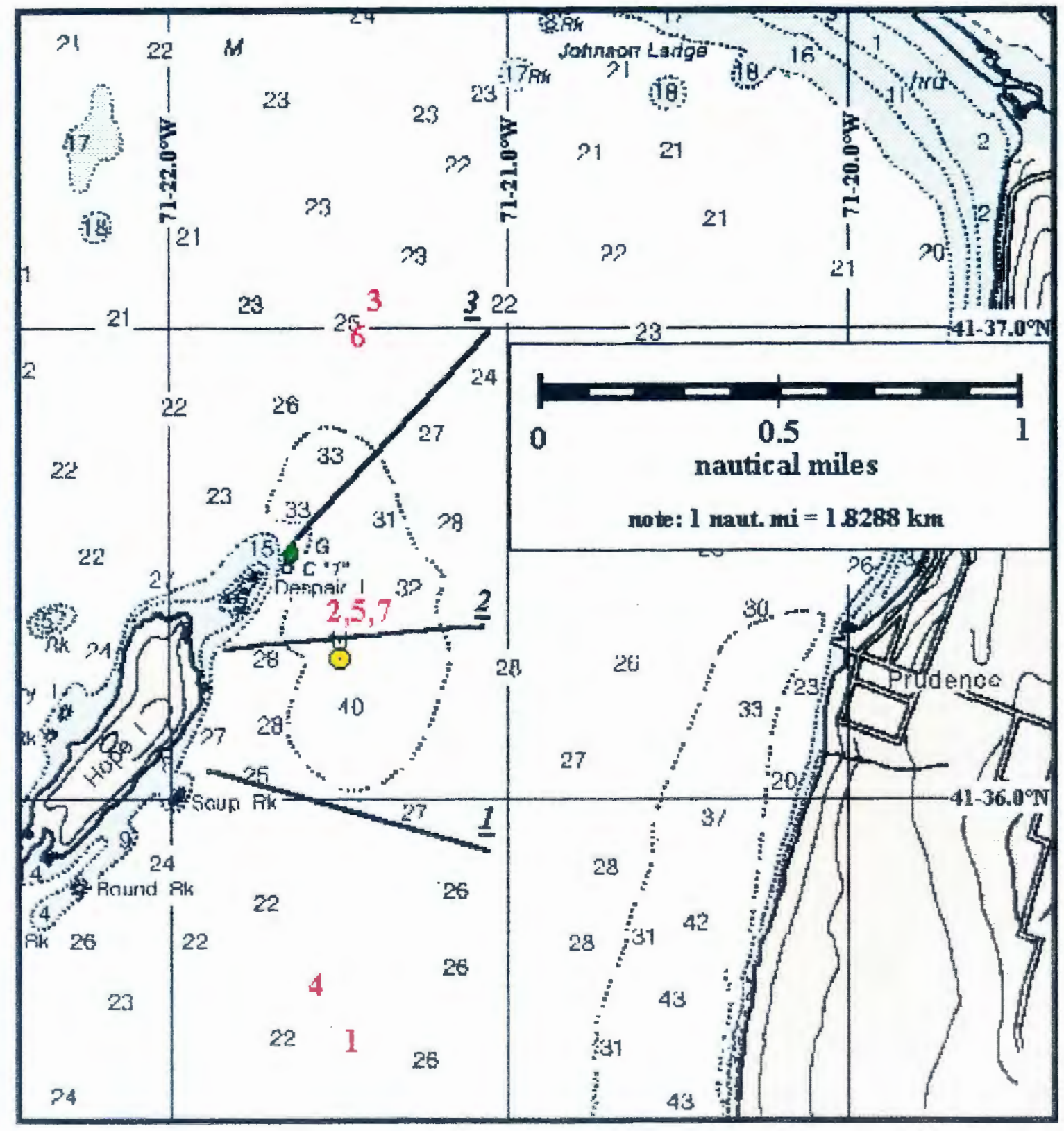


9, however, all other data were extracted with no difficulties. A Unix C-shell written by Dr. Rob Pockalny was used to convert the raw ADCP data files into presentation sheets detailing the horizontal and vertical current structure and converting from ensemble depths and times to actual depths and distances for all transects, and to actual depths and times for time-series stations.

Concurrent with our ADCP work, we conducted discrete vertical profiles and towed surface transects with the YSI-6000 on board the H/Y Melanitta. Overall, seven profiles were taken throughout the study area, along both the longitudinal and zonal axes, and at the buoy station. We used these profiles to verify the data from the buoy, to determine any calibration drift of the buoy instruments' sensors over time since deployment, and to gain a sense of the characteristics of the water masses in the study area.

\section{YSI Profiles}

We attempted to follow a consistent procedure with regards to all vertical profiles taken during this study using the YSI-6000. These profiles were taken at the buoy station on 24 Jamuary, 31 January, 24 March, 5 April, 22 April and 8 May. Profiles north and south of the buoy station were taken on 5 April. We used the profiles to resolve the water quality parameters from less than a meter off the bottom, to the surface in one to two meter intervals. Parameters measured by the YSI-6000 included depth via a stainless steel pressure strain gauge, temperature via a thermistor, conductivity via a four electrode cell, dissolved oxygen via a patented Rapid Pulse Polarographic sensor, $\mathrm{pH}$ via a glass combination electrode, oxidation and reduction potential (ORP) via a platinum tip, two 
electrode system, and turbidity by $90^{\circ}$ optical scattering. More detailed instrumentation data is contained in Appendix 1.

The method for profile measurement was the result of observations concerning the responsiveness of some of the sensors, notably that for dissolved oxygen (Kester and Magnuson, 1994). The YSI-6000 was lowered to the deepest sampling depth, usually within one half to one meter of the bottom, and the sensors were allowed to equilibrate for approximately five minutes. After this period, the instrument was raised to the next sampling depth. Successively sampled depths required only minor equilibration periods of approximately two minutes. We sampled in one to two meter depth intervals toward the surface and continuously monitored the instrument by a laptop computer interface via a 30.5-m (100-ft) data cable. The shortest sampling interval, four seconds, was set for the vertical profiles so that a number of readings were recorded at each depth. The final five readings at a particular depth were then averaged to arrive at a smoothed value for each depth. This smoothing procedure was performed to eliminate microscale variability at a particular depth after the probes had equilibrated, and was performed for all parameters except dissolved oxygen. The longer equilibration time for the teflon membrane on the oxygen sensor required us to use only the last value before the change in depth, without averaging. The membrane is not particularly susceptible to the microscale variability as found in the other probes, but the delay for equilibration increases the accuracy of the measurements.

\section{Meteorological Time-Series}

In addition, we accessed the GSO Pier Meteorological time series, to help ascertain the effects of changes in wind forcing. The meteorological data were taken via 
Sensormetrics ENV-50 modules (air temperature, wind speed, and wind direction). These data were recorded in ten minute intervals, and for comparison were reduced to a 20 minute interval by averaging across three readings, centered at the 20 minute node. This record is continuous from 10 March 1997 until 24 March 1997. There are gaps in the data after this date, between 24 March and 28 March, and again between 1 April and 7 April. During these gaps in the GSO meteorological data, hourly wind data taken from Theodore F. Green State Airport in Warwick, RI, were obtained by Andrea Magnuson and Wendy Woods as part of a long-term time-series monitoring project. These data were interpolated to a 20 minute period. Some overlapping portions of the T. F. Green (PVD) data and the GSO Pier (GSO) data were plotted together and showed good agreement (Figure 7). Therefore, we have produced a data set combining measurements from both sources, to be used for wind-related analyses, which provides data coverage for most of the gaps in each data set. 
Figure 7. A comparison of wind data from the GSO Pier and from T.F. Green Airport in Warwick, RI both interpolated to a twenty minute interval, for a three week period. 


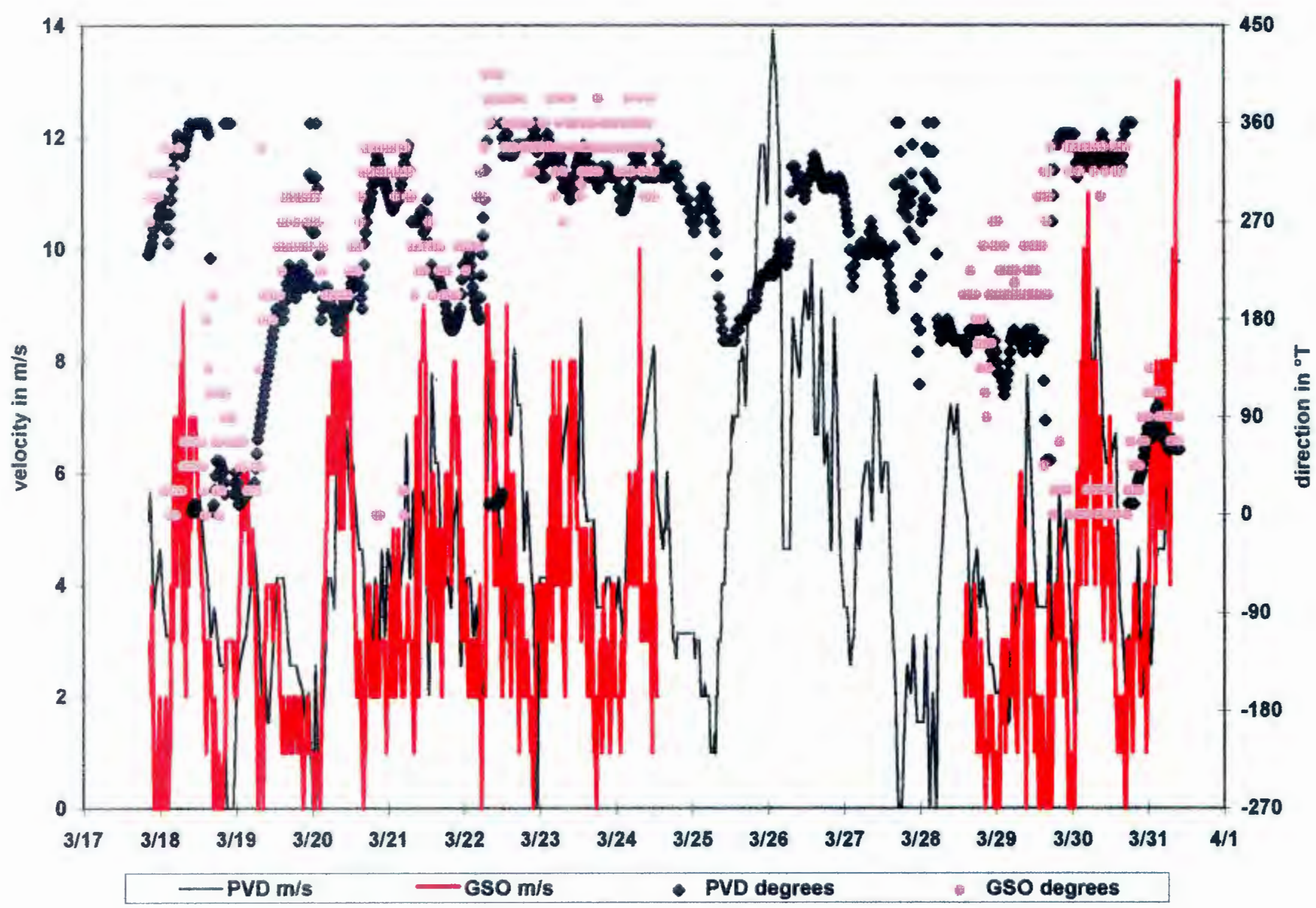




\section{Results}

\section{January Deployment}

From the first deployment, we have a record of the water temperature, salinity, and dissolved oxygen at three different depths as reported by pressure readings from each of the three instruments from 6 January until 24 January 1997 . We will not discuss the $\mathrm{pH}$ data from the buoy in this thesis, however, we hope to include them in a later publication. We also acquired profile data at the buoy station on 24 January and 31 January, via a YSI model 6000 instrument. Each profile reported temperature, salinity, dissolved oxygen, $\mathrm{pH}$, redox potential, and turbidity at depths indicated by a pressure sensor, however, we will show only the data relating to the present work, of temperature, salinity and dissolved oxygen. Problems associated with the initial YSI-600 calibration made interpretation of the salinity records for the middle and bottom instruments difficult. The calibration problem consisted of only partially immersing the conductivity sensor in the secondary seawater standard, so that the instrument was calibrated with an erroneous cell constant. In order to correct this error, we attempted to raise the instrument mooring leg, to remove the instruments, recalibrate them on station and redeploy them on the mooring. Our attempts to raise the mooring, were seen in the buoy data on 15 January, as a broad increase in the oxygen and salinity of the bottom instrument. We were unable to lift the heavy chain and anchor onto the boat, and therefore had to reset the mooring without calibrating either the middle or bottom instrument.

We used temperature as the primary tracer for water stratification, and, using a post-deployment calibration temperature test, were able to derive corrections for the middle and bottom salinities. However, the bottom salinity exhibited an additional drift, 
starting on about 10 January, which made use of the later part of the salinity record impossible. Comparing with the predicted tides for Newport RI and data from a timeseries of meteorological data from the GSO dock, we used temperature and dissolved oxygen data to qualitatively discuss stratification/destratification events for the first deployment, especially within the depression.

\section{Discrete Profiles}

The general structure of the water column for this time of year may be represented from vertical profiles performed at the buoy location on 24 January and 31 January 1997 (Figures $8 \mathrm{a}$ and $8 \mathrm{~b}$ ). We measured temperature, salinity, and dissolved oxygen in \% saturation, at six discrete depths from $0.36 \mathrm{~m}$ to $12.92 \mathrm{~m}$ for 24 January, and eight discrete depths from $0.07 \mathrm{~m}$ to $13.02 \mathrm{~m}$ for 31 January. The 31 January profile showed much larger gradients from the surface to the bottom in practically every parameter, and much lower dissolved oxygen saturation levels, especially at depth. The profile was taken about two hours before high tide, during the neap phase of the lunar period. The 24 January profile was taken between two and three hours after high tide, during a spring phase, and weaker gradients were noted.

The 31 January profile, as well as profiles taken at this location during other times of the year when stratification exists, shows three general characteristics of the water column. The upper $2-3 \mathrm{~m}$ is often uniform in properties with lower salinity than the deeper water. Gradients exist between about 3 and $8 \mathrm{~m}$. The waters beneath $8 \mathrm{~m}$ tend to be fairly uniform in properties. The depth of $8 \mathrm{~m}$ is about that of the seafloor surrounding the Hope Island hole. 
Figures $8 \mathrm{a}$ and $\mathrm{b}$. Data from a YSI-6000 profile performed at the buoy station on 24 January and 31 January 1997. The profile returns temperature, salinity, and dissolved oxygen at discrete depths from approximately one meter from the bottom to less than one meter from the surface. The values representing temperature and salinity at depth are the average of six readings, once every four seconds, after an equilibration waiting period at each depth of between two and five minutes. The values representing oxygen are the final reading after the equilibration waiting period, with no averaging. This procedure was followed for each profile. 


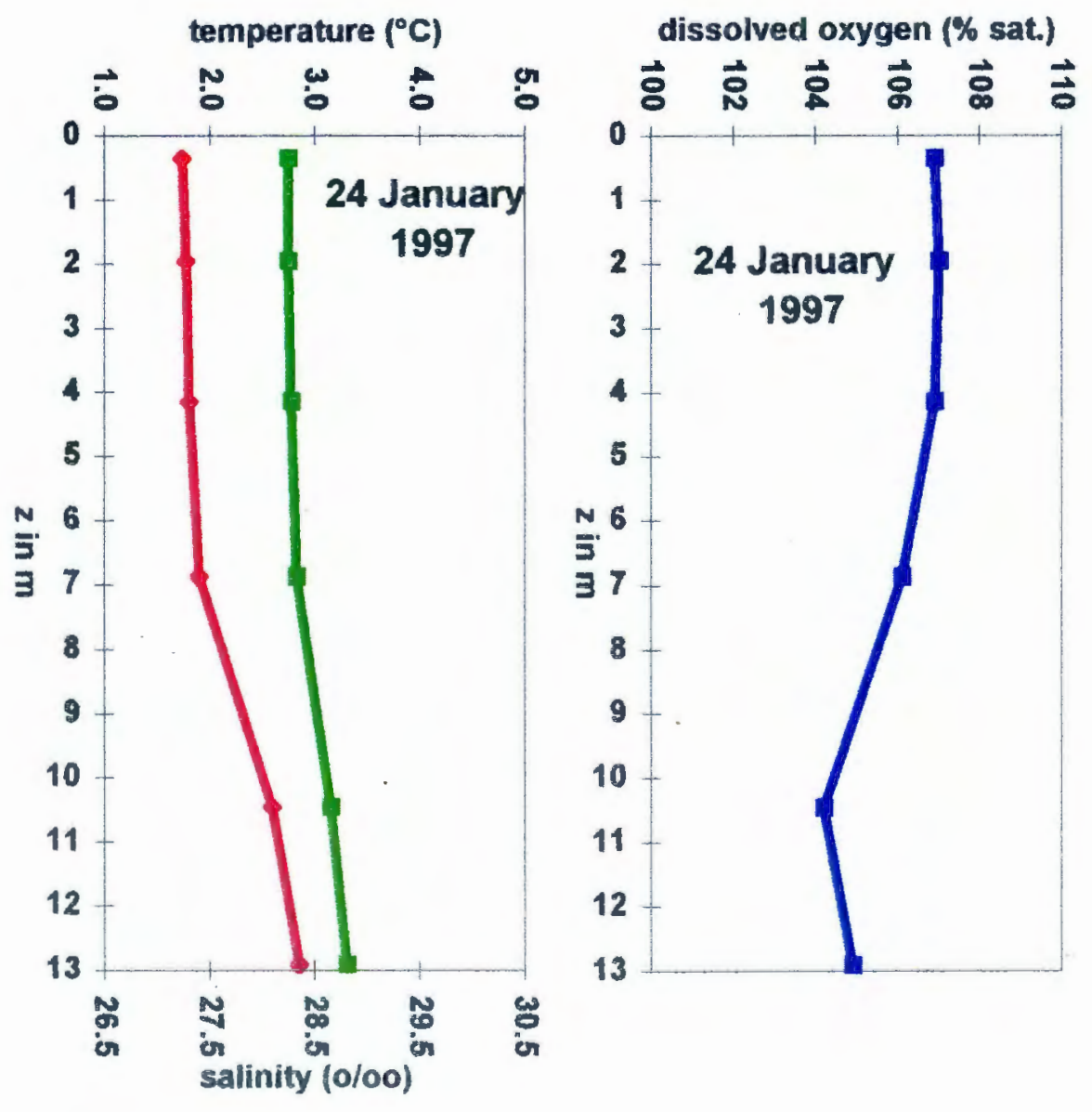




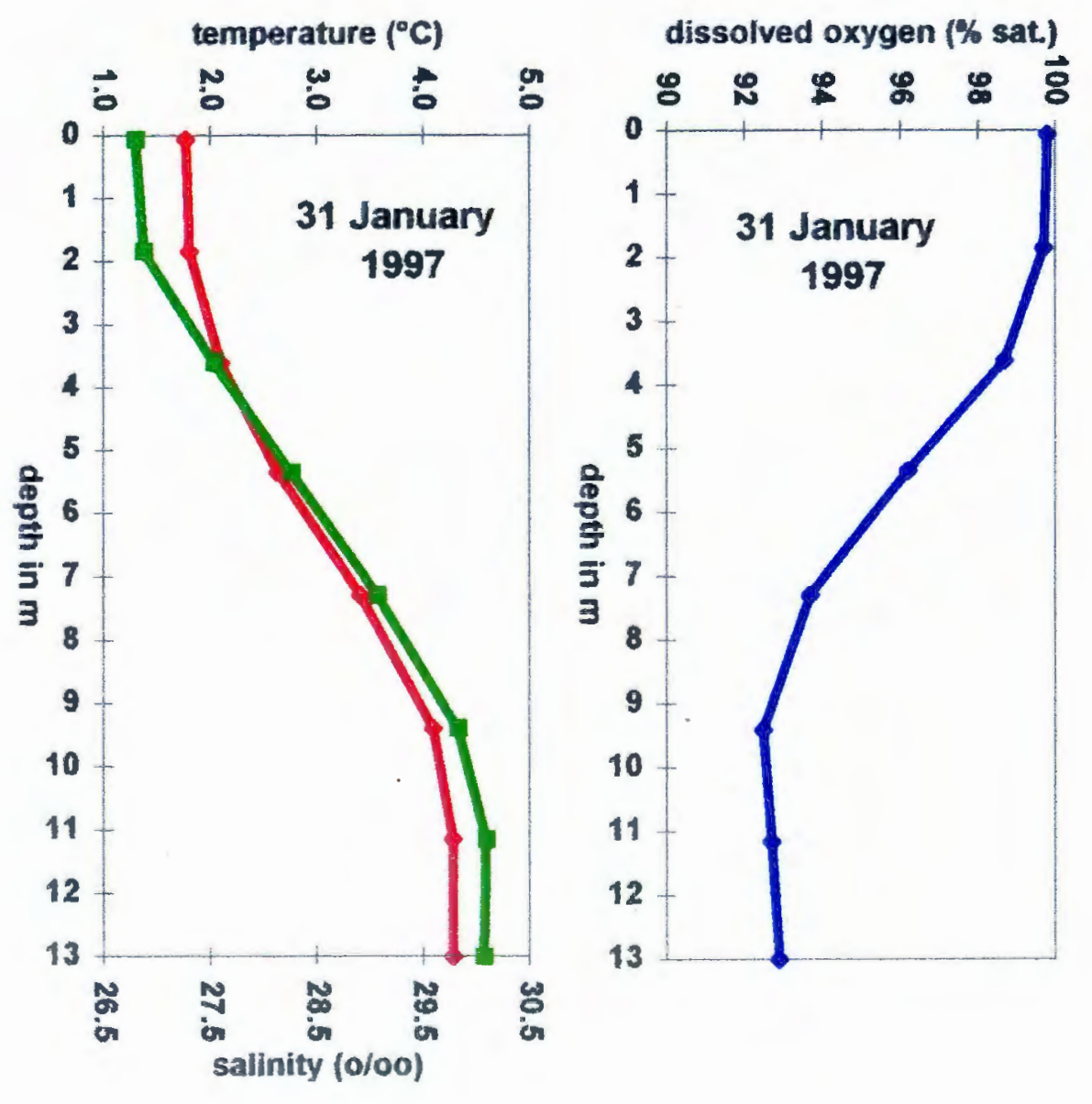




\section{GSO Pier Meteorological Data}

The parameters measured in the time-series of meteorological data being collected at the GSO Pier include air temperature, wind speed and direction, solar radiation, and barometric pressure. We plotted these data over the time span of our buoy deployment (Figure 9). Unfortunately, we experienced a loss of data from midday on 11 January until the evening of 14 January, due to low battery voltage on the meteorological data logger. The recorded data were averaged to match the sampling interval of the buoy data. For the first part of the meteorological record, data were recorded every ten minutes so the averaging was over three values centered on the twenty-minute node. For the second part of the data, ten minute sampling was commenced on five minutes after the hour. In this case, we averaged over four values, two to either side of the twenty-minute node. These data were then plotted for comparison to the buoy data.

The wind data showed several high wind events, greater than 10 meters per second. The directions were variable during the first 4 days of the deployment, were coherent with a passing front on 10 January, and showed alternating bands of variability and invariability from 15-22 January. There were only two days of very low solar radiation. These occurred on 9 January and 16 January. Solar radiation exceeded $550 \mathrm{~W}$ $\mathrm{m}^{-2}$ only once, on 17 January. Barometric pressure showed the passing of several atmospheric fronts during the deployment. There was a broad increase at the end of the record, to values higher than $770 \mathrm{mmHg}$. 
Figure 9. Meteorological data from the GSO Pier Meteorological time-series during the period of the January Buoy Deployment. 

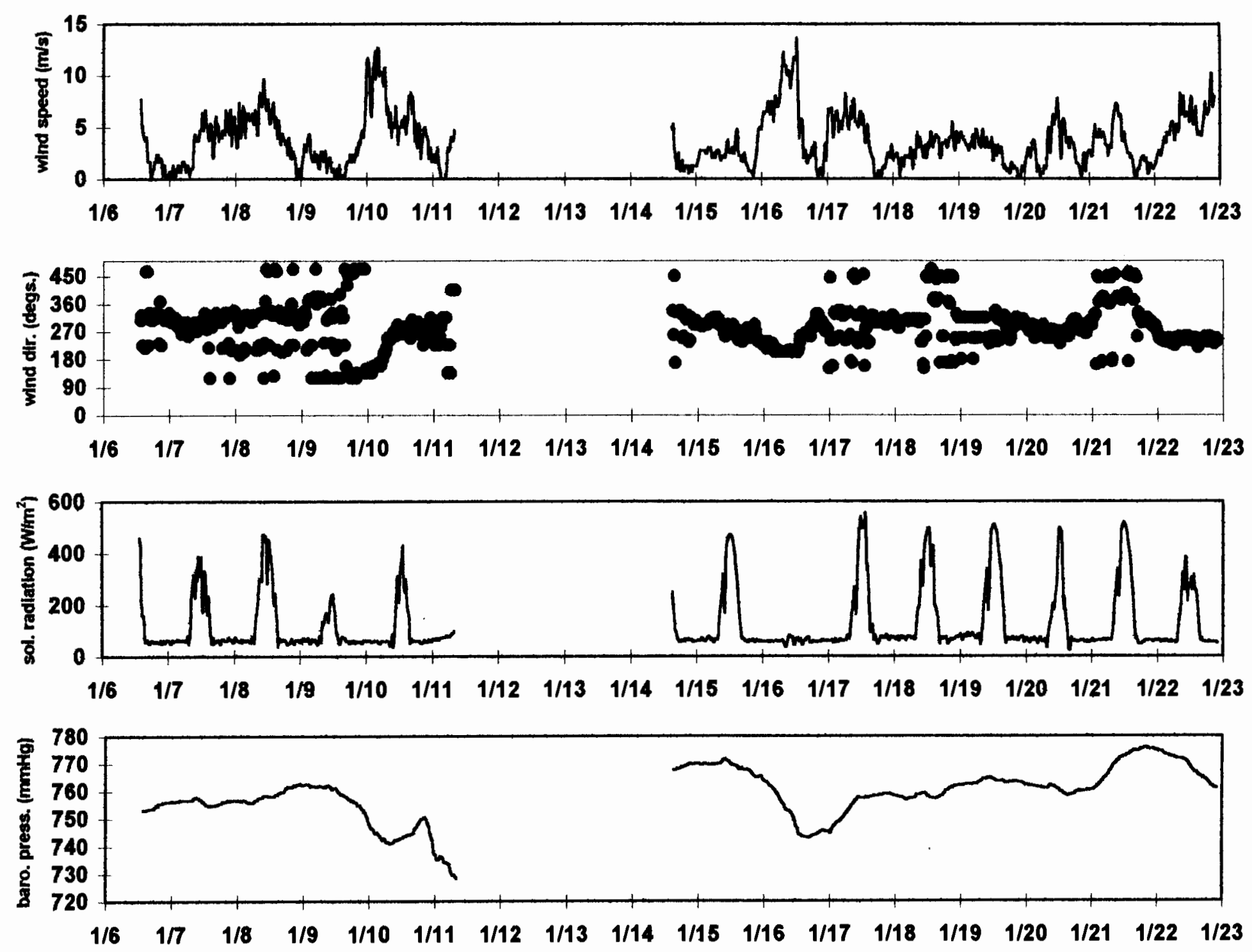


\section{January Buoy Data}

\section{Temperature}

The time-series of temperature at three depths shows an overall cooling of the waters during this period in January (Figure 10). We observed periods when the bottom water was 1.0 to $1.5^{\circ} \mathrm{C}$ warmer than the surface water. Periods of thermal stratification terminated with periods of isothermal conditions through the water column. The temperature variations indicate episodic stratification and destratification events over time scales of 2-5 days.

\section{Salinity and Salinity Correction}

It became apparent from a review of the salinity data that calibration errors occurred in two of the sensors; the mid-depth and bottom instruments gave salinity values of between 42 and $46 \%$ oo, and between 41 and 53 o/oo, respectively (Figure 11). Upon retrieval of the instruments on 31 January, we determined that the erroneous values were due to incorrect conductivity cell constants in the middle and bottom instruments, the determination of which is performed during calibration. We surmised that if the conductivity cell was not fully immersed in the seawater standard during the initial calibration, this would account for an abnormally high cell constant and the observation of abnormally high salinity data. In an attempt to salvage the data from the time-series, an experiment was conducted, after the instrument retrieval, to determine the salinity readings for all three instruments in a seawater medium, $15^{\circ} \mathrm{N}$ in the Pacific, with a salinity at 36.1 
Figure 10. Temperatures at three depths as recorded by the buoy. The red trace denotes the surface instrument, at approximately 0.5 meters, the green trace denotes the mid-depth instrument, at about 4.5 meters, and the blue trace denotes bottom temperature, at between 13 and 15 meters. This color scheme will be maintained throughout the paper, in which red, green and blue represent surface, middle and bottom data, respectively. 


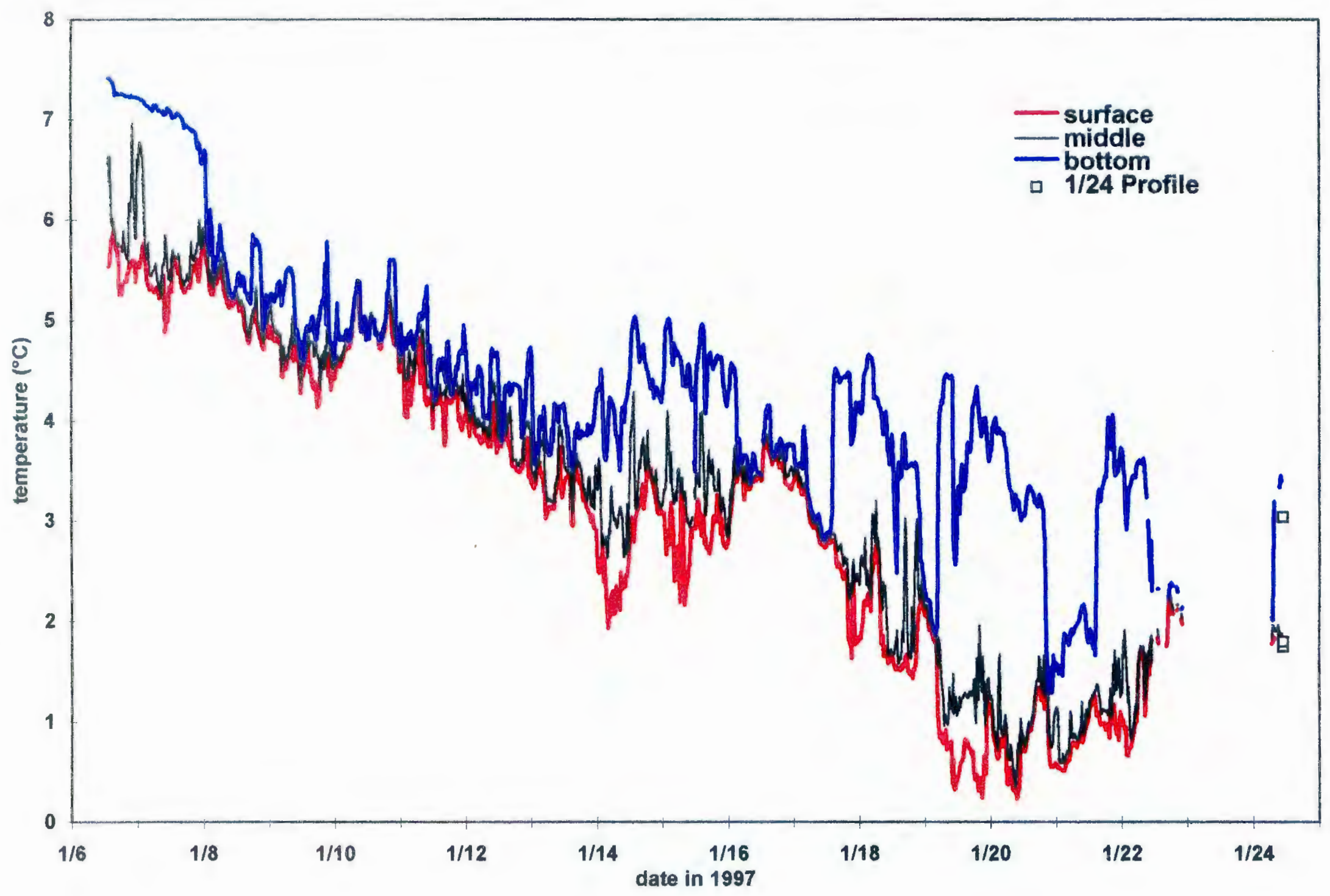


Figure 11. Uncorrected data from the buoy's YSI-600's salinity sensors, at three depths: approximately 0.5 meters, 4.5 meters, and between 13 and 15 meters. The middle and bottom instruments returned unrealistic data, requiring an attempted correction. The bottom instrument displays a broad drift occurring between 10-15 January. The sharp peak in the bottom instrument on 15 January represents our attempts at bringing the bottom instrument to the surface for calibration. The surface salinity sensor appeared to be operating properly. 


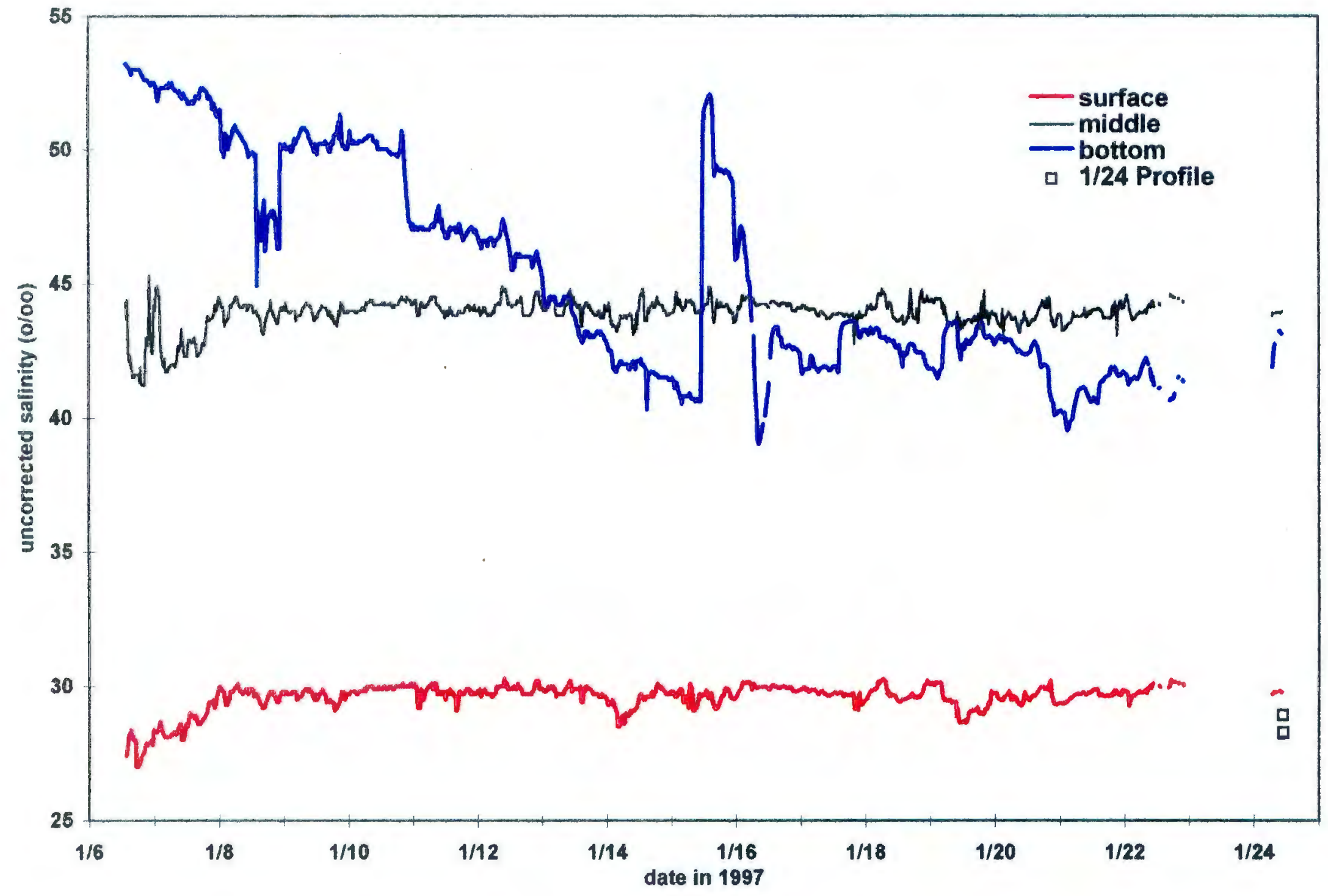


o/oo, over a range of temperatures. Using the results in the temperature range of the January deployment, we determined temperature-dependent factors which, when multiplied by the middle and bottom salinity data, would provide corrected salinity values for each instrument. While salinity does not change with a change in temperature, conductivity does, and since salinity is calculated from conductivity by the YSI-600, this experiment provides a method of arriving at a correction factor for salinity, and accounting for an observed, temperature-dependent error in the salinity calculation. Figure 12 shows the apparent salinity as the temperature increases for each instrument, between $3^{\circ} \mathrm{C}$ and $8^{\circ} \mathrm{C}$. A logarithmic curve is fit to the data for all three instruments' responses, and the logarithmic equation and goodness of fit are given on each graph. To arrive at corrected salinity values for the middle and bottom instrument, each observed value was multiplied by the quotient of the result from the surface logarithmic equation for the observed temperature and the result from the logarithmic equation for the instrument in question, at its observed temperature.

$$
\begin{aligned}
& \mathrm{S}_{\text {corrected }}=\mathrm{S}_{\text {observed }} \times\left[\left(0.3924 \times \ln \left(\mathrm{T}_{\text {surface }}\right)+35.533\right) /\left(0.9237 \times \ln \left(\mathrm{T}_{\text {middle }}\right)+52.37\right)\right] \\
& \text { and } \\
& \mathrm{S}_{\text {corrected }}=\mathrm{S}_{\text {observed }} \times\left[\left(0.3924 \times \ln \left(\mathrm{T}_{\text {surface }}\right)+35.533\right) /\left(0.9792 \times \ln \left(\mathrm{T}_{\text {bottom }}\right)+59.044\right)\right]
\end{aligned}
$$

Equations 1 and 2 give the corrections for the middle and bottom salinity data, respectively.

The corrected salinity data for the middle instrument from the buoy followed the variations seen at the surface extremely well, however the bottom instrument showed features which indicate that other factors affected its values (Figure 13). We suspect that the bottom instrument may have been too close to the bottom, so that the conductivity cell 
Figure 12. Salinity sensor response of the surface, middle and bottom YSI-600XI's during a warming experiment, in the temperature range observed in the January deployment, to try to correct for the conductivity cell calibration error. 

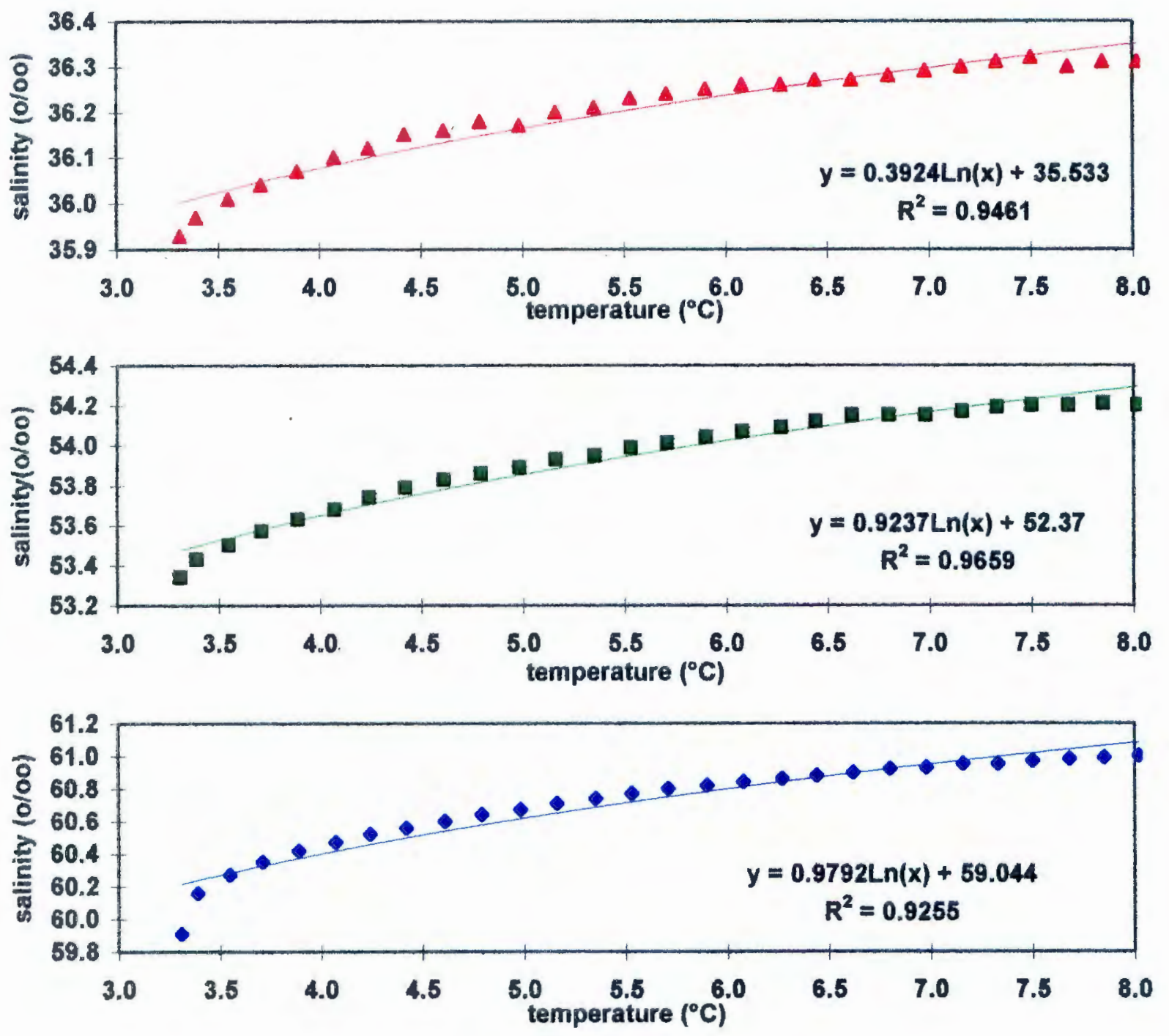
Figure 13. Corrected salinity at three depths. The feature in the bottom record on 8 January has been removed by linear estimation, and the graph is scaled to observe the surface and middle records, and the part of the bottom record before 10 January. The drift and large peak on 15 January are due to clogging of the conductivity cell and lifting the instrument mooring, respectively. 


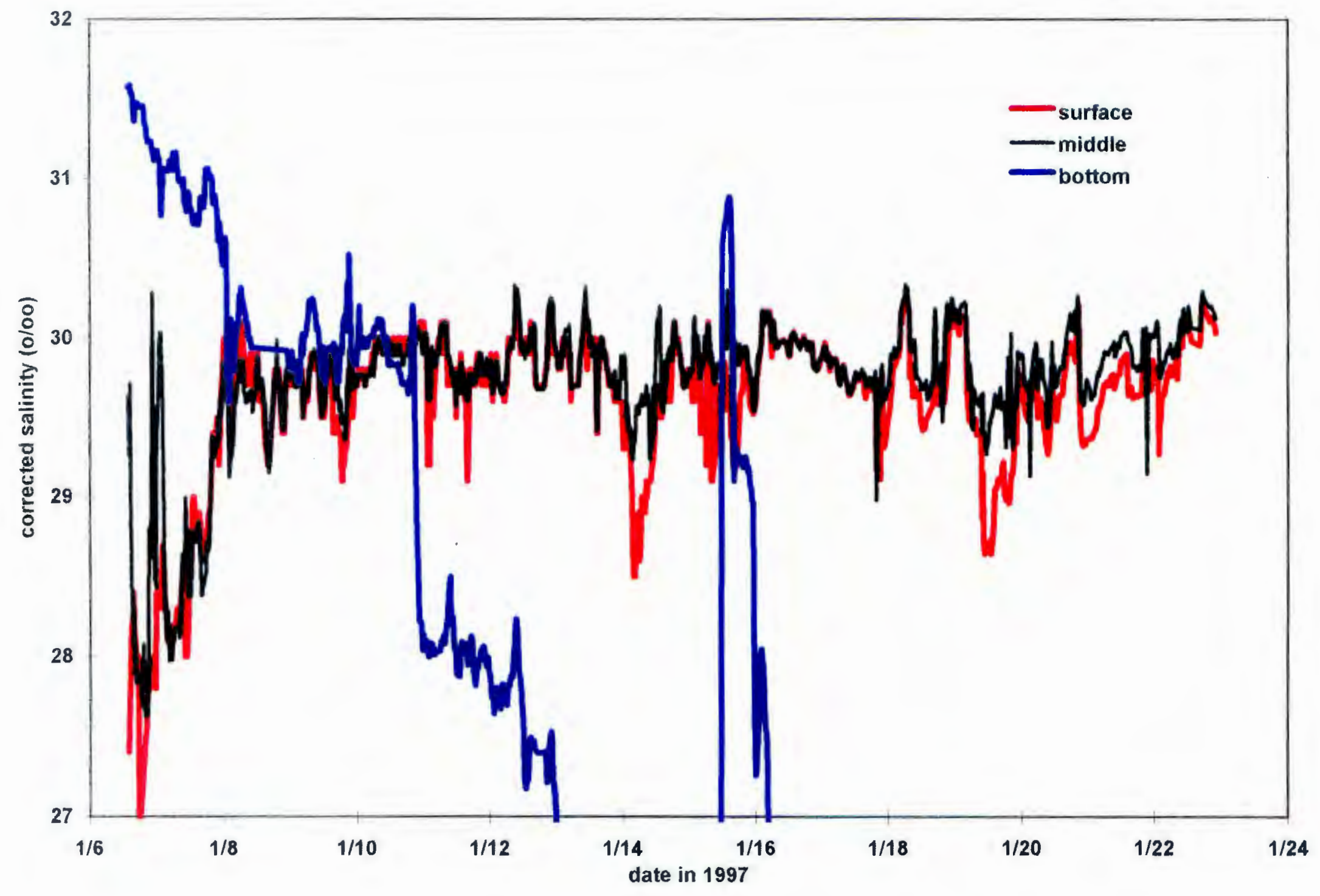


became clogged with particles. The slow drift from 10 January to 15 January suggests that the instrument was gradually being affected, and was removed from the effect on 15 January, when we hauled up the instrument mooring to access the bottom instrument. A final offset can be removed from the data by comparing the salinity values at the surface, middle and bottom, during periods of isothermal mixing as seen in figures 11 and 12 . Comparing the difference between middle and surface instruments during the mixing event on 10 January, we obtained an average difference of $-0.25 \pm 0.05$ o/oo for 46 consecutive measurements. For the isothermal event on 17 January, we obtained an average difference of $-0.20 \pm 0.01 \mathrm{o} / \mathrm{oo}$ for 26 consecutive measurements. Thus, we subtracted 0.20 from all middle corrected salinity values. For the deep instrument only the 10 January mixing event could be compared, because of the drift in the data, and it appeared that no correction was necessary.

\section{Dissolved Oxygen}

The dissolved oxygen record at the three depths showed some variation between instruments, even during mixing events (Figure 14). These inter-instrument variations during these periods were probably not real, as we would expect fairly close agreement among the concentrations of dissolved oxygen at all depths during mixing events over the

entire water column (Table 1). First, we compared the oxygen data from the profile on 24 January to the readings obtained at the end of the buoy's operation. At the surface, the buoy was reading values between $108.3 \%$ and $109.6 \%$, and the profile's dissolved oxygen value at the depth of $0.5 \mathrm{~m}$ at $10: 53$ was $106.9 \%$. Because the buoy stopped logging at $10: 20$, it was necessary to estimate what the buoy might have been reading at the surface at 10:53. High water occurred at 08:20 and coincided with the local minimum in surface 
Figure 14. A plot of uncorrected dissolved oxygen saturation values for the three buoy instruments for the January deployment. The pulses of low oxygen in the bottom record from about 12 January onward are thought to be a result of contact and interference from the seafloor sediments. 


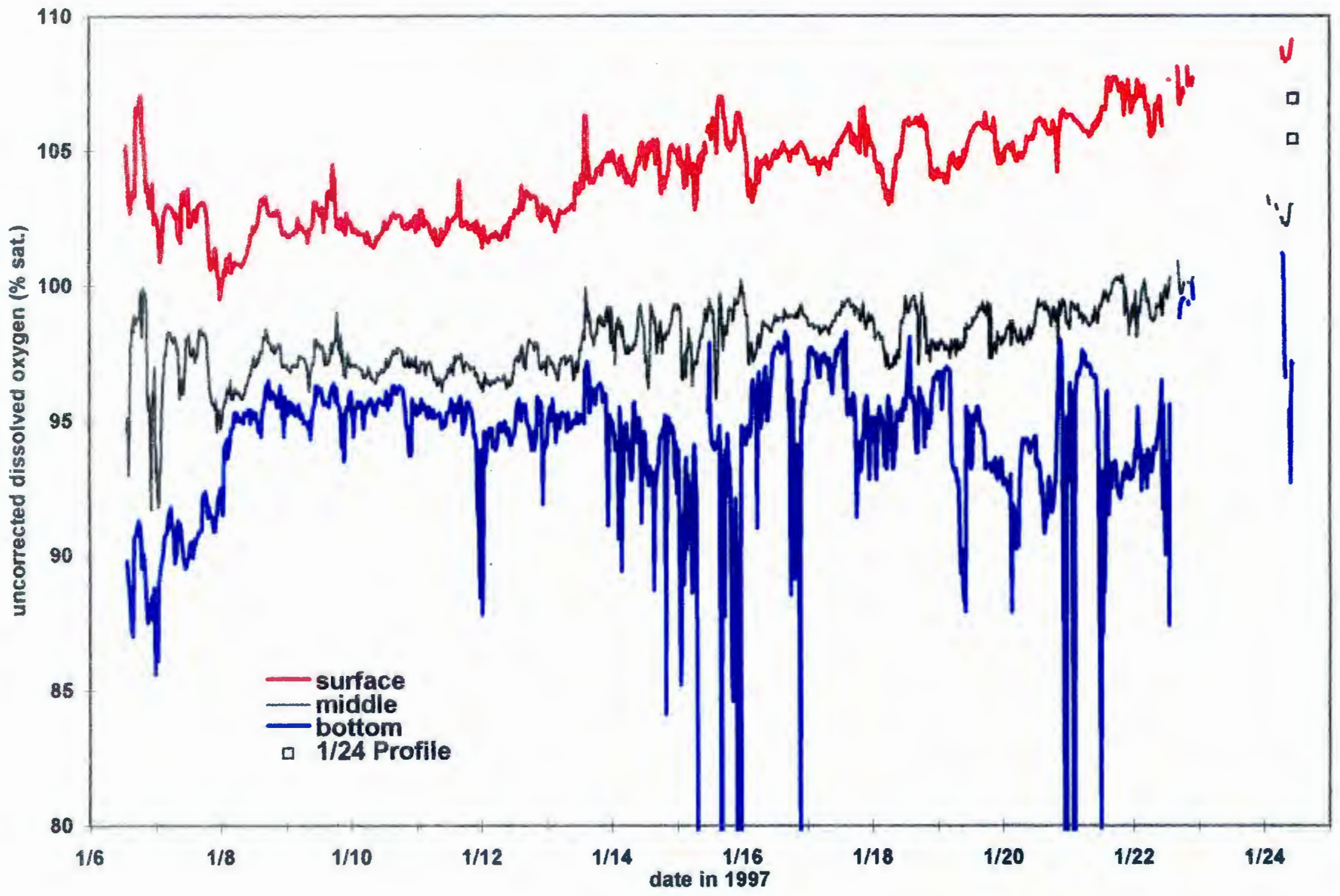


Table 1: Estimated correction factors for offsets between the surface $\mathrm{O}_{2}$ sensor and the middle and bottom sensors. Differences were calculated between the middle and corrected surface, and the bottom and the corrected surface instruments for periods when the difference in temperature between bottom and surface were minimal as indicated in Figure 12. These differences were averaged and plotted against time since deployment for each event. The difference between the buoy and the profile from 24 January was used as an additional value and linear fit was regressed. The linear equations were used to correct the middle and bottom oxygen values.

\begin{tabular}{lcccc|ccccc}
\hline & \multicolumn{4}{c}{ Middle - Surface } & \multicolumn{5}{c}{ Bottom - Surface } \\
\cline { 2 - 9 } date & $\begin{array}{c}\Delta \mathrm{t} \\
(\text { days })\end{array}$ & $\begin{array}{c}\text { Avg } \Delta \mathrm{O}_{2} \\
(\% \text { sat })\end{array}$ & $\begin{array}{c}\mathrm{Std} \Delta \mathrm{O}_{2} \\
(\% \mathrm{sat})\end{array}$ & $\begin{array}{c}\text { \# of } \\
\text { values }\end{array}$ & $\begin{array}{c}\Delta \mathrm{t} \\
(\text { days })\end{array}$ & $\begin{array}{c}\text { Avg } \Delta \mathrm{O}_{2} \\
(\% \text { sat })\end{array}$ & $\begin{array}{c}\text { Std } \Delta \mathrm{O}_{2} \\
(\% \text { sat })\end{array}$ & $\begin{array}{c}\text { \# of } \\
\text { values }\end{array}$ \\
\hline 10-Jan & 3.94 & 4.5 & 0.12 & 43 & 3.94 & 5.8 & 0.23 & 43 \\
17-Jan & 10.83 & 4.7 & 0.15 & 27 & 10.83 & 6.2 & 0.40 & 27 \\
24-Jan & 17.88 & 3.6 & $\mathrm{n} / \mathrm{a}$ & $\mathrm{n} / \mathrm{a}$ & 17.88 & 5 & $\mathrm{n} / \mathrm{a}$ & $\mathrm{n} / \mathrm{a}$ \\
\hline
\end{tabular}

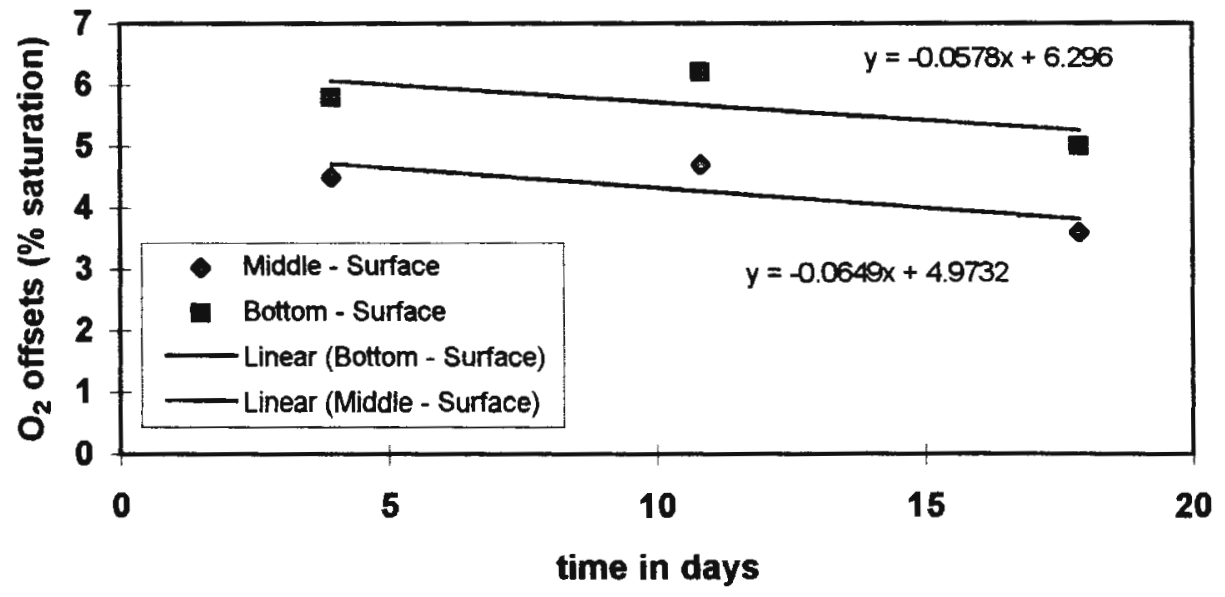


dissolved oxygen, at $108.3 \%$. The time of the profile data was approximately 2.5 hours after high, and dissolved oxygen was increasing. The surface dissolved oxygen 2.5 hours before high water was approximately $109 \%$, and the dissolved oxygen had been increasing since high water at a rate of $0.1 \%$ to $0.3 \%$ per 20 minute reading. Thus, we estimate that the surface instrument probably would have reported about $109.3 \%$ at the time of the profile, which gives a difference of $2.4 \%$. Therefore, we applied a linear drift correction by lowering the buoy's surface dissolved oxygen readings incrementally, by 2.4 over 17.875 days, or $0.0019 \%$ per 20 minute reading. This method assumes that the buoy was reading properly at the beginning of the deployment. With the surface corrected, we were able to use the isothermal events of 10 January and 17 January to develop offsets for the middle and bottom instruments. Averaging 43 values between $05: 00$ and 19:40 on 10 January gave an average difference between surface oxygen and middle oxygen of $4.5 \pm$ $0.12 \%$ saturation. The average difference between surface and bottom was $5.8 \pm 0.23 \%$ saturation. Averaging 27 values between $05: 00$ and 14:00 on 17 January gave average differences from surface oxygen levels of $4.7 \pm 0.15 \%$ and $6.2 \pm 0.40 \%$, for middle and bottom, respectively. The estimate for the buoy's middle instrument dissolved oxygen reading for 10:50, the time of the profile datum from the middle instrument's depth of $3.96 \mathrm{~m}$, was approximately $103.3 \%$. The profile value for the mid-depth was $106.9 \%$, giving a difference of $3.6 \%$. A value for the bottom instrument, buoy minus profile, was calculated as 8.3 , however this value gives rise to over-correction at the end of the deployment. A value of 5 was used instead, and was determined by observing the difference between raw bottom oxygen data and middle and surface corrected data for 9 readings on 22 January, the longest stretch of consecutive readings between gaps in the 
buoy data. The over correction was due to comparing bottom data which was affected by the interaction with the seafloor.

Figure 15 shows the corrected dissolved oxygen data for the three instruments. One sees a broad stratification period to begin the deployment, which is reflected in the salinity data. This condition is broken down on 8 January, and remains destratified until approximately 13 January. This later stratification eventually increases, but is again broken down over 16 and 17 January, after which, the water column once again stratifies with respect to oxygen. The deep spikes down below $90 \%$ are believed to be due to the instrument contacting the seafloor. Additionally, the large distribution of downward peaks and the low bottom $\mathrm{O}_{2}$ values on the afternoon of 15 January can be attributed to our tying the boat to the buoy. When we did this, the drag of the boat pulled slack in the instrument mooring, causing the catenary, and thus the bottom instrument to move lower. The instrument was already close to the seafloor, and these activities certainly brought the instrument into contact with the seafloor.

\section{Depth or Pressure}

The pressure readings from the three instruments (Figure 16), provided useful information about water level variations and the mooring. The surface instrument displayed an overall deepening trend, with three low pressure events on 10 January, 16 January, and 20 January. This deepening trend of the buoy could have been caused by the mooring anchors settling into the seafloor. The low pressure events reflected atmospheric pressure changes. The bottom instrument captured the tidal signal with peaks associated with deeper water, or flood high water, and the nadirs associated with low water. The prominent downward spike on 15 January represented our attempts to haul the instrument 
Figure 15. Corrected dissolved oxygen. The surface has been adjusted by applying a linear drift correction of $0.0019 \%$-sat. per 20 minute reading, or $2.4 \%$ over the entire data set. The middle oxygen data have been adjusted by multiplying by Equation 1, and the data in Table 1. The bottom data have been adjusted using Equation 2, and data in Table 1. The downward spikes are indicative of contact by the instrument with the seafloor. 


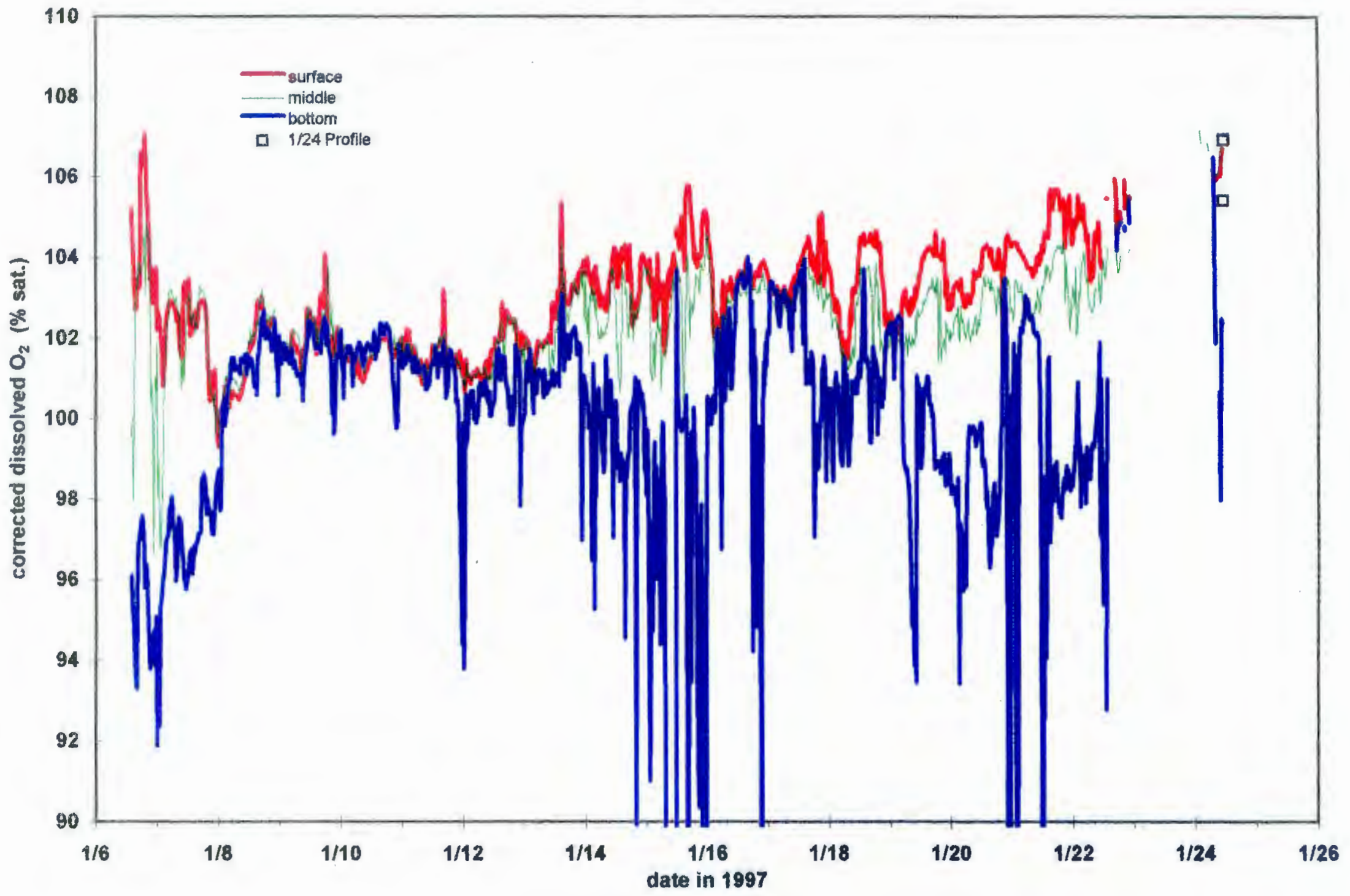


Figure 16. A plot of the pressure readings from each instrument in meters depth of water. On 10 January, a surge of water entered the Bay and pulled slack into the instrument mooring. The spike on 15 January was our attempted retrieval of the instrument mooring. 


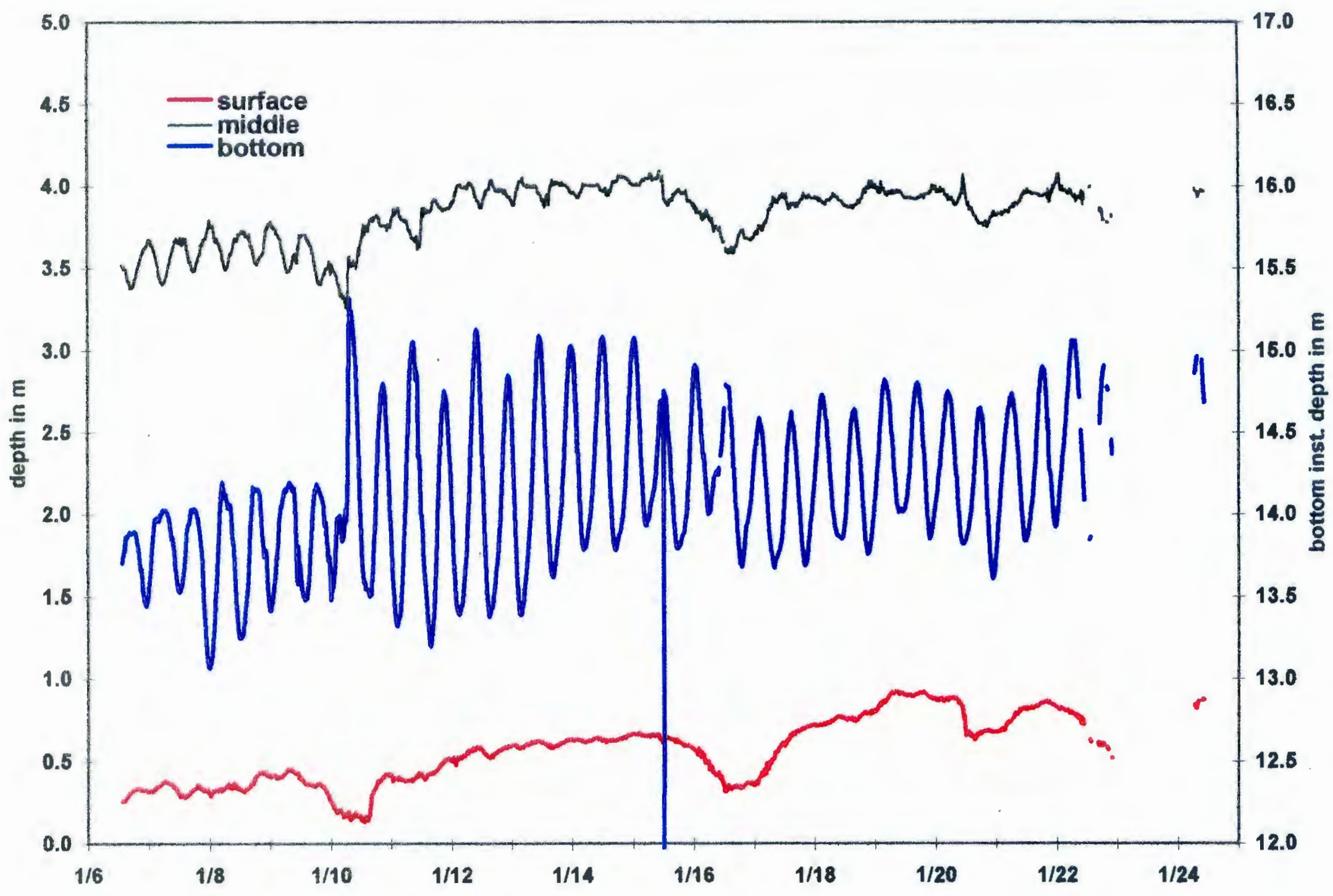


to the surface. Also obvious in the depth record was the apparently wind- and barometric pressure- induced event on 10 January in which unusually high water levels and a surge of water entered the Bay. This event resulted in coastal flooding in the northern portion of the Bay. The dynamics of the mooring system can be deduced by observing the middle and bottom pressure records. Between 6 January and 9 January, the instrument mooring is extremely taut, and takes up some of the buoyant force of the buoy on high tides. The truncated signal in the bottom instrument and the full signal by the middle instrument indicate this. As the surge on 10 January impacts the buoy, the instrument mooring is pulled towards the buoy, and when normal water levels resume, this mooring now carries more slack. The more fully recorded tidal signal in the bottom instrument, and the fact that the mid-depth instrument begins recording the atmospheric changes, similarly to the surface instrument, suggest the increased slack in the instrument mooring. The downward spike shows when we lifted the mooring, and after this point, no tidal variations are noted in the middle instrument, suggesting much more slack in the mooring. 


\section{March Deployment}

On 10 March 1997, the buoy was redeployed on the same two anchor-float systems as before but the instrument mooring leg was removed and changes made to facilitate retrieving the YSI-600 instruments (see page 15 and Figure 5). Data have been collected at the three depths every 20 minutes since 10 March. This thesis presents the results obtained up through 8 May 1997. Results of the buoy data for temperature (Figure 17a and b), raw salinity (Figure 18a and b), and dissolved oxygen (Figures 19a and b) are presented in two page plots, each approximately 30 days in length. In addition to the buoy data, profiles at the buoy site were obtained using a YSI Model 6000 on 24 March, 5 April, 22 April and 8 May.

\section{Buoy Temperature Data}

Over the period of 19 March to 8 May, the water at this location in the Bay showed a warming trend. Brief periods of stratification occurred until mid-April, after which the stratification became persistent with occasional mixing events (Figure 17a and b). Mixing events occurred on 15 and 18 March. An intrusion of warmer bottom water was evident between 16 March and 18 March. During the winter, waters in the Bay are colder than those offshore, whereas in the summer, the waters in the Bay are warmer than those in Rhode Island Sound. The buoy data show that at this site in the Bay, a cross-over point occurred in which bottom waters were warmer than surface waters up until 25 March and they then became cooler than surface waters after that date, except for a brief period on 1-2 April, during the 1 April blizzard. Periods of large scale stratification are observed between 15 and 18 March, 29 to 31 March, 13 to 19 April, 20 to 23 April, 24 to 27 April, 28 April to 1 May, and on 5 and 6 May. Since the temperature sensor needed no 
Figure $17 \mathrm{a}$ and $17 \mathrm{~b}$. Temperature at three depths as measured by the three YSI-600XL's attached to the buoy, in twenty minute intervals. The red record indicates the surface, or 0.6-m temperature, green indicates the middle, or 4.4-m temperature and blue indicates the bottom, or $\sim 12.6-\mathrm{m}$ temperature. This color scheme with depth for the three instruments is maintained in all subsequent plots for all parameters. Plots of buoy data from the March-May deployment will all be presented as two page figures, each approximately 30 days in length, in order to show small scale details. 


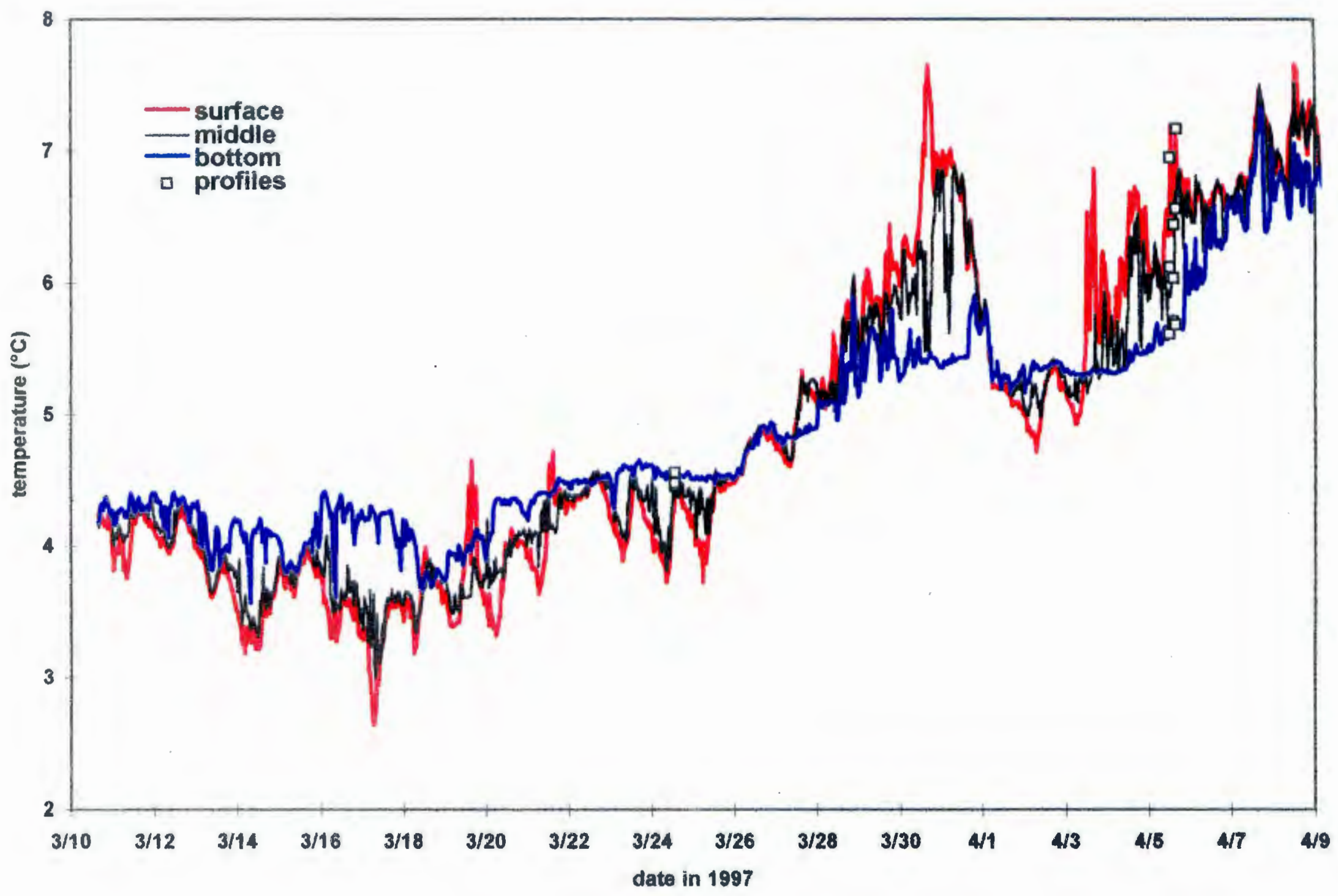

9 


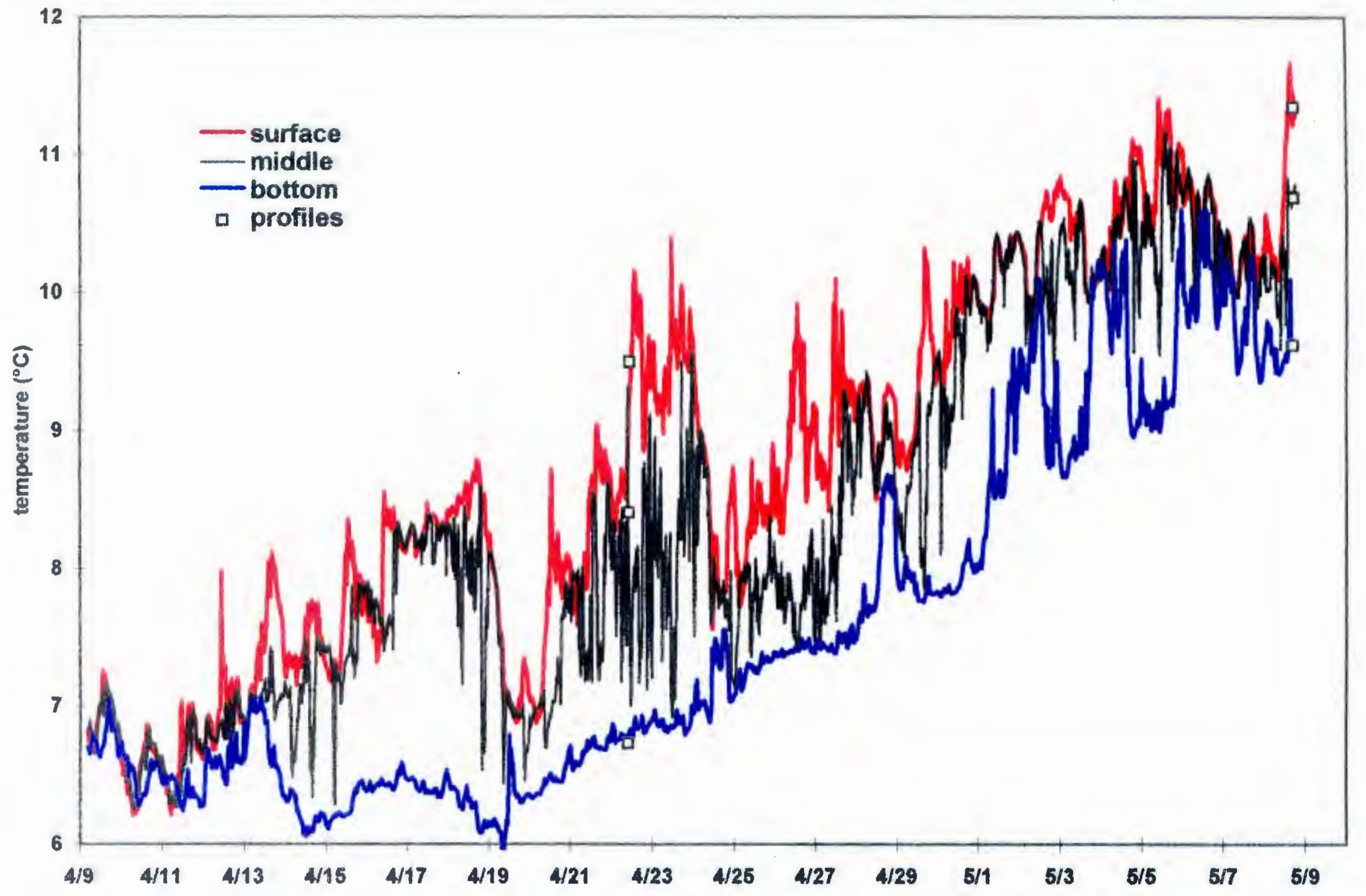


Figure $18 \mathrm{a}$ and $18 \mathrm{~b}$. Uncorrected salinity at three depths: surface, or $0.5-\mathrm{m}$, middle, or 4.4-m, and the bottom, or $\sim 12.6-\mathrm{m}$ as measured by the three YSI-600XI's attached to the buoy, in twenty minute intervals. 


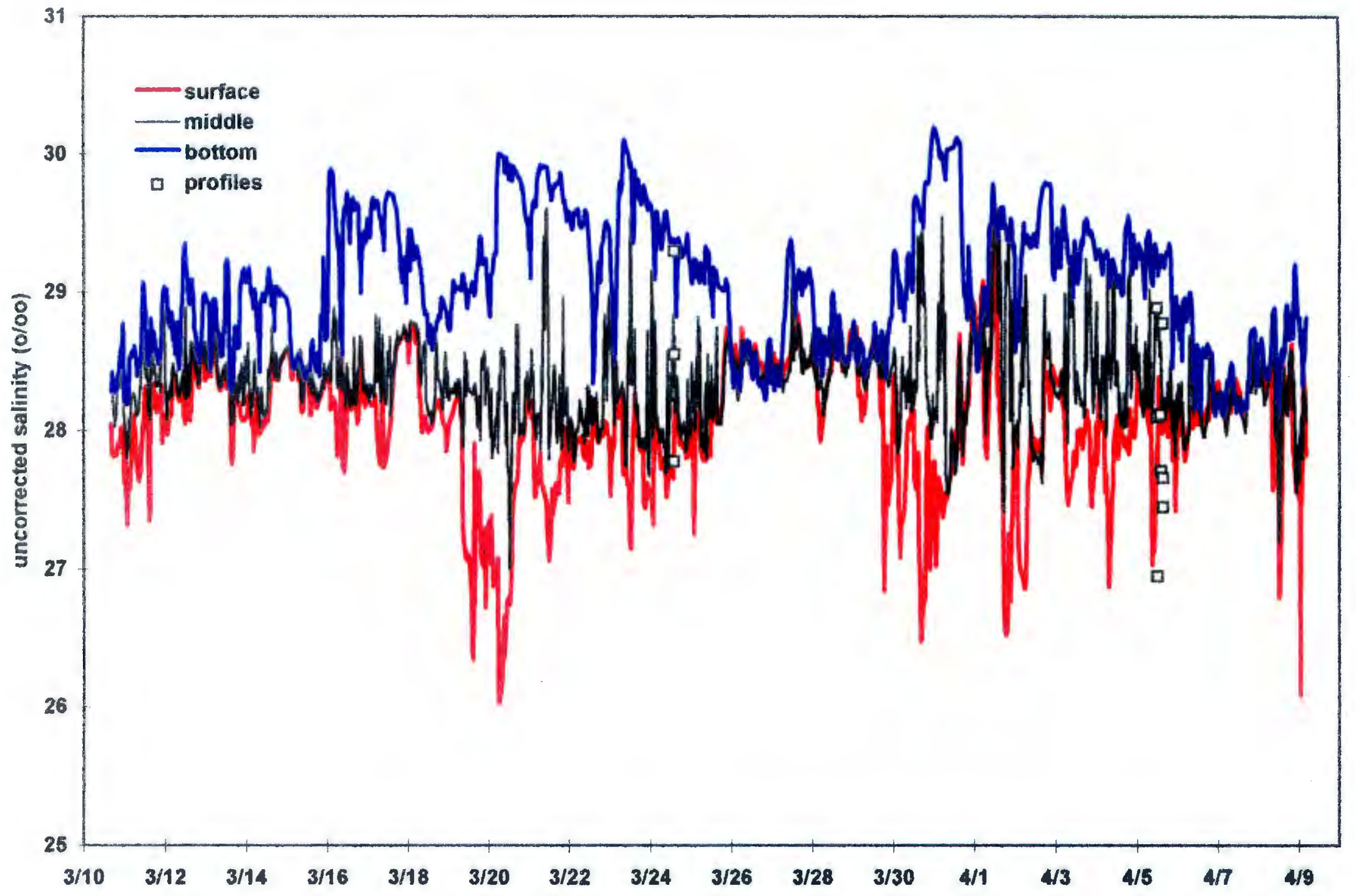




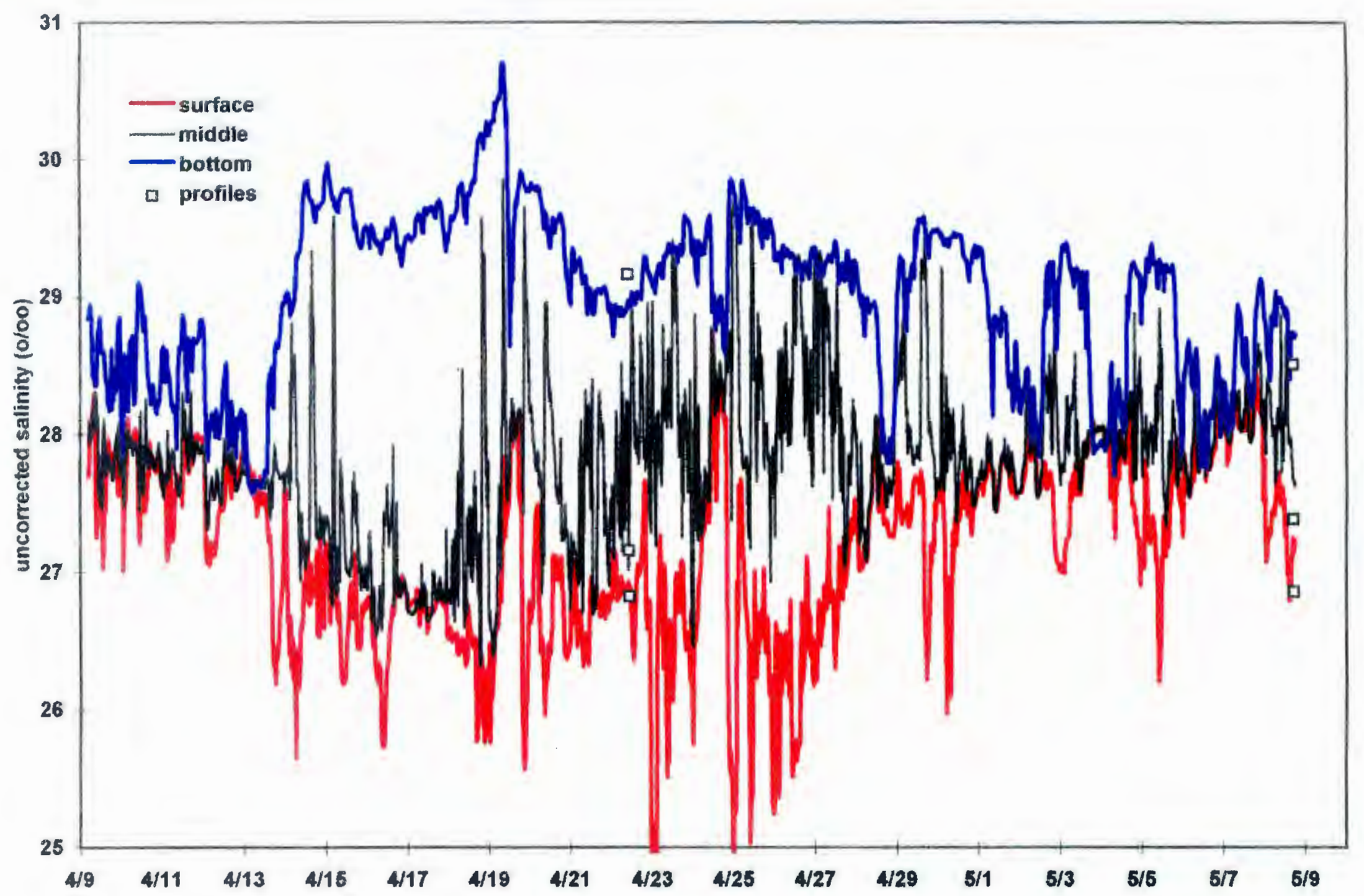


Figure 19a and 19b. Uncorrected dissolved oxygen at three depths, surface, or $0.5-\mathrm{m}$, middle, or 4.4-m, and the bottom, or $\sim 12.6-\mathrm{m}$, as measured by the three YSI-600XI's attached to the buoy, in twenty minute intervals. 


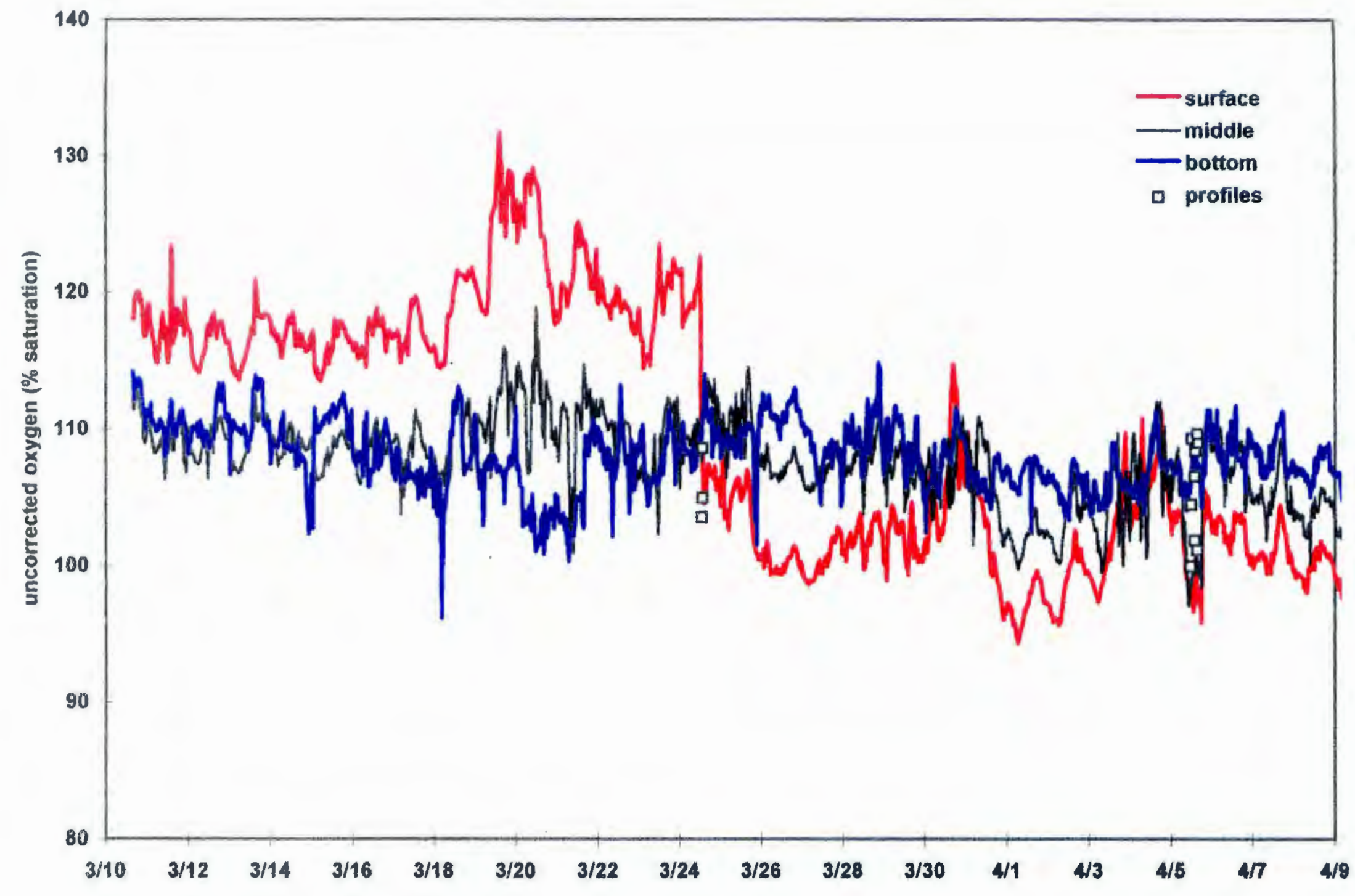




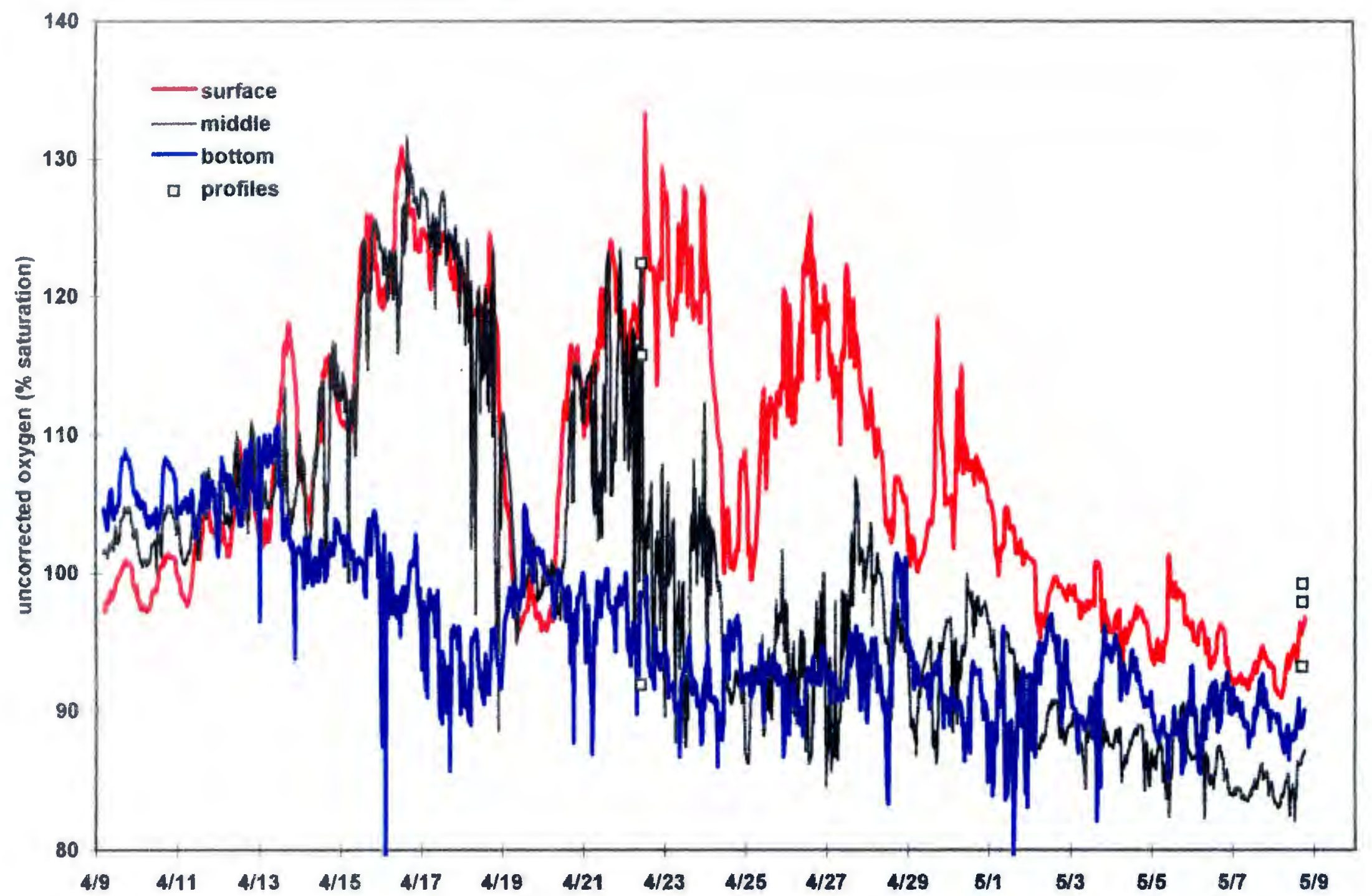


periodic calibration, we used the strongest mixing events which resulted in an isothermal water column to test for calibration offsets in the salinity and oxygen, along with supporting data from the profiles. Isothermal events occurred briefly on $15 \mathrm{March}$, over the entire day on 26 March and over most of 28 March, briefly again on 1 April, over most of 7 April, again briefly, early on 13 April and again on 6 May. There were also events which may be recognized as partial mixing in which the parameters in question converge, but the water column does not quite become homogeneous before stratification once again occurs. These partial events occurred just after noon on 19 April, prior to noon on 24 April, as a partial stratification on 2 May, and as a partial destratification on 3 May.

\section{Raw Salinity Data and Development of Correction Factors}

A number of factors must be considered to apply post-collection calibration to the observed data. To determine finally calibrated values, we employed the field calibration offsets from calibrations on 24 March and 22 April, and used the profiles from 24 March, 5 April, 22 April and 8 May to constrain the possible offsets among the sensors.

Unfortunately, the deployment operations made it impossible to conduct a profile of the waters at the site, so we have no additional data about the initial deployment conditions, other than those from the buoy. The tidal lunar phase was just past the spring tide conditions of 8 March (Figure 20a and b). Thus, there was a relatively large amount of tidal energy available for mixing. The weather was still cold, and water temperatures were between 3.5 and $4.5^{\circ} \mathrm{C}$, and close to isothermal (see Figure $17 \mathrm{a}$ and $\mathrm{b}$ ). The raw salinity values for the three sensors are shown in Figures 21a and b, along with the readings obtained during profiles on 24 March, 5 April, 22 April and 8 May. The surface salinity 
Figure 20a and 20b. Predicted tides for Newport, RI from 10 March until 8 May 1997. The strong spring tides are on 8 March, 7 April, and 6 May. Weaker spring tides are observed on 24 March and 22 April. 


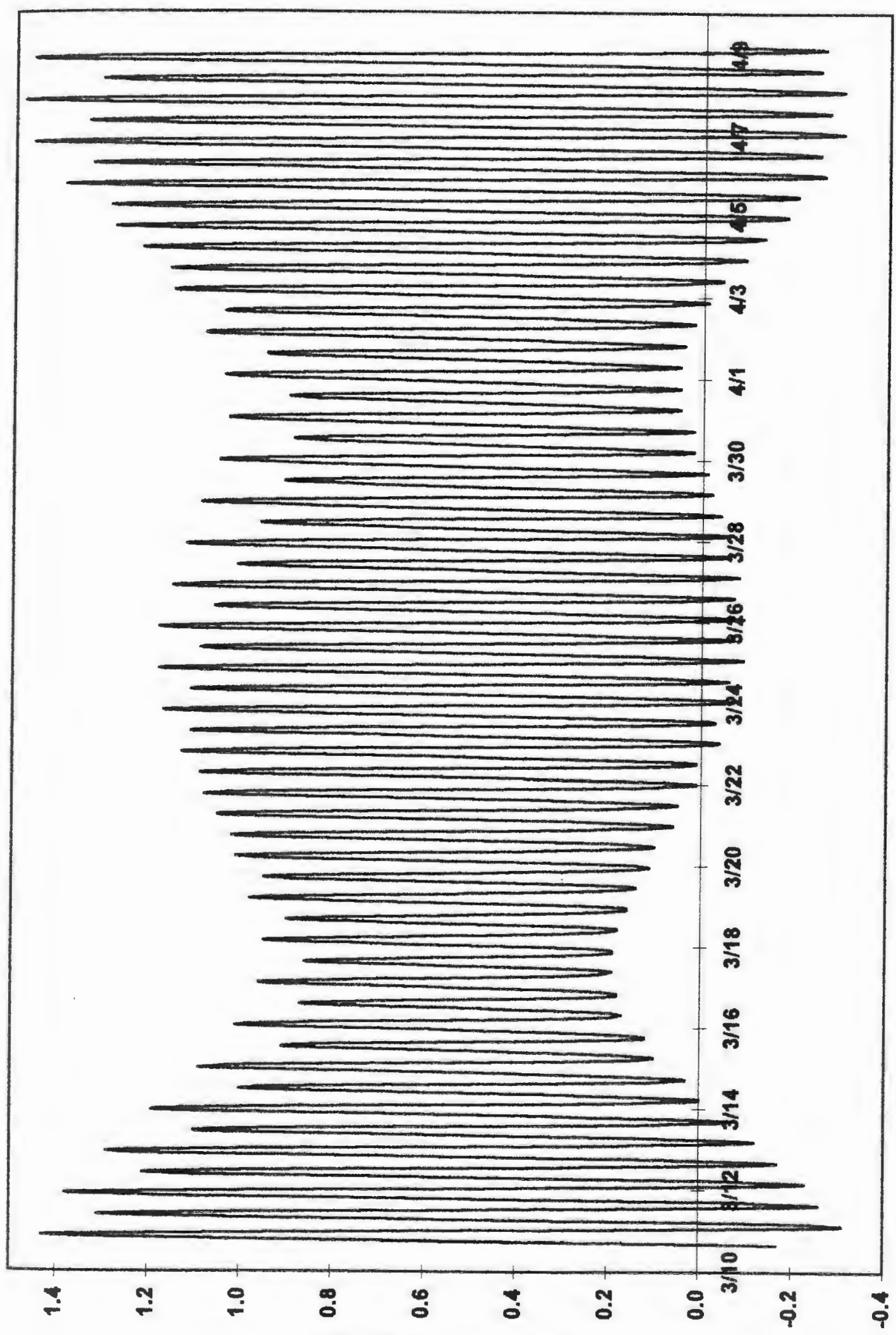

(u) $746 !$ 


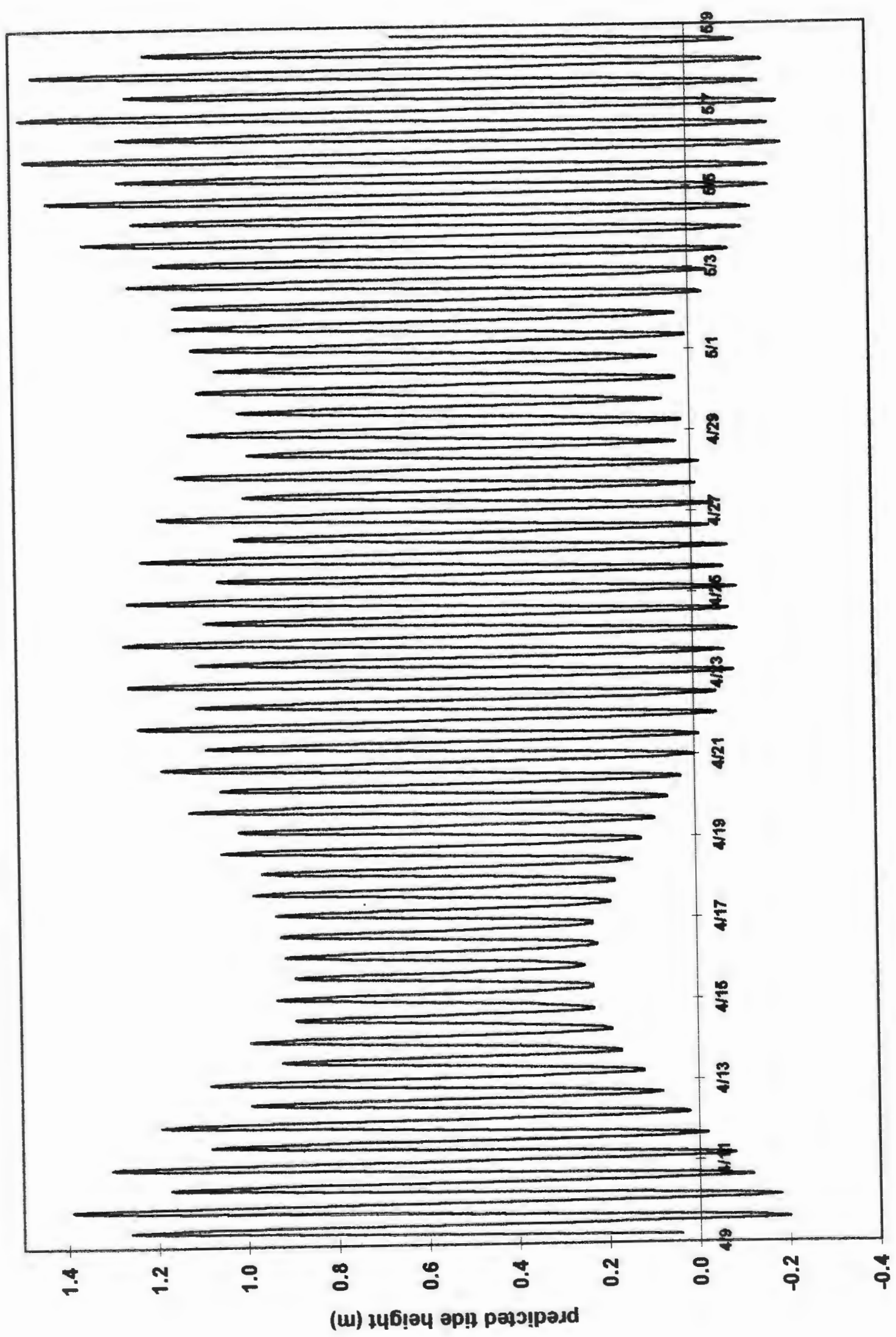


shows low salinity events $(<27.50 / 00)$ on a number of occasions. The bottom salinity shows occasional injection of high salinity water $(>29.0 \mathrm{o} / \mathrm{oo})$ The water column appears to be isohaline at several times, such as March 15, 25, 28 and April 6 and 12. During the last two weeks of the record, there are events in which the bottom salinity approaches but does not quite reach the surface and middle salinity values. The conductivity sensors were re-calibrated on 24 March and 22 April. The profiles provide opportunities to examine calibration offsets among the sensors between calibrations. These possible offsets must be examined to arrive at a final data set and draw more definitive conclusions about mixing or partial mixing events.

Table 2 contains offset data from calibrations in the form of pre-calibration minus post-calibration differences and from profiles in the form of profile reading minus buoy reading, where both data are interpolated to the same time and depth. After consideration of all the data, the values which were determined to be applicable were placed in boldface, and were applied to the raw data to derive post-collection, calibrated data. The boldface values were applied to the raw data by fitting a curve to the offset data, as a function of time since deployment. The superscript code for the unused values indicate our reasons for disregarding the value or other processing which may have taken place with the value. The 5 April values were all disregarded due to the large, negative offsets observed for all profiles on this day. We suspect that the problem resided in the YSI- 6000 salinity calibration, and thus, the profile-buoy comparison could not be used, in order to avoid applying a correction unsupported by the other observations. In the 22 April profiles, the offsets for the surface and middle instruments were of similar magnitude and opposite direction as the offsets for the calibration on the same day. The profile values were 
Table 2. The calibration offsets and profile-buoy offsets for the salinity sensors for the three buoy YSI-600's. Boldface values were used to determine a correction curve, with mid-point values added on 17 March and 30 April, to constrain the shape of the curves. Values which were not used are in normal type and a superscript indicator of the reason for disregarding these values is included.

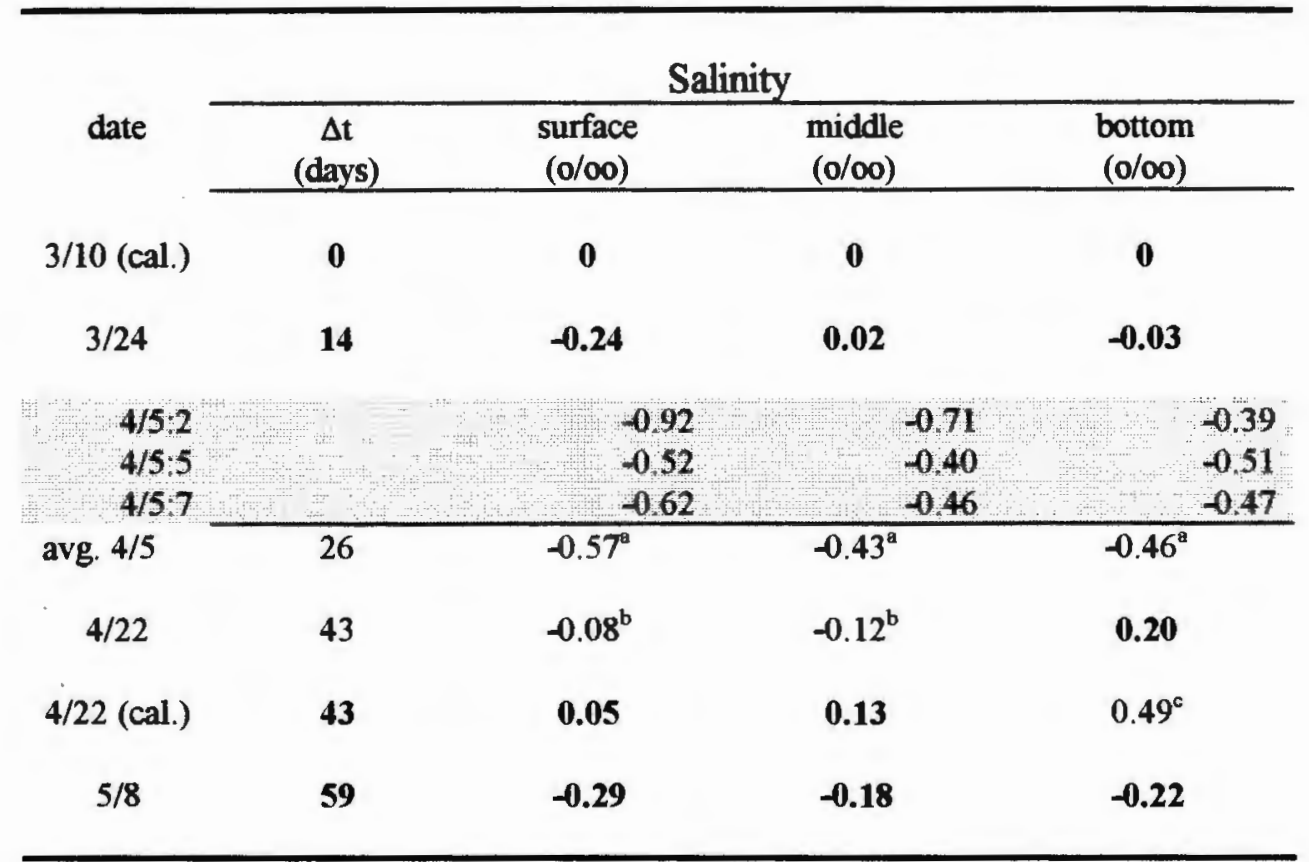

${ }^{\text {a }}$ Disregarded due to suspicion of a calibration error in the YSI-6000 used for the profiles. Any consideration of these values would apply a correction unsupported by the data.

${ }^{b}$ Disregarded, because these values were of a similar magnitude but opposite direction as those given in the calibration offsets. The calibration offsets were given precedence.

${ }^{c}$ This offset was determined to be due to a calibration error, and thus, its effect on the time-series was determined to be biased. The offset was removed from the data following the 22 April calibration. 
disregarded, and the calibration offsets were given precedence. The 22 April bottom instrument calibration offset was $0.49 \mathrm{o} / \mathrm{oo}$. There was no indication that this instrument's salinity calibration had actually drifted by one-half of a part per thousand, and though not used in this thesis, following calibration on 16 June, applied a calibration correction of the same magnitude and opposite direction, indicating that this offset was the result of a calibration procedural error. This type of error may occur if the conductivity cell did not remain fully immersed during the calibration, and calibration on small boats are conducive to rocking and unsteadiness. Therefore, the $0.49 \mathrm{o} / \mathrm{oo}$ offset was removed from the data set from the 22 April calibration to the end of the deployment, by subtracting 0.49 from all bottom salinity values following the 22 April calibration. All other values were used. These values were then plotted against time and a curve was fit to the data (Figure 21). Additional data points were added at $17 \mathrm{March}$, and $30 \mathrm{April}$, to constrain the data. These added points were inserted as the midpoint of the line formed between each point's two adjacent offset values. The curve was sampled every twenty minutes and the resulting values were added as correction factors to the raw data to produce a plot of corrected salinity at three depths (Figure 22a and b).

The corrected salinity data show periods of stratification and destratification similar to that in temperature. The value of $310 / 00$ is an upper bound on the deep salinity, and the deep waters seem to reside at between $28.5 \mathrm{o} / 00$ and $29.0 \mathrm{o} / 00$. There are several excursions on the part of surface salinity to levels at or below $26 \mathrm{o} / \mathrm{oo}$. It is interesting that, unlike the mid-depth temperature, which mostly follows the features seen in the surface instrument, the mid-depth salinity is more evenly spaced between the surface and the bottom data. During times of mixing, however, the middle salinity more closely 
Figure 21. The correction curves for the salinity sensors for the three buoy YSI-600's. The open black squares indicate the positions of the data used from table 2 in generating the curves. The filled black squares indicate mid-point, tie-points added to constrain the curves to a form supported by the data. 

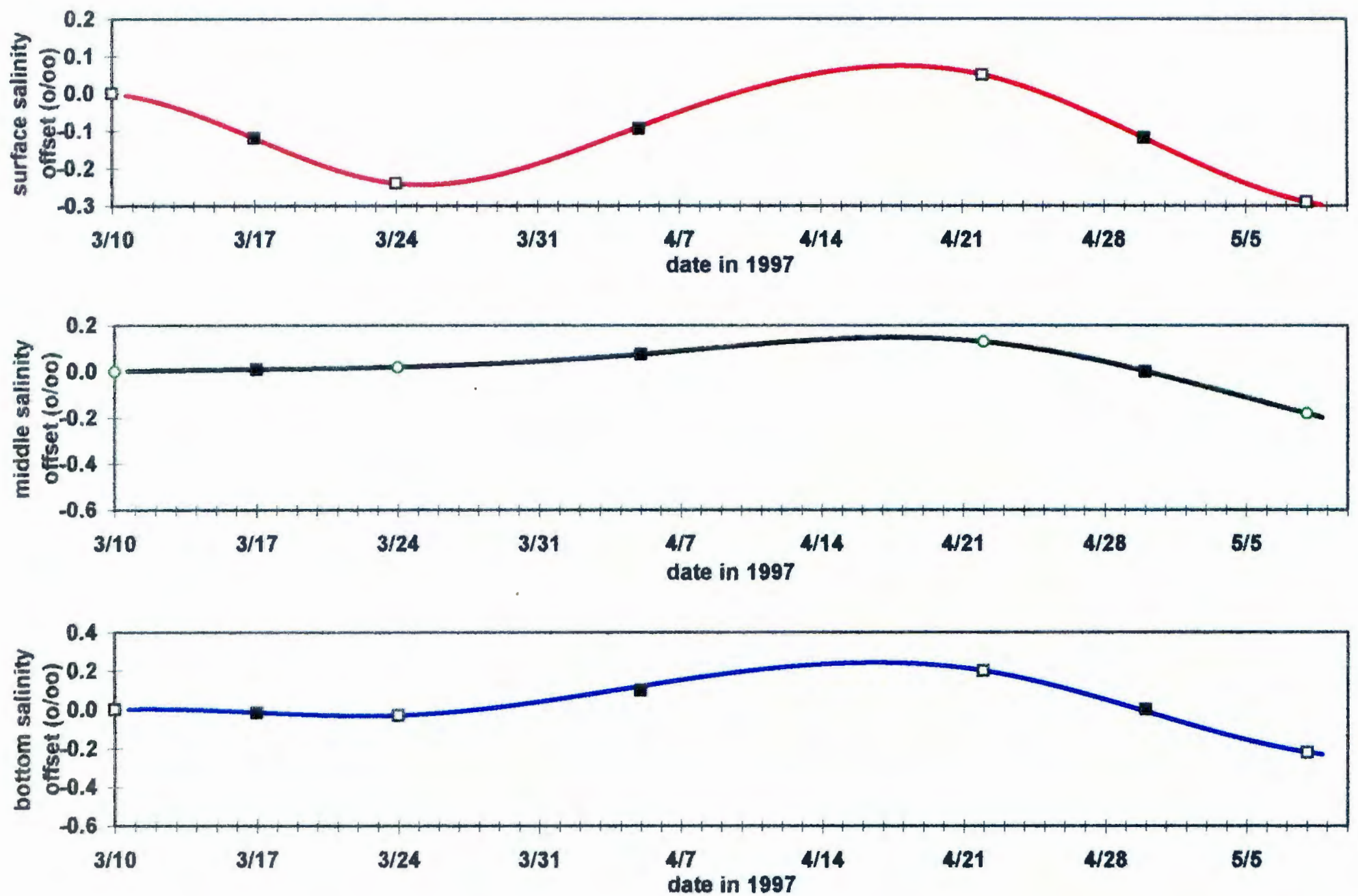
Figure $22 \mathrm{a}$ and $\mathrm{b}$. Corrected salinity at three depths, $0.5-\mathrm{m}, 4.4-\mathrm{m}$, and $\sim 12.6-\mathrm{m}$, as measured, in twenty minute intervals, by the three YSI-600XL's attached to the buoy. 


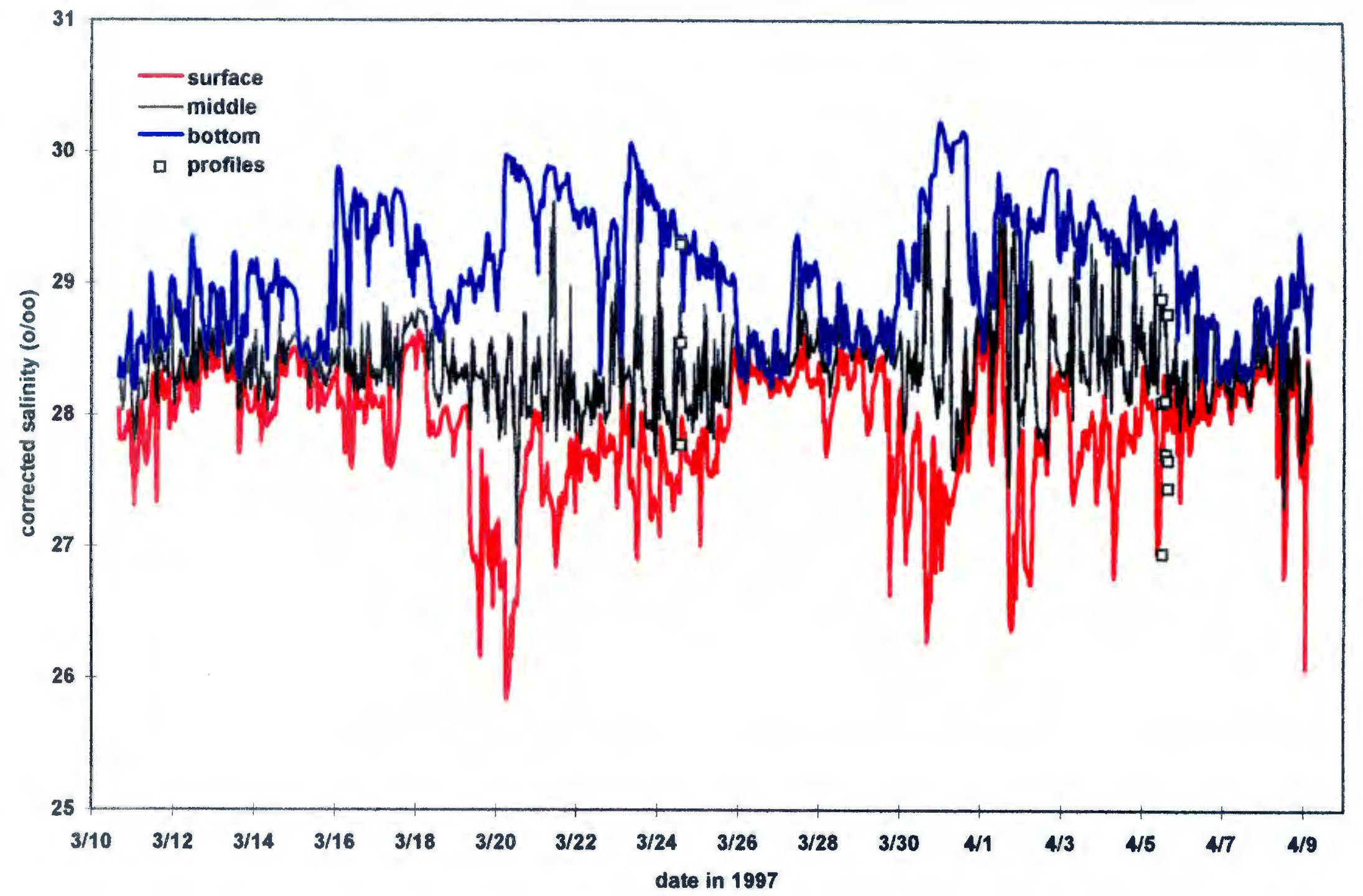




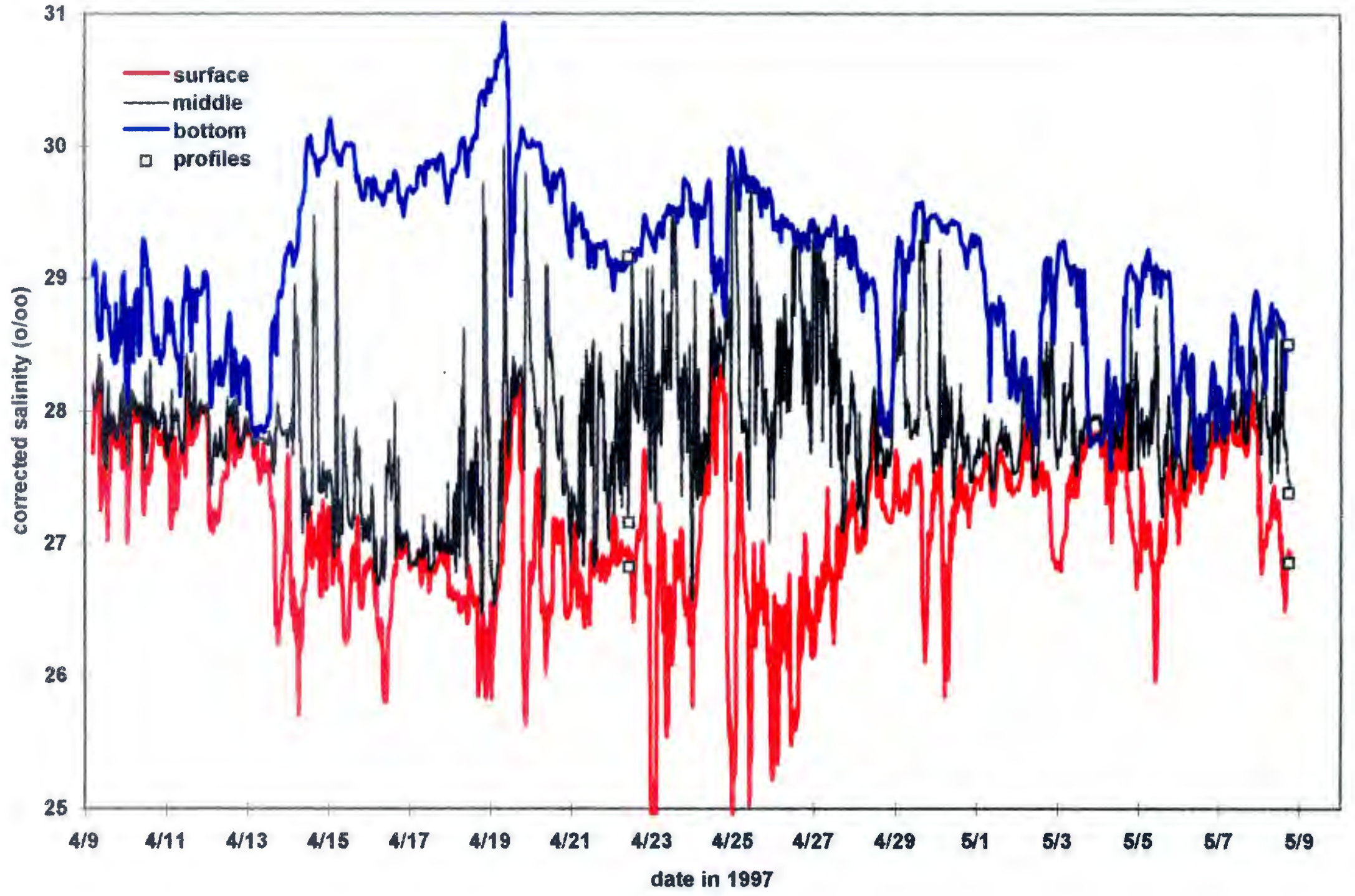


follows the features at the surface. Clearly the dominant feature, however, in the salinity record is the stratification on 13 April, in which deep salinity climbed by $20 / 00$ and the surface dropped by about $2 \mathrm{o} / \mathrm{oo}$, in a few brief hours.

\section{Raw Dissolved Oxygen Data and Development of Correction Factors}

From the raw oxygen data, a few needed corrections are apparent (Figure 19a and b). Two corrections were made to the dissolved oxygen time-series before the final calibration offsets were calculated. These corrections were necessary to develop accurate offsets, and consisted of correcting the first 14 days of surface oxygen data, based on the calibration offset for the air calibration performed on 24 March. The calibration offset, pre-calibration minus post-calibration was $14 \%$, and this offset was applied to the surface data from the deployment until the 24 March calibration. The second preliminary correction consisted of rotating the surface and middle instruments' oxygen data from 06:40 to $18: 00$ on 5 April. This period encompassed the time period during which we changed the logging interval to 5 minutes, for the ADCP profiling. It appears that changing the logging interval also changed the oxygen sensor's ability to continue logging at the same accuracy. The reduction in the sensor's "sleep" time introduced a gradual drift in the instruments' oxygen sensors (Figure 23), apparently related to the energized period for the sensors (Kester and Magnuson, 1994). We determined the overall drift by comparing the last value at the 5 minute interval, taken at 18:00 with that from the first succeeding 20 -minute sample, a $5.6 \%$ difference for the surface instrument, and a $6.7 \%$ difference for the middle instrument, and a $3.2 \%$ difference for the bottom instrument. This change over the 11 hour period was incrementally applied from the start of the 5minute sampling until the return to 20 -minute sampling (Figure 24). 
Figure 23. Temperature, Salinity and Dissolved oxygen for three depths, $0.5 \mathrm{~m}, 4.4 \mathrm{~m}$ and $\sim 12.6 \mathrm{~m}$, on 5 April 1997. At 06:00 the buoy was switched from a 20 minute sampling interval to a 5 minute sampling interval. At 18:00 the buoy was switched back to a 20 minute sampling interval. This switch caused a drift in the three instruments, evident by the large difference between the $18: 00$ reading and the $18: 20$ reading. The profiles 2,5 , and 7 , at noon, 14:15 and 15:30, respectively, are marked with the readings at the depths of the buoy instruments marked as " $\mathrm{S}$ ", " $\mathrm{M}$ " and " $\mathrm{B}$ ", for surface, middle and bottom. 

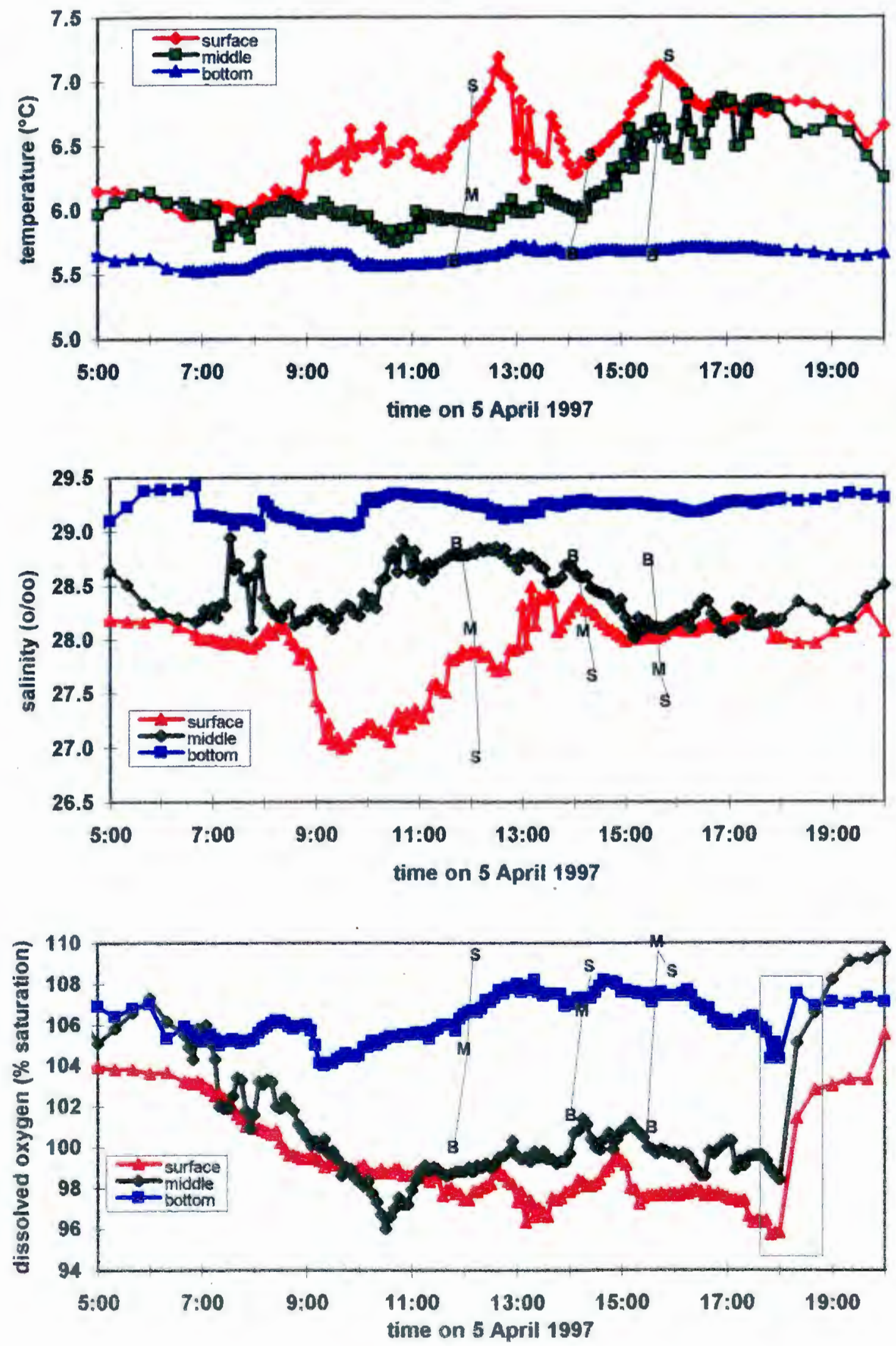
Figure 24. Dissolved oxygen as recorded by the surface, middle and bottom instruments.

The data marked as " + " markers are raw data, and the filled squares indicate the corrected data, having been incrementally offset to remedy the drift as indicated in Figure 23. The profiles 2,5 , and 7 , at noon, $14: 15$ and $15: 30$, respectively, are marked with the readings at the depths of the buoy instruments marked as " $\mathrm{S}$ ", "M" and " $\mathrm{B}$ ", for surface, middle and bottom. 

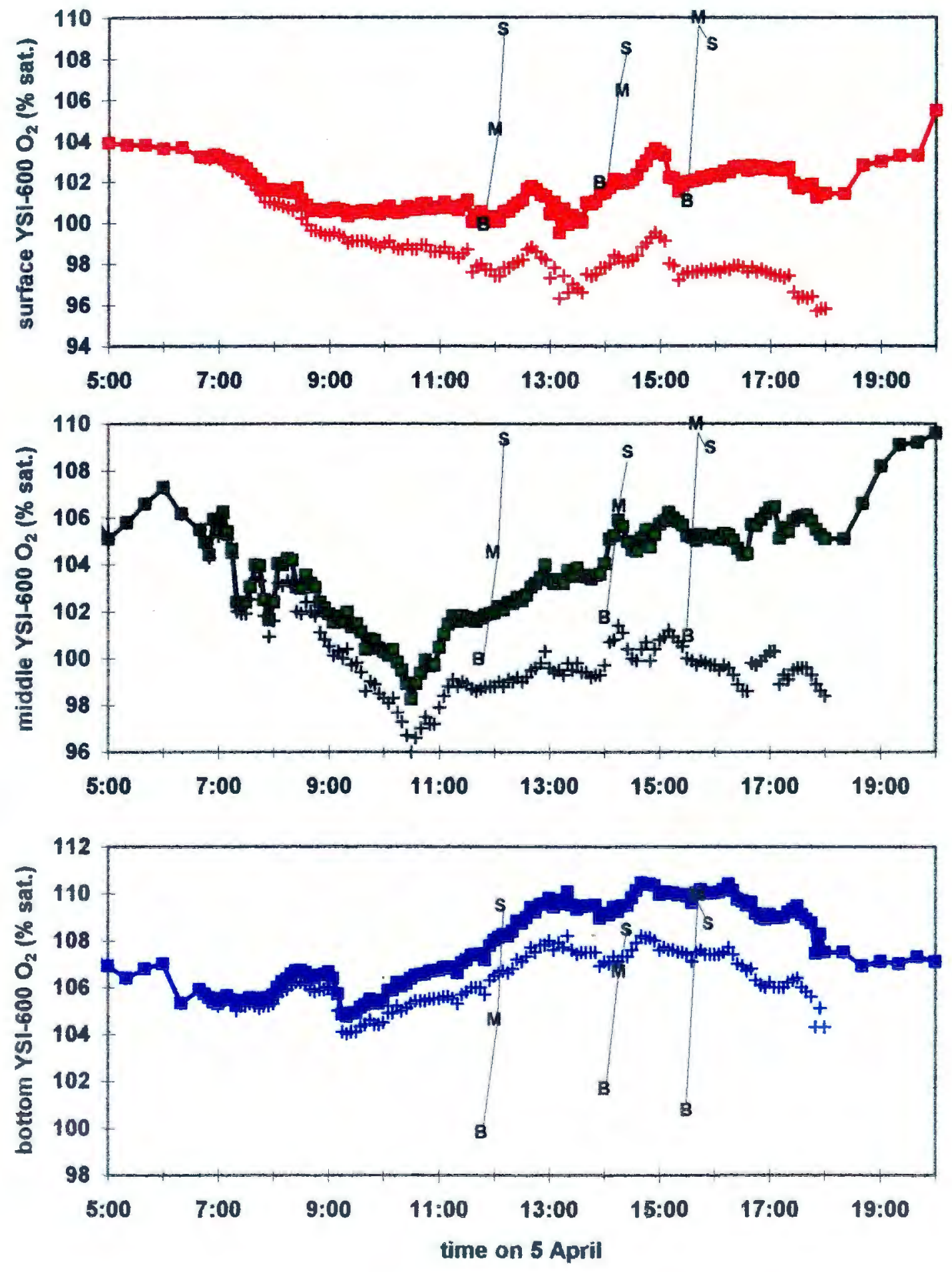
We constructed a table similar to that for salinity, to compare the calibration and profile offsets (Table 3). The fact that the surface dissolved oxygen pre-deployment calibration was offset suggested that the middle and bottom initial calibrations should not be assumed to be valid, therefore we assumed that the $1.7 \%$ offset for the surface instrument, based on the 24 March profile comparison, could be applied back to the beginning of the deployment. Using this corrected surface oxygen data, we averaged the surface - middle and surface - bottom oxygen offsets for four mixing events, on 13 March, 15 March and two on 26 March. We obtained $-4.4 \%$ for the middle - surface difference and $-8.3 \%$ for the bottom - surface difference over 40 values, with 0.3 and 0.8 as standard deviations for the middle and bottom averages, respectively. As in the salinity correction, the offsets were plotted versus time since deployment of the buoy and a curve in 20 minute intervals was fitted to the offset data. Points as midpoints of the line described by adjacent offset data were added on 17 March and 31 April, to constrain the curves (Figure 25). These correction factors were then added to the preliminarily corrected raw data to obtain corrected oxygen time-series for the surface, middle and bottom instruments (Figure 26a and $b$ ).

In the corrected oxygen data, we observed trends in stratification which mirror those in temperature and salinity. There was a period of stratification from about 16-26 March, brief and understated stratification on 29 March and 3 April, and a broad and persistent period of stratification from 13 April until 3 May, which is interrupted on 19 April, 24 April and 28 April by partial mixing events. In general, the surface instrument recorded the highest $\%$ saturation readings of the three instruments. The middle 
Table 3. The calibration offsets and profile-buoy offsets for the oxygen sensors for the three buoy YSI-600's. Boldface values were used to determine a correction curve, with mid-point values added on 17 March and 30 April, to constrain the shape of the curves. Values which were not used are in normal type and a superscript indicator of the reason for disregarding these values is included. The parentheses mark assumed offsets for the initial readings, calculated via four mixing events prior to 26 March 1997.

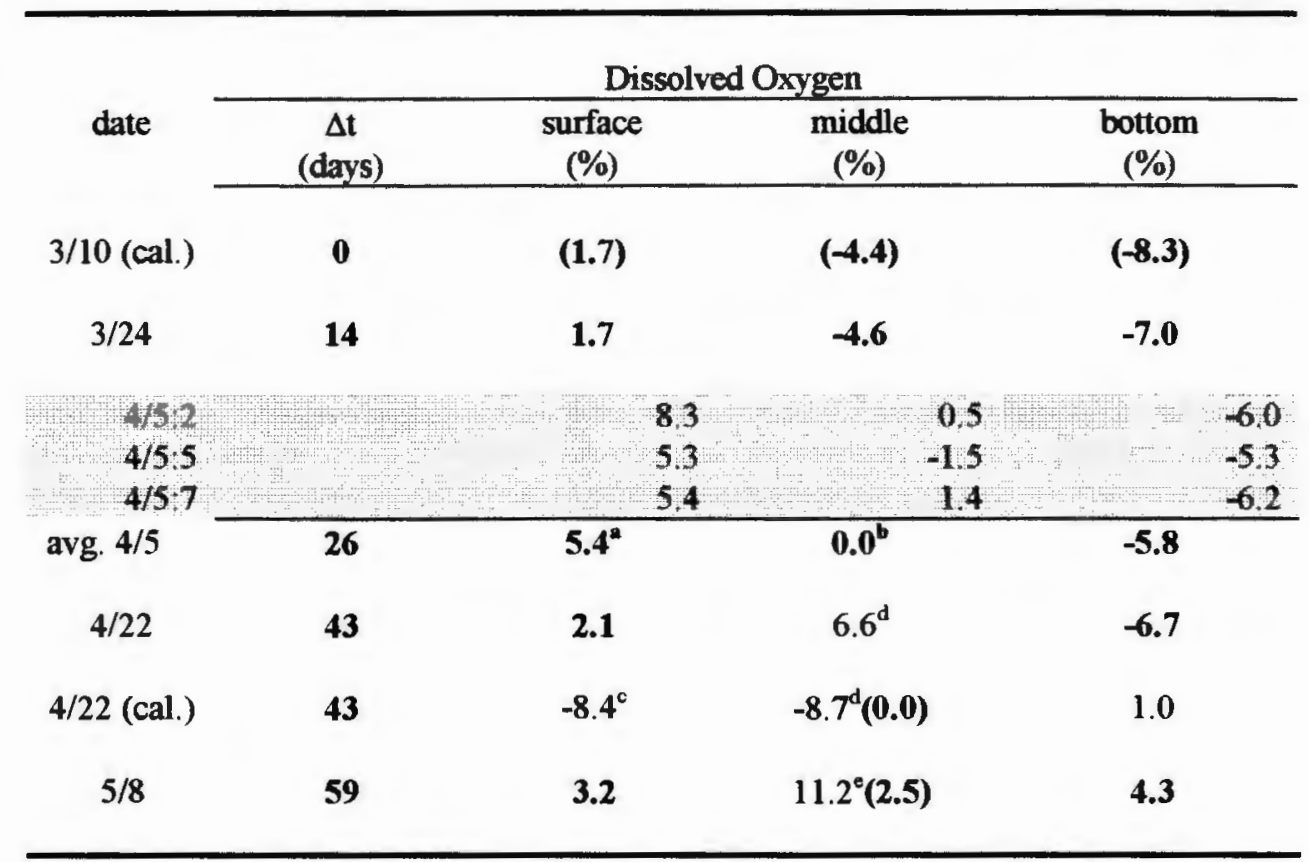

${ }^{a}$ The average for this value was computed using only the 5 and 7 profile, as the offset from the 2 profile was greatly different from the other two offsets.

${ }^{b}$ The offsets for all three profiles for the middle instrument were of similar, and minor magnitude, and mixed sign, therefore no offset was applied.

${ }^{c}$ This offset was greatly different from both the profile offset, and from the other offsets for this instrument, therefore, the 2.1 offset from the profile comparison was applied, vice the calibration offset.

${ }^{d}$ The offsets for the middle instrument for 22 April were of similar magnitude and opposite direction for the profile and calibration, so no offset was applied. However, an examination of the raw data suggested that the $-8.7 \%$ calibration offset was applied in error. We therefore removed the effects of this calibration offset from the middle instrument's oxygen data from 22 April until the end of the record.

e The raw data offset was $11.2 \%$, however, after adding in the $8.7 \%$ from the erroneous offset on 22 April, the difference becomes $2.5 \%$, and this value was used for the 8 May offset. 
Figure 25. The correction curves for the oxygen sensors for the three buoy YSI-600's. The open black squares indicate the positions of the data used from Table 3 in generating the curves. The filled black squares indicate mid-point, tie-points added to constrain the curves to a form supported by the data. 

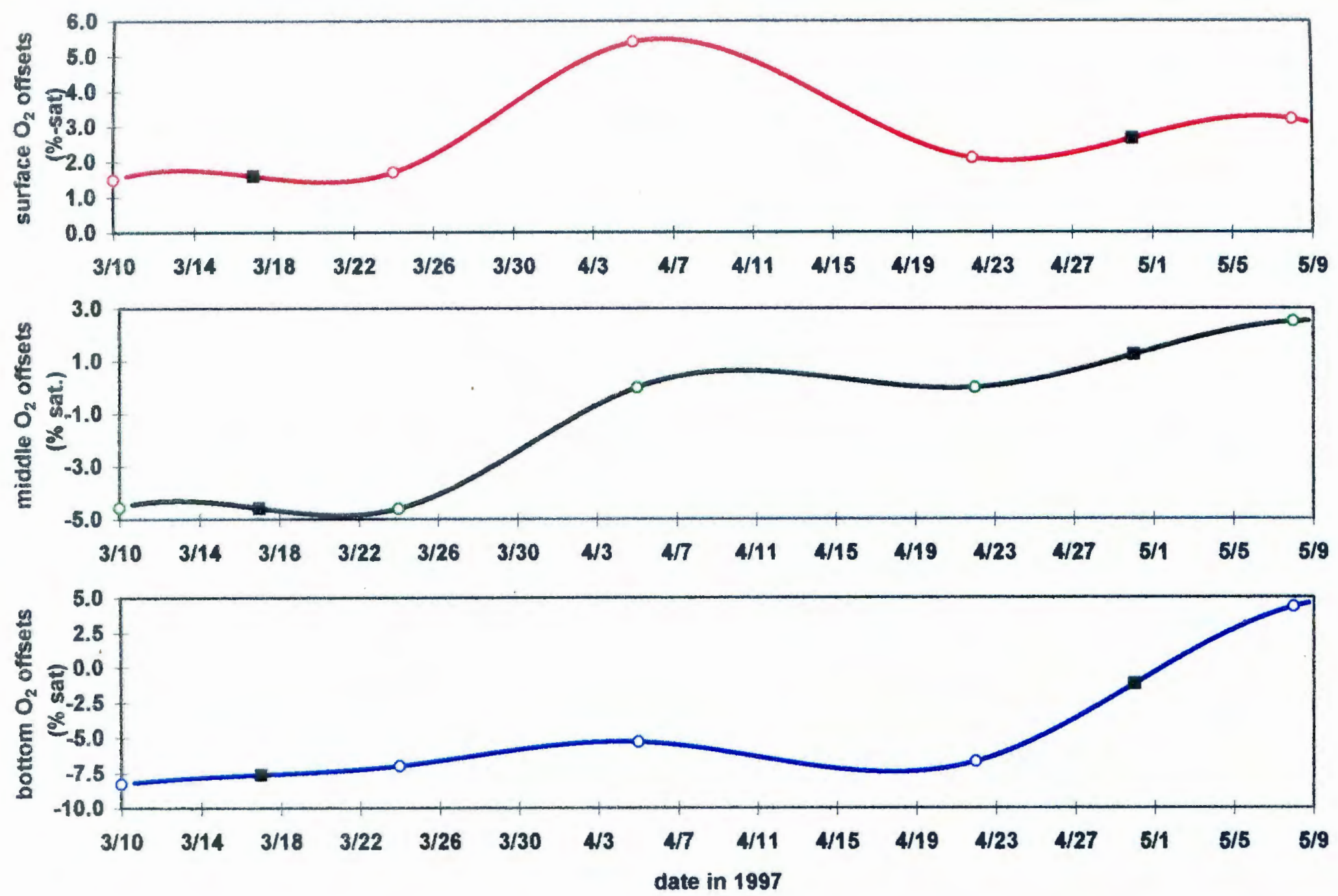
Figure 26a and $\mathrm{b}$. Corrected dissolved oxygen at three depths, $0.5-\mathrm{m}, 4.4-\mathrm{m}$, and $\sim 12.6-$ $\mathrm{m}$, as measured, in twenty minute intervals, by the three YSI-600XI's attached to the buoy. 


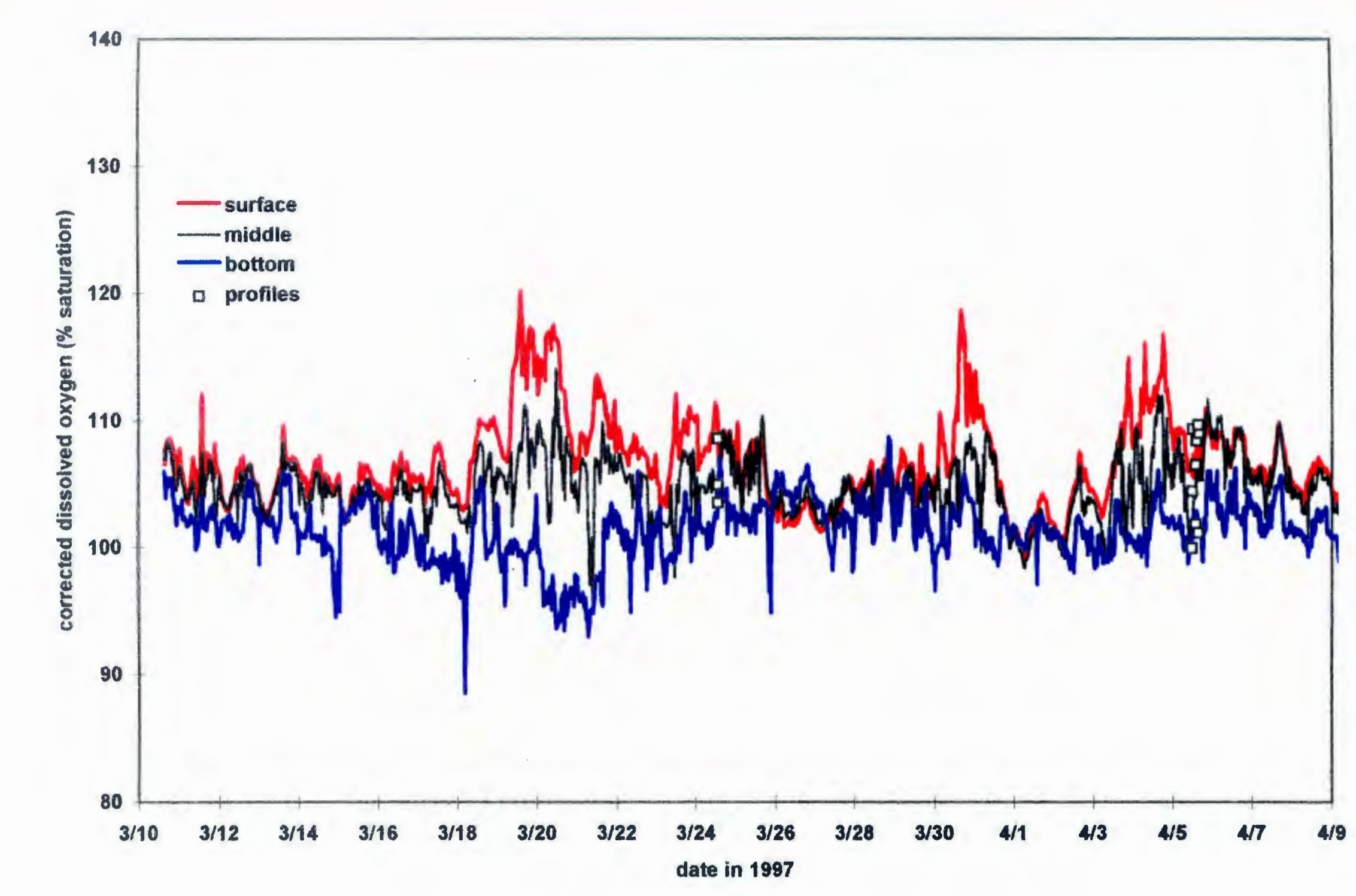




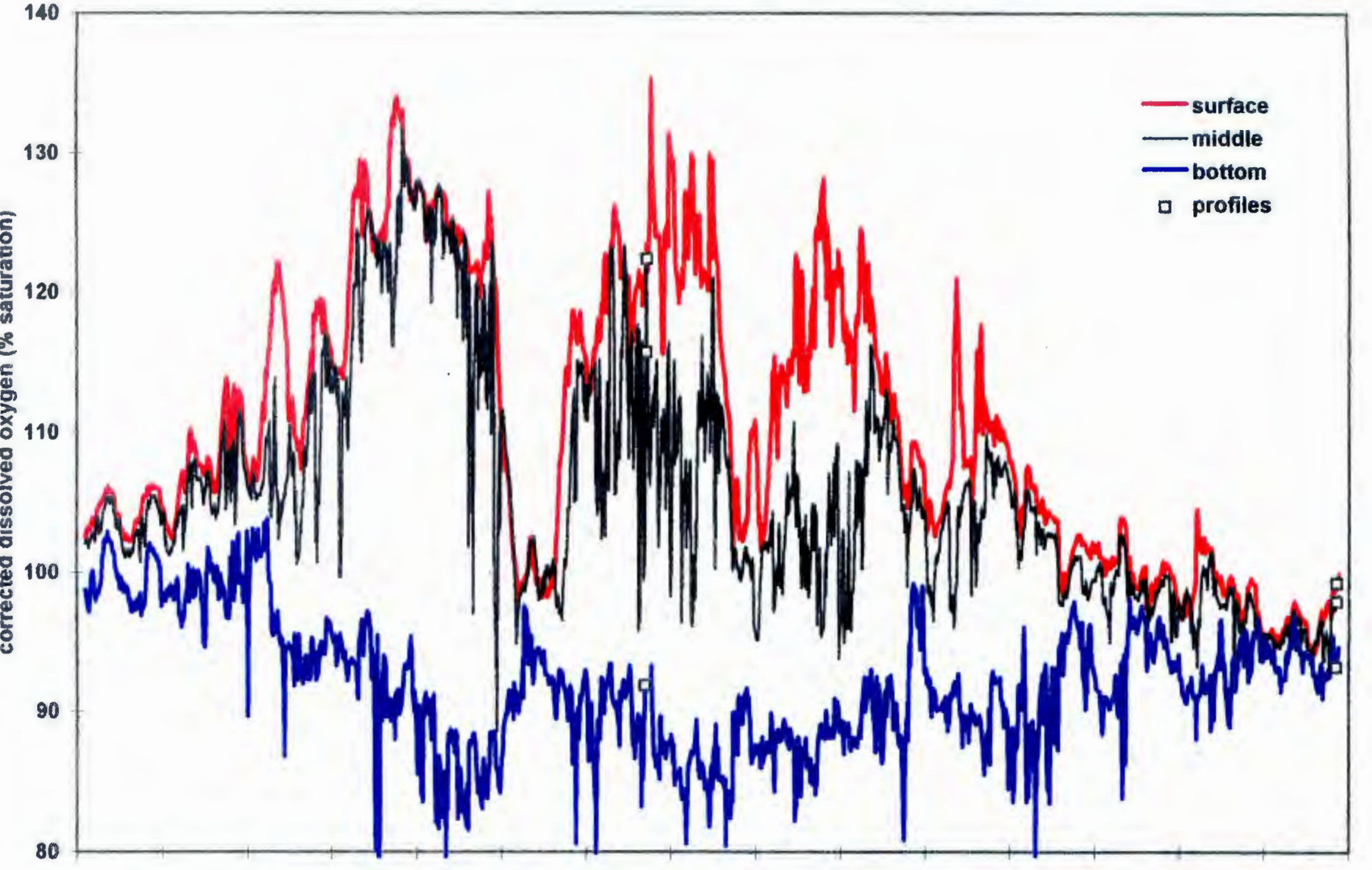


instrument more closely followed the features of the surface instrument than the bottom instrument. There were several occasions when bottom oxygen levels were equal to or greater than those at the surface. These occasions included portions of $13 \mathrm{March}, 15$ March, 26 March, 1 April and 6 May.

\section{Buoy Pressure or Depth Data}

Raw pressure data was collected by all three instruments, to indicate the depths over the time-series (Figure 27a and b) Observations of the depth records for the three instruments convey a sense of the conditions at the buoy. The deep instrument was moored to the bottom, and thus provided a record of the observed tides. The middle instrument was suspended approximately 4.4 meters below the bottom of the buoy on its data cable and a nylon line. This instrument was not rigidly attached to the buoy and was able to swing freely in the current, but it was weighted with a $4.5 \mathrm{~kg}$ weight, designed by Mr. David Butler, from GSO Equipment Development Lab (EDL). The surface instrument was contained in a perforated PVC pipe, attached to the side of the buoy. The surface instrument's data cable was fastened such that it.was positioned within the PVC pipe at about 0.6 meters depth.

There are two factors which must be accounted for in correcting the pressure data from the buoy. First, the sensors are prone to drift from their calibrated values over time. Second, the instruments measure absolute pressure via a strain gauge, meaning that in addition to the pressure of the water column above the instrument, the instruments also indicate the atmospheric pressure above the instrument as well. Thus, when atmospheric pressure is low, the pressure reading is lower for an equal height of water (of equal density), as when the atmospheric pressure is higher. In order to obtain observed tide 
Figure $27 \mathrm{a}$ and $\mathrm{b}$. Raw pressure data at three approximate depths, 0.5-m, 4.4-m, and $\sim 12.6-\mathrm{m}$, as measured, in twenty minute intervals, by the three YSI-600XI's attached to the buoy. 


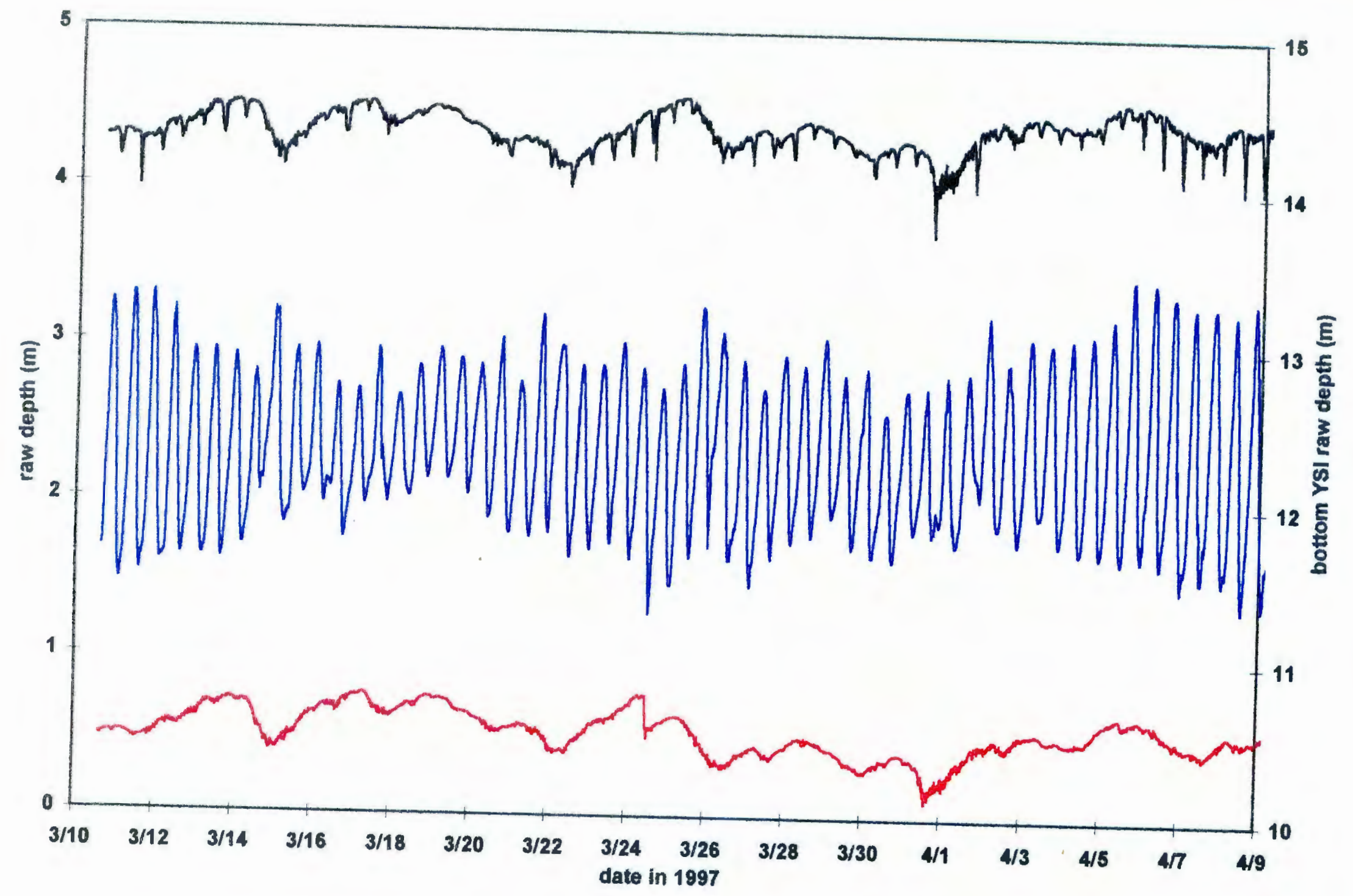




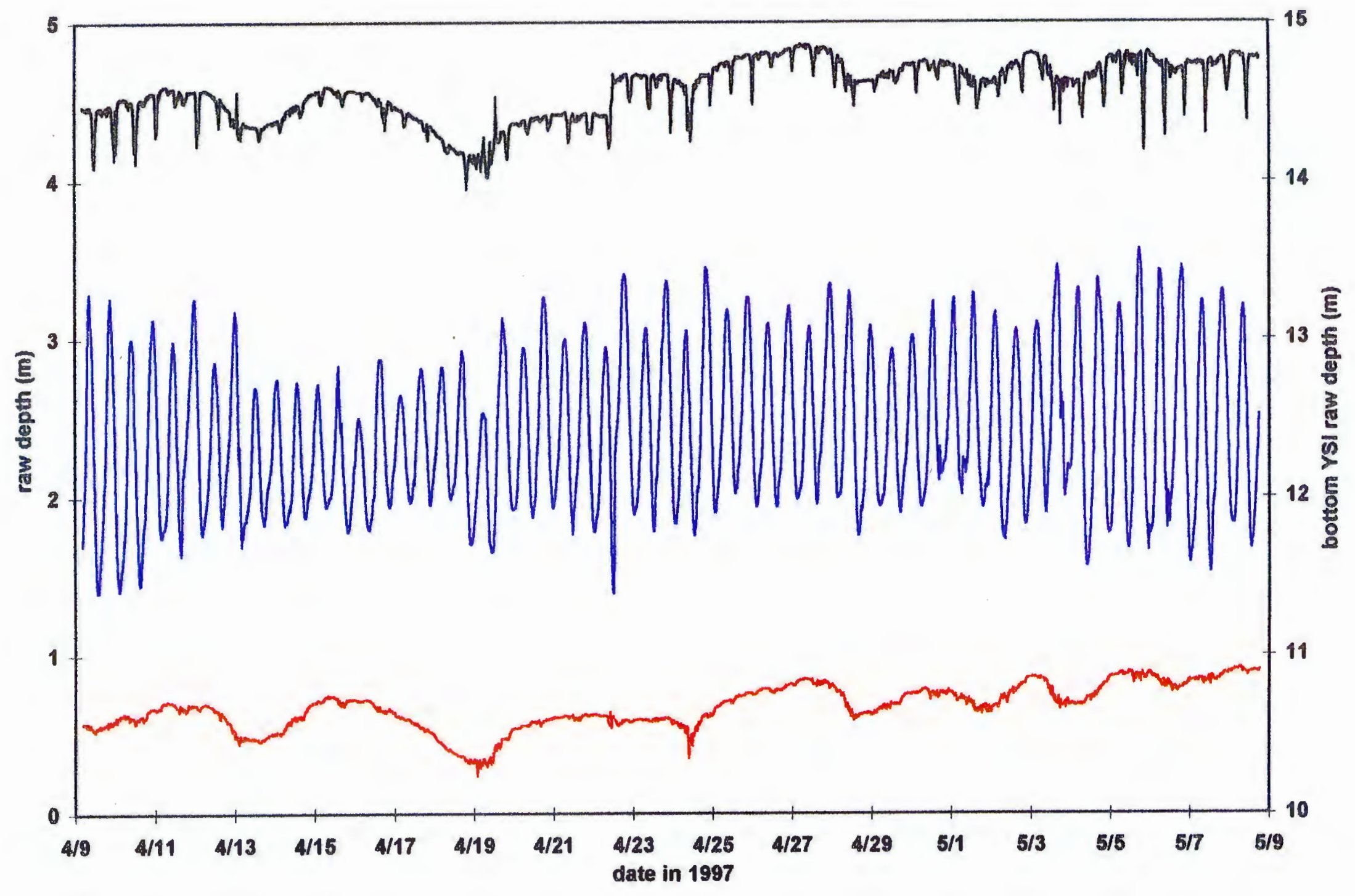


information from the bottom instrument, one must first remove the effects of these two factors from the data set. To remove the drift from calibration, the data set was separated into two sections, before 22 April and after 22 April, because after the 22 April calibration, the drift rate may have changed for each instrument. Figure 28 shows the linearly-estimated drifts for each instrument both before and after the 22 April calibrations, plotted against time since deployment, or $\Delta \mathrm{t}$. One also notes the box around the data shift at 13.5 days. This offset of $0.216 \mathrm{~m}$, the pre-calibration minus post-calibration, was removed from the data set by adding $0.216 \mathrm{~m}$ to values following the 24 March calibration. The drifts were then removed from the first portion of the time-series by adding the slope $\mathrm{x} \Delta \mathrm{t}$ to the raw value. The same process was performed on the second portion of the data, in that the slopes $x \Delta t$ were multiplied to the raw data. Then the calibration offsets from 22 April were removed from the data to create a fully corrected pressure data set (Figure 29).

The spring-neap cycle in the tidal signal was clearly observed with neap conditions prevailing around $16 \mathrm{March}, 30$ March and 15 April, and spring tides evident on 24 March and 8 April. By subtracting the surface data from that of the middle and bottom data, we were able to determine the observed tidal signal at the buoy. When this was compared to the predicted tide from Newport, RI for the same period, we were able to observe some occasions where the observed signal exceeded the predicted depths, considering similarly scaled values (Figure 30). These occurred on 15 March, 22 March, 26 March, 2 April, 57 April, and quite often between 18 April and 7 May. The curve greatly departed from prediction, to lower values, on $25 \mathrm{March}$, on 9 through 11 April, and 14 through 17 April. 
Figure 28. Raw pressure data from three depths versus $\Delta t$, showing the linear drift for all three instruments over time, from the beginning of the deployment to 22 April at 13:00, and a separate linear drift, per instrument, for 22 April at 13:20 to the end of the deployment. The surface instrument had an additional correction, on 24 March at 13:40, which consisted of the addition of $0.214 \mathrm{~m}$ from 24 March until 22 April. 


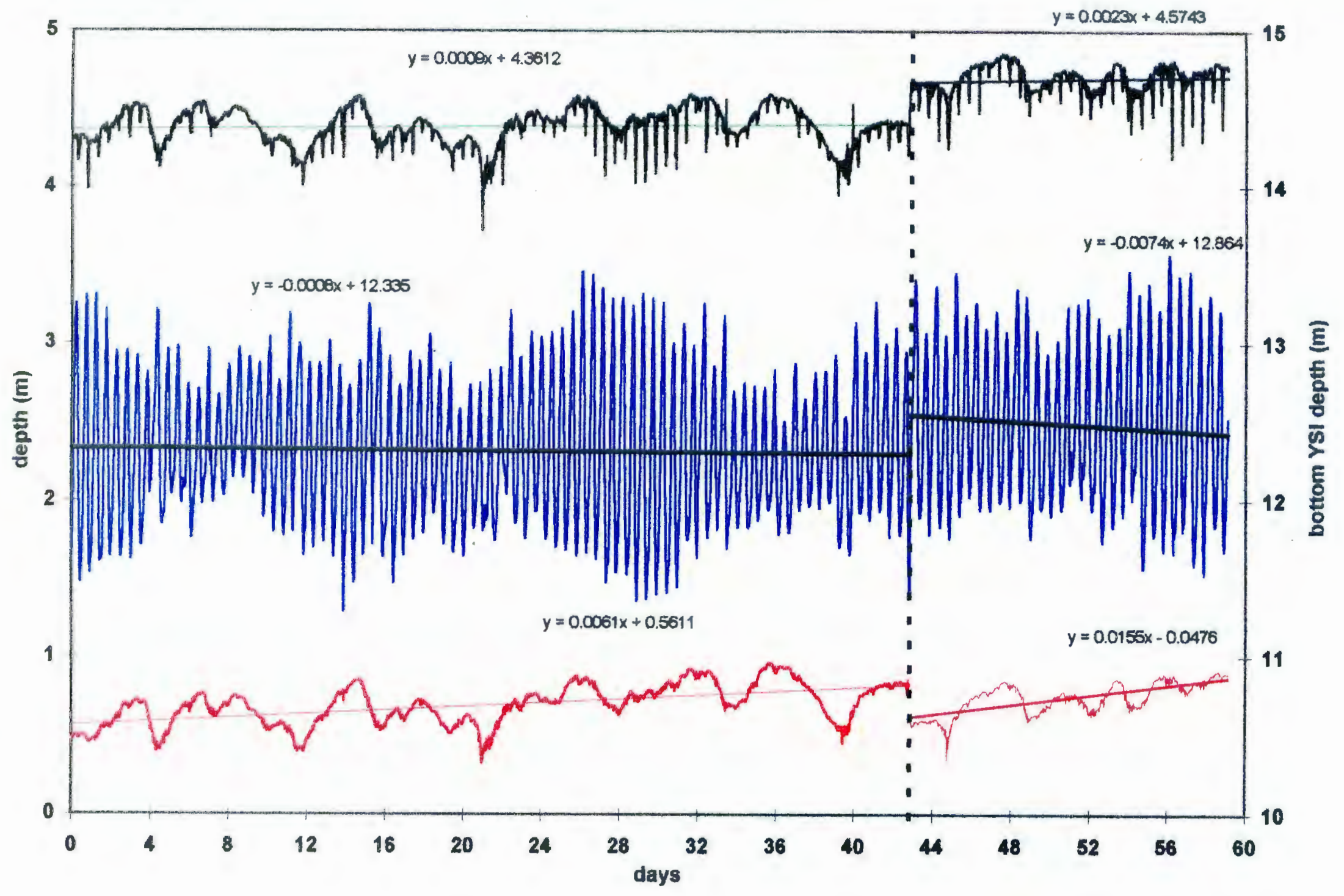


Figure 29. Corrected pressure data from three depths versus $\Delta t$, corrected using the drifts from Figure 40 and the calibration offsets. The surface and middle instruments' data are plotted on the left-hand y-axis, and the bottom instrument data is on the right-hand y-axis. 


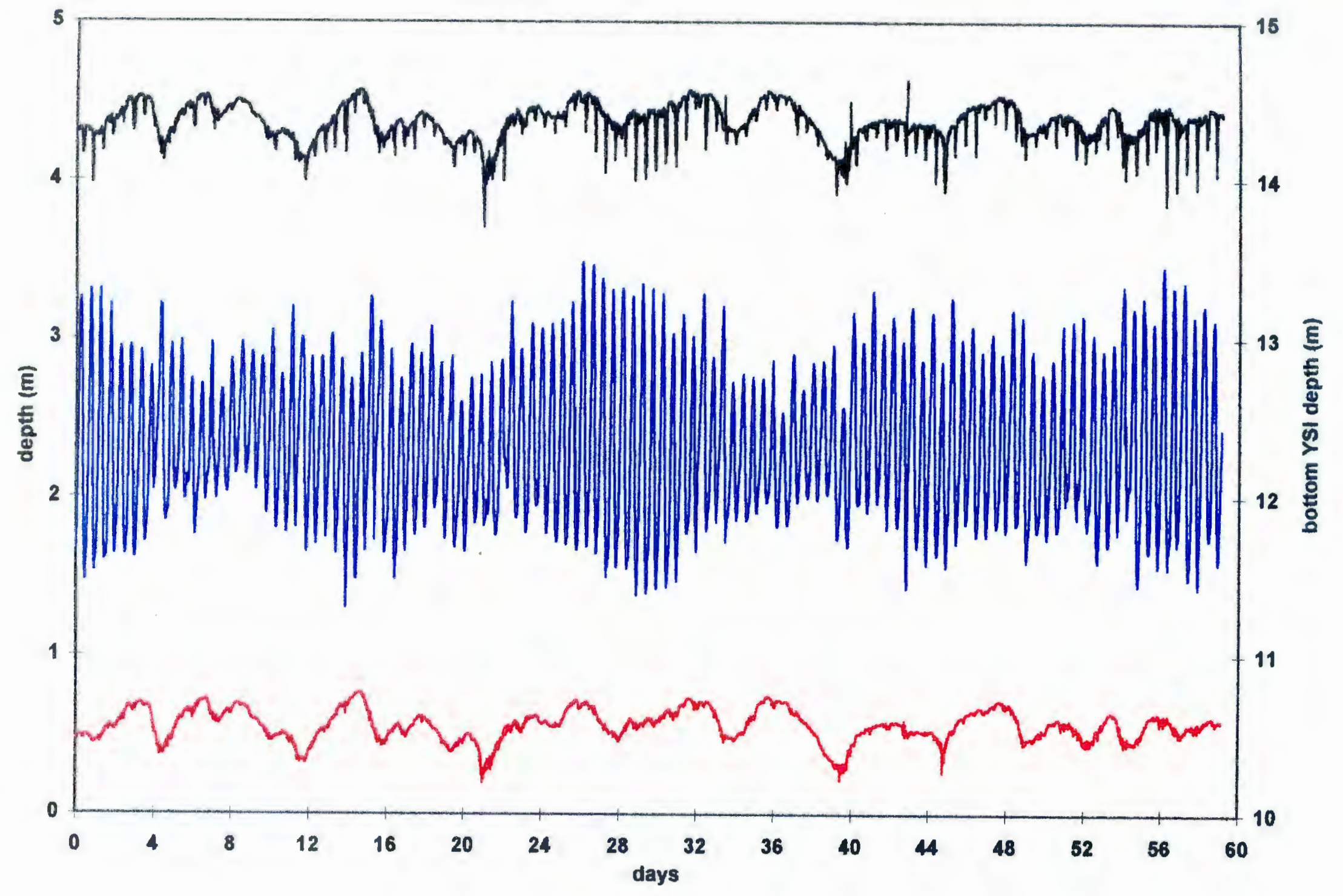


Figure $30 \mathrm{a}$ and $\mathrm{b}$. The difference between bottom and surface depth readings, giving the corrected tidal signal, with the offsets and the inverted barometer effect removed. It is plotted against time, and compared to the predicted tides from Newport, RI astronomical predictions, and both scaled to the same magnitudes. 


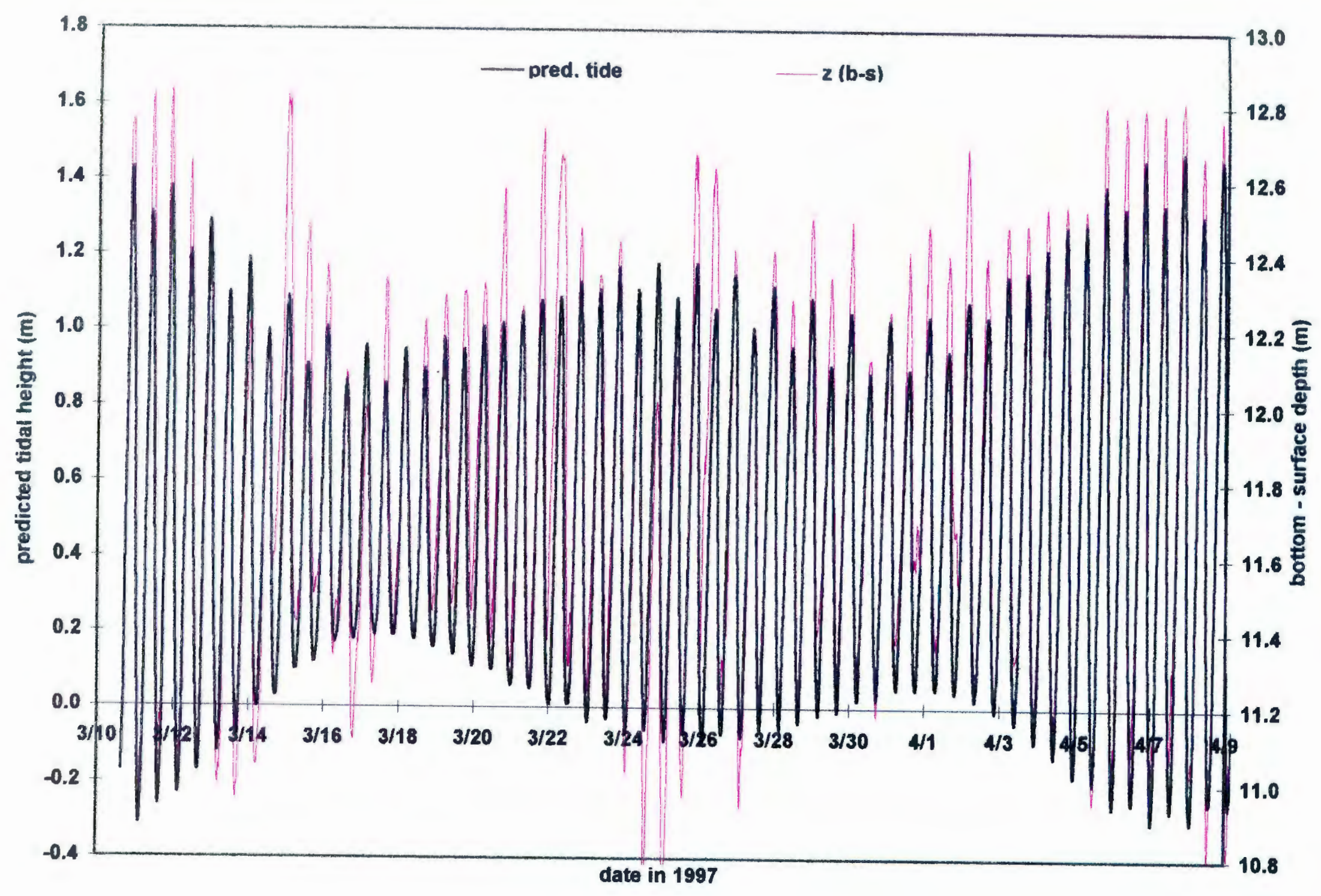




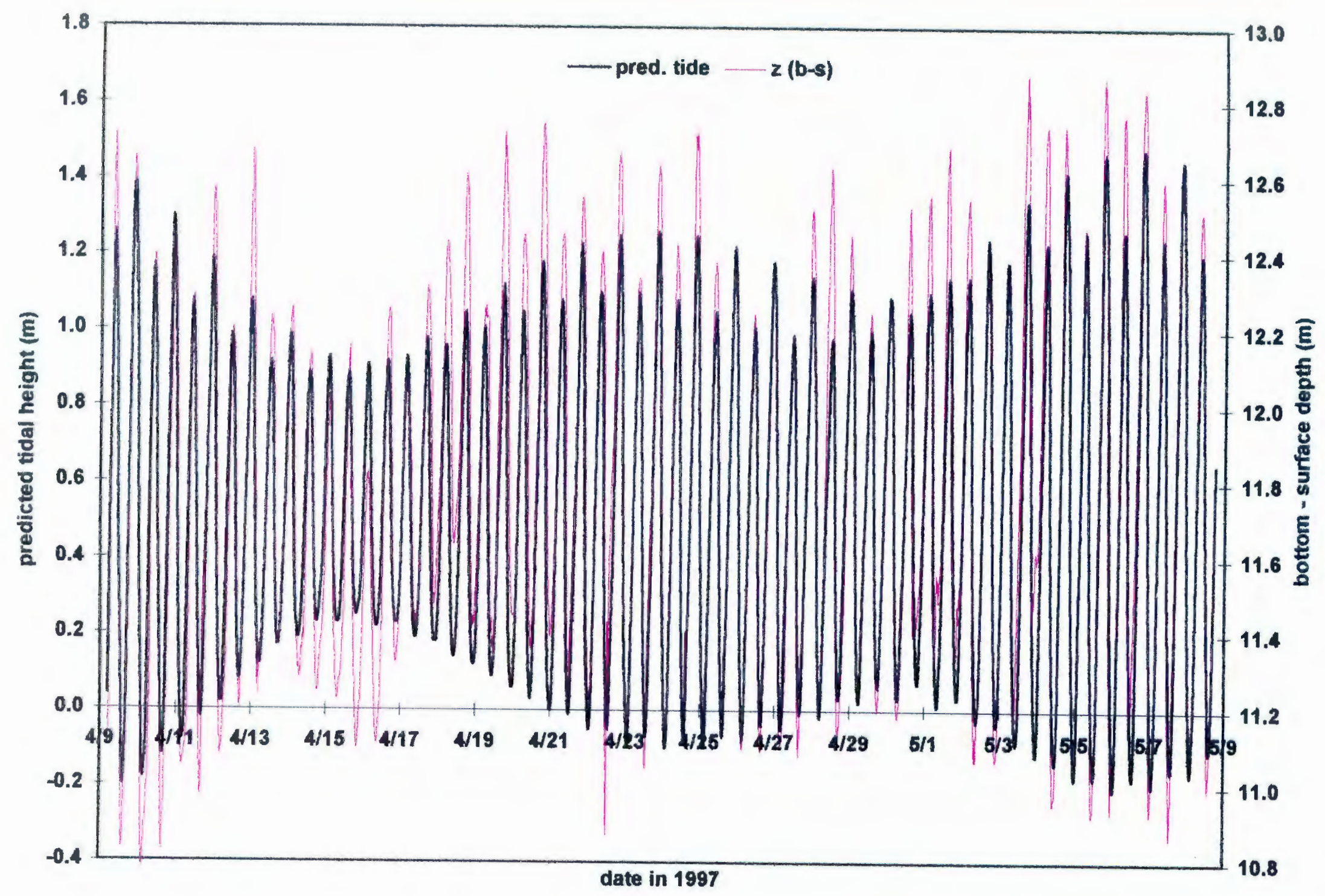




\section{Discrete Profiles at Buoy Station}

Vertical profiles were taken at the buoy station on 24 March, 5 April, 22 April and

8 May. All profiles were taken using a YSI-6000 sensor, capable of measuring

temperature, salinity, dissolved oxygen, $\mathrm{pH}$, redox potential, turbidity and pressure, however, only temperature, salinity and dissolved oxygen will be displayed and discussed in this thesis. It should be noted that there were some differences between some of the profiles. The profile on 24 March was taken during a routine download from the buoy, and while the boat was tied to the buoy. The profiles from 5 April were taken during the ADCP transects, and were taken by the Melanitta which was anchored between 15 and 60 meters to the northeast of the buoy. The profiles on 22 April and 8 May were both taken about an hour after a download from the buoy, and the boat was tied to the buoy. Distance from the buoy sensors, in both space and time, in the case of the 5 April profiles may have introduced uncertainty in the comparison with buoy data, however, given the level of tidal mixing in Narragansett Bay, we expect that the errors resulting from horizontal gradients and temporal differences are minimal, especially during periods of actively rising or falling tides.

The 24 March profile showed the warming of Bay surface water to nearly the same temperature as that in the deep layer (Figure 31). The surface layer extended down to about $2 \mathrm{~m}$. Salinity was gradually increasing from the half-meter estimation of $27.77 \mathrm{o} / \mathrm{oo}$. A mixing layer was found between $2.4 \mathrm{~m}$ and $6.4 \mathrm{~m}$, in which dissolved oxygen was decreasing with depth and salinity was increasing with depth, to the top of a fairly homogenous deep layer, at around $7 \mathrm{~m}$. All parameters were roughly homogenous with depth in this deep layer, but salinity increased slightly near the bottom to $29.4 \mathrm{o} / 00$ 
Of seven profiles taken on 5 April, in conjunction with the ADCP fieldwork, three were obtained in the vicinity of the buoy. Profiles 2,5 and 7 were taken at 11:57, 14:11 and 15:38, respectively, and were obtained less than 100-m northeast of the buoy station. Profiles 1 and 4 were taken to the south, and profiles 3 and 6 were taken to the north. These other profiles do not add to this analysis, and therefore will not be discussed. At the time of profiling at the buoy station, the Bay was approaching low tide, with slack water calculated from the Newport, RI prediction at 12:09 pm. The following high tide was at $18: 00$.

Profile 2 (Figure 32 ) shows that the water column was very similar to conditions during the 24 March profile, with a deep homogeneous layer extending from approximately $7 \mathrm{~m}$ to the bottom. Within this deep layer, salinity was high at almost 29 o/oo, and temperature was lower than at the surface, at about $5.5^{\circ} \mathrm{C}$. Dissolved oxygen was slightly supersaturated. There was no distinct surface layer, instead parameters gradually changed from the top of the deep layer to the surface. Temperature gradually rose to over $7^{\circ} \mathrm{C}$ at the surface and salinity gradually faded to $26.80 / 00$. Dissolved oxygen increased to maximum values at the surface, of $110 \%$ saturation.

Profile 5 (Figure 33) shows the relative effect of the incoming tide as surface salinities increased from the previous profile by almost $1 \mathrm{o} / 00$. Temperatures decreased at the surface and it should be noted that the southerly winds had begun to increase, wave height increased from negligible levels before noon to about $0.5 \mathrm{~m}$ by $14: 00$, and air temperature began to drop. The increase in wave action may have accounted for the mixing at the surface down to $1.5 \mathrm{~m}$. Below $2 \mathrm{~m}$, gradual changes in the water column were observed to about $12 \mathrm{~m}$, mostly observed in dissolved oxygen. 
Figure 31. A profile of Temperature, Salinity and Dissolved Oxygen taken on 24 March at approximately $13: 40$ at the buoy station. 


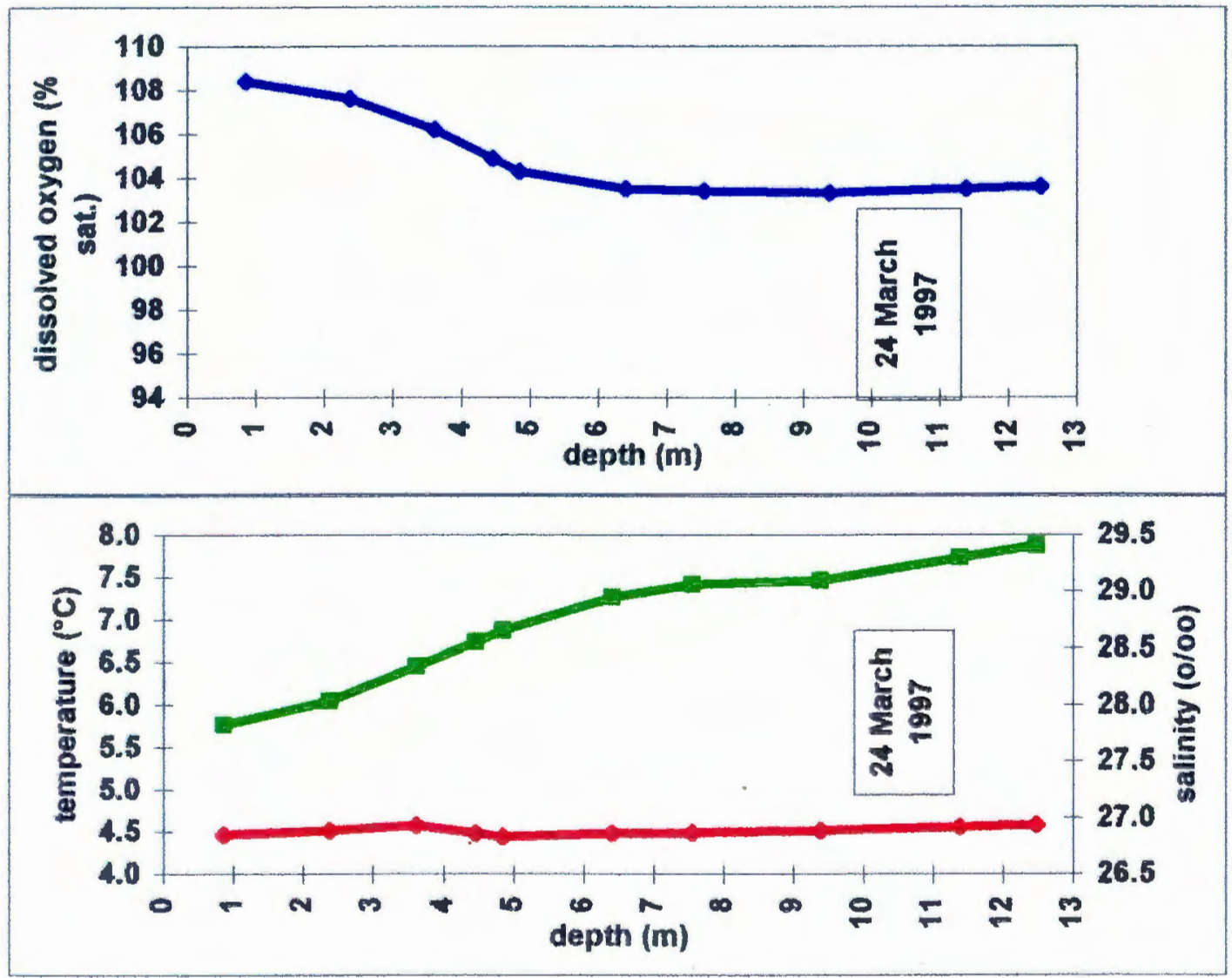


Figure 32. A profile, numbered " 2 ", of Temperature, Salinity and Dissolved Oxygen on 5 April at approximately noon at the buoy station. 


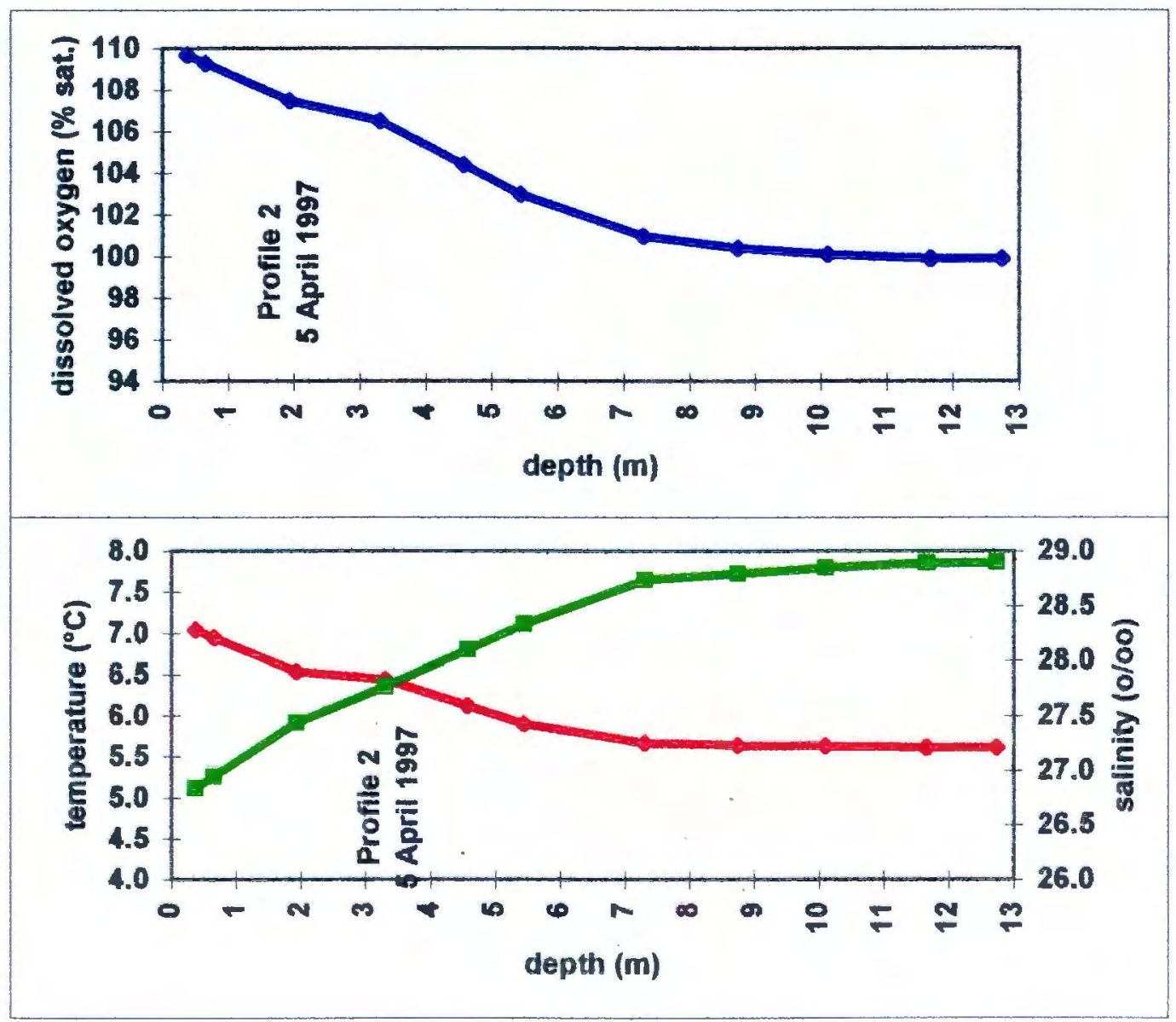


Figure 33. A profile, numbered " 5 ", of Temperature, Salinity and Dissolved Oxygen on 5 April at approximately $14: 15$ at the buoy station. 


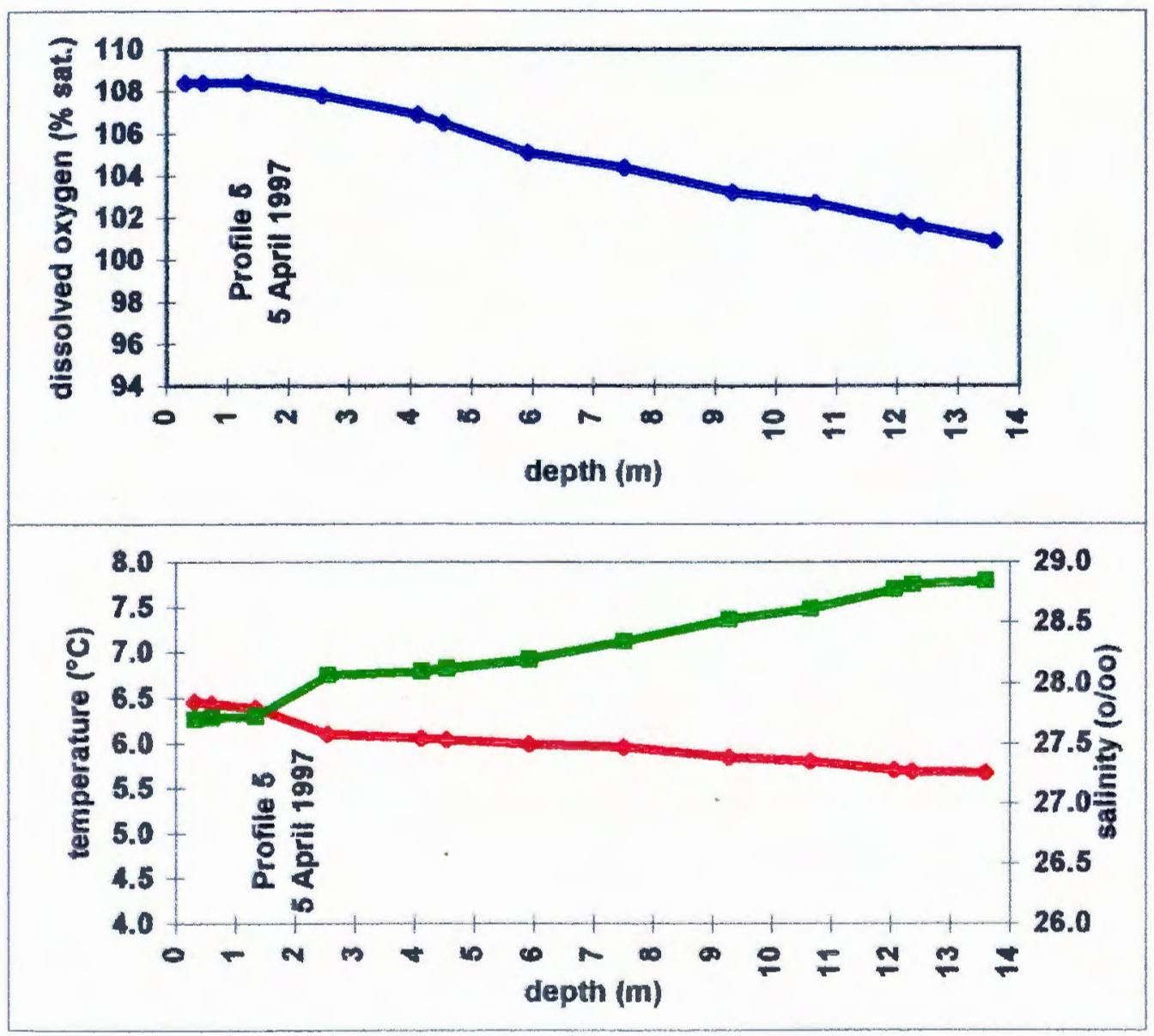


There was less than $1^{\circ} \mathrm{C}$ difference between the surface and bottom waters and the difference between surface and bottom in salinity was only $1.10 / 00$. Dissolved oxygen showed a nearly linear increase from bottom to surface with deep values near $100 \%$ saturation and surface values at about $108.5 \%$ saturation.

Profile 7 (Figure 34) showed slightly more dramatic gradients, especially in the dissolved oxygen record. Temperature and salinity are fairly homogeneous in a surface layer of about $2.4 \mathrm{~m}$ thickness, and in a deep layer from about $11.5 \mathrm{~m}$ to the bottom. Temperatures are slightly higher at the surface and salinity is lower. There is an interesting feature in the dissolved oxygen profile, in that there appeared to be a distinct mid-level layer, with high dissolved oxygen values, of almost $110 \%$-saturation. This midlevel layer began at about $4 \mathrm{~m}$ depth and extended down to about $7.2 \mathrm{~m}$ depth, and may be a result of the tide change.

The profile conducted on 22 April showed a much different situation than the previous profiles (Figure 35). The stratification was much more dramatic, and layering was distinct in all parameters, especially salinity. The surface layer extended to about 3.5 $\mathrm{m}$. This mixing layer extended to about $7 \mathrm{~m}$, below which the water column was absolutely homogeneous in salinity $(29.20 / 00)$, temperature $\left(6.73^{\circ} \mathrm{C}\right)$, dissolved oxygen $(91.9 \%)$. The differences in this profile from previous profiles was that this was the only profile obtained on an ebbing tide. Every other profile was obtained close to low tide or on a flooding current.

The 8 May profile displayed an interesting vertical structure, in all parameters, though the gradients were not large (Figure 36). The surface meter was distinct from the water immediately below it, down to about 6 meters. There appeared to be an interface 
Figure 34. A profile, numbered "7", of Temperature, Salinity and Dissolved Oxygen on 5 April at approximately 15:45 at the buoy station. 


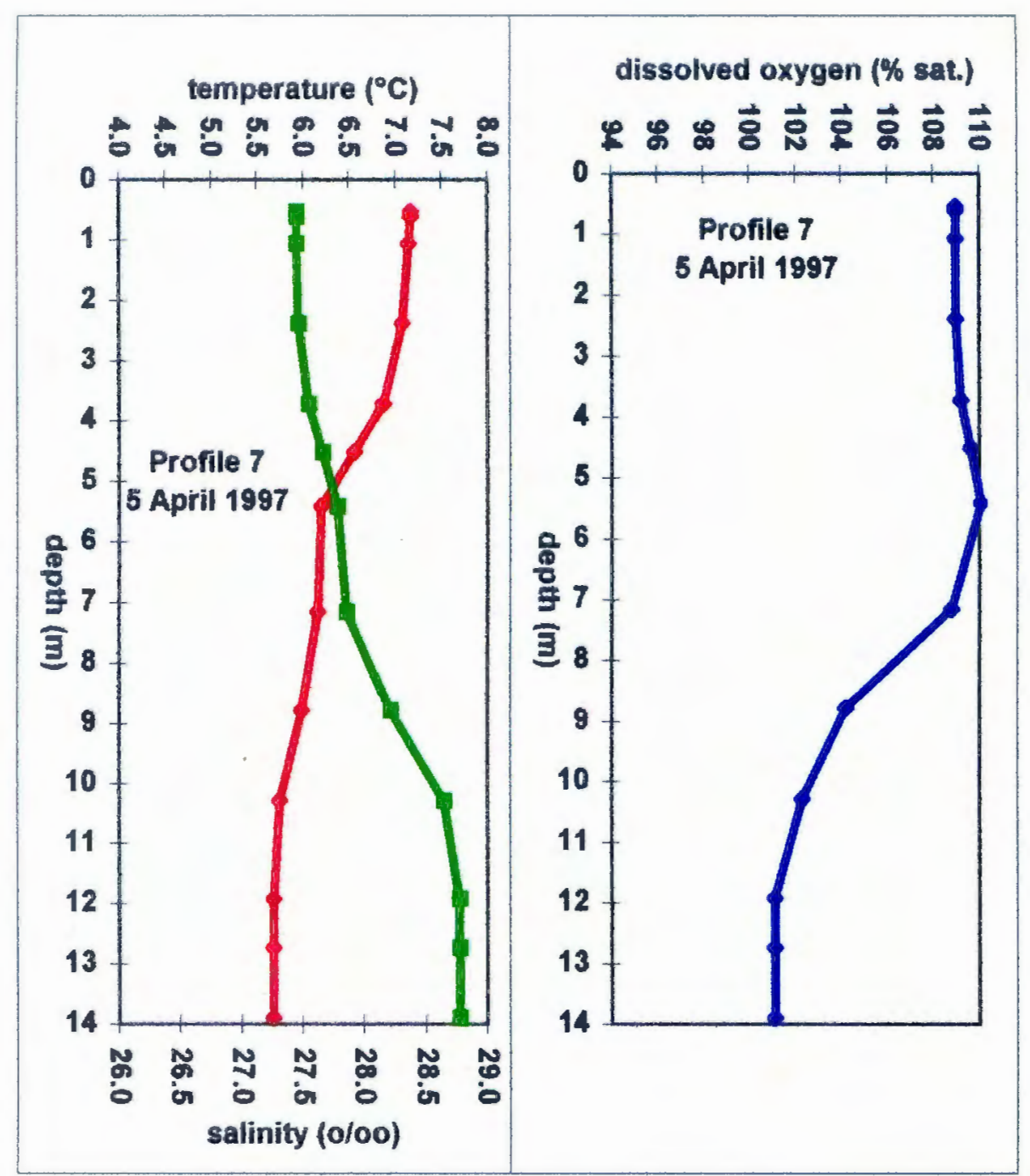


Figure 35. A profile of Temperature, Salinity and Dissolved Oxygen from 22 April at about 10:45 at the buoy station. 


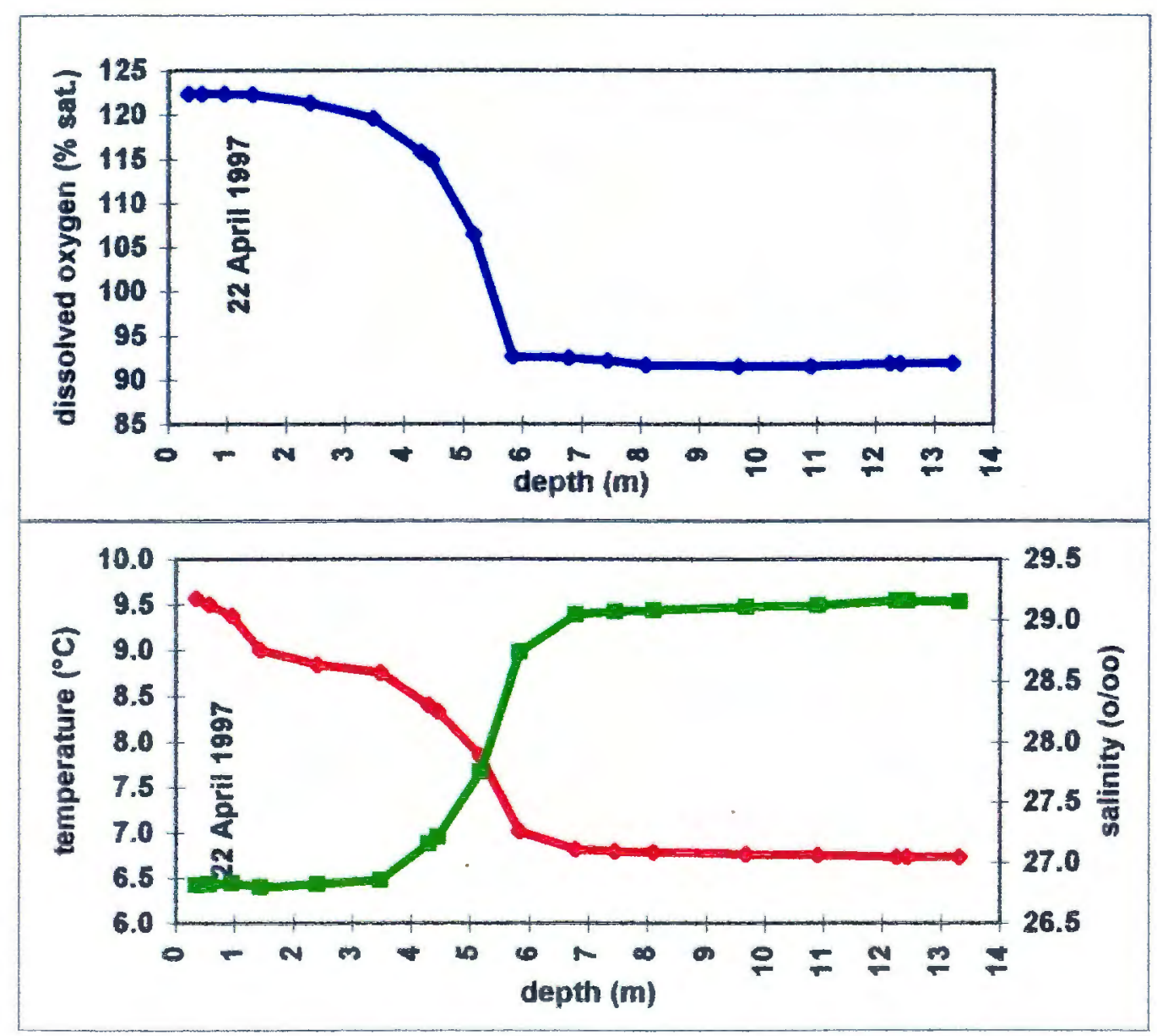


Figure 36. A profile of Temperature, Salinity and Dissolved Oxygen from 8 May at about 17:00 at the buoy station. 


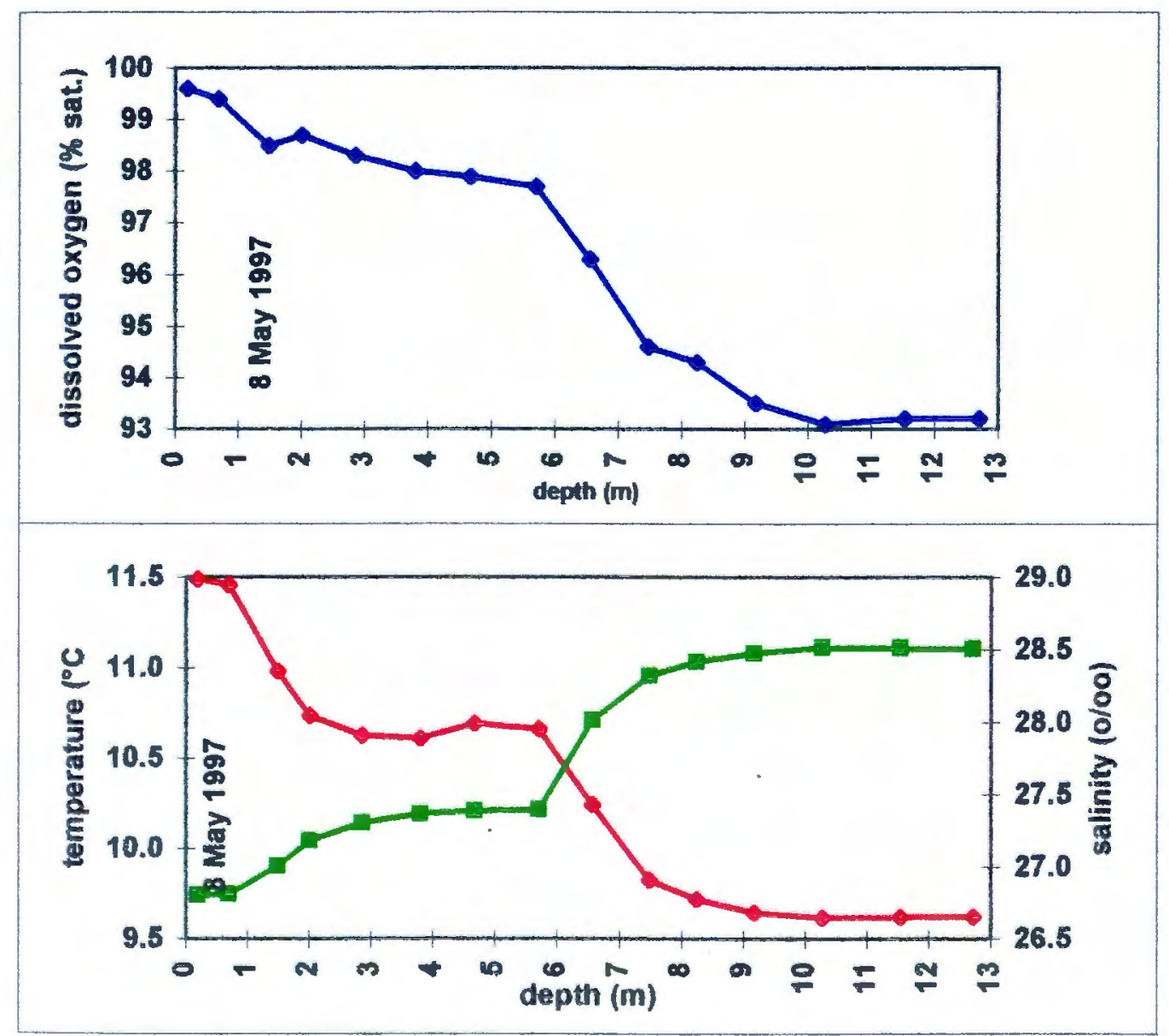


layer between this middle mixing layer and the deep layer from about 9 meters down to almost 13 meters. The structure was a result of the increasing tidal currents with the recent maximum in the spring-neap cycle on 6 May, and the gradients in temperature, $<2^{\circ} \mathrm{C}$ over $13 \mathrm{~m}$, and salinity, $<2 \mathrm{o} / \mathrm{oo}$ over $13 \mathrm{~m}$, and $<7 \%$ oxygen saturation over 13 meters reflected the increased mixing of the period.

\section{Meteorological Data}

As mentioned in the previous section, a record of meteorological data was compiled by filling gaps in the GSO Pier meteorological time-series with data from T.F. Green Airport. These data span the period of the buoy deployment (Figure 37a and b). In the wind record, we observed maximum velocities of approximately 20 to $22 \mathrm{~m} / \mathrm{s}$. These major wind events occurred twice during the buoy deployment, once on 31 March-1 April, and again on 19 April. The modal velocity was approximately $4 \mathrm{~m} / \mathrm{s}$, and over $90 \%$ of the wind velocities during the period were less than $10 \mathrm{~m} / \mathrm{s}$ (Figure 38a). Wind directions were much more variable, and displayed somewhat of a bimodal distribution, with over 500 frequency events of directions coming from both $210^{\circ}$ and $340^{\circ}$ (Figure 38b). The majority of wind directions were from the northwest, between $270^{\circ}$ and $360^{\circ}$. In order to facilitate plotting and quantitative consideration, all directions less than $90^{\circ}$ were plotted as $360^{\circ}$ plus the observed direction, so that directions between $360^{\circ}$ and $450^{\circ}$ actually represent those winds between $0^{\circ}$ and $90^{\circ}$.

Two sources of data pertaining to fresh water delivery were accessed (Figure 39). We obtained a record of daily precipitation from the NOAA, National Climatic Data Center compilations for T.F. Green Airport in Providence, RI, for March - May of 1997. Data are reported in inches of water equivalent precipitation per day. These data are 
Figure $37 \mathrm{a}$ and $37 \mathrm{~b}$. A plot of the wind speed and direction from a Meteorological timeseries at the GSO pier, with gaps filled by data from T.F. Green Airport observations, all sampled at a 20 minute interval. Wind directions less than $90^{\circ}$ have had $360^{\circ}$ added to them, for ease in plotting. 


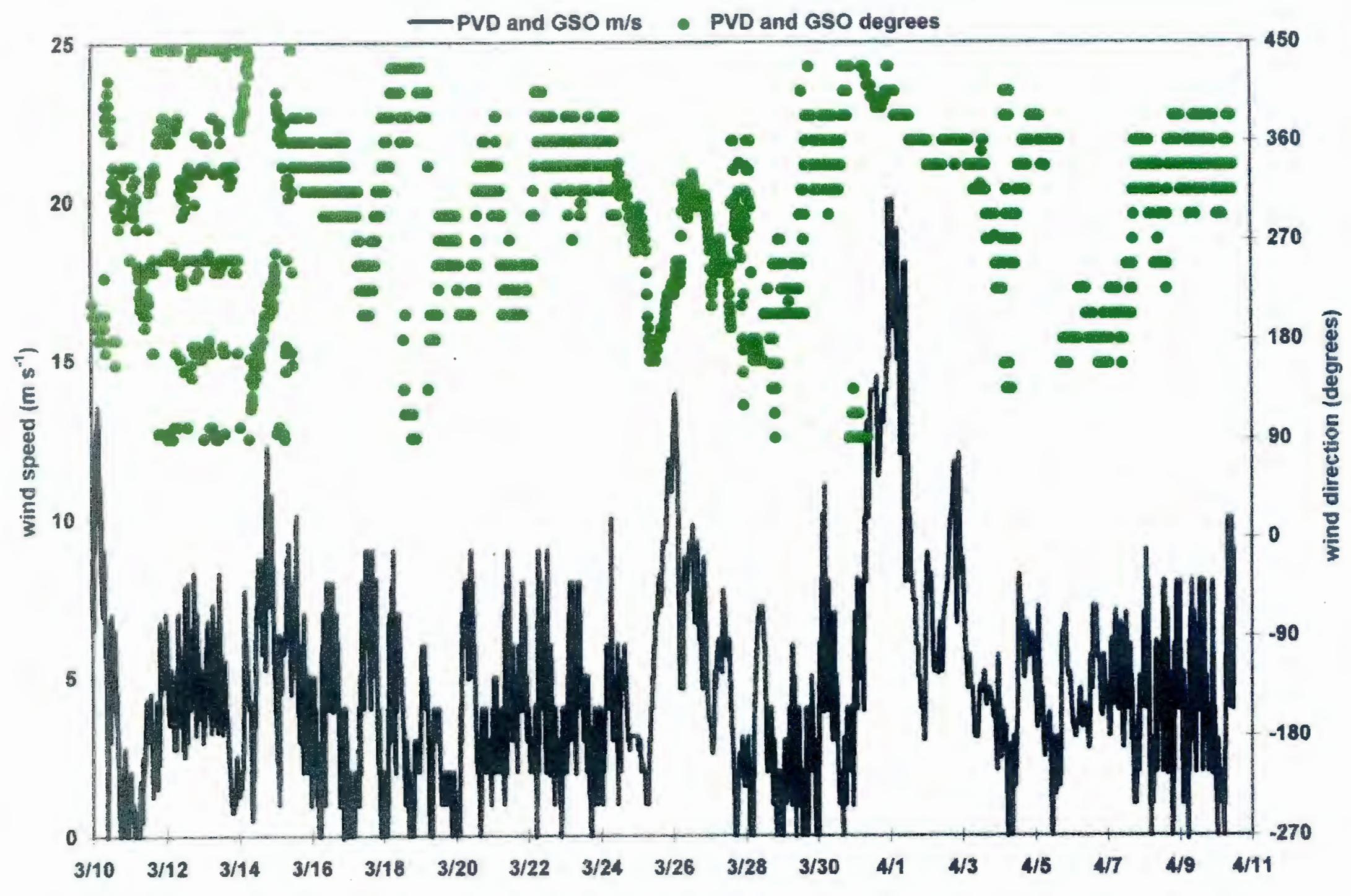




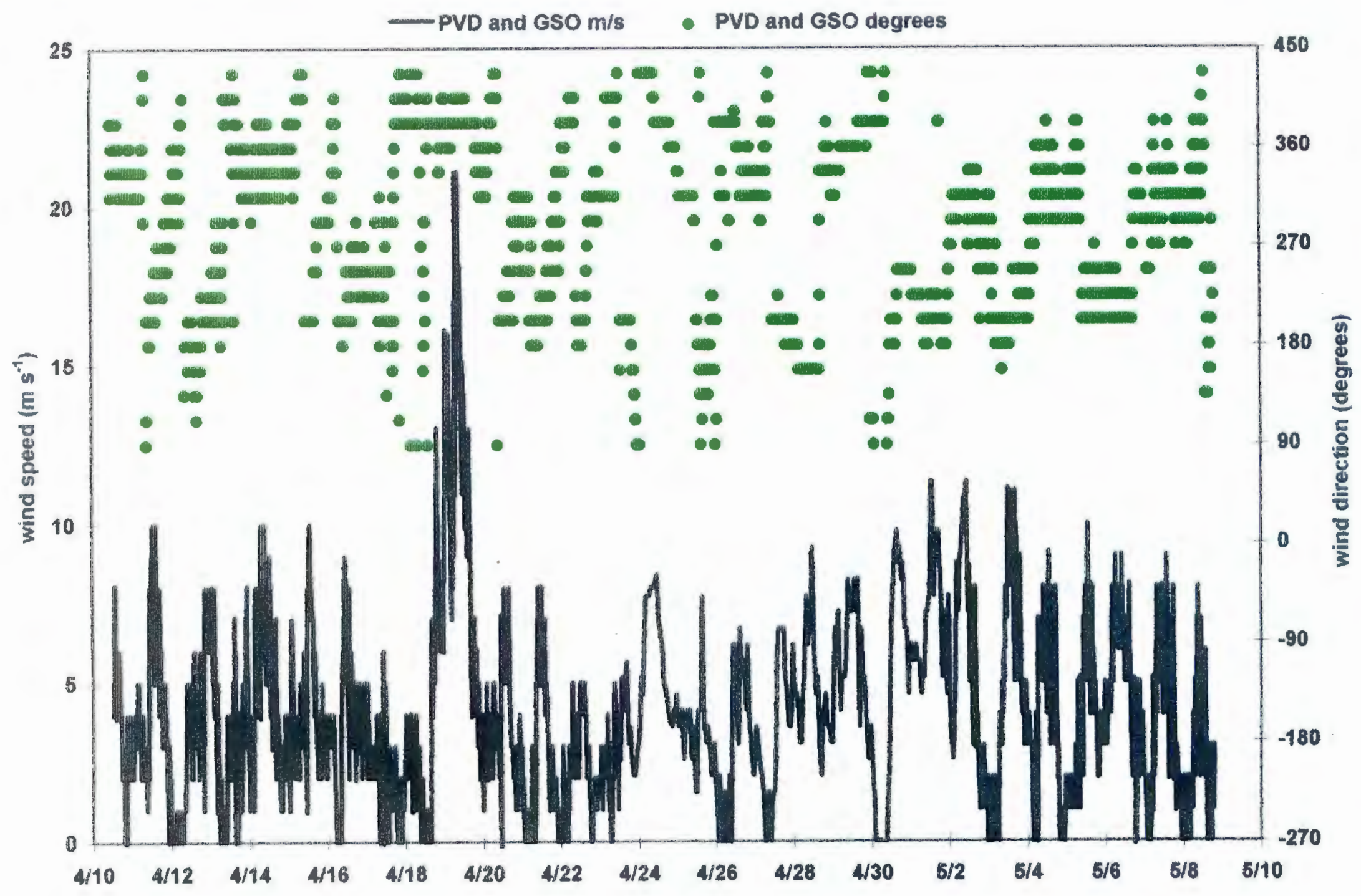


Figures $38 \mathrm{a}$ and $38 \mathrm{~b}$. A chart of histograms for the wind time-series, in $1 \mathrm{~m} / \mathrm{s}$ and $10^{\circ}$ bins for velocity and direction, respectively. 

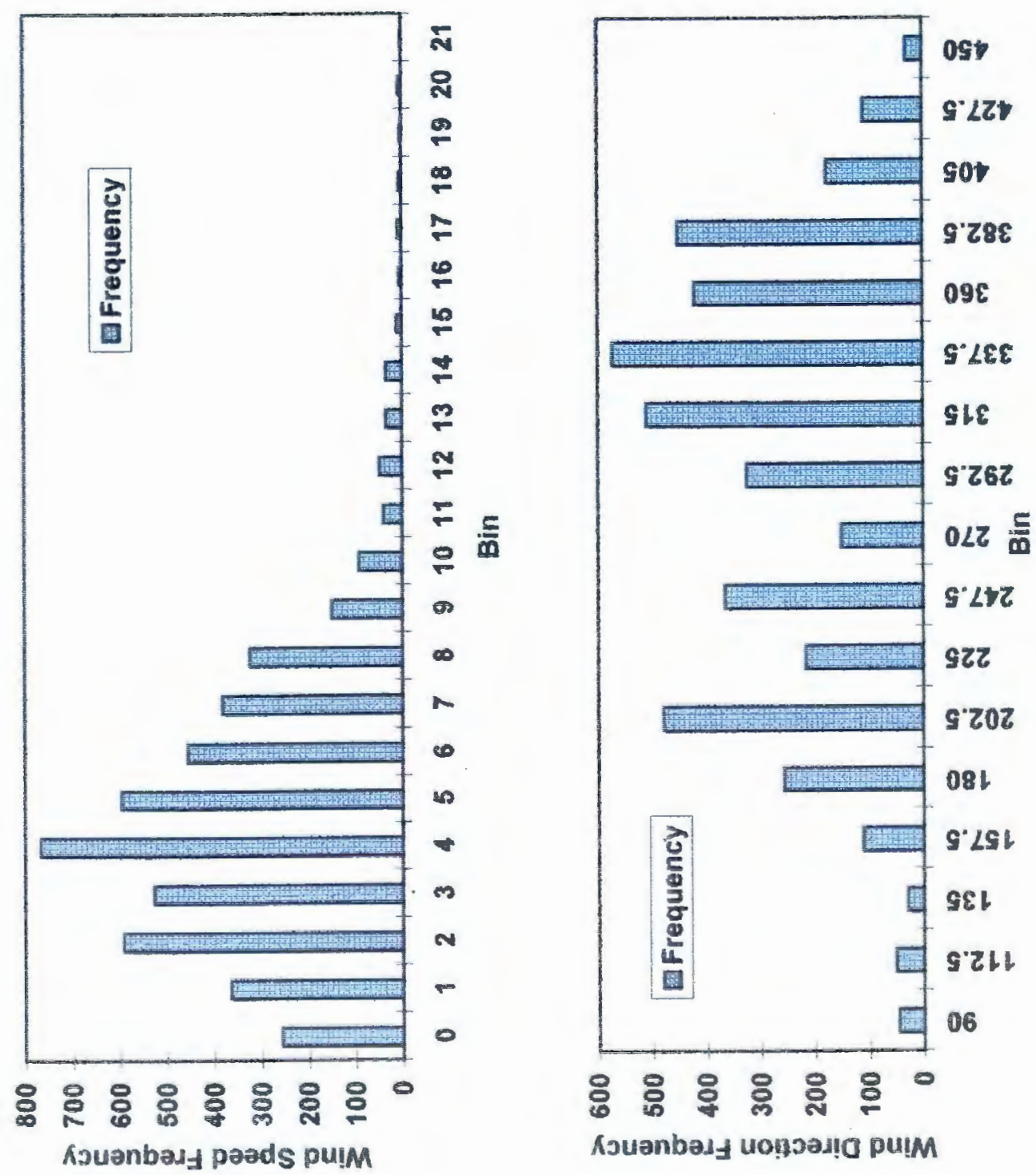
plotted with the U.S. Geological Survey's Provisional Stream Flow Daily Mean values for the Blackstone River, Woonsocket Station, station number 01112500. These data are reported in cubic feet per second. Since the Blackstone River is the source of the largest riverine input of freshwater to Narragansett Bay (Olsen, et al., 1992; Pilson, 1985), this stream flow data can represent the overall riverine freshwater input to the Bay.

The precipitation delivered during the 1 April Blizzard is immediately obvious, and the resulting increase in river flow is also readily observed, the fresh water from the rain and snow melt from this storm caused the stream flow to almost triple. One also notes that the largest stream flow volume resulted from a weather event occurring from 17 April to 19 April, in which a total of about 1.5 inches of precipitation was delivered over three days. The longer lag between precipitation and stream flow volume associated with the 1 April storm compared to the 17-19 April storm was likely a result of the type of precipitation, snow versus rain. 
Figure 39. Stream flow data from USGS Station 01112500, Blackstone River at Woonsocket, RI (provisional data) and NOAA National Climatic Data Center Daily Precipitation Summary for T.F. Green Airport in Providence, RI. Stream flow data are reported in cubic feet per second, and precipitation data in water equivalent inches. 

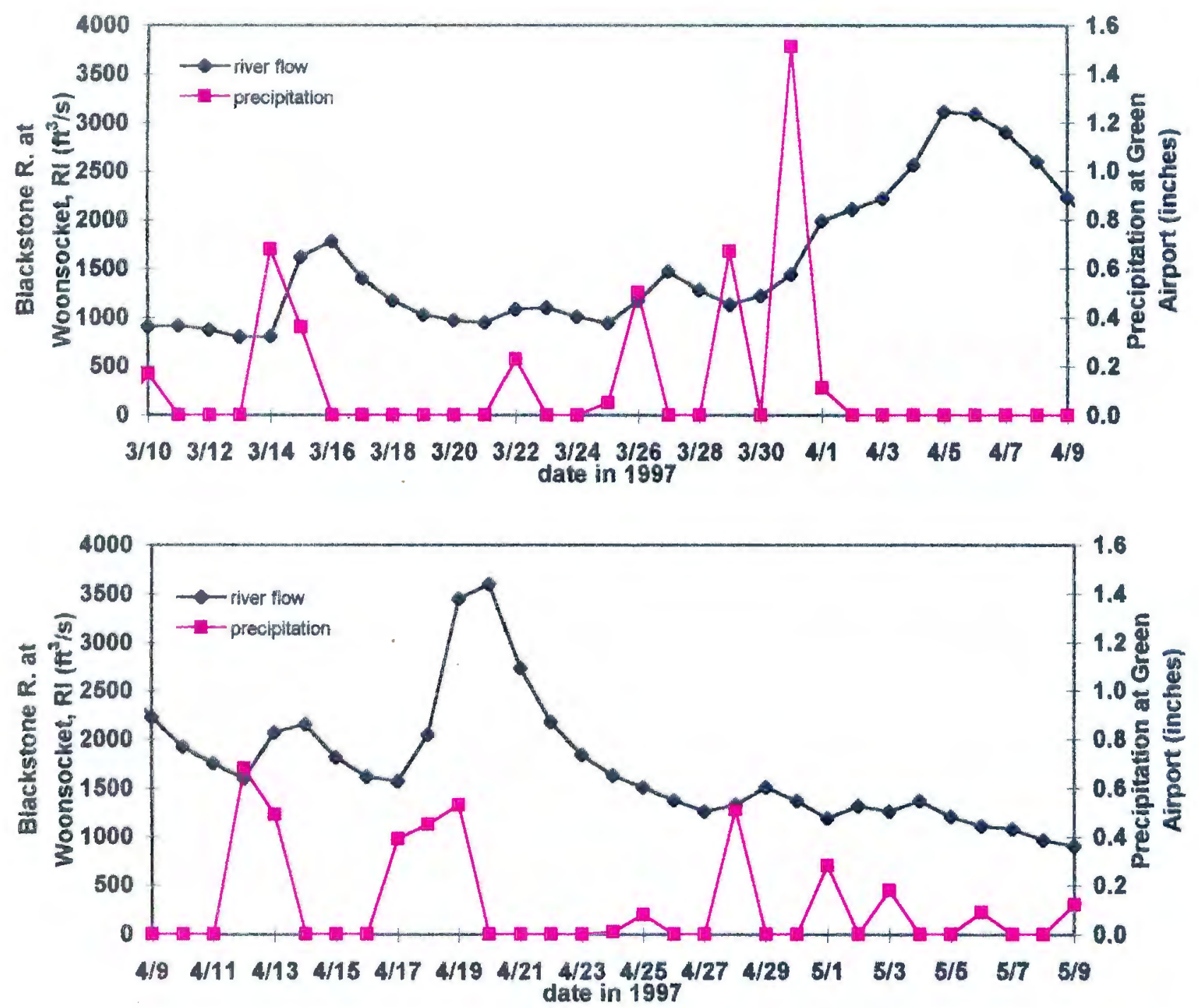


\section{ADCP Images}

To explain the filename convention, the files are named HOL21XXA, where HOL refers to the location of our data collection, 2 indicates that it is our second time performing ADCP work in the area, 1 represents the fact that two steps were required in image processing and the filename changed from 0 to 1 . The $\mathrm{XX}$ represent a sequential number referring to the chronology on scene, starting with 1 and ending with 28 . The $\mathrm{A}$ indicates that the raw data was translated into ASCII format. There are two basic types of ADCP image files, and they are based upon the type of sampling operation (Table 3). The first type of sampling consisted of transects, in which the instrument was pulled through the water over some lateral distance, generally over 150 meters. Almost all of these transects were oriented roughly east-west. Only one of them, filename HOL2122A, consisted of a south-to-north transect across the middle of the hole. The rest were across the hole in an east-west direction, either north or south of the feature. We have seventeen transect files, not including HOL2122A, covering from 07:00 until 13:00. This sampling was conducted during the morning, and the ebbing tide, when surface conditions were much more conducive towards transect operations. Each of the transect files in a triplet (HOL2101A through HOL2103A) is part of a circuit, starting south of the hole, running back across the feature and finally back across at the north end of the hole. For ease in discussion, transects which ran south of the island were numbered 1 , transects abeam of the island were numbered 2 and those north of the island were numbered 3 . Files HOL2101A through HOL2108A, HOL2111A through HOL2113A, HOL2115A through HOL2117A, and HOL2119A through HOL2121A are transects. HOL2009's file was corrupted and unreadable. 
The other type of file in this study is a time-series, in which the ADCP was held at or near the buoy and was allowed to measure the currents in the same area over some period of time. These time-series formats were predominately conducted later in the day, when surface conditions worsened and transect data quality deteriorated. These data were taken while the skiff was fast to the buoy, allowing the instrument to sample over a long period, starting from file HOL2123A at 13:50, until file HOL2028_2A, which ended at 17:58, or through most of the flood tide. HOL2010A, HOL2014A and HOL2018A were brief timeseries operations inserted between transect circuits earlier in the day, during the ebb tide. Filenames HOL2124A and HOL2126A were aborted files. The display images were created with a C-shell written by Dr. Robert Pockalny from GSO, and convert all transects into planar images oriented from west to east, looking from left to right, with the viewer's perspective looking northward. The color scheme is such that red contours are northward currents, into the page and blue contours are southward currents moving out of the page. The time-series display images show an integrated flow magnitude and direction at the top of the page, and raw and processed data below. In all images, absolute horizontal magnitudes and directions are shown in the bottom two panels, and vertical velocities can be observed in the middle panel, labeled Transect Parallel Flow Magnitude.

\section{Morning (Falling) Tide}

The early period of this study showed mostly a uniform picture for the area. The ebb tide in general was directed between about $165^{\circ}$ and about $190^{\circ}$. Flow magnitude was between 40 and $45 \mathrm{~cm} \mathrm{~s}^{-1}$ in the main axis of the current. This main axis was found close to the island at the north end of the circuit (Figs. A-3, A-6, A-12) and further to the 
Table 4. A chart of ADCP transects and profiling, indexed by figure number. The ADCP images are contained in an appendix, and thus, the images are labeled A-1 through A-26.

The transects are broken into three categories, representing transects performed south of the hole, across the hole, or north of the hole, respectively. Time-series profiles are predominantly found in the latter portion of the day, and are denoted by TS. Transect 23, figure A-21, was the last transect performed, and was taken across the hole from south to north.

\begin{tabular}{|c|c|c|c|c|c|c|c|c|}
\hline \multirow{2}{*}{$\begin{array}{c}\begin{array}{c}\text { Figure } \\
\text { Number }\end{array} \\
\text { A-1 }\end{array}$} & \multirow{2}{*}{$\begin{array}{l}\text { ADCP } \\
\text { fileneme } \\
\text { HOL2101 }\end{array}$} & \multicolumn{2}{|c|}{ start posn } & \multicolumn{2}{|c|}{ end posn } & \multirow{2}{*}{$\begin{array}{c}\text { Transect } \\
1\end{array}$} & \multirow{2}{*}{$\begin{array}{r}\text { start } \\
\text { time } \\
7: 11\end{array}$} & \multirow{2}{*}{$\begin{array}{l}\text { end } \\
\text { time } \\
7: 33\end{array}$} \\
\hline & & $41-36-04.6$ & $71-21-48.4$ & $41-36-31.7$ & $71-20-65.7$ & & & \\
\hline A-2 & HOL2102 & $41-36-20.8$ & $71-21-01.8$ & $41-36-27.0$ & $71-21-08.3$ & 2 & $7: 36$ & $7: 47$ \\
\hline$A-3$ & HOL2103 & $41-36-32.6$ & $71-21-31.7$ & no GPS & no GPS & 3 & 7:47 & 8:06 \\
\hline$A-4$ & HOL2104 & $41-36-04.6$ & $71-21-48.4$ & $41-35-41.5$ & $71-21-00.3$ & 1 & 8:11 & $8: 24$ \\
\hline A-6 & HOL2105 & $41-36-22.8$ & $71-21-01.8$ & $41-36-17.0$ & $71-21-48.0$ & 2 & 8:29 & $8: 46$ \\
\hline A-6 & HOL2106 & $41-36-32.6$ & $71-21-31.7$ & $41-36-40.1$ & $71-21-11.3$ & 3 & 8:61 & 9:00 \\
\hline A-7 & HOL_2107 & $41-36.02 .0$ & $71-21-63.6$ & $41-35-65.4$ & $71-20-69.2$ & 1 & $9: 06$ & 9:19 \\
\hline \multirow[t]{2}{*}{$A-8$} & HOL2108 & $41-36-20.6$ & $71-21-07.6$ & $41-36-18.5$ & $71-21-42.4$ & 2 & 9:26 & 9:38 \\
\hline & Hed & 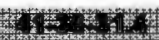 & 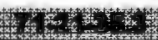 & WII & Why & wis & text & 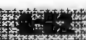 \\
\hline$A-9$ & HOL 2110 & $41-36-20.6$ & $71-21-27.6$ & $41-36-20.6$ & $71-21-27.6$ & TS & $9: 66$ & $9: 69$ \\
\hline A-10 & HOL2111 & $41-36-02.8$ & $71-21-46.3$ & $41-36-62.0$ & $71-21-03.2$ & 1 & 10:06 & 10:15 \\
\hline A-11 & HOL2112 & $41-36-21.8$ & $71-21-08.1$ & $41-36-18.3$ & $71-21-46.4$ & 2 & $10: 19$ & 10:29 \\
\hline A-12 & HOL2113 & 41-36-28.6 & $71-21-364$ & $41-37-00.4$ & $71-21-02.4$ & 3 & $10: 32$ & $10: 46$ \\
\hline A-13 & HOL 2114 & $41-36.23 .7$ & $71-21-30.8$ & $41-36-20.3$ & $71-21-28.3$ & TS & $10: 50$ & 11:00 \\
\hline A-14 & HOL2115 & $41-36-03.6$ & $71-21-48.0$ & $41-35-64.1$ & $71-20-62.2$ & 1 & 11:03 & 11:16 \\
\hline A-16 & HOL2116 & $41-36-25.5$ & $71-21-09.6$ & $41-36-26.2$ & $71-21-52.8$ & 2 & 11:20 & 11:31 \\
\hline A-16 & HOL2117 & $41-36-36.0$ & $71-21-41.1$ & $41-37-06.0$ & $71-21-06.8$ & 3 & $11: 34$ & 11:46 \\
\hline A-17 & HOL2118 & $41-36-23.7$ & 71-21-27.7 & 41-36-23.7 & $71-21-27.7$ & TS & 11:53 & $11: 59$ \\
\hline A-18 & HOL.2119 & $41-36-01.1$ & $71-21-51.2$ & $41-35-40.1$ & $71-21-61.2$ & 1 & $12: 04$ & $12: 20$ \\
\hline A-19 & HOL2120 & $41-36-23.6$ & $71-21-07.1$ & $41-36-21.8$ & $71-21-41.2$ & 2 & 12:25 & $12: 41$ \\
\hline A-20 & HOL2121 & $41-36-31.4$ & $71-21-38.0$ & $41-37-00.0$ & $71-21-19.0$ & 3 & $12: 48$ & $12: 58$ \\
\hline A-21 & HOL2122 & $41-35-69.3$ & $71-21-31.6$ & $41-36-36.2$ & $71-22-32.1$ & $S$ to $N$ & 13:21 & $13: 30$ \\
\hline A-22 & HOL 2123 & $41-36-24.1$ & $71-21-29.0$ & $41-36-24.1$ & $71-21-29.0$ & TS & 13:50 & $14: 04$ \\
\hline & A d & & & & & & & \\
\hline A-23 & HOL2125 & $41-36-24.1$ & $71-21-29.0$ & 41-36-24.1 & $71-21-29.0$ & TS & 14:17 & 15:00 \\
\hline$x^{2}=4$ & Het 1 & & & & & 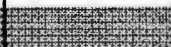 & & \\
\hline A-24 & HOL2127 & $41-36-24.1$ & $71-21-29.0$ & $41-36-24.1$ & $71-21-29.0$ & TS & $15: 09$ & $15: 68$ \\
\hline A-25,-26 & HOL2128 & $41-36-24.1$ & $71-21-29.0$ & $41-36-24.1$ & $71-21-29.0$ & TS & $16: 04$ & $17: 68$ \\
\hline
\end{tabular}


east down towards the southern end of the circuit (Figs. A-4, A-7, A-10). Much slower currents were observed in Transect 2 close to the island, presumably due to a lee effect from the extension of the shoals between Hope Island proper and Despair Island to the northeast (Figs. A-2, A-5, A-8). In fact, two of the Transect 2 files (Figs. A-5 and A-8) show the development of a back eddy close to the island, on the shelf between the island and the depression. As time progressed, the ebb current weakened in the deep layer, and the cross-section of ebbing water shoaled and moved eastward. This can be seen in the first time series (Fig. A-9), where current flow was on the order of 5 to $10 \mathrm{~cm} \mathrm{~s}^{-1}$ below 5 m depth. Between the time 9:56 and 10:50, a significant shear layer was set up at the buoy station, between about four and eight meters depth (Figs. A-9, A-13). This appears to be a result of the developing condition, especially close to the island and within the deep layer, in which water was moving into the Bay from below and from the west, while the surface water was still ebbing. Velocities in the deep northward-flowing region were much slower than those in the surface ebb jet (Fig. A-11), however, this counter-current region continued to expand in cross-section through the end of the ebb period (Figs. A-13 and A-15) until the tide reversed, when current magnitudes became very low, and current direction was extremely variable (Figs. A-18, A-19, and A-20).

\section{Evening (Rising) Tide}

After the tide turned, the conditions in the small boat worsened. Through the afternoon and evening seas built from negligible conditions to approximately $0.5 \mathrm{~m}$ waves. The southerly wind picked up in intensity as well. We determined that the boat time might be better and more safely spent conducting time-series data acquisition. Therefore, files HOL2123 to HOL2128 (Figs. A-22, A-23, A-24, A-25 and A-26) are completely time- 
series data. The quality of data is lower than that from the morning, however, the prevailing situation during the flood-tide is easily discernable. Over the course of the four hours from $14: 00$ to $18: 00$, the incoming surface flow, above approximately $5 \mathrm{~m}$ depth intensified from about $28 \mathrm{~cm} \mathrm{~s}^{-1}$, to about $37 \mathrm{~cm} \mathrm{~s}^{-1}$. Again a counter-flowing current developed at the bottom and, though it was less well defined than that observed earlier, by the final time-series, it had become firmly established. The surface layer, initially broad and uniform, began to develop shear until there was a significant shear layer between 4 and 8 meters depth by the end of the last time-series. In general, the deep layer flow appeared broad and of uniform velocity, averaging between 15 and $25 \mathrm{~cm} \mathrm{~s}^{-1}$, but its direction appeared to vary more with depth. In the surface, the opposite prevailed, in that the velocity magnitude increased with decreasing depth, and direction was more uniform within the layer.

\section{Vertical Velocities}

Considering that the morning period, ebb tide condition was sampled during a time of negligible wind effects, we considered vertical current data from only this period. The flood period showed higher magnitude vertical structure, however, due to the pitching of the boat and the higher waves, we felt that some of these data may have been biased by the boat movement. We are more confident that the vertical velocities represented in the earlier transect data were unaffected by wind forcing and boat movement. As expected, vertical velocities were much lower than the horizontal velocities. It appeared that, early in the ebb, water was moving downward at the north end of the hole, especially over the deepest area (Figs. A-3 and A-6). Later in the ebb, slight but upward currents could be noted in some of the transects (Figs. A-12, A-16, and A-20). Across the center of the 
hole (Figs. A-2, A-5, A-8, A-11, and A-19) water was moving upward on the western slope of the hole, near where the buoy was placed, and was moving downward near the eastern slope. As the ebb ended, alternating bands of upwelling and downwelling were observed across the diameter of the hole (Fig. A-19). 


\section{Discussion}

\section{January Deployment}

The January deployment contains some very valuable information, because it shows events occurring at the buoy site during mid-winter conditions. This initial deployment suffers from a relatively short duration and it required substantial postdeployment calibration corrections for salinity and oxygen as described in the Results section.

The temperature time-series in January did not require corrections to the measured values. Over the twelve-day period of 6-17 January, the waters showed a general cooling trend at all depths, with periods of an isothermal water column, a well-stirred and nearly isothermal water column, and a significant thermal gradient in the water column with warmer waters near the bottom and cooler waters at the surface (Figure 40). The difference in bottom temperature minus surface temperature provides an index of thermal stratification (Figure 41). The water column was "well-stirred" from 8 to 10 January, and briefly on 12 January, and on 16 January. This condition was represented by a narrow difference between the surface and bottom temperatures, but the difference is significant $\left(\Delta \mathrm{T} \sim 0.25^{\circ} \mathrm{C}\right)$ and it appears to vary with the tidal state. At other times the water column is isothermal. This situation is represented in the time-series on 10 January and on 17 January. This more dramatic destratification was indicated by insignificant differences between surface and bottom conditions $\left(\Delta \mathrm{T} \leq 0.05^{\circ} \mathrm{C}\right)$ and it appeared to be related to meteorological forcing from high velocity wind events such as observed on $10 \mathrm{January}$, or perhaps persistent winds of moderate velocity such as on 17 January, which may result in the release of potential from a "wind set-up" situation (Figure 42). During this period, the 
Figure 40. Temperature record from the January deployment, exhibiting the two observed classifications of destratifications, and the stratified period. The water column is well stirred $\left(\Delta \mathrm{T} \sim 0.25^{\circ} \mathrm{C}\right)$ on $8 \mathrm{January}$ and $16 \mathrm{January}$, and is isothermal $\left(\Delta \mathrm{T} \leq 0.05^{\circ} \mathrm{C}\right)$ on 10 January and 17 January. On 6-7 January and on 13-16 January, the water column is stratified. 


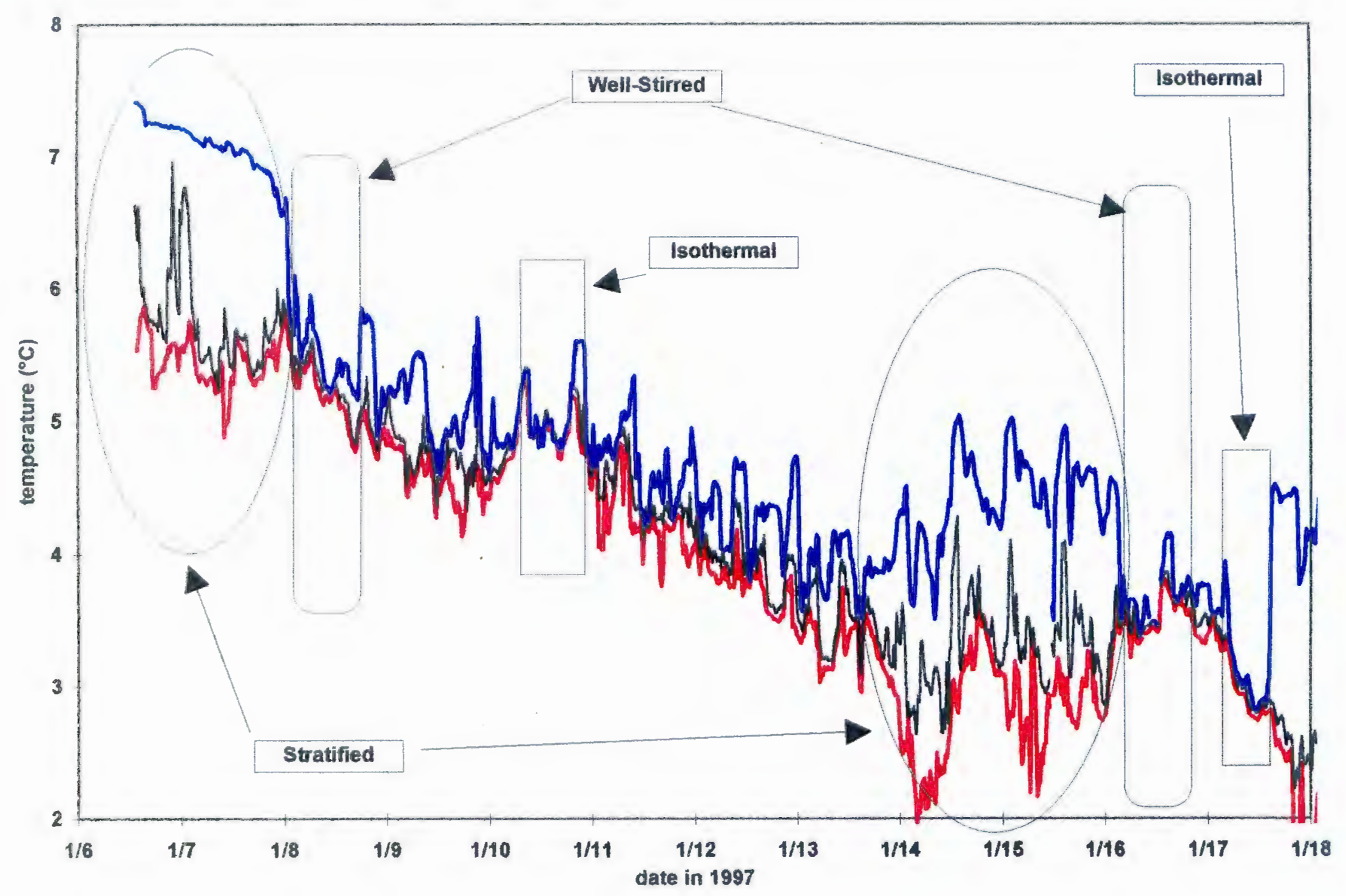


Figure 41. Thermal stratification time-series and tidal height. The red line is the difference between surface water temperature and bottom water temperature, with larger values representing greater stratification. The dark line represents the predicted tidal height for Newport, Rhode Island. 


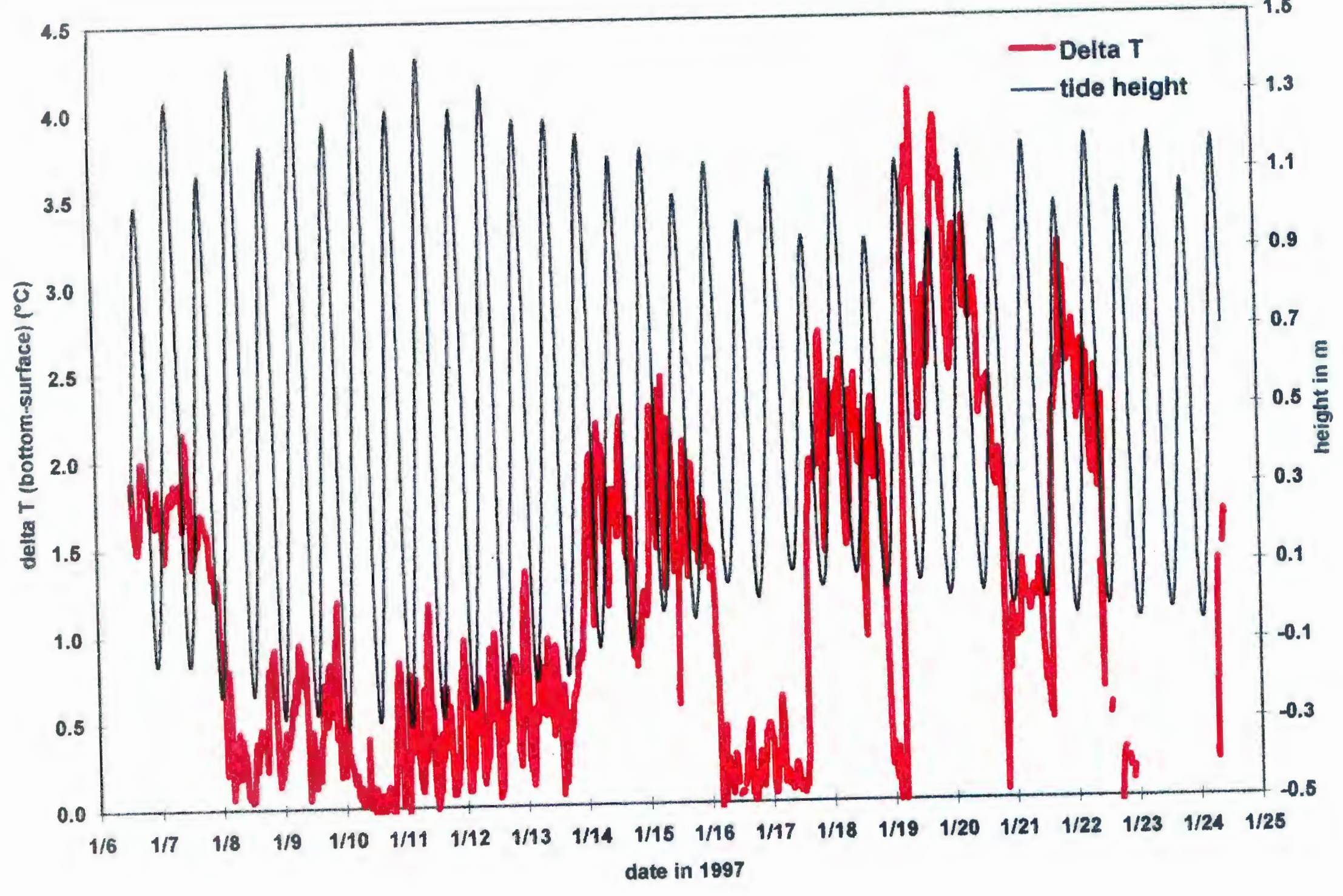


Figure 42. Temperature from the three buoy YSI's is displayed in the upper panel.

Stratification is broken down on 16 January and isothermal conditions dominate on 17 January. Following this, stratification once again develops early on 18 January. In the bottom panel, wind directions are in green, and are from the west until 16 January when they come from the southwest. Just prior to midnight before 17 January, the winds change to a more northerly orientation and then become variable over most of 17 January. Wind speeds are shown in red and show two broad events: high speeds up to $14 \mathrm{~m} / \mathrm{s}$ over most of the day on 16 January, and a weaker event over most of 17 January of about 8 $\mathrm{m} / \mathrm{s}$. The blue record is the $\Delta \mathrm{T}$ (bottom - surface) and shows complete destratification over the two wind events, and a strong stratification after the winds die on 17 January, coincident with high tide. 

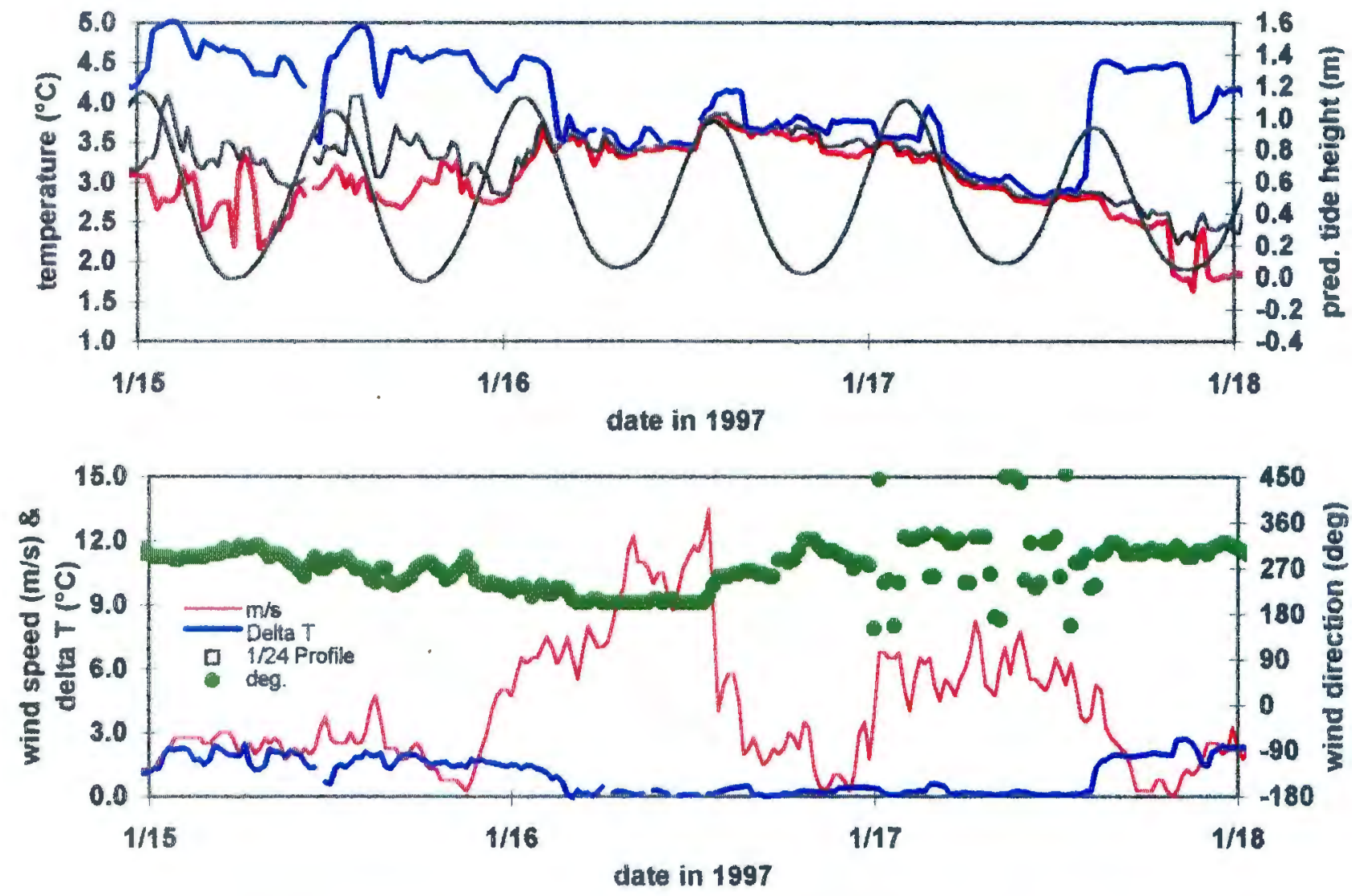
Temperature variations show pulses of warm water at the bottom instrument (Figure 43). These warm water pulses occur during high tides and are quickly mixed to lower temperatures during the outgoing tides. The rapidity of change of the bottom temperature increase during the flood is suggestive of an advective process rather than a mixing event It is also interesting that the local low temperature at the bottom occurs at the end of the ebb, but prior to, slack low water.

Given that we had no meteorological data from 11 January to 14 January, and that most of the salinity record was unusable, we decided to investigate a few large scale events, discussing only the usable buoy data and meteorological and tidal data. The first event investigated was the destratification early in the record, on 7 January. The second event is the stratification event between 14 and 16 January, and the third event is the stratification on 17 January, which lasted, at various strengths, until the end of the data set.

The destratification on 7 January appeared to be produced through the contribution of several forces. First, the spring-neap tide phase was extremely important, as a new moon, and thus a maximum in the lunar phase, occurred on 9 January. From the first low tide in which water heights were below mean lower low water (MLLW), early on 8 January, until the first low tide in which water levels were above MLLW, the thermal stratification was held to very low levels, $\Delta \mathrm{T}$ averaged about $0.43^{\circ} \mathrm{C}$ between low tide on 8 January and low tide on 14 January. This was a period of high tidal amplitude, exceeding $1.6 \mathrm{~m}$ difference between high and low tide and this source of energy in the water column could be a factor in breaking down the stratification observed prior to 8 January. 
Figure 43. Temperature at the bottom YSI and predicted tide height from 6 January to 19 January. The local incidences of warmer water are coincident with high tides. These warm waters are rapidly mixed on the outgoing tide between 8 January and 14 January. Between 14 January and 18 January, during the deployment's lower tidal range, the warmer waters associated with high tide are more gradually mixed during the outgoing tide 


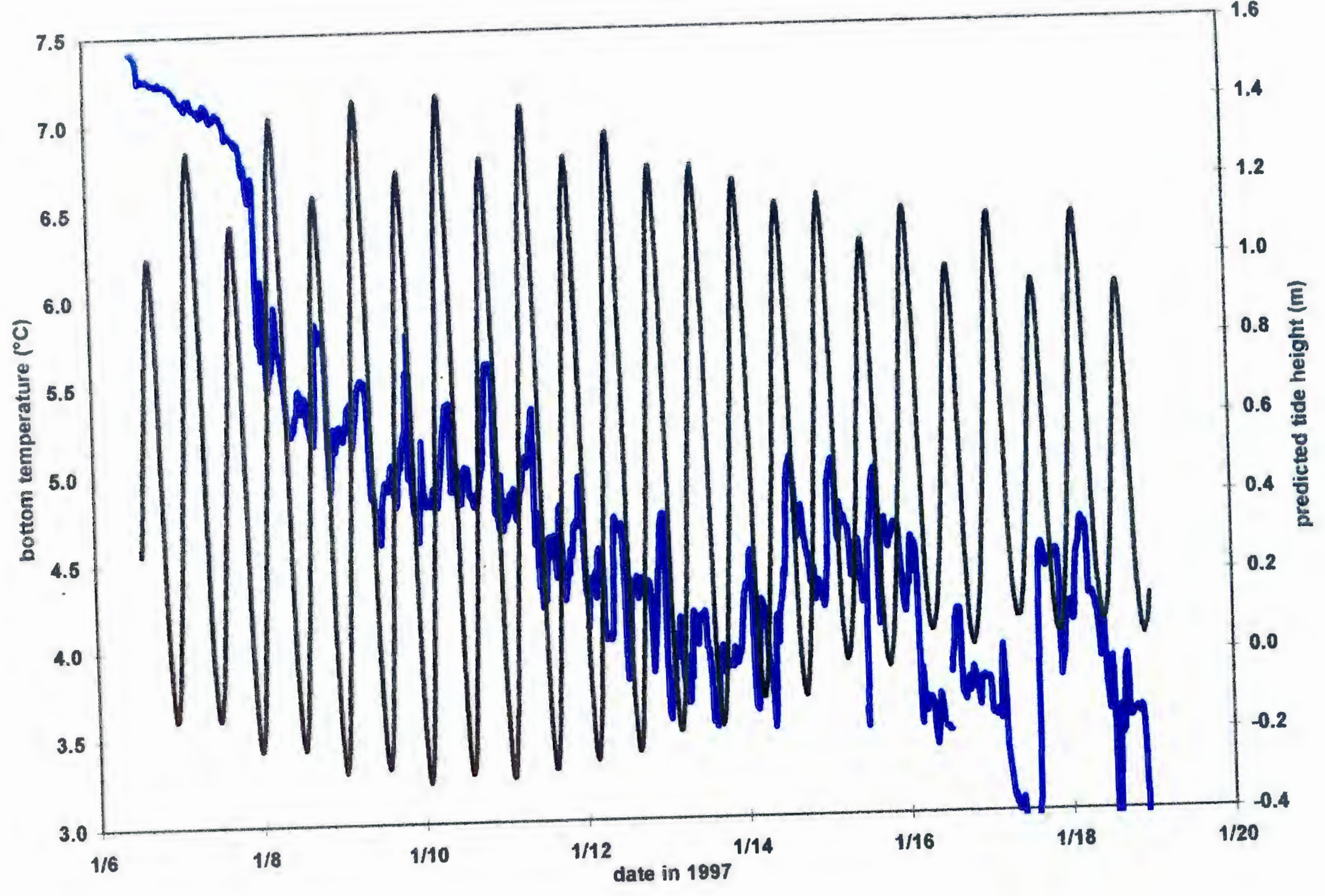


Another factor important in this event was the wind. From wind data taken from the GSO Pier, during the time of the January deployment, we observed that wind directions from 6 January until late on 9 January were consistently from the north and northwest and that there was an increase in wind speed starting on 7 January and peaking at almost $10 \mathrm{~m} / \mathrm{s}$, midday on 8 January. After this peak, winds gradually decreased to about 1 to $2 \mathrm{~m} / \mathrm{s}$ late on 9 January, before a frontal system moved through, in the early hours of 10 January. This system was responsible for wind speeds in excess of $10 \mathrm{~m} / \mathrm{s}$ over most of 10 January. The direction of these winds began from the southeast and south, and gradually clocked to the west and eventually the north and northwest, as the system passed. It is thought that the combination of high wind speeds and wind setup produced through an extended wind fetch, in which winds which persistently blow at moderate to high velocities from one particular direction for long periods of time, up to 24 hours or more. This set-up may cause Narragansett Bay's waters to be forced and held in the leeward section of the Bay, until the winds subside, when the waters are free to move back to lower elevations. In the case of this destratification event, the northerly winds may have caused a set-up in which estuarine waters were forced out into Rhode Island Sound, until late on 9 January, when the change in wind direction came about and speeds increased. In fact, the entrance to the West Passage exhibited anomalously large waves, approximately 2-3 meters in height, directed into the Bay, on 10 January. Release of this set-up condition, the contribution of spring condition tidal currents and stirring effects of $>12 \mathrm{~m} / \mathrm{s}$ winds all contributed to the isothermal event on 10 January and the destratification which was observed from 8 January until 13 January. The effects of the destratification on the oxygen data was to mix oxygen down into the deep layer, and saturation levels rose from a low near $92 \%$ during 
the early stratified period, to a sustained level near $100 \%$ saturation during the 4 days of the mixing event, with the localized peaks associated with the tidal cycle superimposed on this constant oxygen saturation level. The $\Delta \mathrm{O}_{2}$ was calculated in a manner similar to that for temperature. Values for bottom oxygen which appeared to be affected by instrument contact with the seafloor were removed by averaging across adjacent, reasonable values. The difference between surface $\mathrm{O}_{2}$ and bottom $\mathrm{O}_{2}$ were plotted along with tidal height (Figure 44). Periods of significant $\mathrm{O}_{2}$ gradients are observed between 6 and 8 January, from 13 January to 16 January, and intermittently from 17 January to 22 January. During the period from 8 January to 13 January, there was only a small difference between the surface and deep oxygen saturation levels, mostly less than $2 \%$. In addition, the features of oxygen variability are very similar to those for temperature. These results indicate the sensitivity of oxygen variations to stratification events, even in mid-winter.

Following the extended period of destratification between 8 and 13 January, the surface and deep conditions began to diverge, as surface temperature continued to decrease from $4^{\circ} \mathrm{C}$ on 13 January to approximately $2^{\circ} \mathrm{C}$.on 14 January, while deep temperatures leveled off at about $4^{\circ} \mathrm{C}$ to $5^{\circ} \mathrm{C}$ between 12 January and 16 January. The lunar tide component continued to weaken as the neap phase approached, and tidal stirring was insufficient to break the developing stratification, although the tidal excursion made its impression on the time-series at all three depths during this brief period of stratification. It appeared that, in the absence of the mixing event from 16-17 January, the stratification might have had the opportunity to persist and strengthen as surface temperatures dropped considerably from the mixed conditions during 17 January, into the much more strongly stratified conditions of $19-20$ 
Figure 44. Oxygen stratification and predicted tides for Newport, RI. Stratified periods are noted between 6 and 8 January, between 13 and 16 January, and between 17 and 22 January, with brief destratified periods. A prolonged mixing event is seen between 8 January and 12 January. 


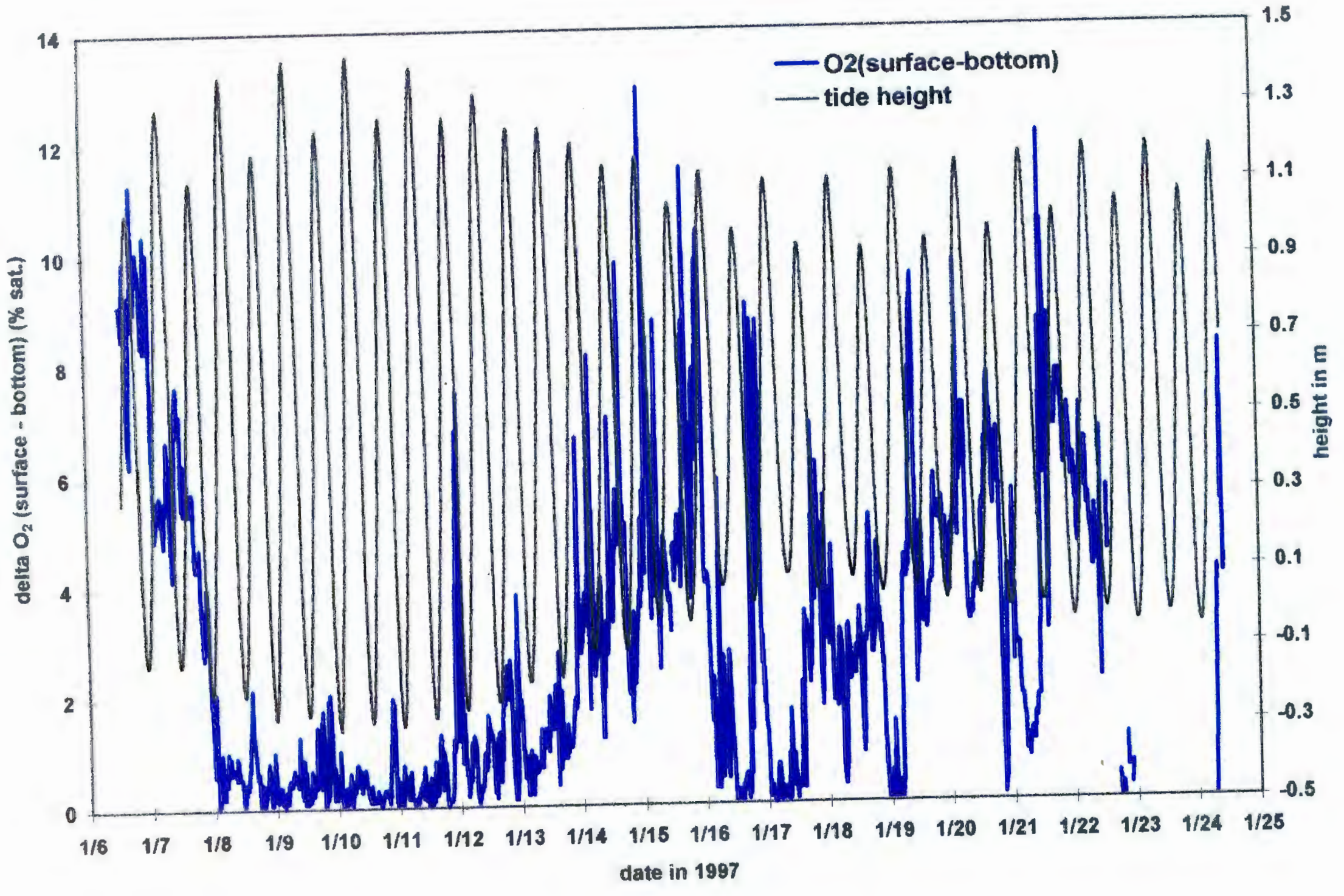

$\underset{\infty}{\Phi}$ 
January. The input of fresh water decreased over the period 11 January to 15 January as measured by USGS stream gauge data from the Blackstone River, at Woonsocket, RI, to very low levels, and the lack of fresh water input likely reduced the magnitude and stirring energy of the non-tidal circulation as well (Figure 45). Unfortunately, there is a lack of wind data between 11 January and 14 January, however observing the pressure record from the YSI-600 from the surface, and recognizing that the variations observed in this record give an indication of atmospheric pressure changes, we note that the surface pressure changes, and thus, atmospheric pressure changes are minimal between 11 January and 14 January, suggesting that there were no major storm or wind events during that time. Though the stratification was small, it amounted to a difference between surface and bottom of between $2{ }^{\circ} \mathrm{C}$ and $3^{\circ} \mathrm{C}$ and led to an increase in surface oxygen of about $6 \%$, to $106 \%$ saturation, late on 15 January. After this, a wind event with $14 \mathrm{~m} / \mathrm{s}$ winds from the southwest caused another isothermal event, and the stratification was extremely weak until late on 17 January. On 18 January, wind speed dropped briefly near zero, but gradually climbed to about $5 \mathrm{~m} / \mathrm{s}$ over the day and by 19 January, the wind had been blowing at almost $5 \mathrm{~m} / \mathrm{s}$, from the north and northwest continuously for almost 72 hours when the stratification eroded on 19 January. This occurred at low tide, and well mixed conditions persisted only until the following high tide, when winds were decreasing to below $2 \mathrm{~m} / \mathrm{s}$. Pulses of stronger winds, up near $8 \mathrm{~m} / \mathrm{s}$ occurred on 20 January and 21 January, from the northwest and north, respectively. On 22 January, a stronger wind pulse occurred, again from the north. It seemed that the wind direction may have affected the bottom conditions, in that the northwest wind allowed colder water to dominate the bottom, while the northerly winds set up more prominent thermal 
Figure 45. Provisional Daily Flow from USGS stream flow data for the Blackstone River, as gauged at Woonsocket, $\mathrm{RI}$ in $\mathrm{ft}^{3} \mathrm{~s}^{-1}$, and daily average precipitation as measured by NOAA and the National Climate Data Center, from T. F. Green Airport in Warwick, RI, for the period of 6 January through 22 January. 


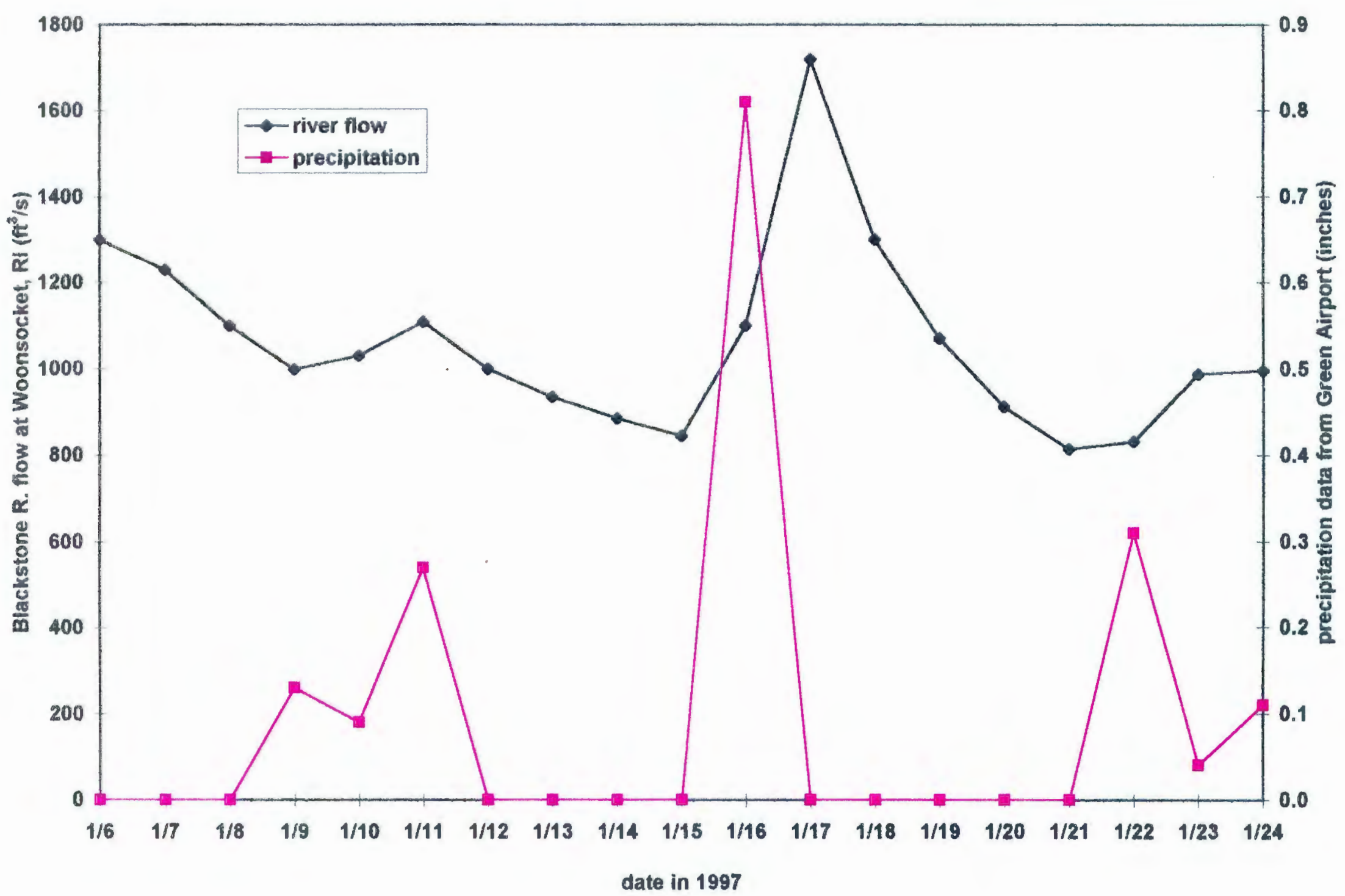


stratification, as the bottom water was much warmer than that at the surface or middle. It appears, for the period of the January buoy deployment that the winds were responsible for short term, transient mixing events, on the order of hours, and that the tides were more closely related to longer term mixing events, on the order of days. The direction of the wind and its persistence may affect the bottom conditions by allowing a set-up of higher water levels to the leeward side of the Bay's basin, and possibly a fjord-like venting through pycnocline tilting (Kuo and Park, 1992). The lack of salinity data prevented a more quantitative test of this possibility. One must also consider that the sense of thermal stratification for this deployment, that is, for more strongly, thermally-stratified conditions in January, the surface is much colder than the deep, and the greater this sense of thermal stratification, the lesser the density stratification will be. We can see the relative effects of the tides and winds in these vertical mixing processes. We also note the sensitivity of the dissolved oxygen data to the presence of stratification in the water column. When stratification is permitted to persist for a few consecutive days, dissolved oxygen is able to respond with supersaturated levels in the surface waters, even in the middle of winter.

Even though benthic oxygen utilization is low for the cold winter season, bottom oxygen levels are able to drop to and below $90 \%$ saturation, further increasing the gradient in dissolved oxygen.

\section{March Deployment:}

Though the position of the buoy did not change between deployments, it is important to note that the positions of the middle and deep sensors changed due to the change in the mooring configuration. Previously, the bottom instrument was deeper, and further towards the center of the hole. In the second deployment, the bottom instrument 
was shallower because of the setup of the mooring, with about 1 meter of line between the anchor and the instrument with no catenary because of the float above the instrument, and because the mooring was situated further to the west, up on the western slope of the hole. However, in the re-rigging of the instrument mooring, we gained the opportunity to more accurately measure the observed tides, since the bottom instrument was a fixed distance above the bottom. The float and slack in the line above the instrument isolated it from the movements of the buoy.

On about 29 March, surface temperatures began to consistently exceed bottom water temperatures, interrupted only by the 1 April blizzard (Figures 17a and b). On 3 April, surface temperatures warmed following the storm event, and except for during destratification events, remained warmer than the bottom waters. There were three "modes" of variability in the water column temperature record for the surface and middepth waters. The first mode was of smaller scale variability in which the middle instrument closely followed the features in the surface instrument. This mode was especially evident during longer duration mixing events, where there was not a large gradient between surface and bottom. This mode also occurred during stratified periods coincident with weak wind speeds, such as on 14 March, between 23 March and 26 March, and during most of 17 April. The second mode was the condition wherein the middle temperature was somewhat following the surface temperature, and then made a sharp and rapid change to conditions similar to the bottom instrument, and back again to surface-like conditions. This mode can be observed on 31 March, 14 April, 19 April and 29 April. This mode seems to follow or precede mixing events, and may signify water column conditions in the midst of a transition between two stable states, a mixed and a 
stratified water column. The third mode was that of rapid oscillations of larger magnitude, over extended periods between 24 and 96 hours in length. This mode can be observed on 17 March, on 3-4 April, and from 21 to 24 April. Over the 21 to 24 April event, wind speeds are very low, there was no precipitation reported and stream flow for the Blackstone River is falling rapidly. The oscillations in the middle instrument appear to be on a half-tidal cycle, but the bottom water shows no oscillations, only a steady increase over several tidal cycles. This suggests that the oscillations of this mode are related to a response of off-shore waters following the outflow of a large volume of fresh water. The deep layer appeared to be "re-filling" and the oscillations in the middle instrument, apparent in both temperature and salinity, but not oxygen, may be related to the up-Bay movement of the deep water which has been in contact with the surface, perhaps out in Rhode Island Sound.

The mean salinity for the water column appeared to follow the river flow data (Figures 22a and b, and Figure 45). The destratified-condition salinity before 1 April was approximately $28.30 / 00$. It began to decrease after 1 April but rose again between 7-9 April. It then began a long-term decrease to approximately 28.0 or 27.9 o/oo on 8 May, when it started to increase again as tidal energy increased. Periods of maximum salinity stratification, $\Delta S$ (bottom-surface) $\geq 4$ o/oo are noted on 20 March, 30 March, 14 April, 19 April, 23 April, and 25 April. There are also periods of lesser stratification, of varying duration between 12 hours and 5-7 days at several points in the time-series.

Periods of destratification based on salinity correspond well with those based on the temperature record. They are also of varying duration, from approximately 1 hour to about 2 to 4 days. In the bottom layer, both stratification and destratification appear to 
occur in stages, mostly as seen on 18 through 20 March, 30 March, 6 April, and 1 through 3 May. In these incremental events, the changes in water column structure are based on tidal cycle events, and especially in a destratification, it is the outgoing tide that primarily modifies the conditions of the bottom water (Figure 46). Examination of the timing of changes in the water column at the surface and in the deep layer indicates that, for some of these destratification events, the bottom salinity begins its decrease an hour or more prior to the increase in surface salinity.

There are a few occasions where stratification is a more precipitous event, such as on 15 March, and 13 through 14 April. Also, there are rapid transient events, apparently wind related, in which salinity drops rapidly and rebounds rapidly soon after. These occur on 23 March, 31 March, 19 April and 24 April. These events are all preceded by increases in surface salinity, between 6 and 12 hours earlier, reinforcing the idea that these events, in particular, originate at the surface as wind events.

The largest amplitude variability in salinity is seen at the surface and the middle instrument, especially after the strong stratification on 13 April. Greater variability is observed in the bottom salinity during strong spring tides on 10 March, 9 - 11 April and after 5 May. These oscillations are on the order of 0.5 to $0.8 \mathrm{o} / \mathrm{oo}$, and more normal oscillations are smaller, on the order of 0.1 to $0.4 \mathrm{o} / \mathrm{oo}$.

Using the One-Atmosphere Equation of State of Seawater (UNESCO 1981), density was calculated for each instrument. Density at all three depths was plotted with dissolved oxygen at all three depths (Figure $47 \mathrm{a}$ and $\mathrm{b}$ ). The density stratification leads to a rapid vertical gradient in dissolved oxygen. The largest differences in dissolved oxygen 
Figure 46. Surface salinity (red) and bottom salinity (blue) during an incremental destratification event from 5 to 7 April 1997. Predicted tide height in meters is plotted on the secondary y-axis. The stratification required four consecutive tidal cycles to break down. 


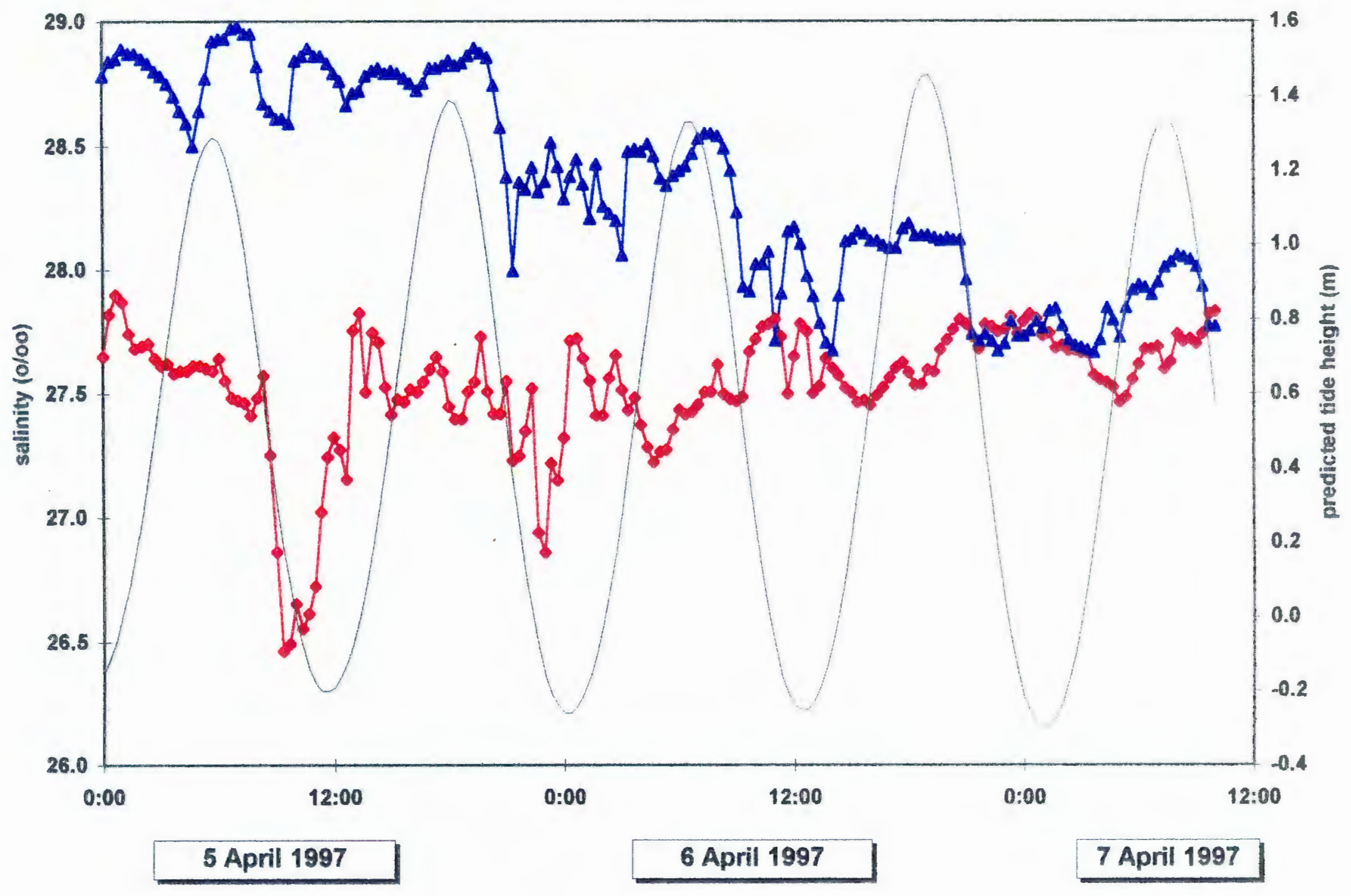


Figure $47 a$ and $b$. Density as calculated from temperature and salinity at three depths is represented in the upper and thicker curves, corrected oxygen at three depths is represented in the lower and finer curves. The consistent relationship between density stratification and oxygen stratification is seen. Note that the scales are different for both density and oxygen between Figure $47 \mathrm{a}$ and Figure $47 \mathrm{~b}$. This was necessary to show the features in stratification before 9 April. 


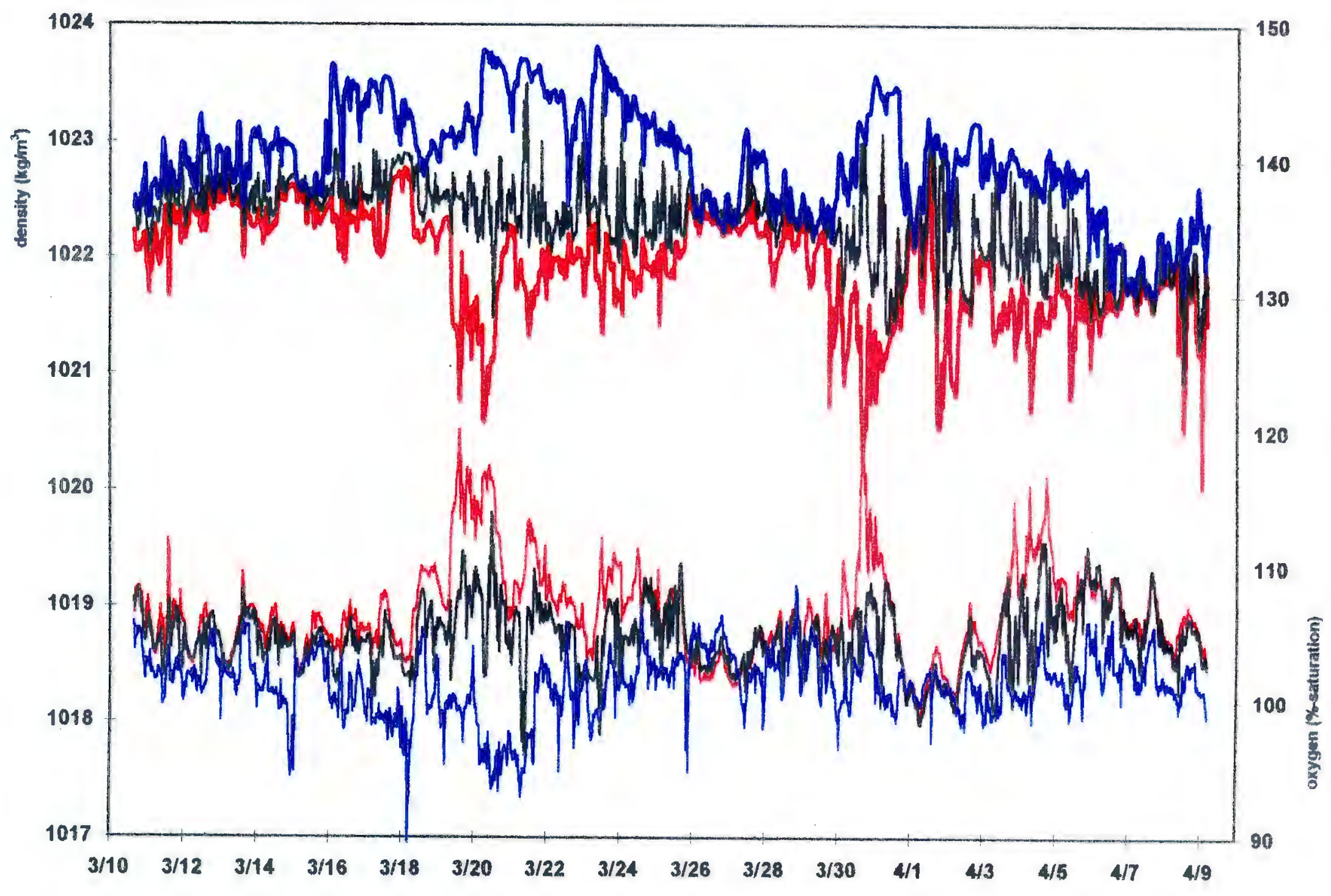




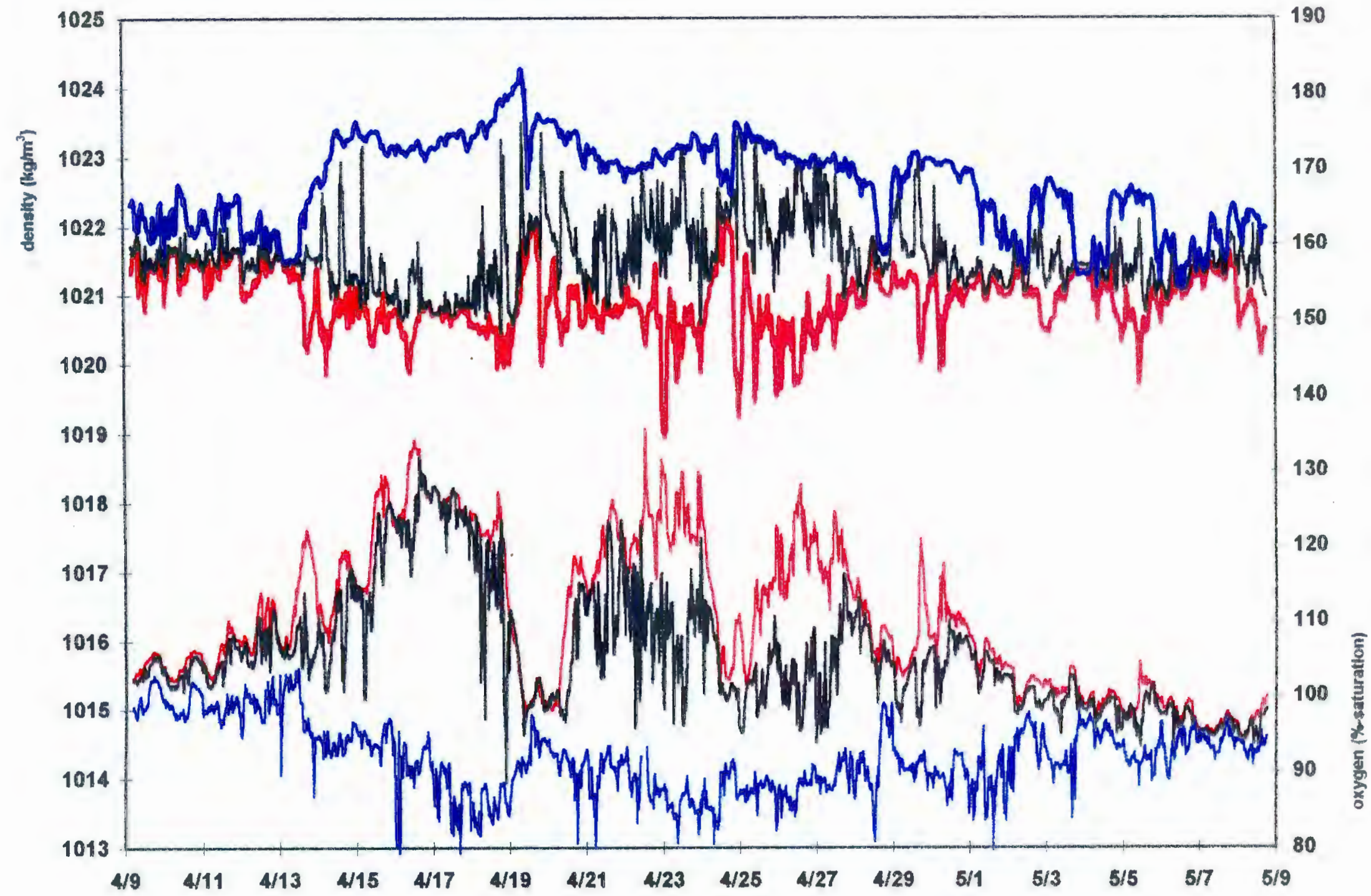


between the surface and bottom occur during the largest vertical differences in density. The bottom oxygen values are mostly between $90 \%$ and $100 \%$ before 13 April. In fact, the oxygen variability is relatively subdued in the first half of the data set, and even surface oxygen, though supersaturated, only briefly approaches $120 \%$ saturation three times. The 1 April storm disrupted the Spring phytoplankton bloom. Four days following this brief but thorough mixing event was the maximum in tidal amplitude, which encompassed the peak period of fresh water runoff from the Blackstone River, and high levels of precipitation, which could provide a significant nutrient input from further up in the Bay (Pilson, 1985).

The combination of these conditions and warming of the local waters, with the seasonal increase in solar radiation, resulted in a large-scale oxygen stratification, with surface saturations greater than $130 \%$ during the last half of April. However, this bloom was interrupted by three apparent mixing events, on 19 April, 24 April, and 28 April. After both the 19 April and 24 April destratifications, surface dissolved oxygen grew exponentially over the first day, but surface oxygen concentration growth slowed as time progressed. The surface dissolved oxygen progression flattened out in the case of the 24 April event, and began to drop in the case of the 19 April event, just prior to the mixing. From 27 April to 29 April, surface density gradually increased despite the weakening of the spring-neap tidal cycle. The winds, however, increased in magnitude to over $10 \mathrm{~m} / \mathrm{s}$ and direction varied between approximately $350^{\circ}$ and between $180^{\circ}$ and $200^{\circ}$. Freshwater river flow decreased from an absolute peak of over $3600 \mathrm{ft}^{3} \mathrm{~s}^{-1}$ on 20 April to around 1500 $\mathrm{ft}^{3} \mathrm{~s}^{-1}$ on 27 April. Eventually, the deep waters were affected, late on 28 April, as density dipped about $0.75 \mathrm{~kg} \mathrm{~m}^{-3}$ over a tidal cycle, but it rebounded to previous levels. In the 
following surface oxygen bloom, the surface values were lower than those previously, and the surface oxygen decreased steadily from about 30 April until the end of the data set on 8 May.

With respect to bottom oxygen, we also noted a recurring feature. The bottom oxygen data showed occasions, all associated with high tide, wherein the oxygen level would rapidly decrease, on the order of 10 to $30 \%$, and then return to its previous level. These spikes appeared to be coincident with rapidly changing wind directions, and frequently appeared immediately before a destratification event, although a strong spike appeared in the middle of a strongly stratified period on 16 April. The relationship between the bottom oxygen and bottom salinity variations do not indicate a hydrographic or water-mass cause for the low oxygen spikes (Figure 48). The oxygen variability is probably a result of processes occurring locally within the hole, and are not due to horizontal exchange with the East Passage of Narragansett Bay. Observing that they occur after a period of stratification or during strong stratification, they may indicate the normal fate of the isolated, deep water, before the outgoing tide is able to mix the oxygendepleted water out of the hole.

The difference between bottom density and surface density and one-tenth of the difference between surface oxygen and deep oxygen, can be used as indices for stratification in the physical structure, and the gradient in oxygen, respectively. The oxygen saturation values were scaled by a factor of 0.1 to allow plotting of both indices on the same graph (Figures 49a and b). We plotted the two indices along with the Newport Tide Height predictions for 10 March through 8 May, 1997. The tide data show periods of greater and lesser tidal amplitudes. Higher tidal amplitude and thus higher 
Figure 48. Bottom salinity and bottom oxygen from 9 April to 8 May 1997. Note that the downward spikes in the dissolved oxygen data are not replicated in the salinity data. 


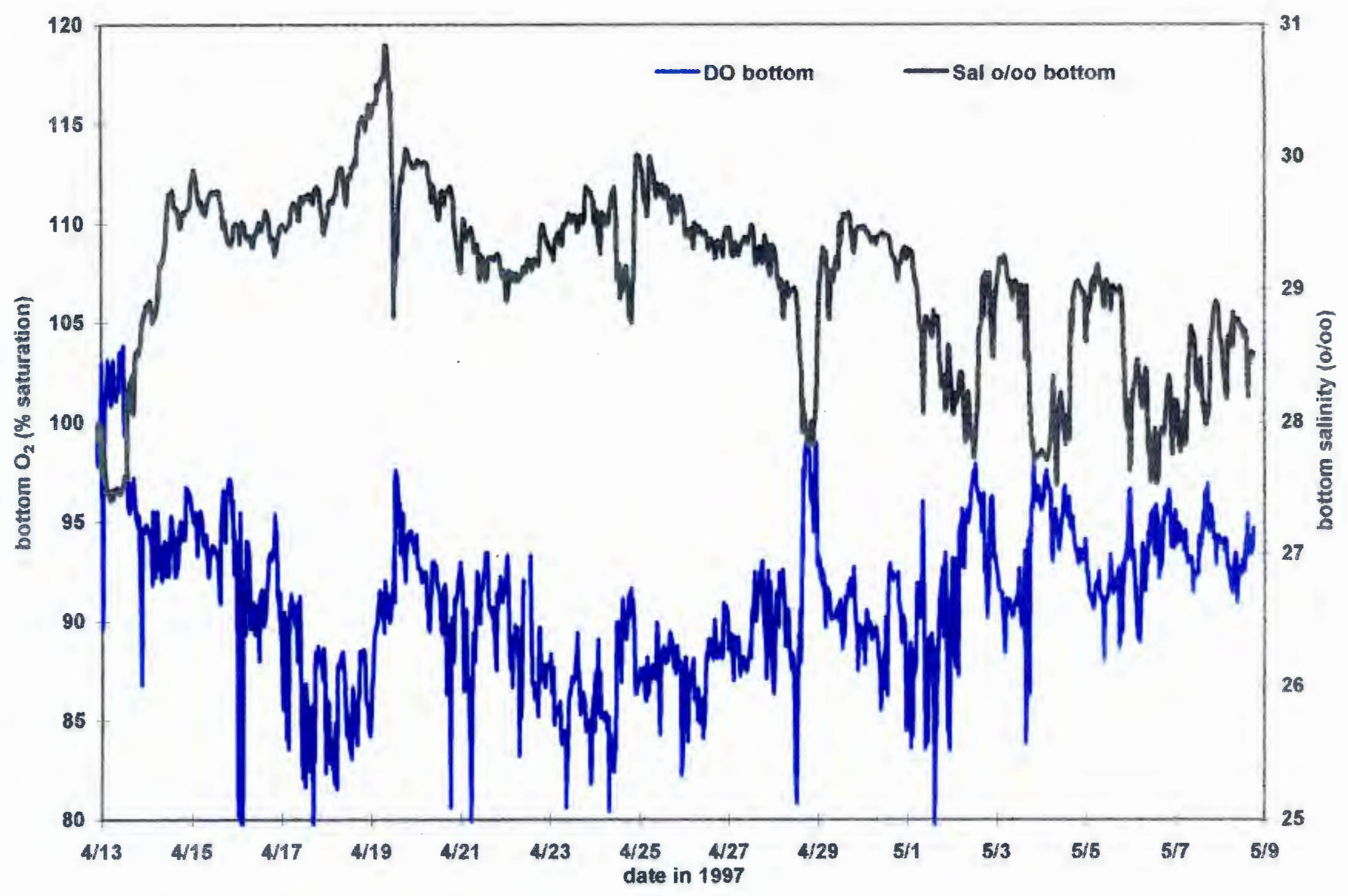

$\overrightarrow{+}$ 
Figures $49 a$ and $b$. Density stratification and oxygen gradient versus time. The density stratification is calculated by taking the difference between the bottom density and surface density. The oxygen gradient is calculated as one-tenth of the difference between the surface oxygen and the bottom oxygen. Density stratification is in $\mathrm{kg} \mathrm{m}^{-3}$ and the oxygen gradient is in $\%$ saturation. The predicted tide heights for Newport, RI for the period are plotted as well. The density stratification and oxygen gradient relationship, and their dependence on the state of the spring-neap tidal cycle is observed. 


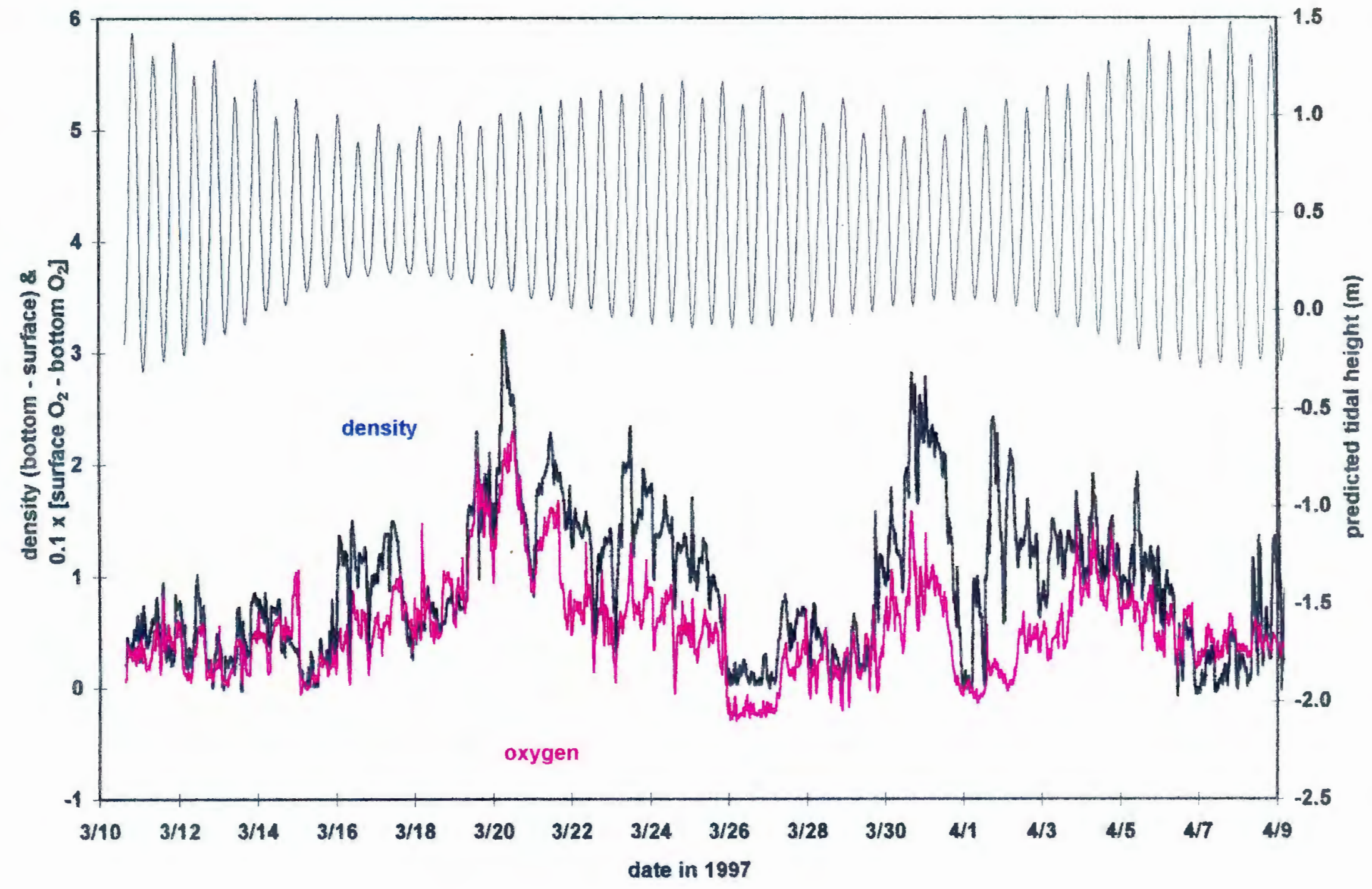




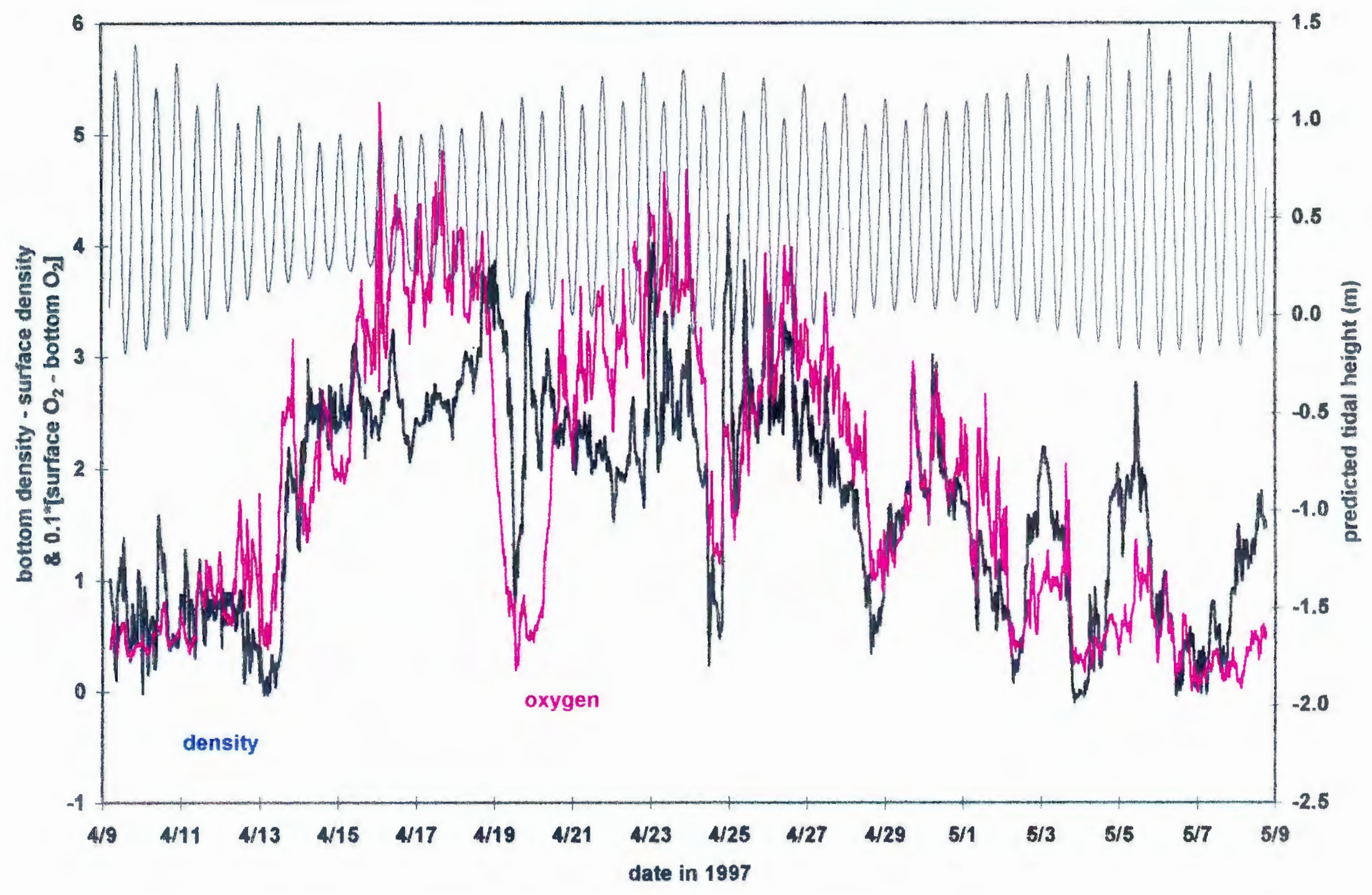


water column energy for mixing are found between 6 and 9 April and between 5 and 8 May. The two stratification indices coincide remarkably closely. The fact that the peaks and the mixing periods plot so closely suggests that dissolved oxygen stratification and hydrological stratification are related and that a $1 \mathrm{~kg} \mathrm{~m}^{-3}$ difference in the surface to bottom density can be accompanied by an approximately $10 \%$ surface to bottom dissolved oxygen difference. The data from this deployment were summarized in a table of conditions observed in these two months, to indicate the forcings responsible for stratification and destratification (Table 5). A destratification event was defined as a difference between the bottom and surface densities of about $0.5 \mathrm{~kg} \mathrm{~m}^{-3}$ or less for the 12 m deep water column. The event on 19 April was an exception to this, in that the difference between the two depths was about $1 \mathrm{~kg} \mathrm{~m}^{-3}$. However, considering the nature of the event, in which winds were over $18 \mathrm{~m} \mathrm{~s}^{-1}$, and the previous stratification was between 2.5 and $4.0 \mathrm{~kg} \mathrm{~m}^{-3}$, we classified this event as a destratification. Events of stratification and destratification seem to correspond to the departure from predicted tides, which can indicate either localized winds or large scale weather patterns which can drive subtidal flushing and filling of the estuary (Goodrich, 1988). It appears that the critical wind speed for inducing destratification is between 7 and $9 \mathrm{~m} \mathrm{~s}^{-1}$, although lower winds are required when the tidal amplitude is high, as on 6-7 April. Conversely, after the delivery of a large volume of fresh-water, which may strengthen stratification, this stratification may resist higher velocity winds, as on 9-12 April.

Observing the predicted high tide data for Newport, RI and the temperature, salinity and dissolved oxygen records, one sees that early in March and April, periods of thorough vertical mixing coincided with periods of greater tidal range. The periods in 
Table 5. A compilation of parameters over periods of stratification and destratification in the March to May 1997 buoy deployment. The code in column 2 indicates the condition, $\mathrm{S}$ for stratified and D for destratified, column 3 is the bottom instrument density minus the surface instrument density in $\mathrm{kg} \mathrm{m}^{-3}$, the observed tidal range from high tide to low tide in meters is in column 4 , column 5 is the difference between the observed tidal signal as represented by the corrected bottom YSI-600 pressure record minus the Newport predicted tides corrected in time and amplitude to the southern tip of Prudence Island. The next two columns are the wind speed in meters per second, and direction represented by the cardinal direction description from the wind time series. The dash separating individual wind directions indicates the progression of wind direction over time (i.e. N-E indicates that the wind switched from north to east, while NE indicates winds out of the northeast). The final column is the fresh water input in both river outflow from the Blackstone River, as gauged by the USGS at Woonsocket, RI and the rainfall in inches of precipitation as measured by NOAA National Weather Service at T.F. Green Airport in Warwick, RI.

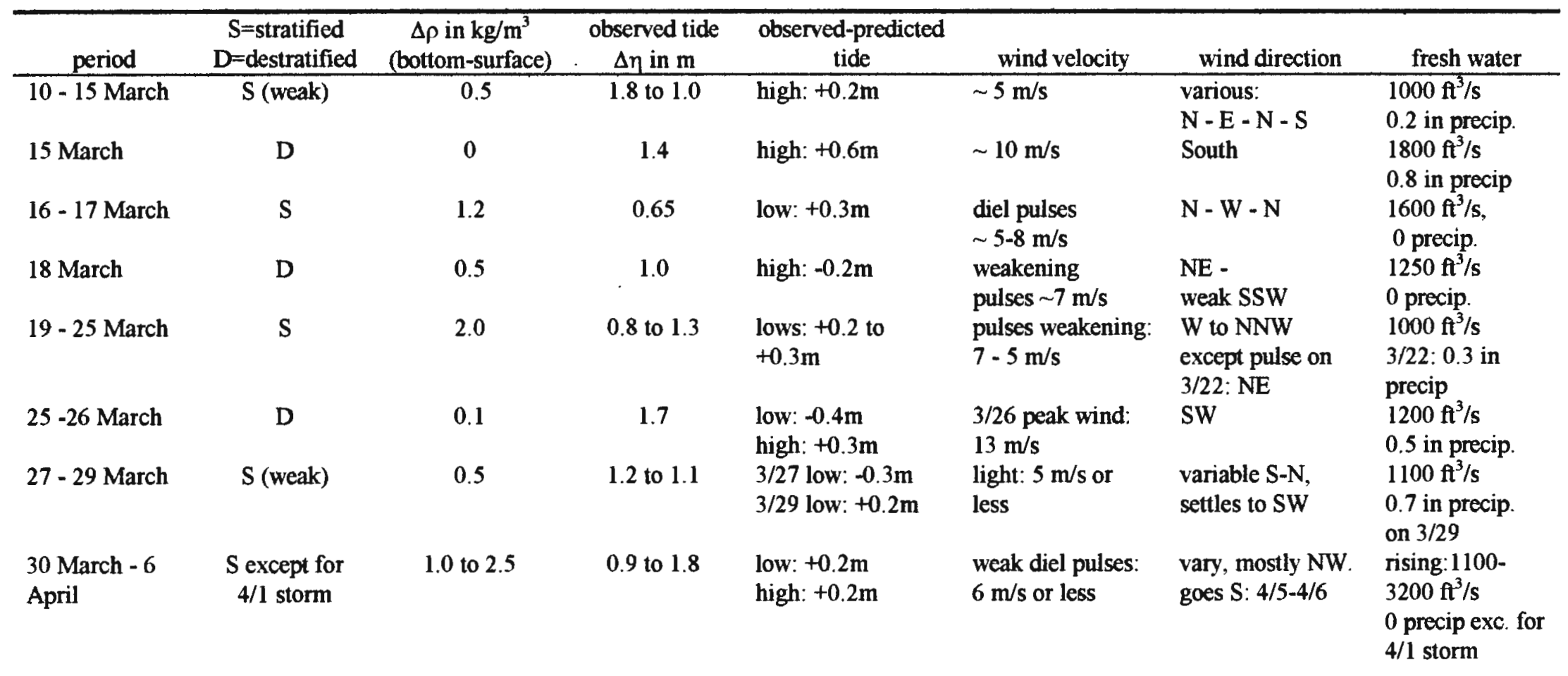




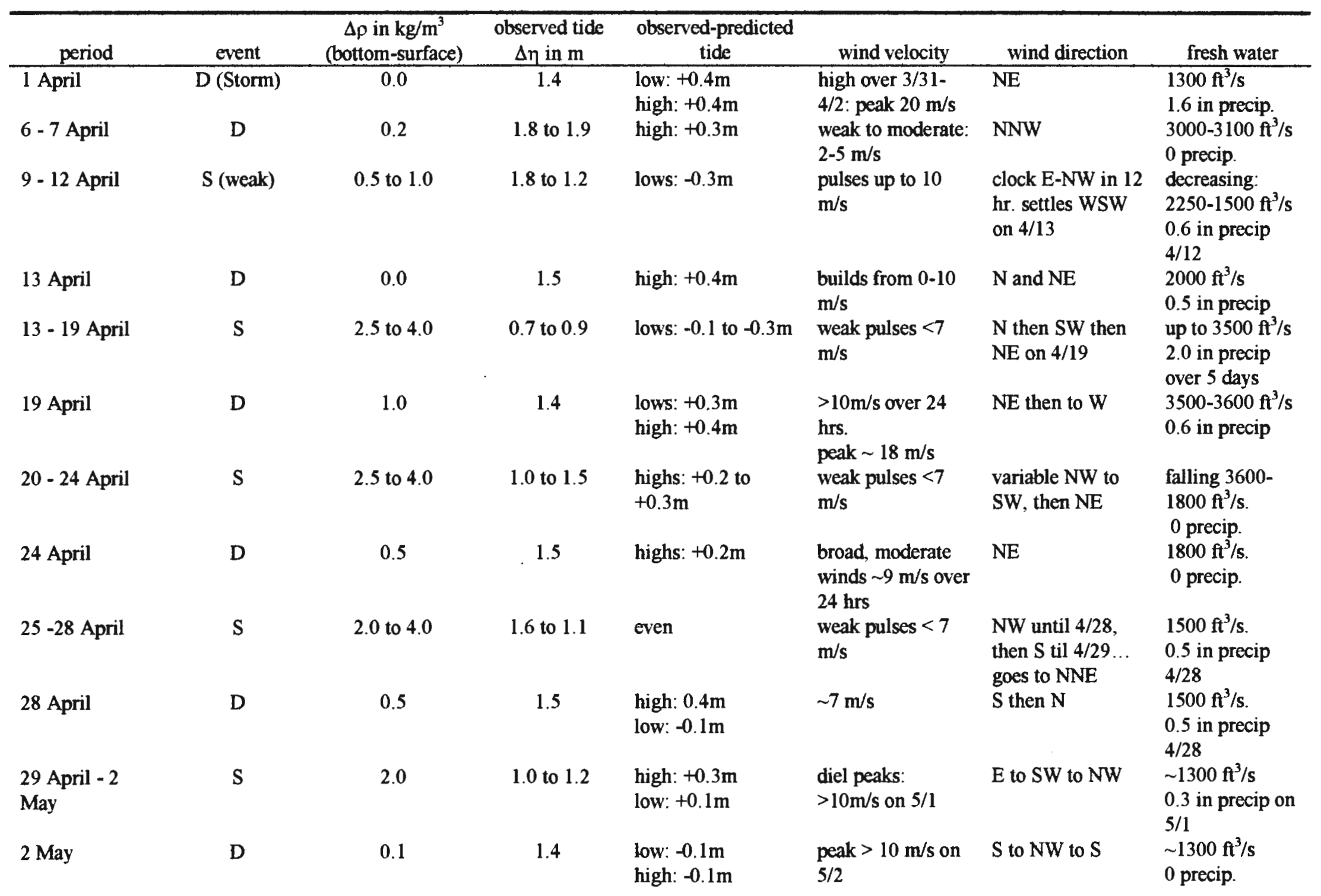




\begin{tabular}{|c|c|c|c|c|c|c|c|}
\hline period & event & $\begin{array}{c}\Delta \rho \text { in } \mathrm{kg} / \mathrm{m}^{3} \\
\text { (bottom-surface) }\end{array}$ & $\begin{array}{c}\text { observed tide } \\
\Delta \eta \text { in } \mathrm{m} \\
\end{array}$ & $\begin{array}{l}\text { observed-predicted } \\
\text { tide } \\
\end{array}$ & wind velocity & wind direction & fresh water \\
\hline 3 May & $\mathrm{S}$ & 1.5 to 2.0 & 1.6 & $\begin{array}{l}\text { low: }+0.4 \mathrm{~m} \\
\text { high: }+0.4 \mathrm{~m}\end{array}$ & 0 to $9 \mathrm{~m} / \mathrm{s}$ to 0 & SSW & $\begin{array}{l}1300 \mathrm{ft}^{3} / \mathrm{s} \\
0.2 \mathrm{in} \mathrm{precip}\end{array}$ \\
\hline 4 May & D & 0 & 1.7 & low: $+0.3 \mathrm{~m}$ & $\begin{array}{l}\text { broad peak up to } \\
8 \mathrm{~m} / \mathrm{s}\end{array}$ & NNW & $\begin{array}{l}1400 \mathrm{ft}^{3} / \mathrm{s} \\
0 \text { precip }\end{array}$ \\
\hline 5 - 6 May & $S$ & 2.0 & 1.5 to 1.8 & highs: $+0.2 \mathrm{~m}$ & peaks of $7 \mathrm{~m} / \mathrm{s}$ & SSW & $\begin{array}{l}1200 \mathrm{ft}^{3} / \mathrm{s} \\
0.1 \mathrm{in} \mathrm{precip}\end{array}$ \\
\hline 6 - 7 May & $\mathrm{D}$ & 0.2 & 1.8 & $\begin{array}{l}\text { low: }+0.2 \mathrm{~m} \\
\text { high: }+0.2 \mathrm{~m}\end{array}$ & weak 2 to $5 \mathrm{~m} / \mathrm{s}$ & NNW & $\begin{array}{l}1100 \mathrm{ft}^{3} / \mathrm{s} \\
0 \text { precip }\end{array}$ \\
\hline 7 - 8 May & $\mathbf{S}$ & 1.0 & 1.7 to 1.5 & low: $-.1 \mathrm{~m}$ & weak $4 \mathrm{~m} / \mathrm{s}$ & S & $\begin{array}{l}1000 \mathrm{ft}^{3} / \mathrm{s} \\
0.1 \text { in precip }\end{array}$ \\
\hline
\end{tabular}


which stratification is sustained for days are coincident with lower tidal ranges. We observed an asymmetry in the tide curve which was most notable in spring phase tidal events (Figure 30). The flood portion of the tidal cycle was extended in time, up to 8 hours, and the ebb portion was as short as 4 hours. This difference may also account for the much stronger mixing observed during the ebb tide, since the change in height was the same for a much shorter period on the ebb, than on the flood.

The data set can be broken naturally into two sections, that before 9 April and that after 9 April. Conditions prior to 9 April are more indicative of winter conditions, in that water temperatures are lower, bottom temperatures are warmer, stratification is more limited and storms, as indicated by higher winds, are more frequent. After 9 April, the water column is warming, surface temperatures begin regularly exceeding bottom temperatures, stratification is stronger and more persistent, and high wind events are fewer, although the diel southwesterly sea-breeze becomes prevalent and strong after 30 April.

On 13 April, the most dramatic stratification event of the time-series occurred. Slightly after mid-day on 13 April, surface density began to drop precipitously with the outgoing tide and bottom density started a steep climb which persisted over the next tidal cycle, and finally steadied at high tide, mid-day on 14 April. An extremely well-stratified condition persisted until the occurrence of a storm event on 19 April. This stratification was remarkable in that it represented a classic evolution of estuarine entrainment in the deeper layer as a result of increased fresh water flow in the surface layer. The overall period from 14 April until 16 April was marked by damped tidal excursion and a general decrease in the day-to-day water level. Figure 50 shows a broad decrease in the surface 
Figure 50. Surface (red), mid-depth (green) and bottom (blue) salinity from 11 April 1997 until 20 April 1997. The thin dark line is observed tidal height in meters above MLLW, and the thick dark line is the twenty-four hour moving average of the observed tide height in meters above MLLW. 


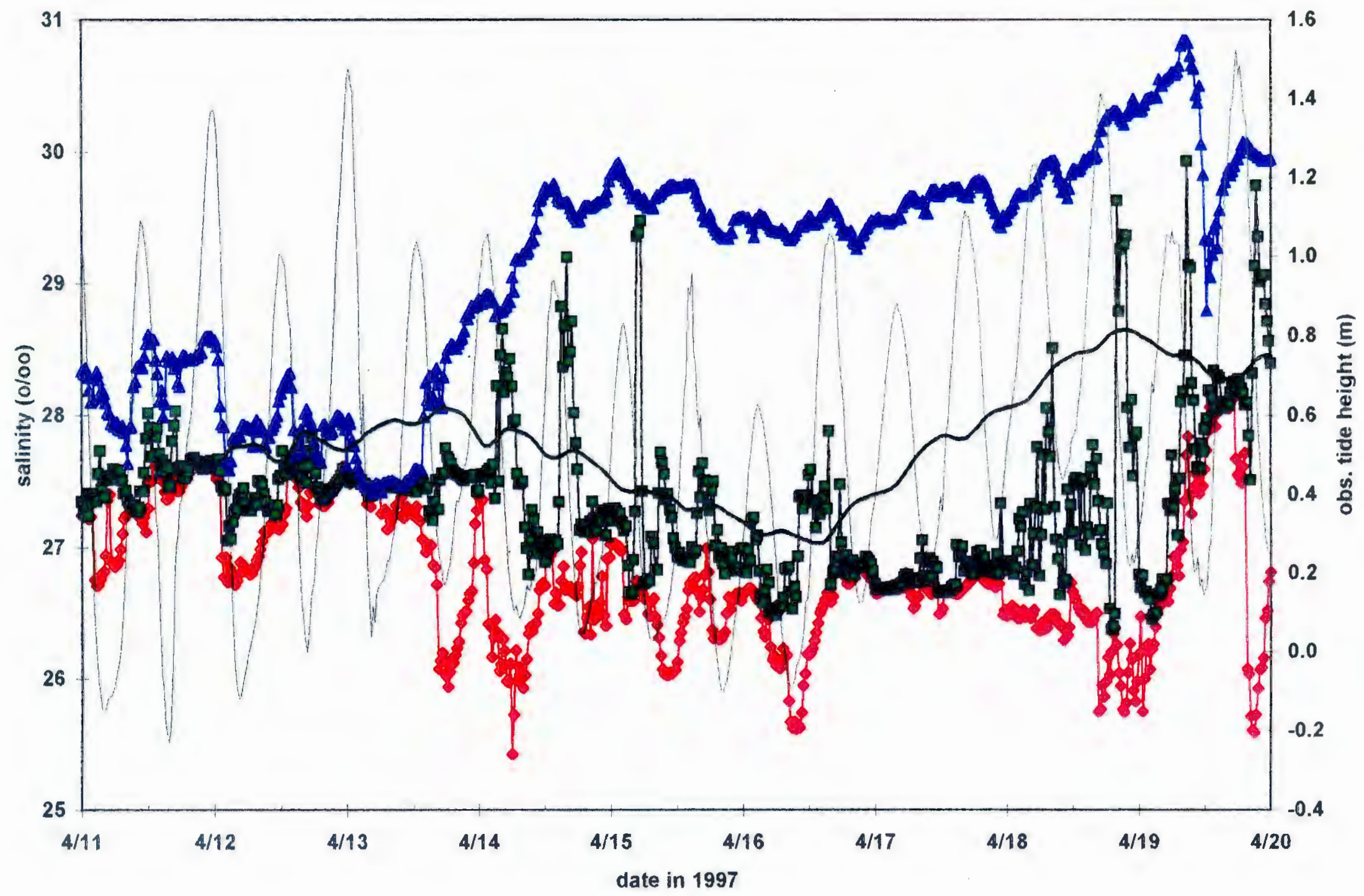


salinity from values greater than $27 \mathrm{o} / \mathrm{oo}$ on 13 April to values less than $26 \mathrm{o} / \mathrm{oo}$ on 16 April. Meanwhile, a change in the wind orientation, from the clocking wind system between 11 April and 13 April, to steady winds from the north between 13 April and 15 April occurred (Figure 51). The combination of winds from the north and the increased river flow represented by the decreasing surface salinity, damped tidal range, and general emptying of the estuary, resulted in deep entrainment of cold, high salinity waters from offshore, and the stratification between the warm, fresh surface outflow and the cold, saline deep inflow. This period was followed by a re-filling of the estuary as the tidalheight moving average indicated rising water levels between late on 16 April and a peak late on 18 April. This peak in the estuarine re-filling occurred just prior to a storm on 19 April as marked in Figure 51 by $20 \mathrm{~m} / \mathrm{s}$ winds from the northeast, which eventually mixed the surface and bottom waters to within about $0.5 \mathrm{o} / \mathrm{oo}$ in salinity near mid-day on 19 April.

A change in T-S properties in the bottom water was further indicative of the changes in the water column resulting from the increased riverine outflow. The water at all three depths was about 27.5 o/oo and well-mixed on 13 April (Figure 52). Over the course of the next five days, surface and deep properties diverged, the properties of the surface and mid-depth varying greatly in temperature and salinity. However, the deep water layer exhibits little variation, other than the steady increase in salinity from a minimum (well-mixed condition) of $27.5 \mathrm{o} / \mathrm{oo}$ to a maximum (well-stratified condition) of almost 31 o/oo. Eventually, the mixing event on 19 April affected the bottom water, and is shown by the peak marked " $\mathrm{A}$ " on the bottom T-S plot. 
Figure 51. Wind speed (red line) in $\mathrm{m} / \mathrm{s}$ and wind direction (green line) in degrees, between 11 April 1997 and 20 April 1997. Wind directions between $0^{\circ}$ and $90^{\circ}$ have $360^{\circ}$ added to them for ease in plotting. 


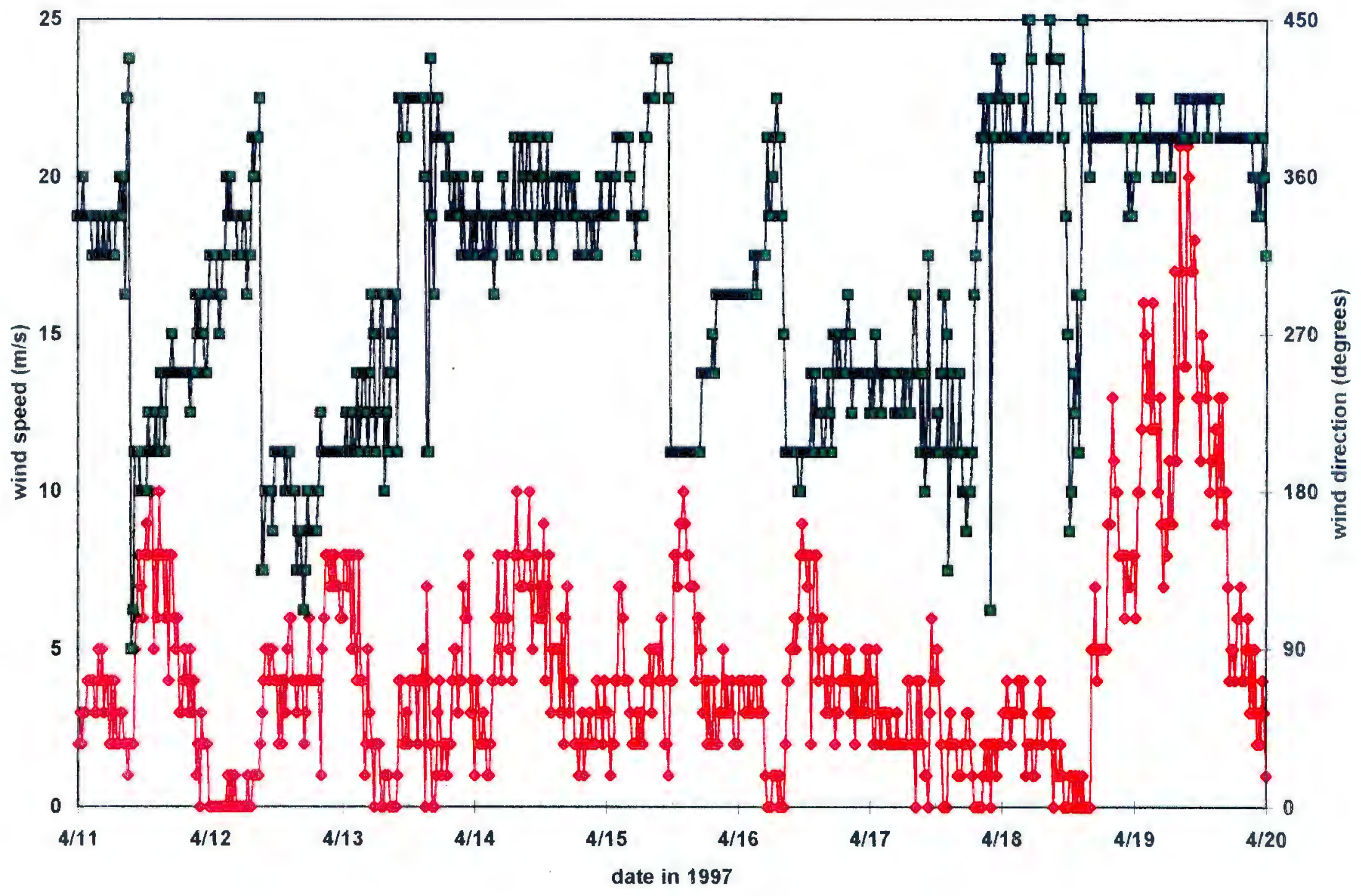


Figure 52. Top panel: Temperature vs. Salinity properties for the surface instrument between 11 April and 20 April 1997. Middle Panel: Temperature vs. Salinity properties for the mid-depth instrument between 11 April and 20 April 1997. Bottom Panel: Temperature vs. Salinity properties for the bottom instrument between 11 April and 20 April 1997. The point marked "A" in the bottom panel indicates mixing event of 19 April 1997 and its effect on the bottom T-S properties. 

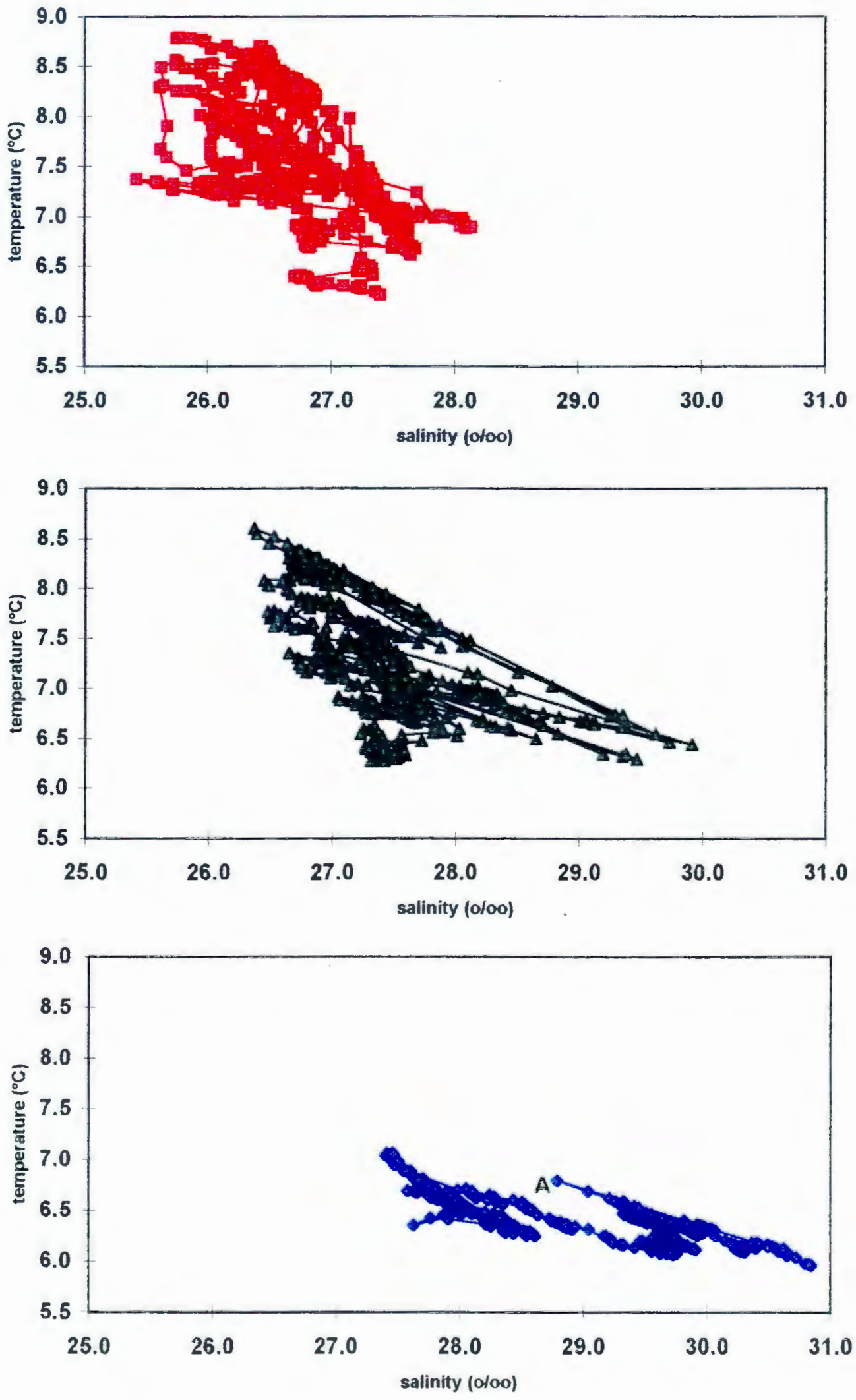
The stratification from 13 April through 18 April suggests that there was no communication between the bottom layer and the atmosphere over the course of several days. Thus, this extended stratification represented the most probable opportunity for development of a low-oxygen, or hypoxic, condition in the deep layer. The dissolved oxygen data show that the stratified condition was represented in this parameter as well, with a maximum vertical difference of about $50 \%$ between surface and bottom, however no drastic hypoxia or anoxia was observed (Figure 53). Between 13 April and 17 April, four consecutive diel maxima in surface oxygen are observed. However, it is interesting that the peaks occur well after mid-day on each of the days. Each of the rises and eventual maxima occurred during the incoming tide and through high water, suggesting that photosynthetic activity was most robust further down-Bay or in the East Passage and that the high-oxygen water was later advected back to the buoy station with the tide. This scenario is supported by the assumption that the down-Bay and offshore waters are colder, and thus metabolic activity which would consume oxygen and photosynthesizing organisms was less further down-Bay and was greater in the warmer, up-Bay waters. Alternately, the surface waters originating in the Providence River and in Mount Hope Bay can be assumed to support greater photosynthesis (Martin, 1957), and these waters may eventually be advected to the West Passage and thus, to the buoy station. This second scenario is more likely, given the northerly winds, and the high level of supersaturation in the surface waters, a condition which would be more readily mixed to saturation offshore. The deep waters, though exhibiting undersaturation, did not show as low a level of oxygen saturation as one might expect given a several day isolation from the atmosphere. Two possibilities are suggested. First, it may be that there was 
Figure 53. Surface (red), mid-depth (green) and bottom (blue) dissolved oxygen from 11 April 1997 until 20 April 1997. The thin dark line is observed tidal height in meters above MLLW. 


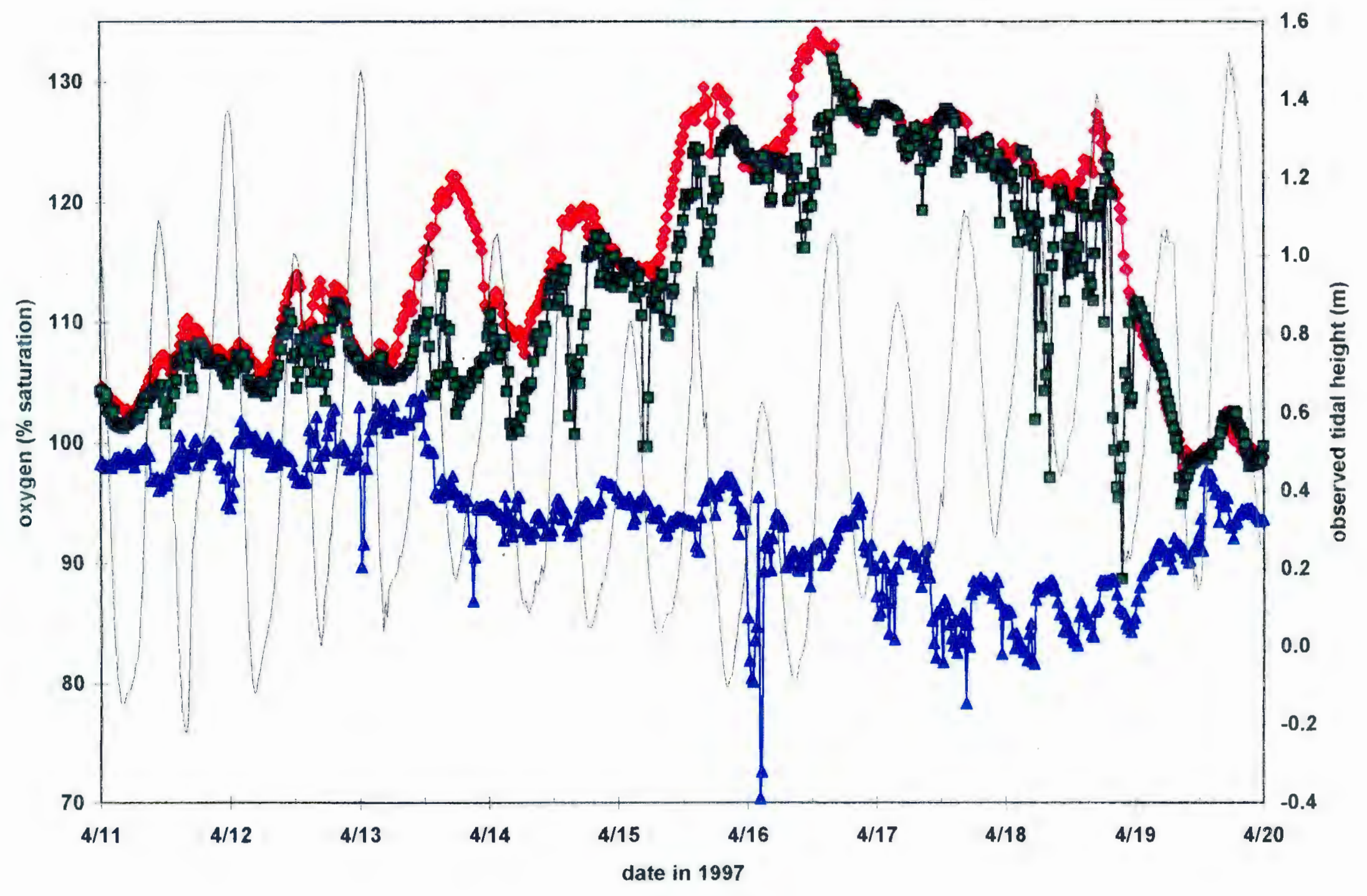


photosynthesis occurring in the deep layer over the period. However, the low levels of surface photosynthesis, and the generally high turbidity of the waters we observed during buoy servicing, suggest another mechanism. If one assumes that the deep waters were from offshore, in the Rhode Island Sound vicinity, and that this offshore surface water was subducted under the less-dense estuarine outflow, then perhaps the deep estuarine waters had been in recent contact with the atmosphere while still offshore, as surface waters. This association between the deep estuarine waters and the surface offshore waters may help explain the lag in warming between the deep waters and the surface waters as observed in the temperature time-series (Figures 17a and b).

The results from our ADCP profiling were not as useful for correlating with the buoy data as we at first hoped. We were unable to compare conditions over both the ebb and the flood, as sea conditions worsened to the point that the data we acquired on the flood was too poor to use. We were able to construct several current sections that crossed the center of the hole, near the position of the buoy, to examine the development of the physical structure over the ebb (Figures 54a through $\mathrm{f}$ ). These images are all of high quality and show, in the upper panel, flow direction as indicated on the azimuth rose immediately to the upper right on the image, and the lower panel indicates flow magnitude as represented on the color bar to the lower right. Images provided are extracted from the full ADCP images provided in Appendix 2, however these are annotated for the time of observation relative to the tidal state. The predicted tide height is given in Figure 55, and the observed water height above the bottom instrument gives an indication of the effect of the weak northerly wind. One can see that the low tide is lowered due to the effect of the winds, and as the southerly winds pick up in intensity, the high tide is elevated, and the 
Figure 54a through $\mathrm{f}$. Sections of ADCP transects, representing flow direction in the upper panel, referenced to the azimuth rose to the upper right, and flow magnitude in color-coded contours and referenced to the color bar to the lower left. Flow is given in $\mathrm{cm} \mathrm{s}^{-1}$. These transects were all taken across the center of the hole, from east to west towards the island, and the location of the buoy is approximately at the western rise from the bottom of the hole, to the left side of the image. Figures $54 a, 54 b, 54 c, 54 d, 54 \mathrm{e}$, and 54f, were taken at approximately 7:30 am, 8:35 am, 9:30 am, 10:25, 11:25, and 12:35, respectively. The entire image printouts can be found in Appendix 2. 

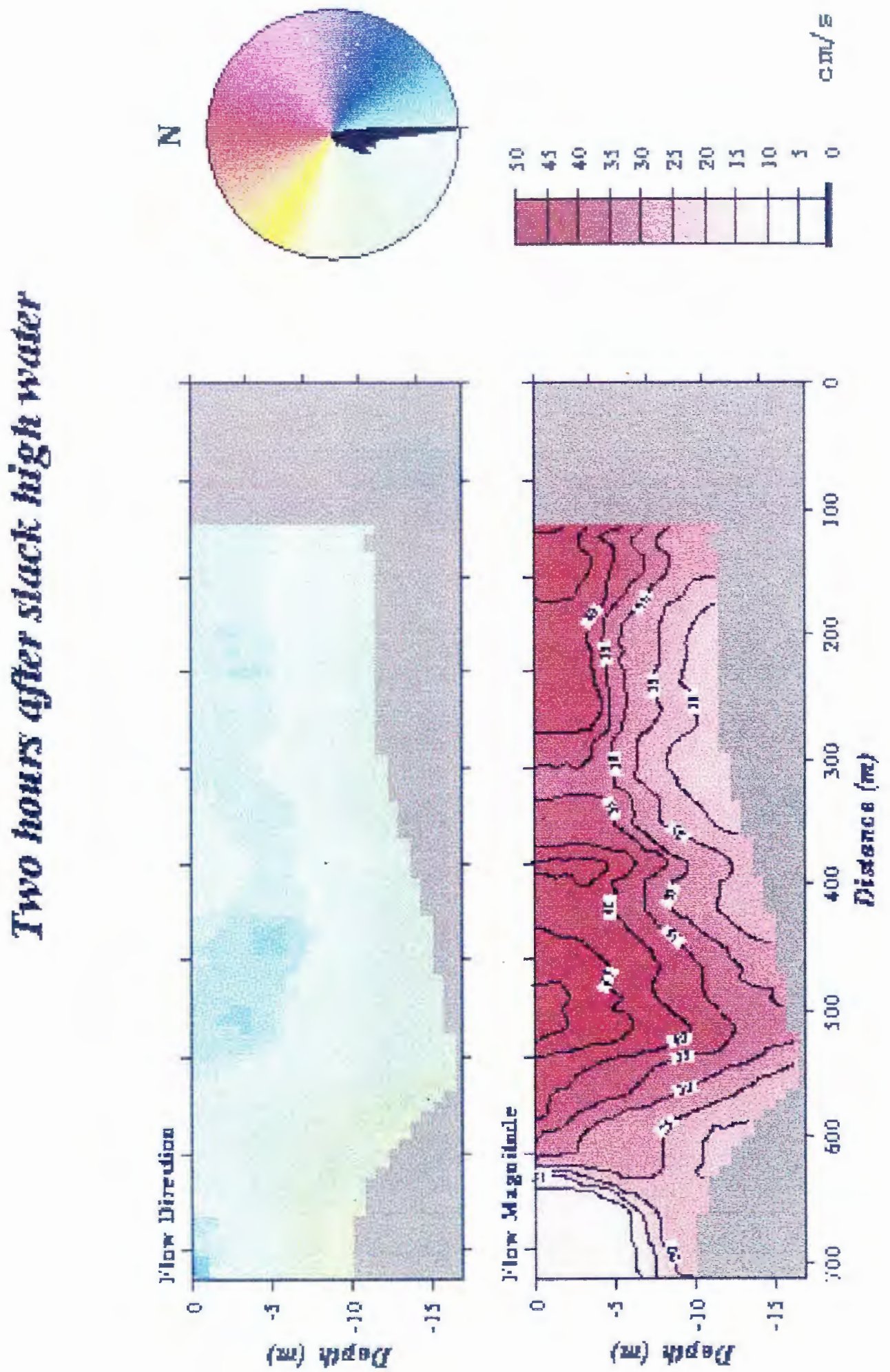

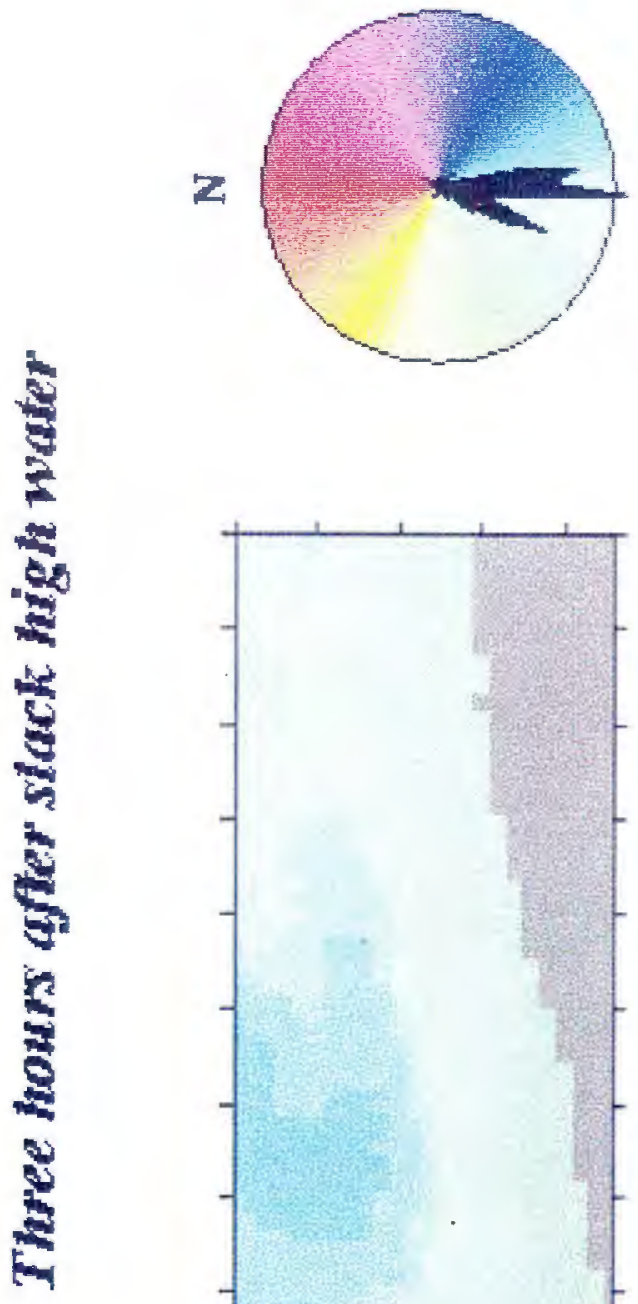

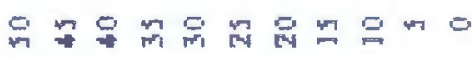
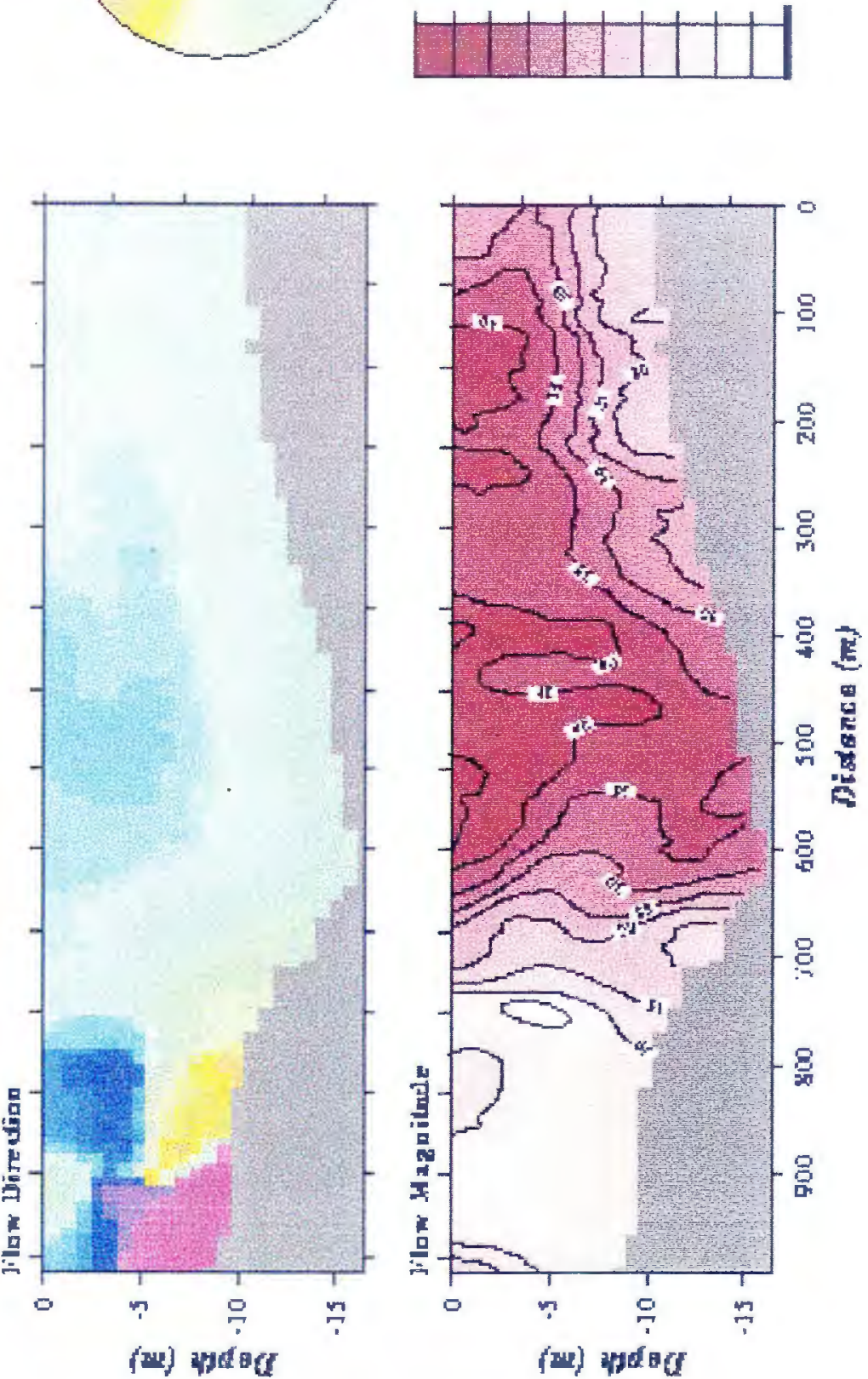


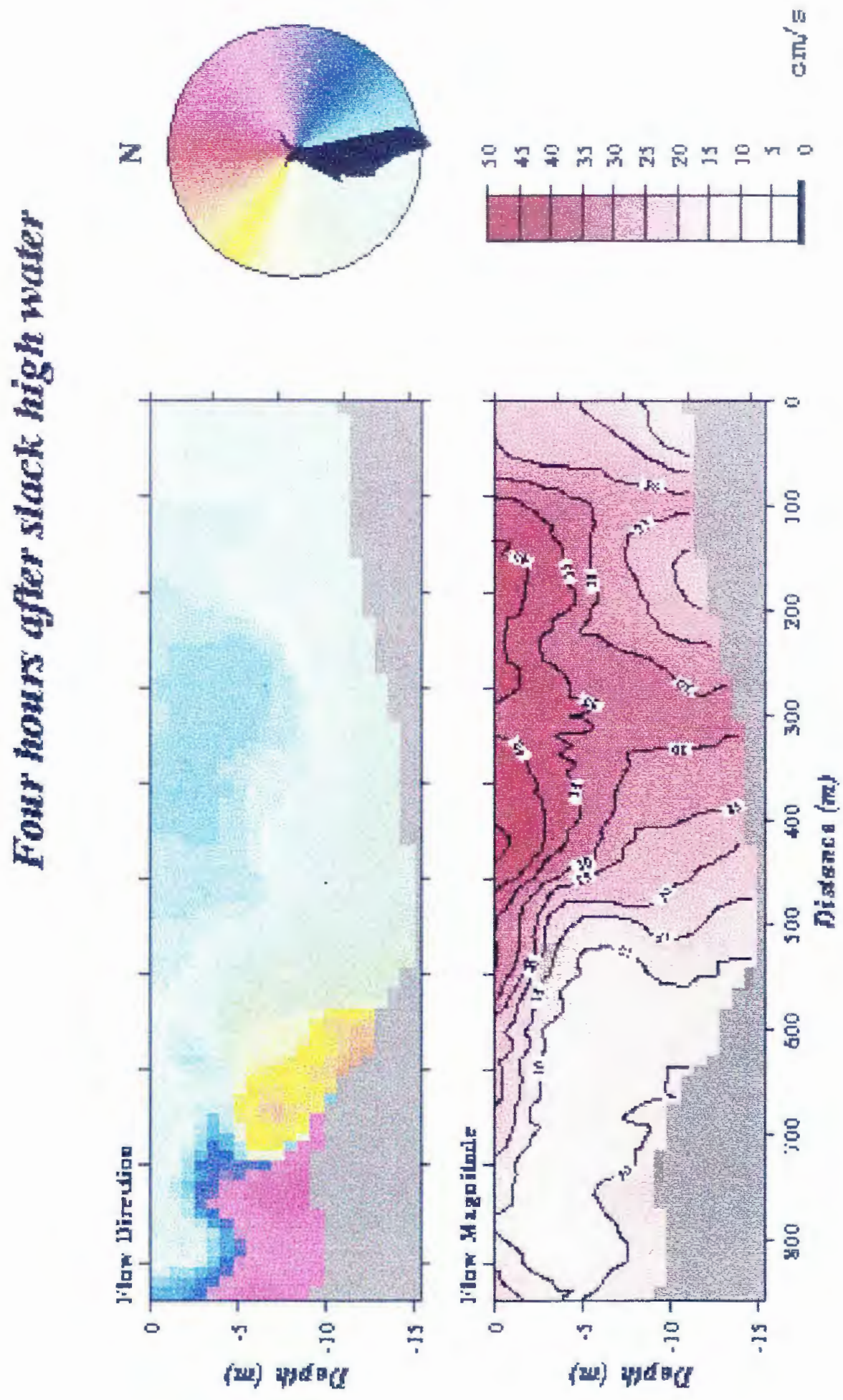



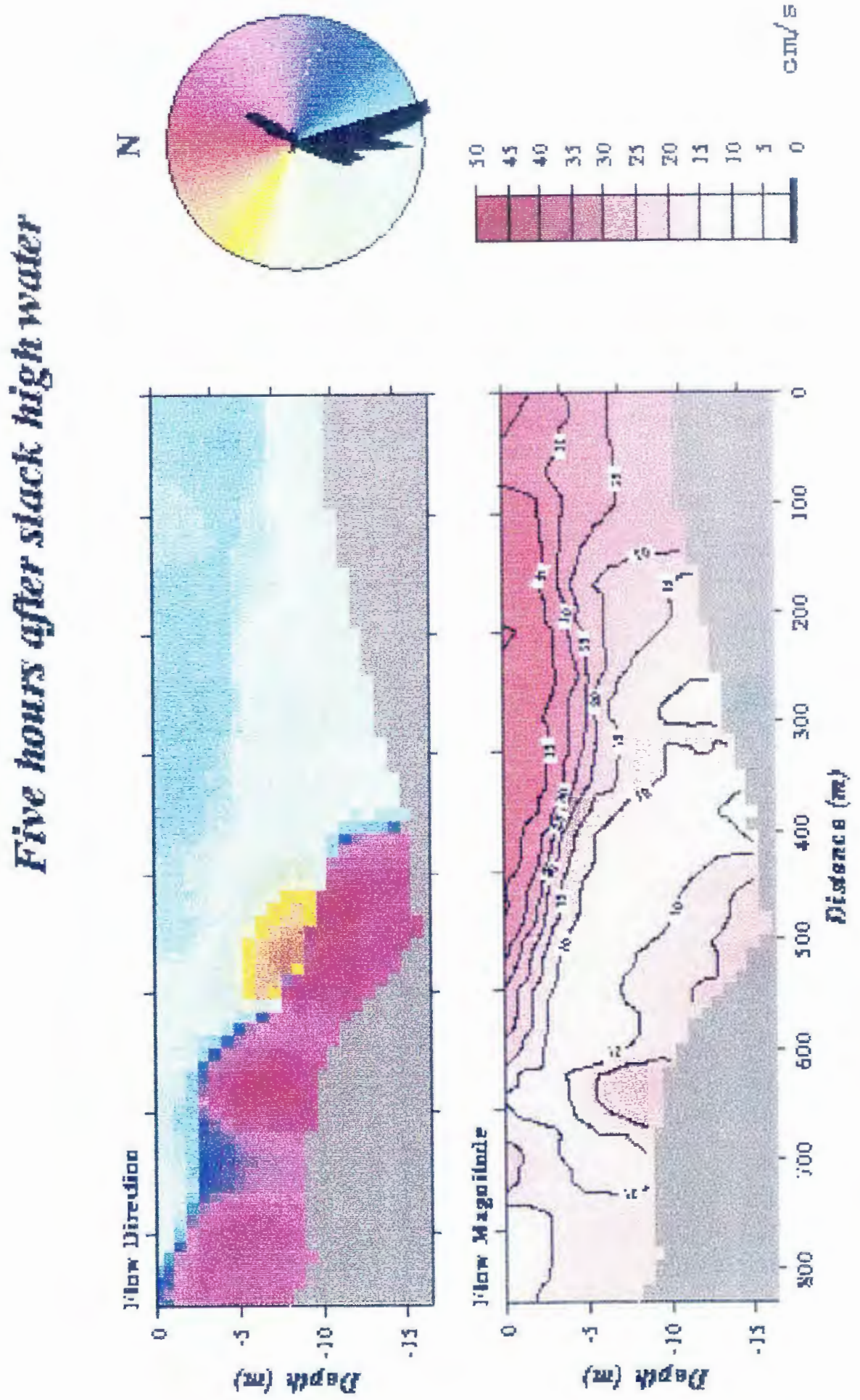

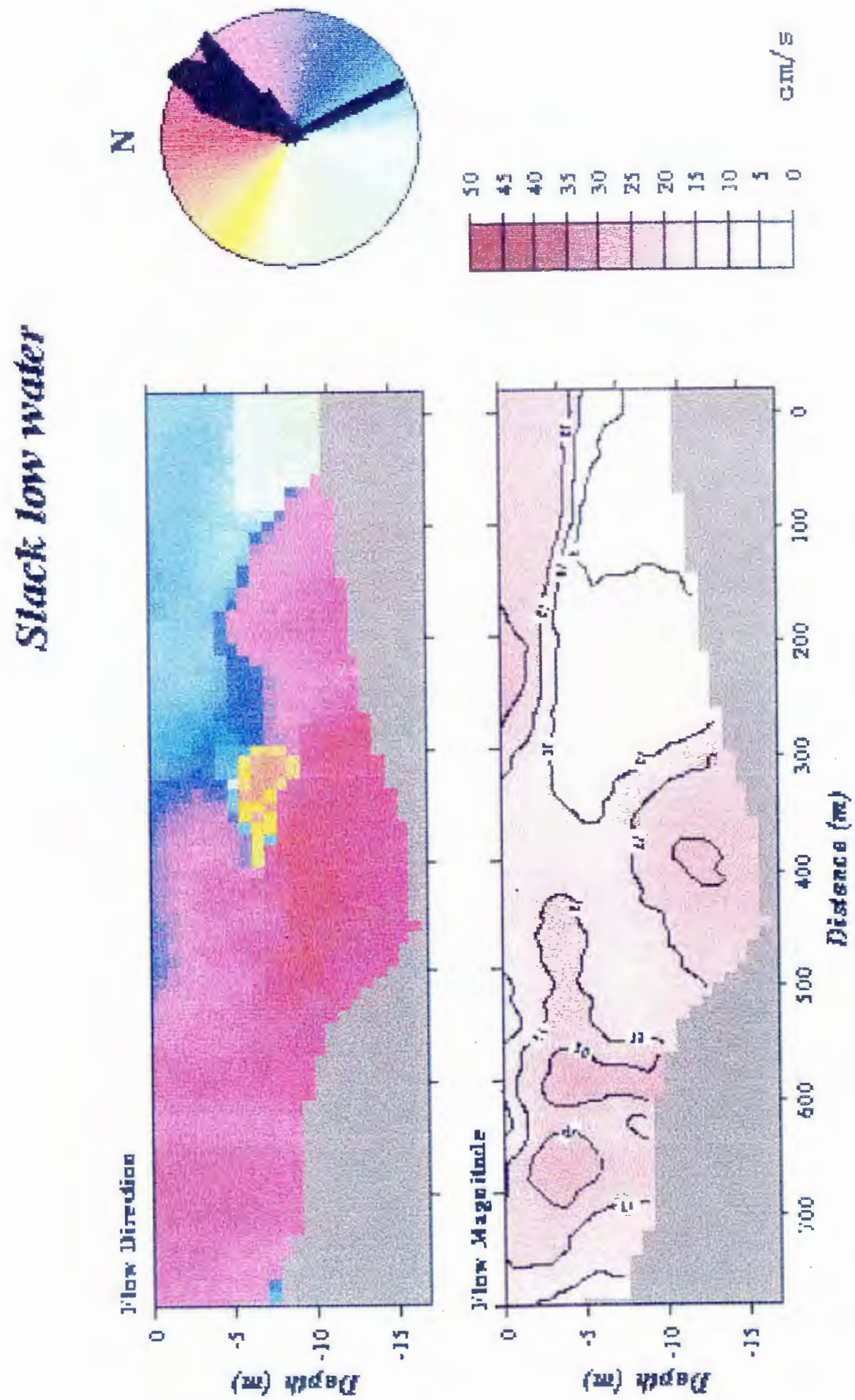


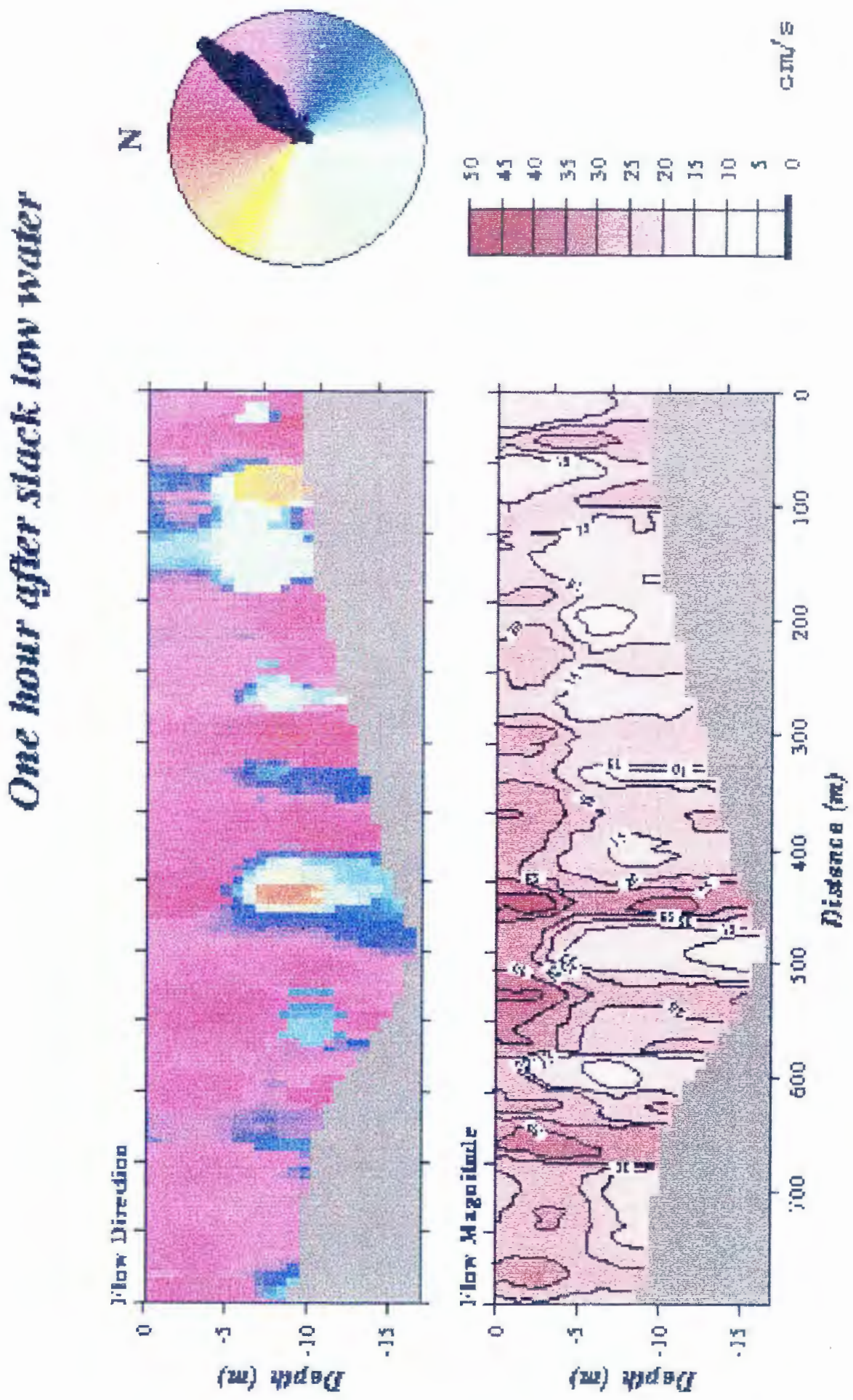


Figure 55. Predicted and observed tide height on 5 April 1997 from high tide at 6:00 to the subsequent high tide at 18:00. 


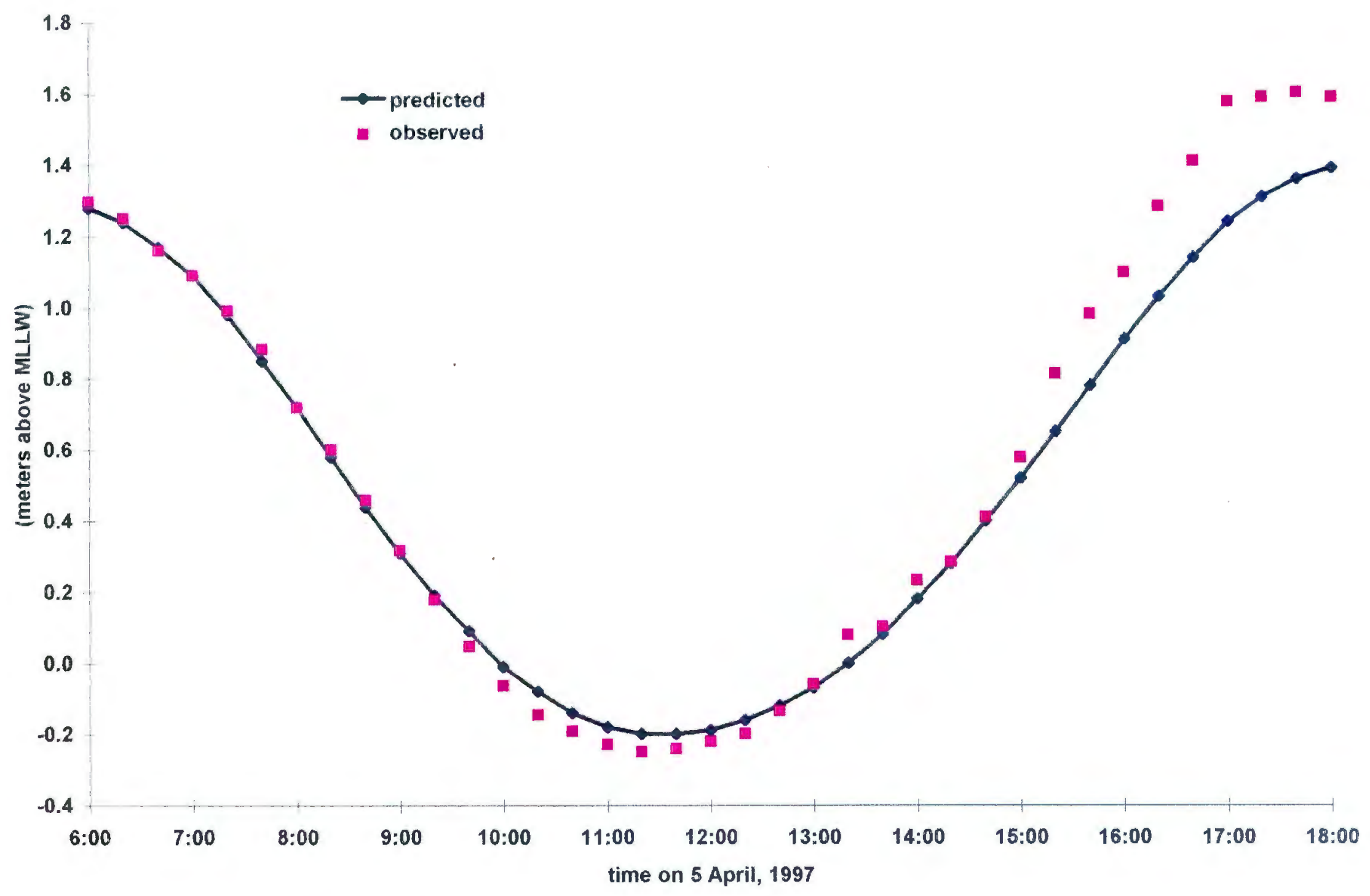


water level curve leads the predicted data as the winds and water begin to move in the same direction. One can observe in the sections that the water column was initially ebbing at 07:40 and this condition was evident through the entire water column. A small area towards the island was characterized by weak currents, and the surface current maximum was centered over the deepest part of the hole. As time advanced, a progressively stronger counter-current started on the shelf between the island and the hole, and the higher surface currents were displaced away from the island towards the middle of the passage between Hope Island and Prudence Island. About 2 hours prior to low tide, this counter-current regime had begun to dominate the entire western portion of the hole, and had worked its way across the deepest part of the hole, to the eastern rise. At about the time of low tide, the western "shelf" waters and the deep center of the hole were flooding at about $20 \mathrm{~cm} \mathrm{~s}^{-1}$, while the surface to the east was still ebbing, also at about $20 \mathrm{~cm} \mathrm{~s}^{-1}$. By about 12:30, almost the entire water column was flooding, in a direction parallel to the Hope Island eastern shoreline, except for a few pockets of ebbing waters. The ADCP data obtained during the afternoon of 5 April was noisy due to choppy sea state caused by increasing wind speeds. From the ebb ADCP Data and from our observations of the surface patterns while at the buoy station, we were able to create a diagrammatic sketch of the surface currents and the deep currents in the vicinity of the hole during the switch from ebbing conditions to slack low water (Figure 56). The size of the arrows are roughly scaled, using our assumptions of the relative flows, and assume that the East and West Passage are slightly out of phase. The main branch of the East Passage begins to flood while the West Passage is still ebbing and vice versa. The pattern is extremely variable near buoy, and the bottom current floods about two hours before the surface goes slack. 
Figure 56. A sketch of the assumed patterns of the surface flows, in red, and of the deep flows, in blue, in the vicinity of Hope Island. This schematic shows the conditions about one to two hours before low tide and is based on the ADCP transects conducted on 5 April 1997. 


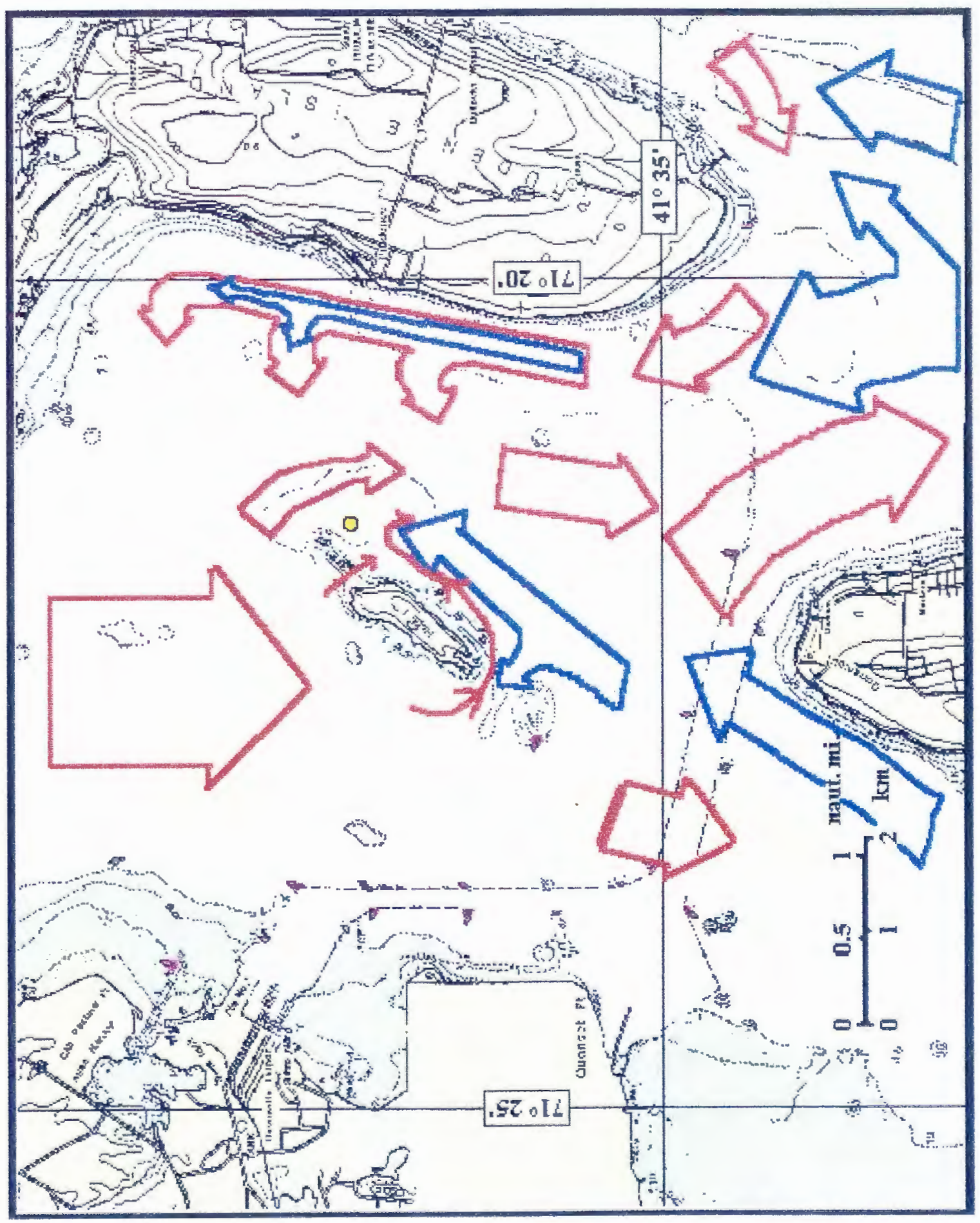




\section{Conclusions}

This thesis represents the first multi-depth time-series study of water quality parameters in Narragansett Bay, and it is remarkable for both its length of study and temporal resolution, of two month duration and twenty minute sampling interval, respectively. The most important results of this thesis pertain to the relationship between the physical stratification and the oxygen variations. The physical stratification was a function of three main effects: tides, winds and fresh-water flux into the area. The stratification and destratification cycles and their effects on the oxygen saturation demonstrate the interdependence of chemical, biological and physical processes in coastal waters. We observed periods of stratification throughout the month of January, which indicates that wind speed and temperature are not the only determinants of stratification; during the winter the injection of saline offshore waters leads to stratification at the midBay location. In both the January and March deployments, we observed occasions when the mid-Bay study area was affected by waters of much different characteristics than those commonly recognized as waters of estuarine origin. The results suggest the importance of exchanges between the Bay and the offshore waters, especially in the setup and destruction of stratification.

There appeared to be several factors which are related to the beginning of stratification and the beginning of destratification. Increased tidal mixing, represented by larger tidal amplitudes in the spring-neap cycle, caused a weakening of stratification, and usually occurred incrementally over several tidal cycles. The destratification caused by this factor usually commenced with a decrease in bottom density and was eventually followed by an increase in density at the surface. High velocity wind events caused rapid 
destruction of stratification. However, these events were of a shorter duration, and stratification, if observed before the event, was usually able to reoccur soon after the wind speed decreased. Increased freshwater flow, as represented by higher stream flow volumes and greater precipitation usually helped to strengthen stratification, but were subject to tidal and wind mixing. Thus, the fresh water effect was more difficult to quantify. However, the classic estuarine circulation in which fresher and less dense surface outflow causes entrainment and inflow of deeper, denser and more saline water was observed for a period of high river outflow. The relatively high oxygen saturation values in the deep layer and the warming lag between bottom and surface waters seemed to suggest that the surface offshore waters are entrained into the deep estuarine layer. The extremely high surface oxygen saturation and the lag and timing between peak sunlight and the local maximum in surface oxygen suggest that the surface waters at the buoy station originate in the East Passage from upper Bay locations.

The dissolved oxygen gradient appeared to co-occur with temperature stratification, however the gradient was greater in the March-May deployment because of higher dissolved oxygen concentrations in the deep water during winter. A main advantage in analyzing and discussing the March deployment was that we were able to calculate density at the surface, at mid-depth and at the bottom, and use density to indicate the stratified and destratified periods. The need to represent stratification in terms of density, rather than temperature alone as in the January deployment, was acute since seasonal warming of the surface waters reduced the vertical temperature gradient over the period between 15 March and 1 April. With respect to winds, it is difficult to measure the effect of wind fetch, on the water column. We were able to observe from our time-series 
that wind plays a role in destratifying the water column by adding stirring energy at the surface, which can work its way through the entire water column, depending on wind speed and persistence. In terms of changing winds, it seemed that between 7 and $9 \mathrm{~m} / \mathrm{s}$ wind speed was in the critical range for causing destratification, in that winds in this range were able to begin causing destratification. This critical wind speed may be lower for persistent wind from a singular direction, where fetch can build up or for periods of higher tidal stirring. The two wind directions from which Narragansett Bay's coastline configuration might allow a maximum effect of fetch to occur are from the south and from the northeast. These two orientations would maximize the area of open water over which the winds might have effects, and the effects would be observed at the buoy.

For the tidal range, it appeared that changes in elevation of about 1.5 to $1.8 \mathrm{~m}$ were the critical levels for causing destratification through tidal mixing. This range of tidal height appeared to be sufficiently energetic to cause even the bottom water to participate in mixing, and these mixing events appeared to be marked by bottom-up destratification, as seen on 5-7 April. Although there are exceptions to this observation of a critical tidal range within the data set, one must consider that it is difficult to separate the effects of tides from that of winds. Also, for periods where stratification persists, even with high tidal ranges, higher freshwater outflow or warmer surface temperatures may serve to maintain stratification in the face of forceful mixing. 


\section{Appendix 1}

\section{YSI Performance Data and Operational Information}

In investigating the relationship between physical stratification and dissolved gas concentration using in-situ time-series measurements, we tested a prototype oceanographic buoy. A 3-m long by 46-cm diameter spar buoy employed three YSI600XI (Endeco/YSI, Inc.) multi-parameter water sensors, situated at the three depths, to help measure the differences in parameters along the vertical axis. A YSI-6000 instrument was used for the profiles at the buoy station on various occasions. The YSI-600XL's, as outfitted for our study, are capable of determining water temperature, conductivity, salinity, $\mathrm{pH}$, depth and dissolved oxygen concentration. They are designed from PVC and stainless steel, measure $4.06-\mathrm{cm}$ in diameter, $35.56-\mathrm{cm}$ in length and weigh $0.8-\mathrm{kg}$. Unlike the YSI-6000, the YSI-600XL does not have internal battery capability or internal datalogging capability. The YSI-600XL's data were logged in a control module on board the buoy, and were be downloaded onto a microcomputer approximately weekly. The YSI600 's were externally powered by a 12 volt battery which is also located within the buoy. Also unlike the YSI-6000, it is not capable of recording turbidity.

The YSI- 6000 , in addition to the parameters measured by the YSI-600, measures turbidity, and includes an internal data logging system and internal power supply. Parameters measured by the 6000 are listed in Table 1. The instrument communicates with an ASCII terminal or a computer with a terminal emulation program and data is easily exported to any spreadsheet program for data processing. It operates on 12 VDC provided by $8 \mathrm{C}$-sized alkaline batteries, and adequate logging and communications 
Table A-1: Performance Data for YSI 6000UPG, from Endeco/YSI (1995).

\begin{tabular}{|c|c|c|c|c|}
\hline$\downarrow$ Sensor $\backslash$ Parameter $\rightarrow$ & Sensor Type & Range & Accuracy & Resolution \\
\hline $\begin{array}{l}\text { Depth Medium Range } \\
(0-61 \mathrm{~m})\end{array}$ & $\begin{array}{l}\text { Stainless Steel } \\
\text { Strain Gauge }\end{array}$ & $\begin{array}{c}\text { Medium } \\
\text { range } 0 \text { to } 61 \\
\mathrm{~m}\end{array}$ & $\pm 0.12 \mathrm{~m}$ & $0.001 \mathrm{~m}$ \\
\hline $\begin{array}{l}\text { Depth Shallow Range } \\
(0-9.1 \mathrm{~m})\end{array}$ & $\begin{array}{l}\text { Stainless Steel } \\
\text { Strain Gauge }\end{array}$ & $\begin{array}{c}\text { Shallow range } \\
0 \text { to } 9.1 \mathrm{~m}\end{array}$ & $\pm 0.018 \mathrm{~m}$ & $0.001 \mathrm{~m}$ \\
\hline Temperature & Thermistor & -5 to $+45^{\circ} \mathrm{C}$ & $\pm 0.15^{\circ} \mathrm{C}$ & $0.01{ }^{\circ} \mathrm{C}$ \\
\hline $\begin{array}{l}\text { Dissolved Oxygen } \\
\text { (\% Saturation) }\end{array}$ & $\begin{array}{l}\text { Rapid Pulse- } \\
\text { Polarographic }\end{array}$ & $\begin{array}{l}0 \text { to } 200 \% \text { air } \\
\text { saturation }\end{array}$ & $\begin{array}{l} \pm 2 \% \text { air } \\
\text { saturation }\end{array}$ & $\begin{array}{l}0.1 \% \text { air } \\
\text { saturation }\end{array}$ \\
\hline Conductivity & $\begin{array}{l}4 \text { Electrode } \\
\text { Cell }\end{array}$ & $\begin{array}{l}0 \text { to } 100 \\
\mathrm{mS} / \mathrm{cm}\end{array}$ & $\begin{array}{l} \pm 0.5 \% \text { of } \\
\text { reading }\end{array}$ & $0.01 \mathrm{mS} / \mathrm{cm}$ \\
\hline Salinity & $\begin{array}{l}\text { calculated } \\
\text { from } T \& \& \\
\text { Cond. }\end{array}$ & 0 to $70 \mathrm{ppt}$ & $\begin{array}{l} \pm 1.0 \% \text { of } \\
\text { reading }\end{array}$ & $0.01 \mathrm{ppt}$ \\
\hline $\mathrm{pH}$ & $\begin{array}{l}\text { glass combo } \\
\text { electrode }\end{array}$ & $\begin{array}{c}2 \text { to } 14 \mathrm{pH} \\
\text { units }\end{array}$ & \pm 0.2 units & 0.01 units \\
\hline Turbidity & $\begin{array}{l}90^{\circ} \text { scatter, self } \\
\text { cleaning }\end{array}$ & $\begin{array}{l}0 \text { to } 1000 \\
\text { NTU }\end{array}$ & $\begin{array}{l} \pm 5 \% \text { of reading } \\
\text { or } 2 \text { NTU, } \\
\text { whichever greater }\end{array}$ & $0.1 \mathrm{NTU}$ \\
\hline
\end{tabular}


capabilities are maintained when the charge remains above approximately 8.5 volts. The 6000 is made from PVC and stainless steel, has dimensions of $8.9-\mathrm{cm}$ diameter, $49.5-\mathrm{cm}$ length, and a $3.0-\mathrm{kg}$ weight with batteries.

Periodic calibration of the instruments is required. This calibration process is relatively simple, is performed in the laboratory, requires about one hour's time, and is very similar for both the YSI-600 and YSI-6000. The dissolved oxygen sensor is calibrated in a water-saturated atmosphere with atmospheric pressure in $\mathrm{mmHg}$ as an entering argument. The conductivity sensor is calibrated with a secondary standard seawater consisting of 2-micron-filtered MERL water. The salinity of this seawater is measured by a Guildline salinometer housed at the National Marine Fisheries Building in Narragansett, RI, which is itself standardized using IAPSO Standard Seawater. The $\mathrm{pH}$ sensor is calibrated with a three- buffer calibration consisting of standard buffers: 0.05 molal $\mathrm{KH}$ phthalate (4.008), 0.008695 molal $\mathrm{KH}_{2} \mathrm{PO}_{4}$ with 0.03043 molal $\mathrm{Na}_{2} \mathrm{HPO}_{4}$ (7.413), and 0.01 molal Borate (9.180); and with each buffer's $\mathrm{pH}$ corrected for temperature (Bates, 1954). An upgrade to the $\mathrm{pH}$ electrode allows the user to calculate a more accurate actual $\mathrm{pH}$, by returning only the $\mathrm{pH}$ in millivolts. This allows the operator to calculate actual $\mathrm{pH}$, using a regression of the calibration millivolt values and the operational form of the Nernst Equation as follows:

$$
\mathrm{pH}_{\text {measured }}=\mathrm{pH}_{\text {buffer }}+\frac{\left(\mathrm{E}_{\text {buffer }}-\mathrm{E}_{\text {measured }}\right)}{\text { slope }}
$$

where $\mathrm{pH}_{\text {buffer }}$ is the temperature-adjusted $\mathrm{pH}$ of a buffer from the calibration. The $\mathrm{Na}_{2} \mathrm{HPO}_{4}$, or 7 buffer was used since its $\mathrm{pH}$ is closest to what we would expect to measure in the field. The $\mathrm{E}_{\text {buffer }}$ is the temperature adjusted millivolt reading from the the 
calibration for the 7 buffer. The $E_{\text {measured }}$ is the actual millivolt reading from the field. The slope is the linear regression of the calibration curve, millivolts versus $\mathrm{pH}$ of the three buffers. Turbidity is calibrated with a one- point calibration in distilled water with a turbidity of zero. Depth is calibrated in air, for a depth of zero. Upon completion of the calibration procedure, the instrument is stored with its sensors in a moist atmosphere. 


\section{Appendix 2}

Figures A-1 through A-26. ADCP images from the 5 April field work. Images are referenced by Table 3, page 134 as to location, filename, transect number, and start and end time. There are two types of files: transects and time-series. Transects are numbered 1,2 , or 3 depending on if the transect passes south of, through, or north of the hole, respectively. The time-series are taken on position near the buoy. There are five panels to the images: transect normal-distance corrected, transect normal, transect parallel, flow direction and flow magnitude. In the time series images, the transect normal-distance corrected is replaced by two panels of flow magnitude change with depth and flow direction change with depth. Persistent striping, indicating low quality data, is seen from about file HOL2019A to the last file HOL2028_1A and HOL2028_2A. These last two images are actually one file, broken into two equal parts, in order to show some of the features in the plot. The only useful information in these two time-series is the suggestion of a deep counter current slowly developing and shoaling with progressing time. 


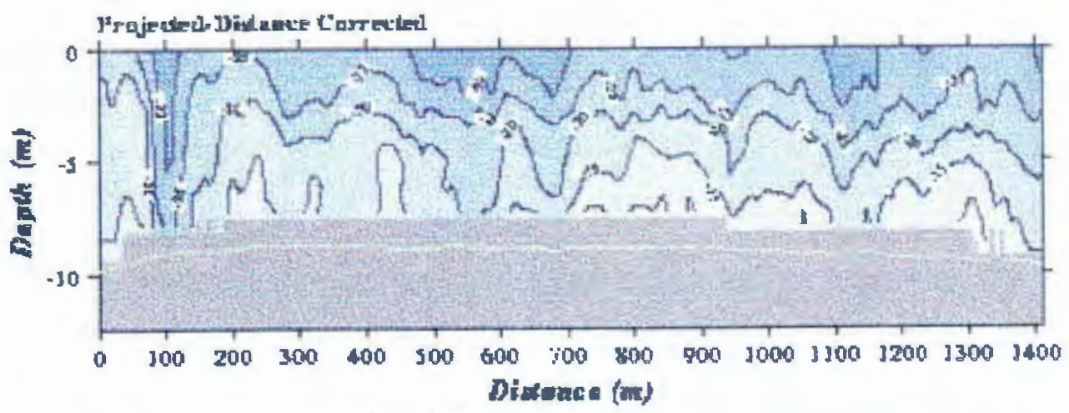

\section{HOL2101A}
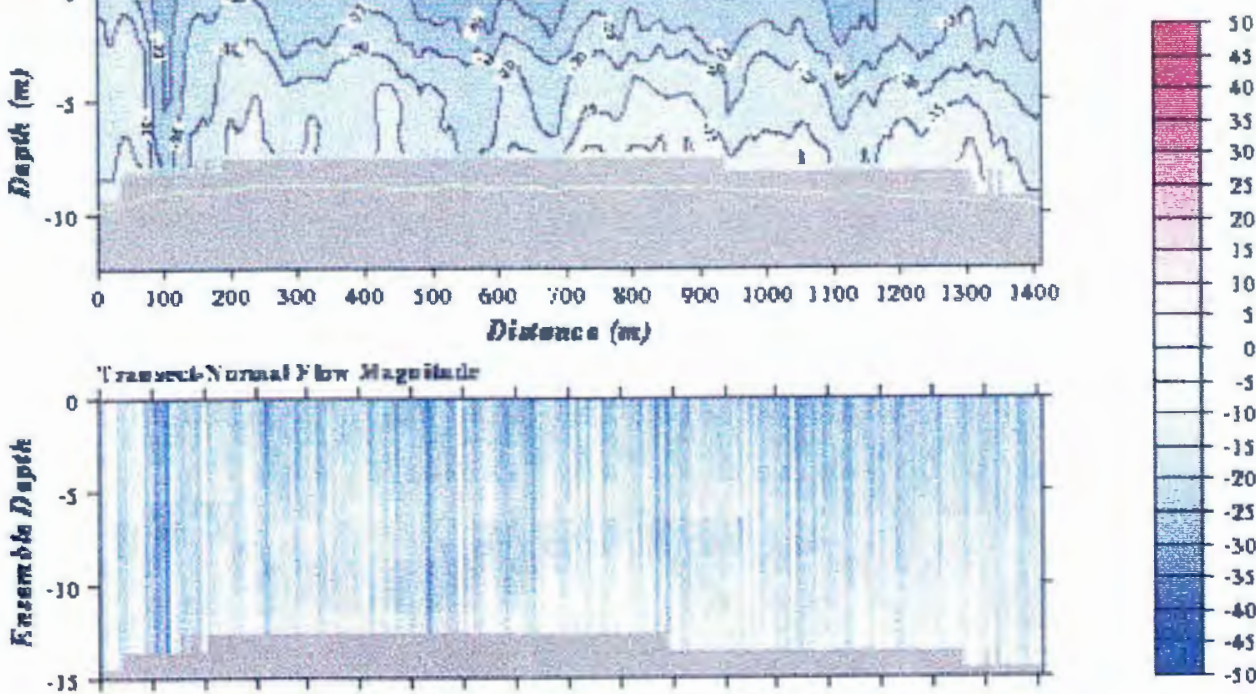

In to Page

$\cos / s$

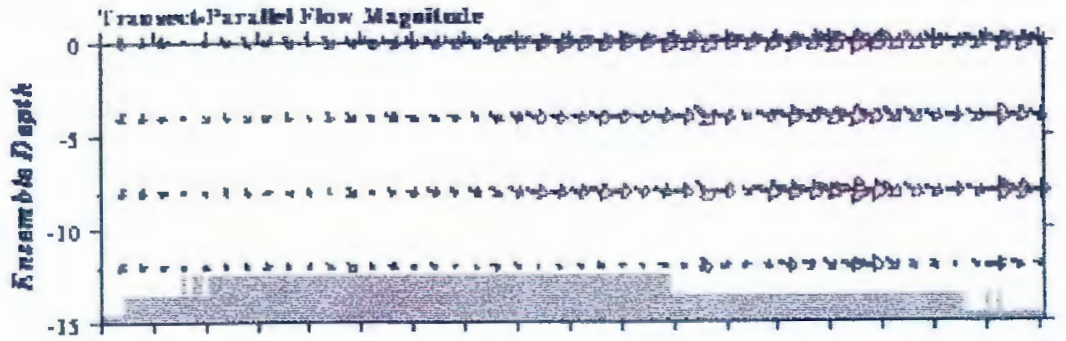

I0A and

5it anily

10 unis $\rightarrow$
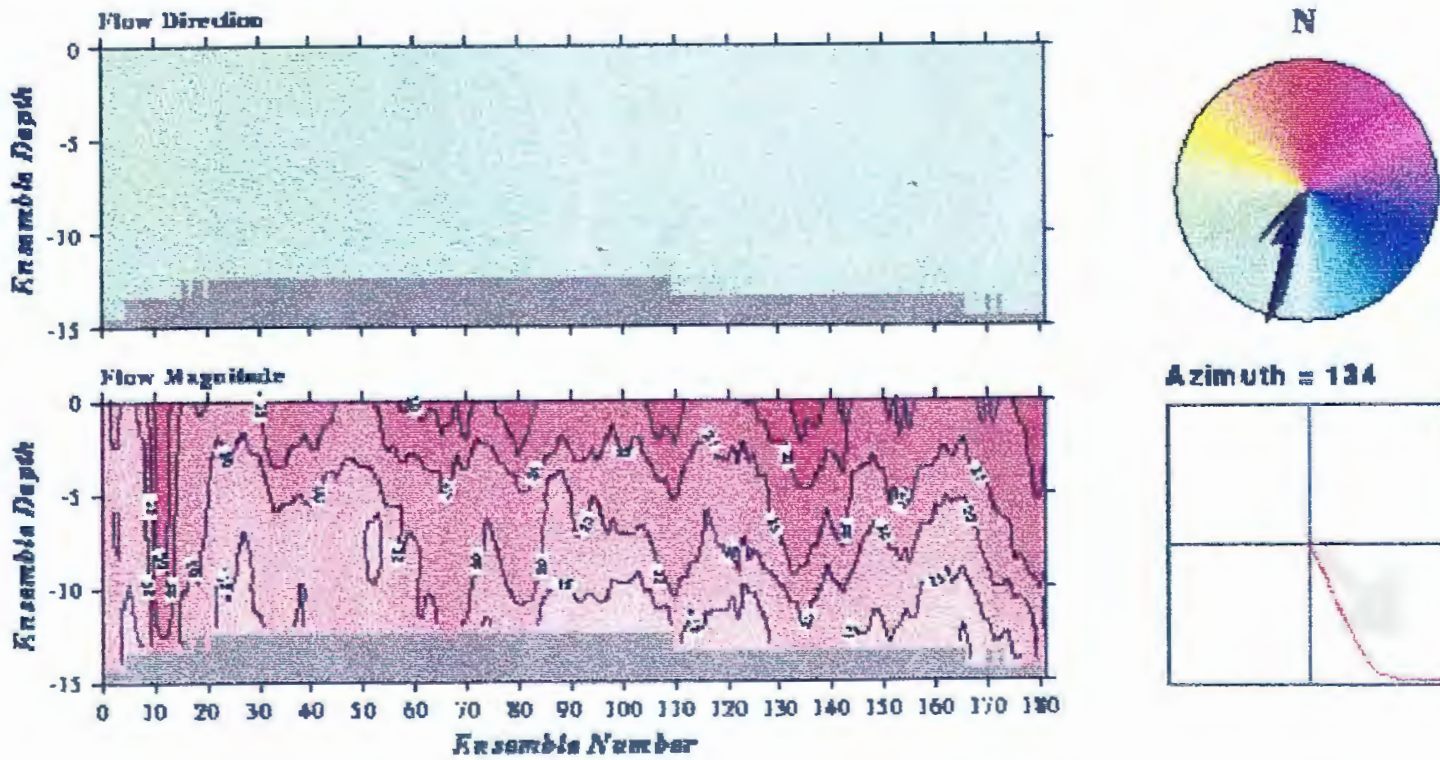

Azinuth $=124$

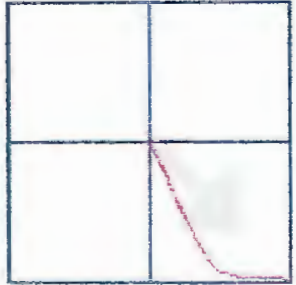




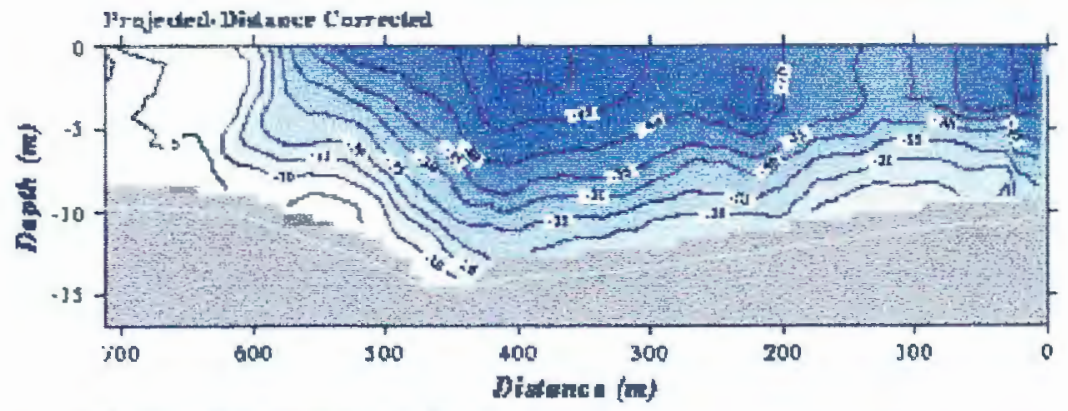

\section{HOL2102A}
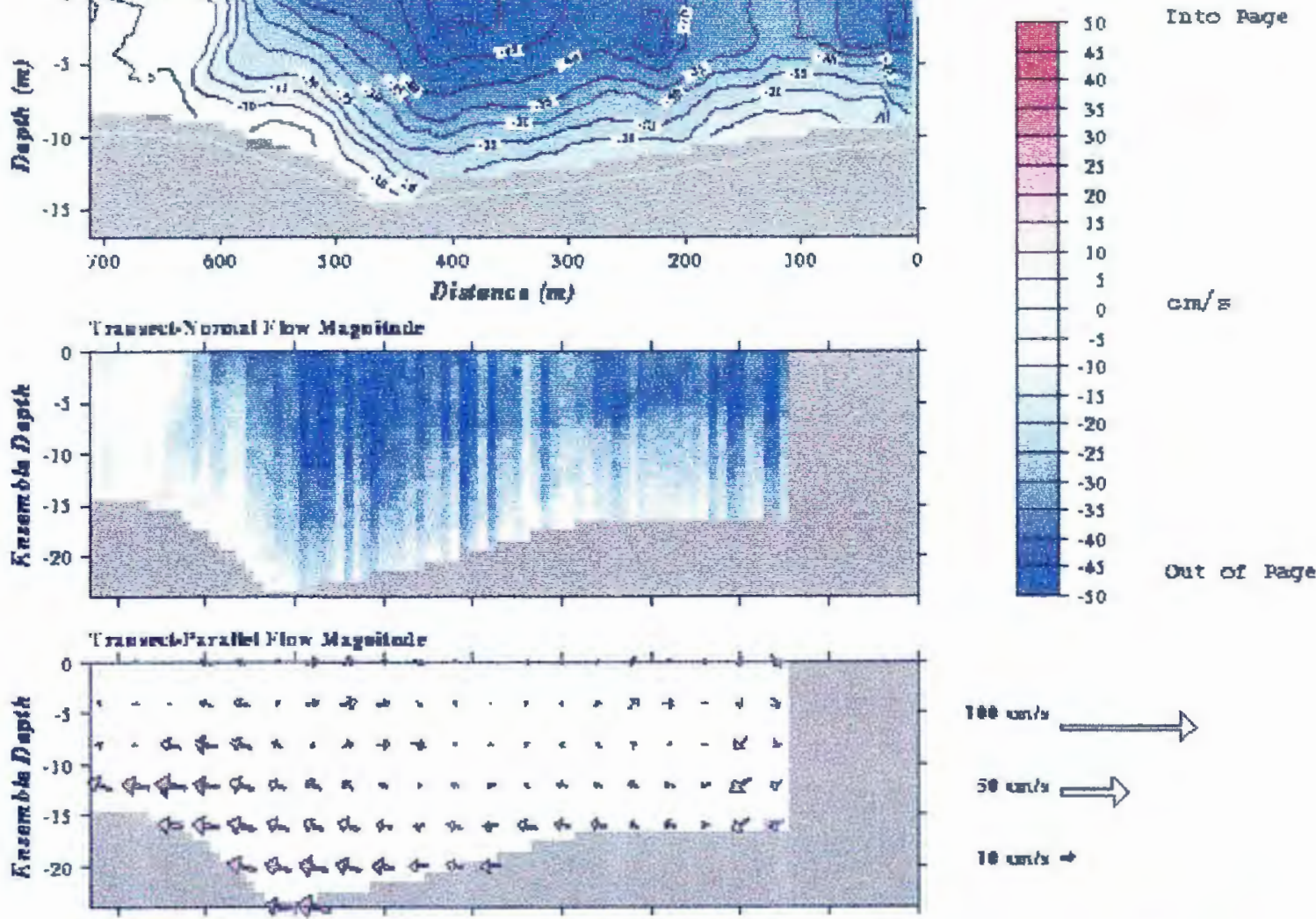

104 conds

st coris $\Longrightarrow$

10 unix -
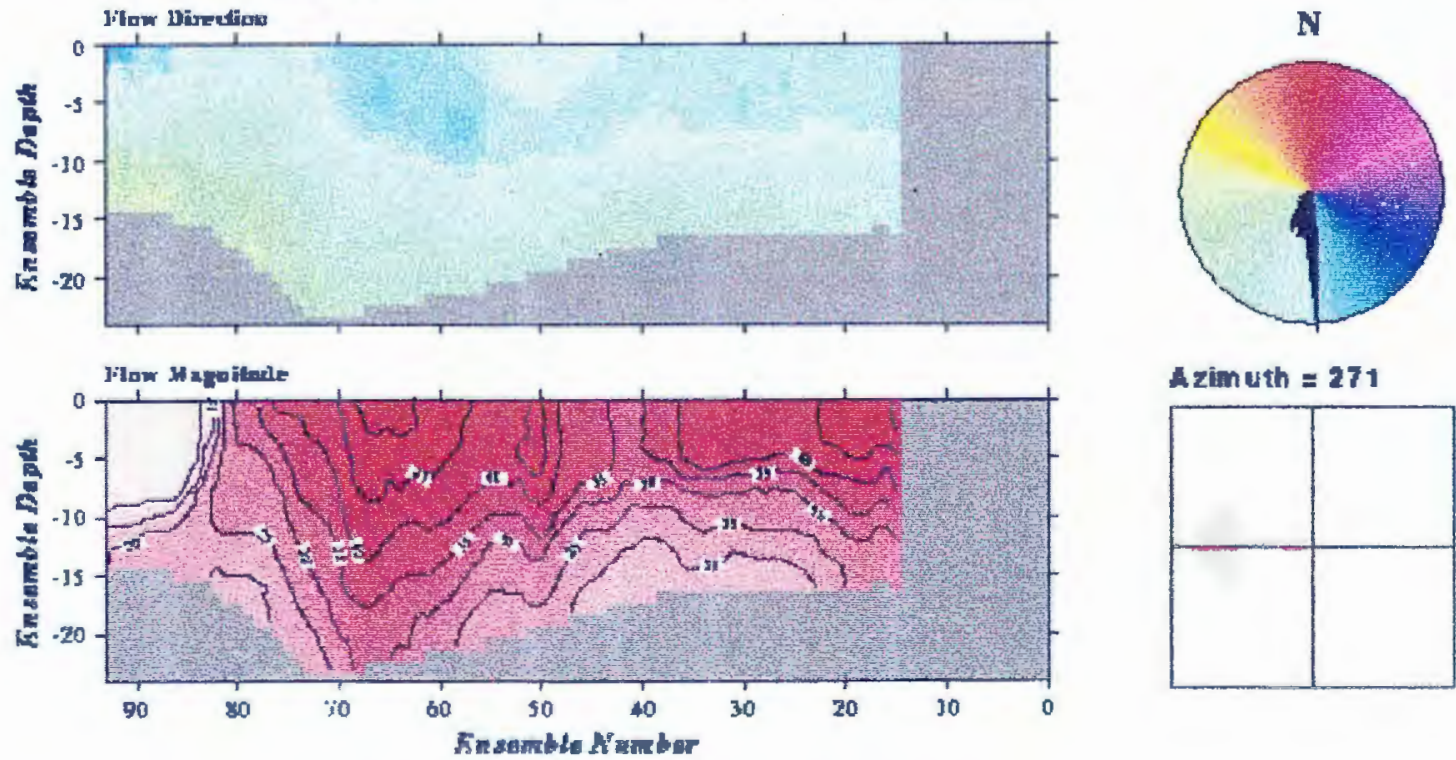

himuth $=271$

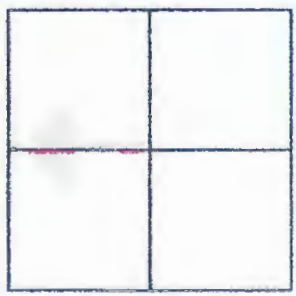




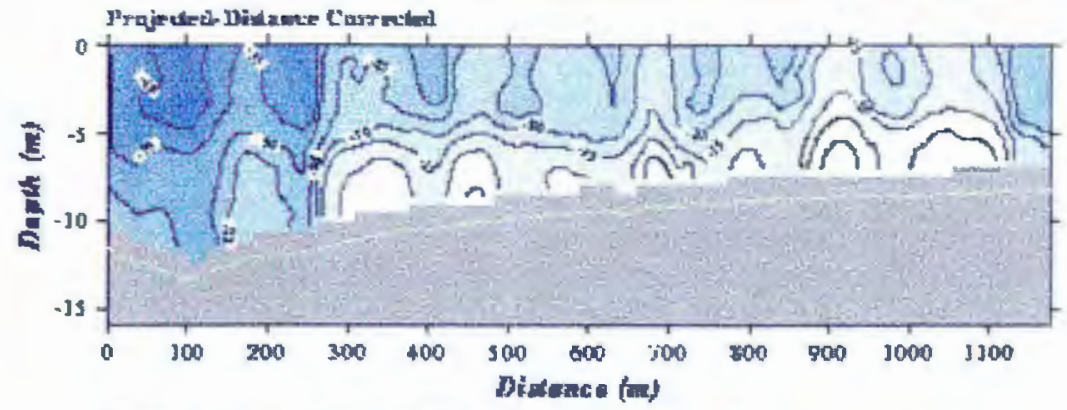

\section{HOL2103A}
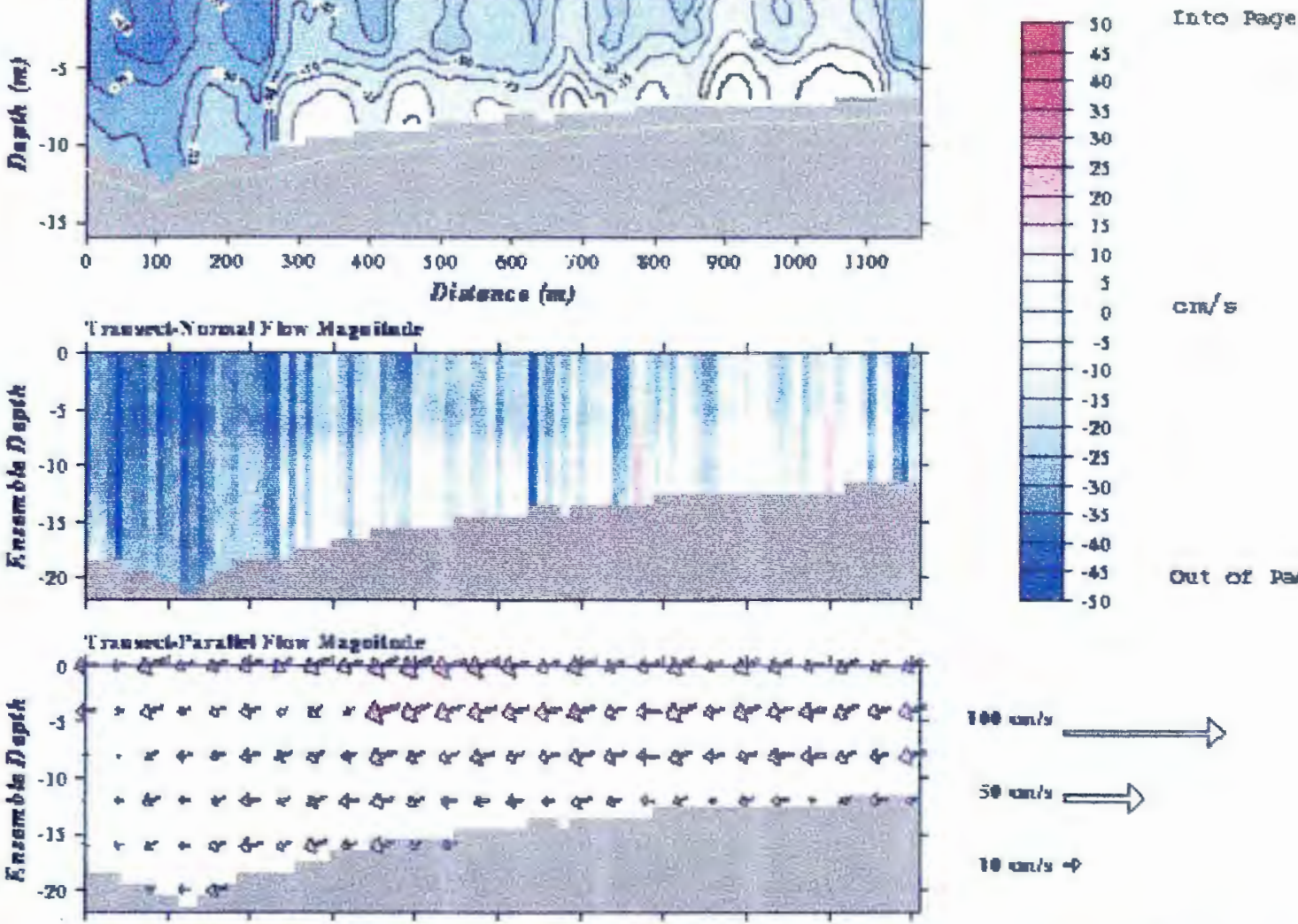

100 ands

$\mathrm{cm} / \mathrm{s}$

30 oria $\rightleftharpoons$

10 andy $\rightarrow$
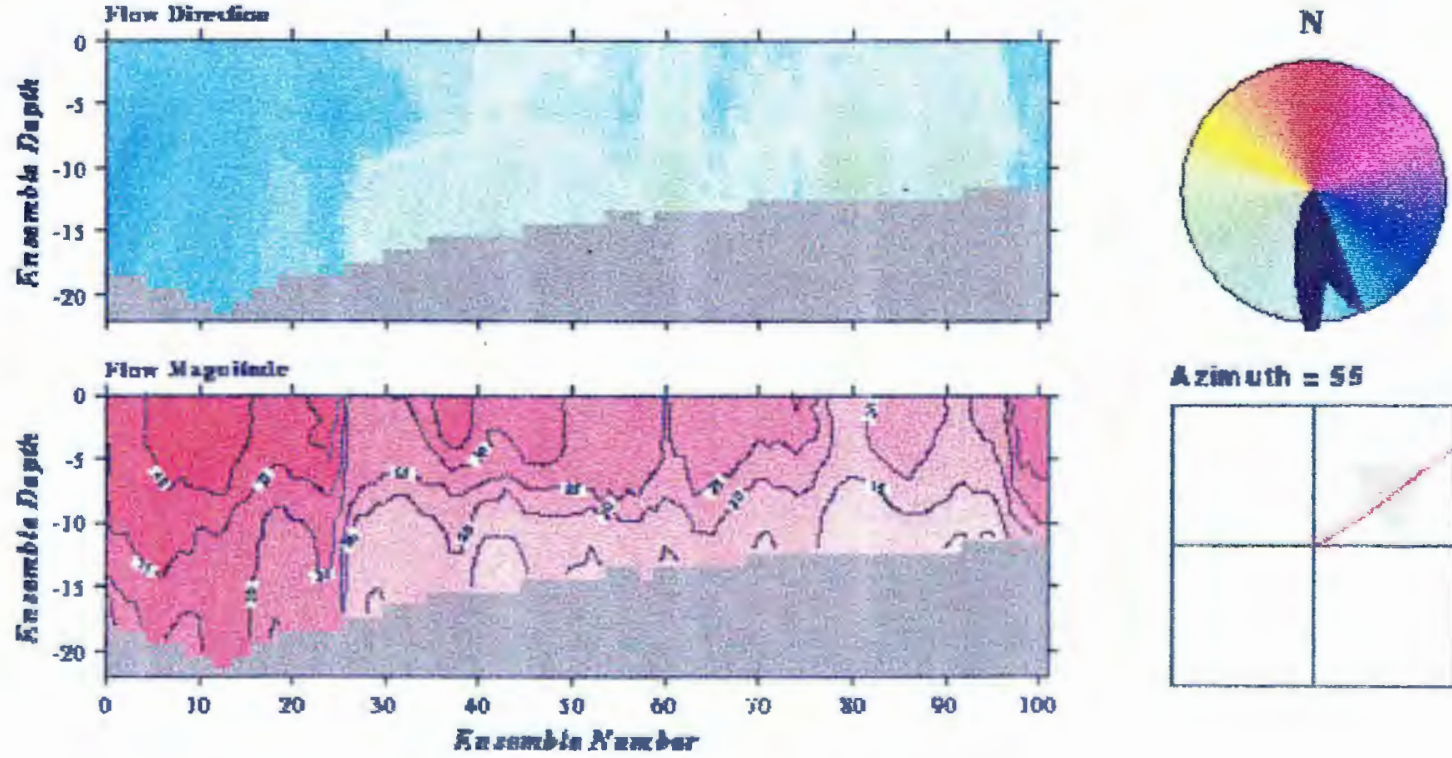

Arimuth $=55$

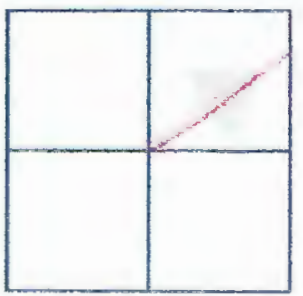




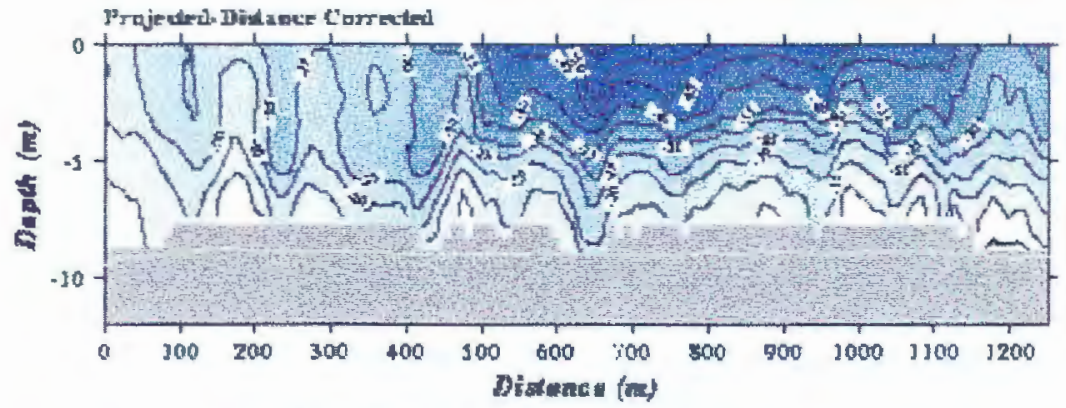

\section{HOL2104A}
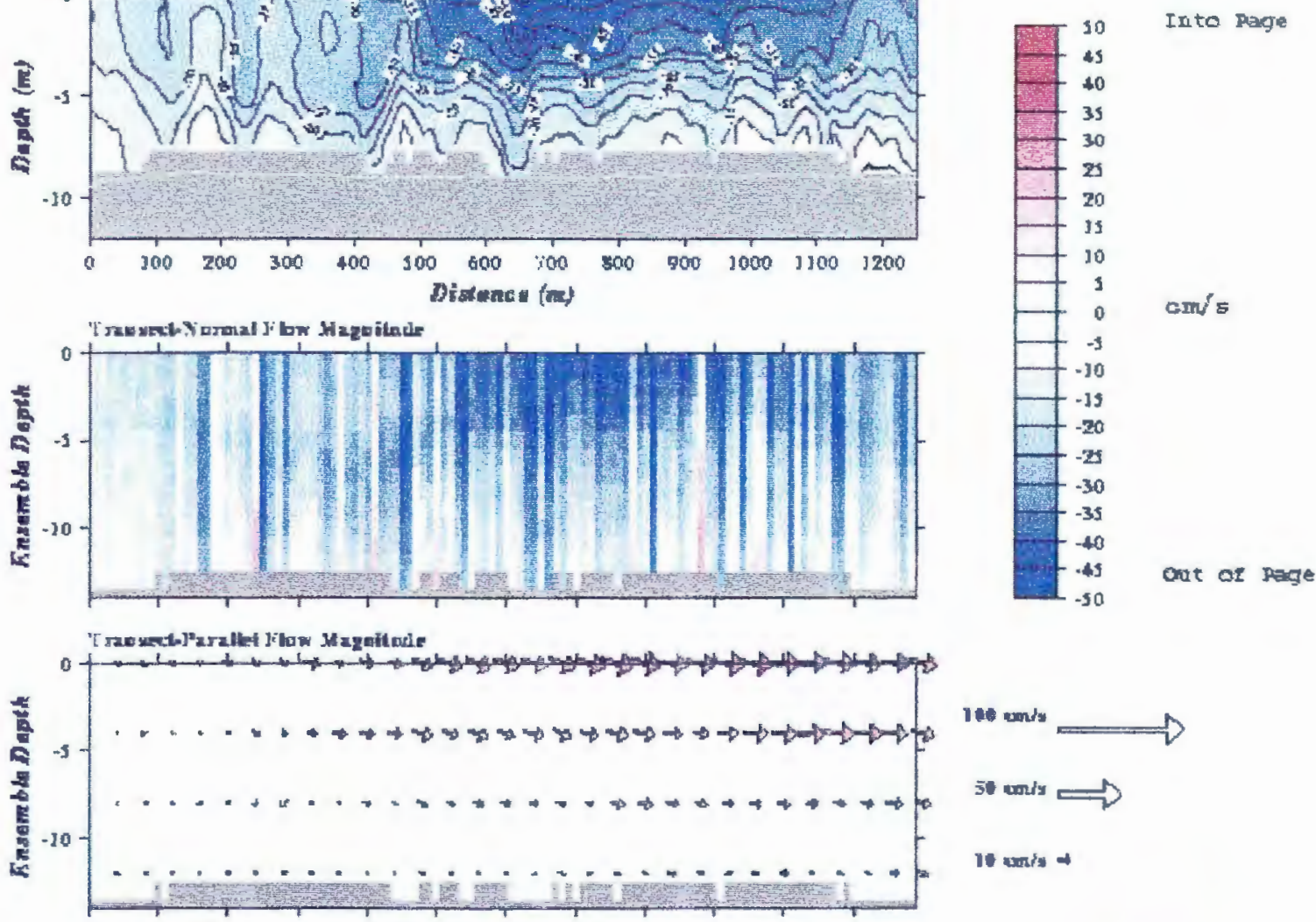

Ite ente

$50 \mathrm{ur} / \mathrm{s}$

$18 \operatorname{ant}$ *
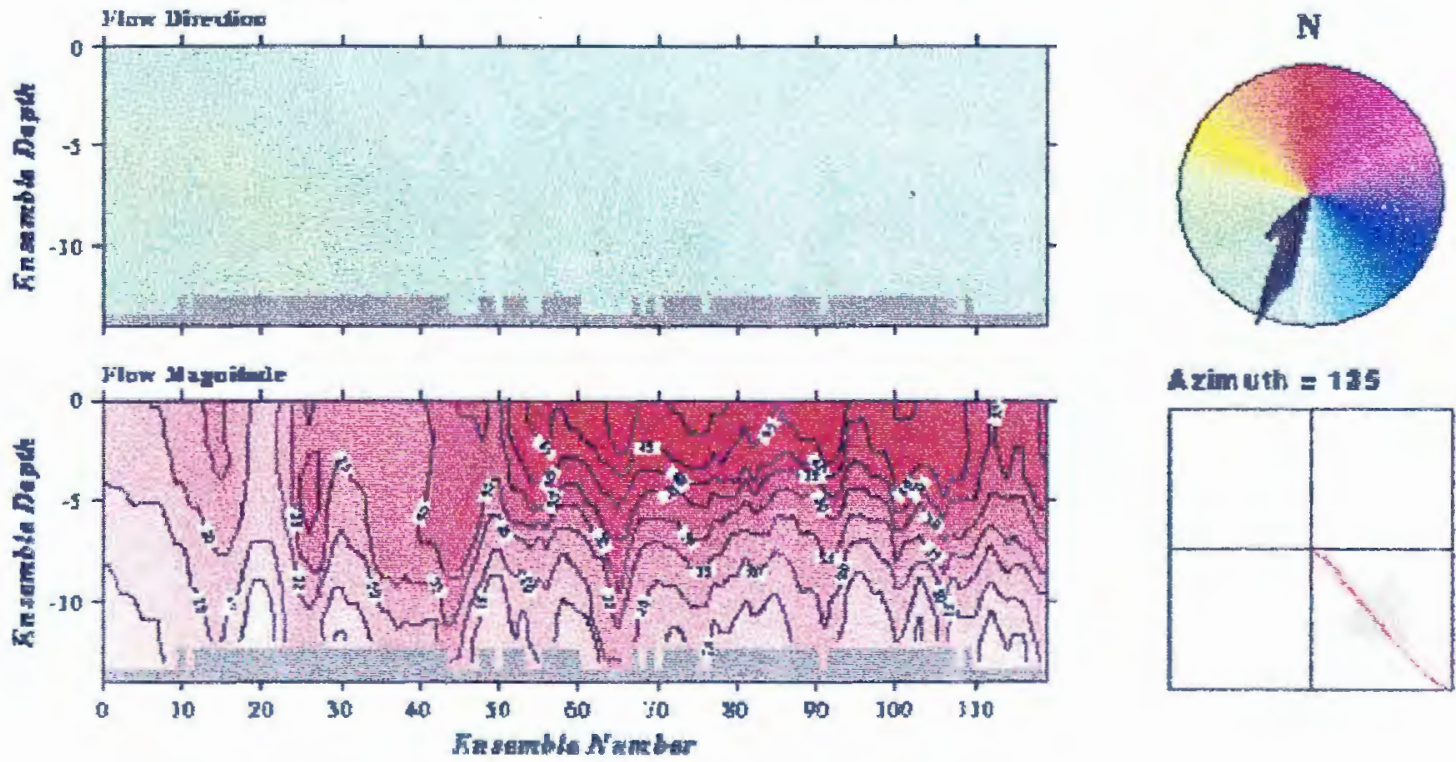

Aximuth $=115$

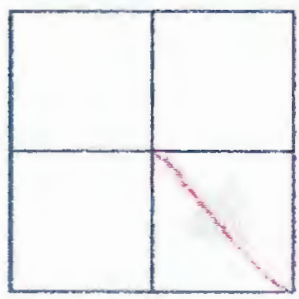




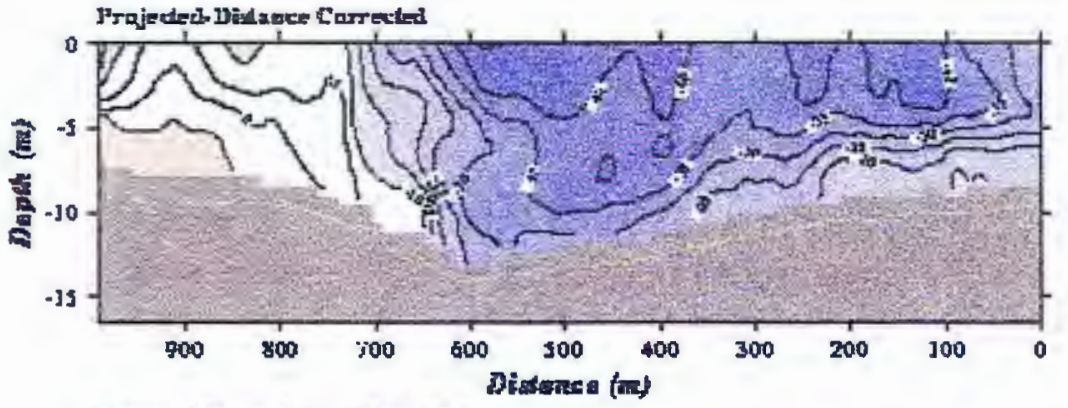

\section{HOL2105A}
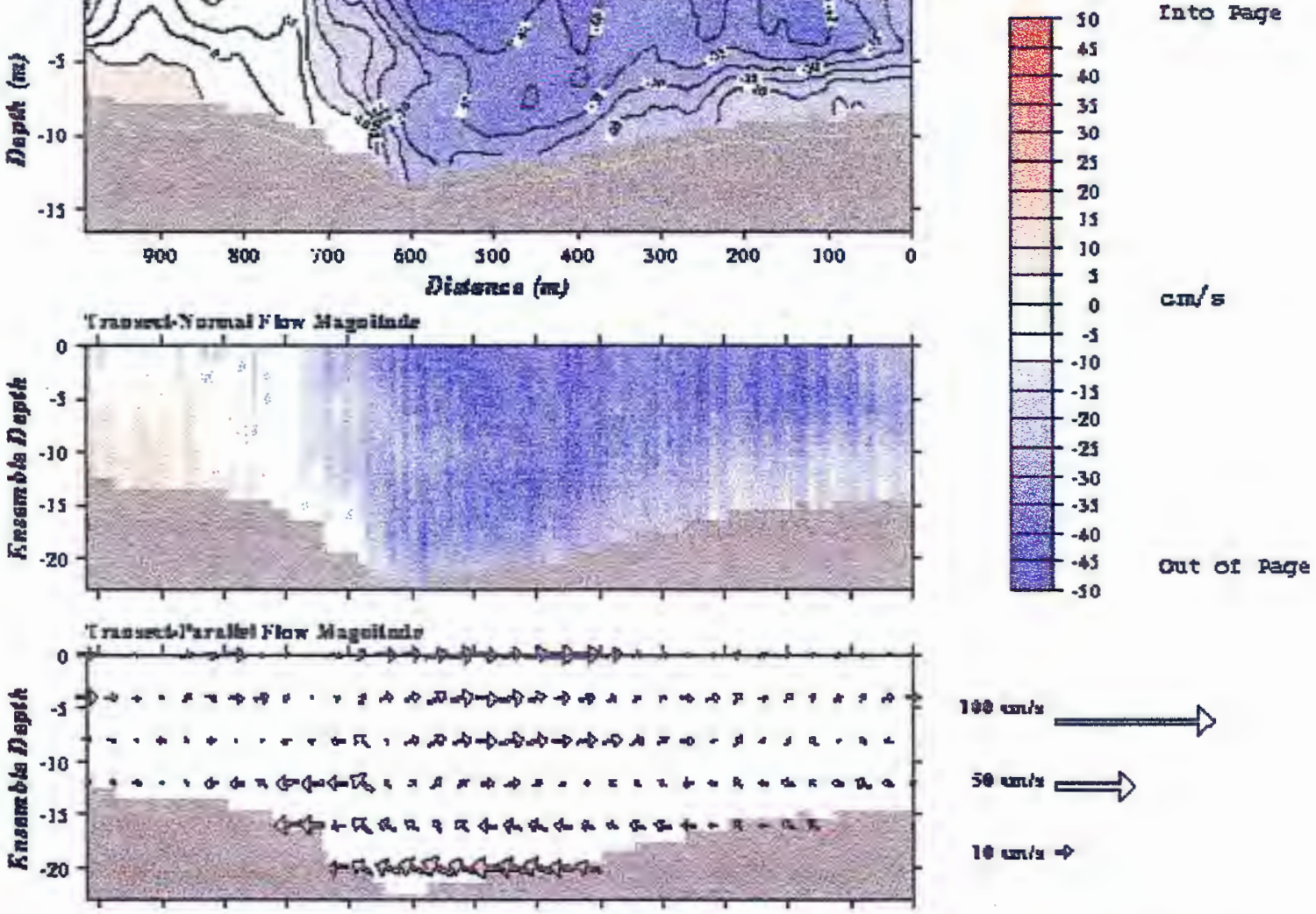

140 conts

30 unit $\longrightarrow$

$10 \operatorname{sen} \rightarrow$
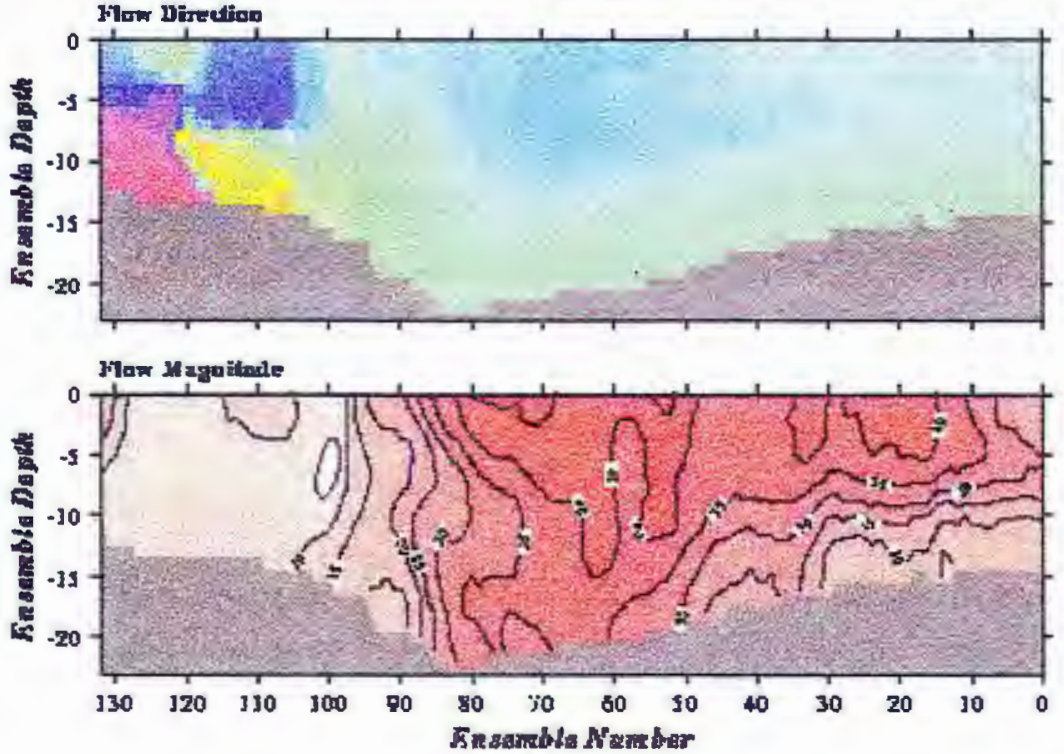

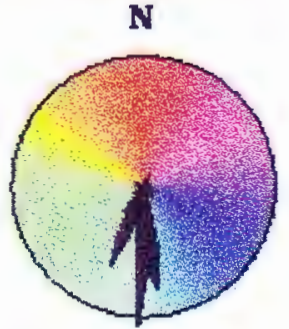

A zimuth $=277$

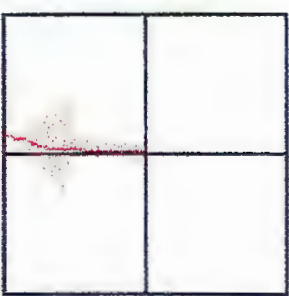



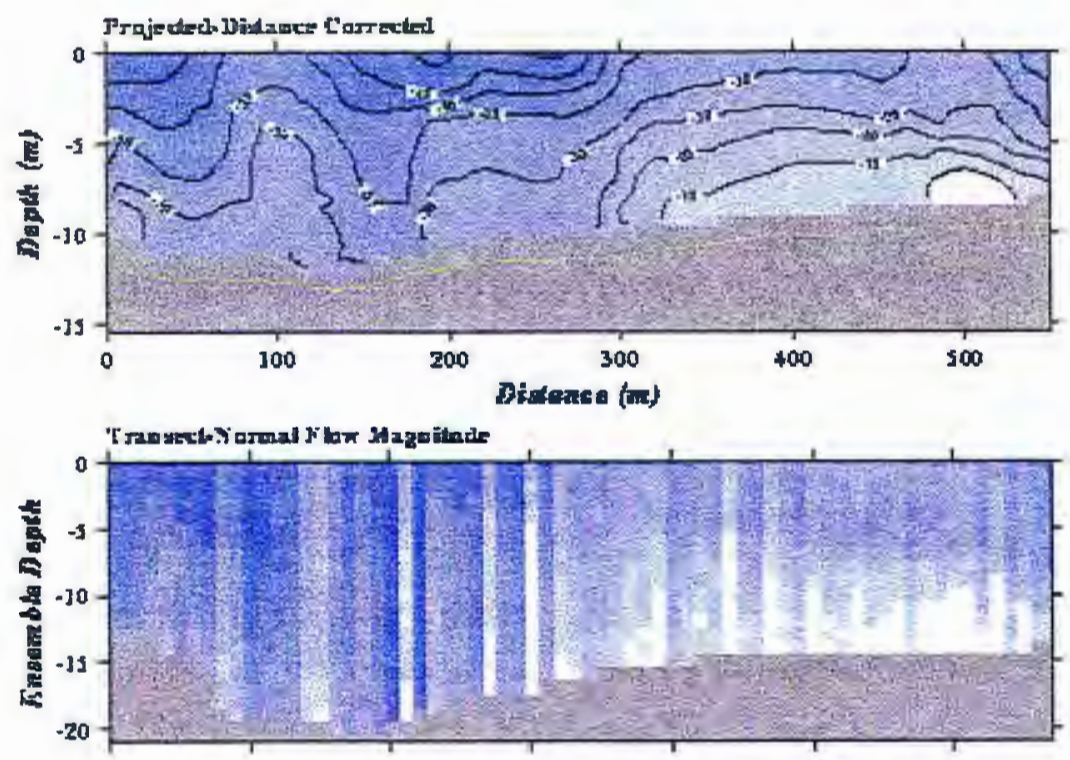

\section{HOL2108A}
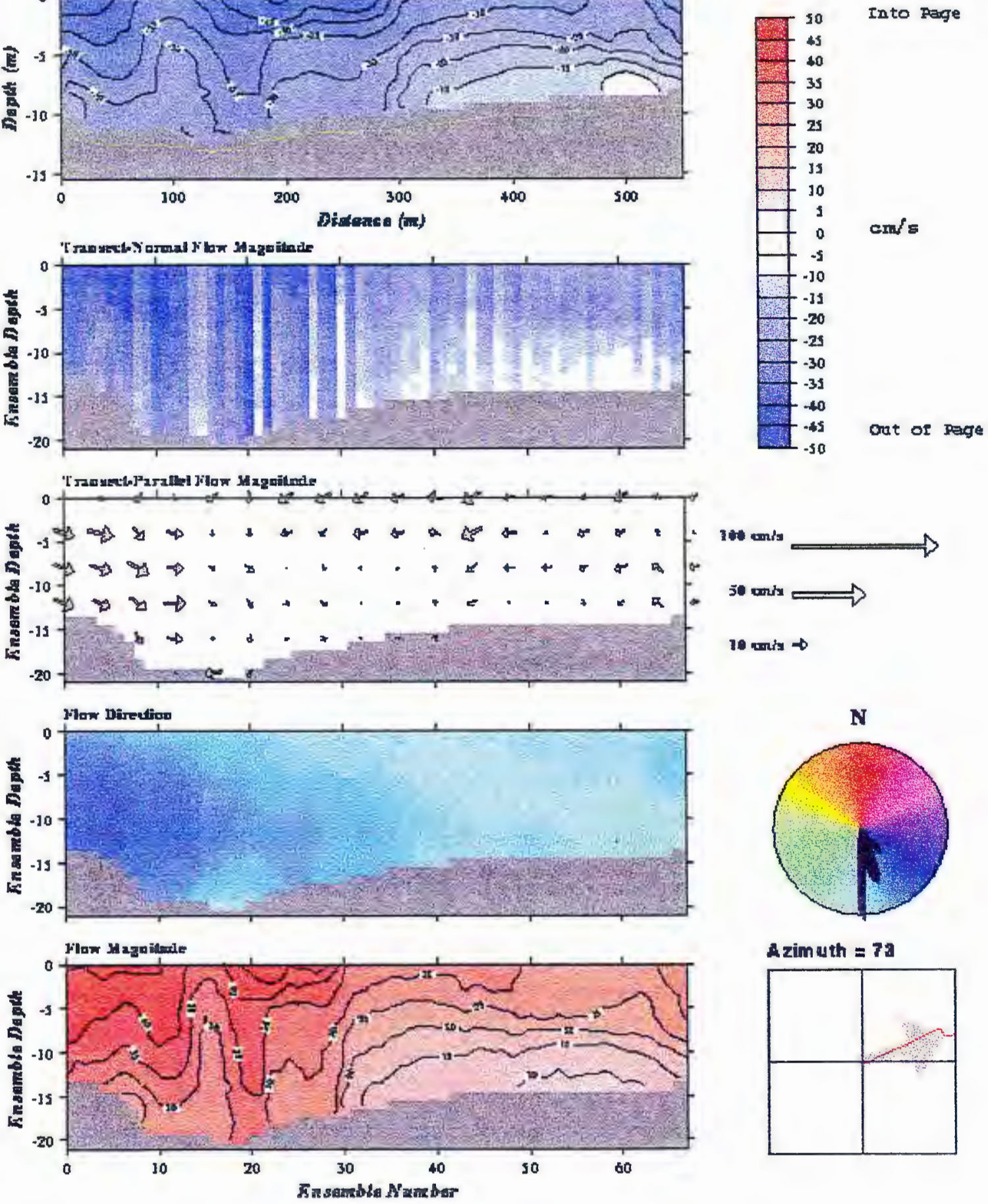

Azimuth $=72$

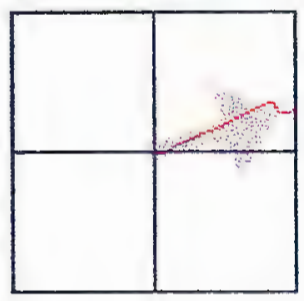




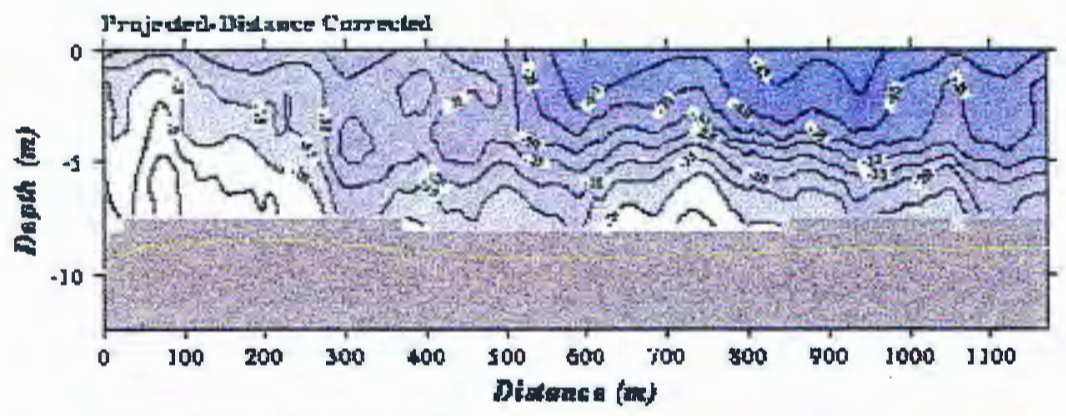

\section{HOL2107A}
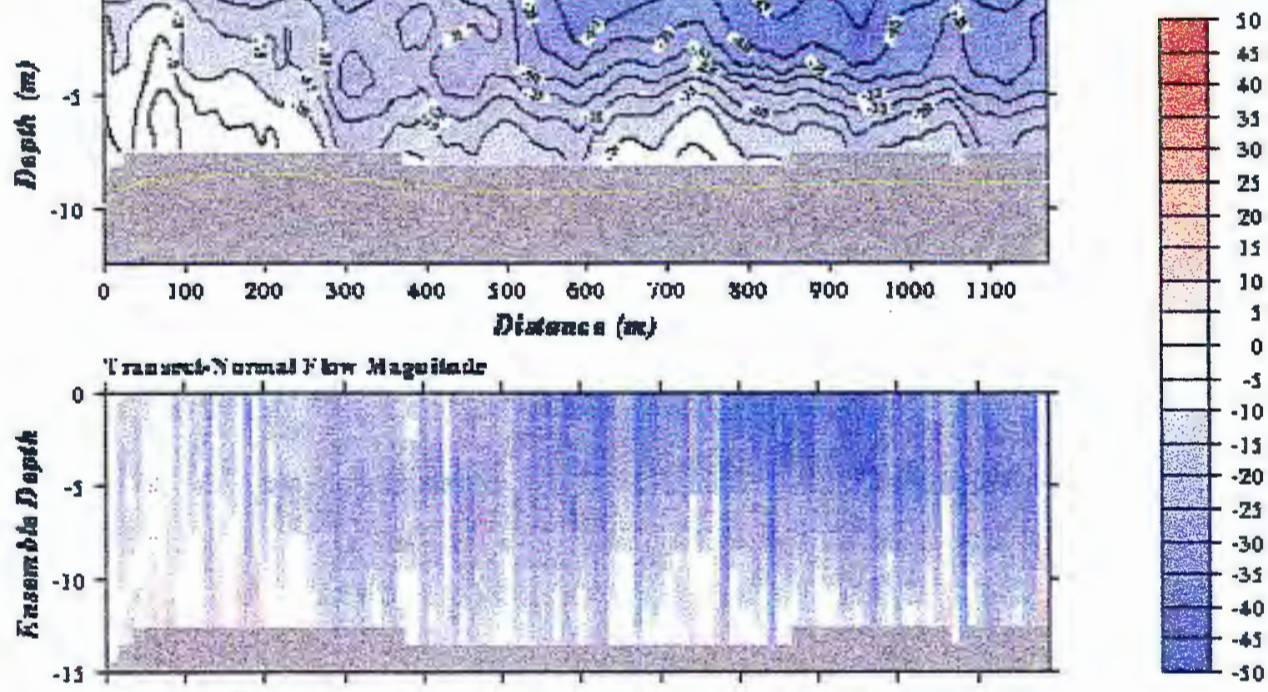

Into Fage

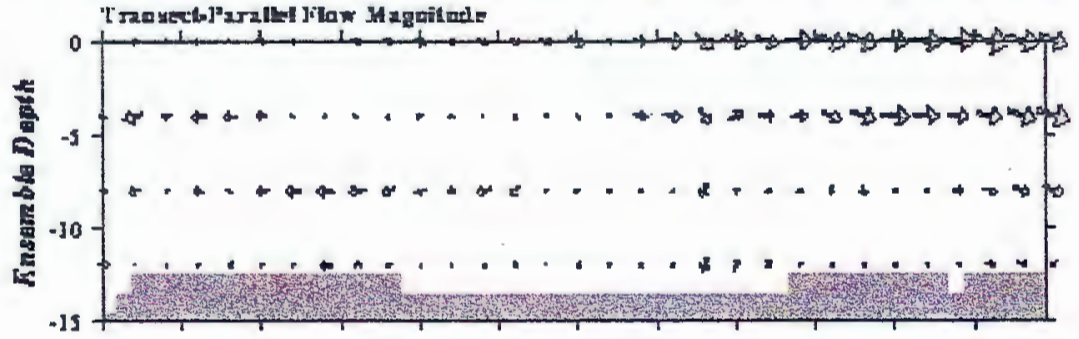

140 urits

50 conla $\rightleftharpoons$

1 exis $\Rightarrow$
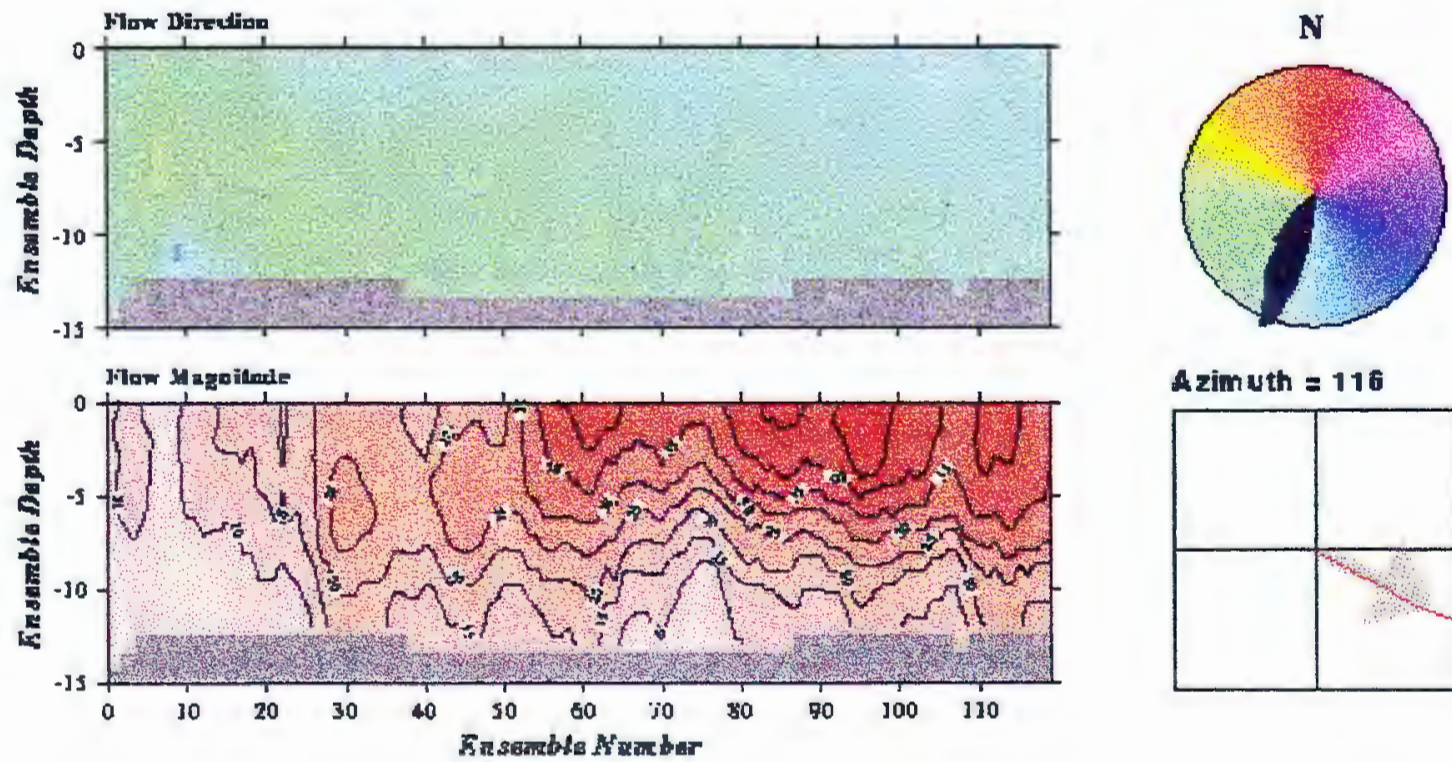

Azimuth $=116$

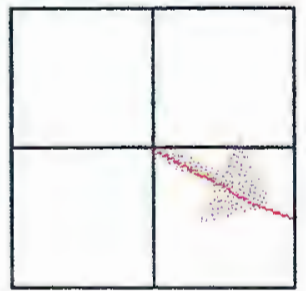



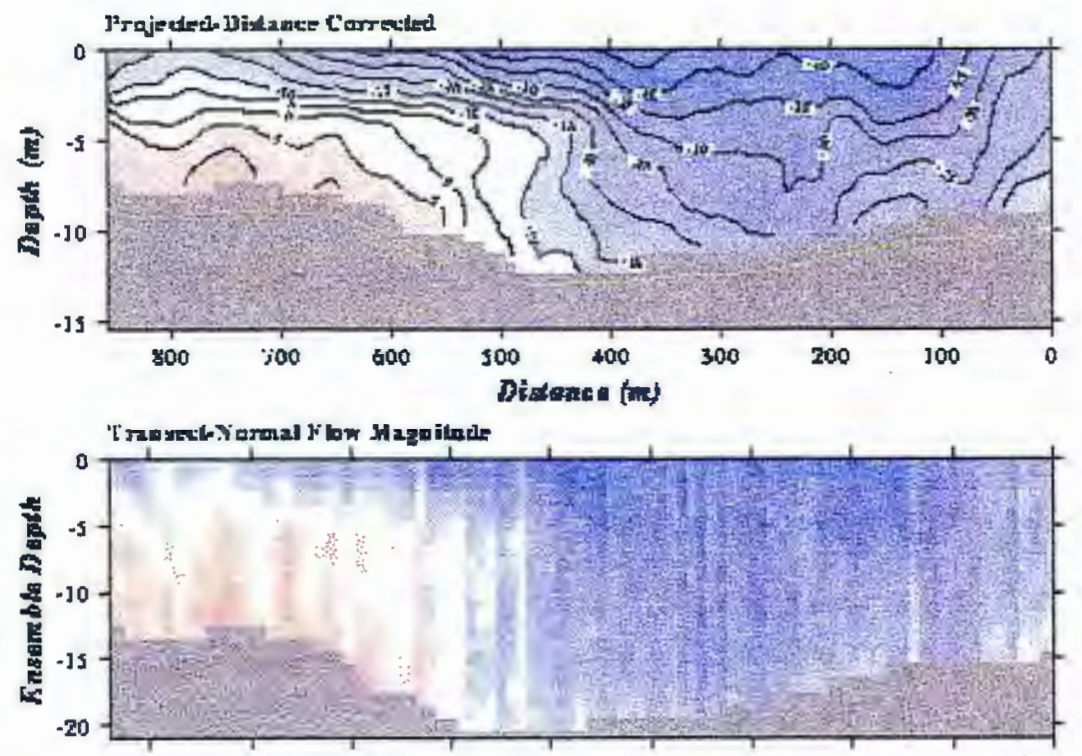

\section{HOL2108}
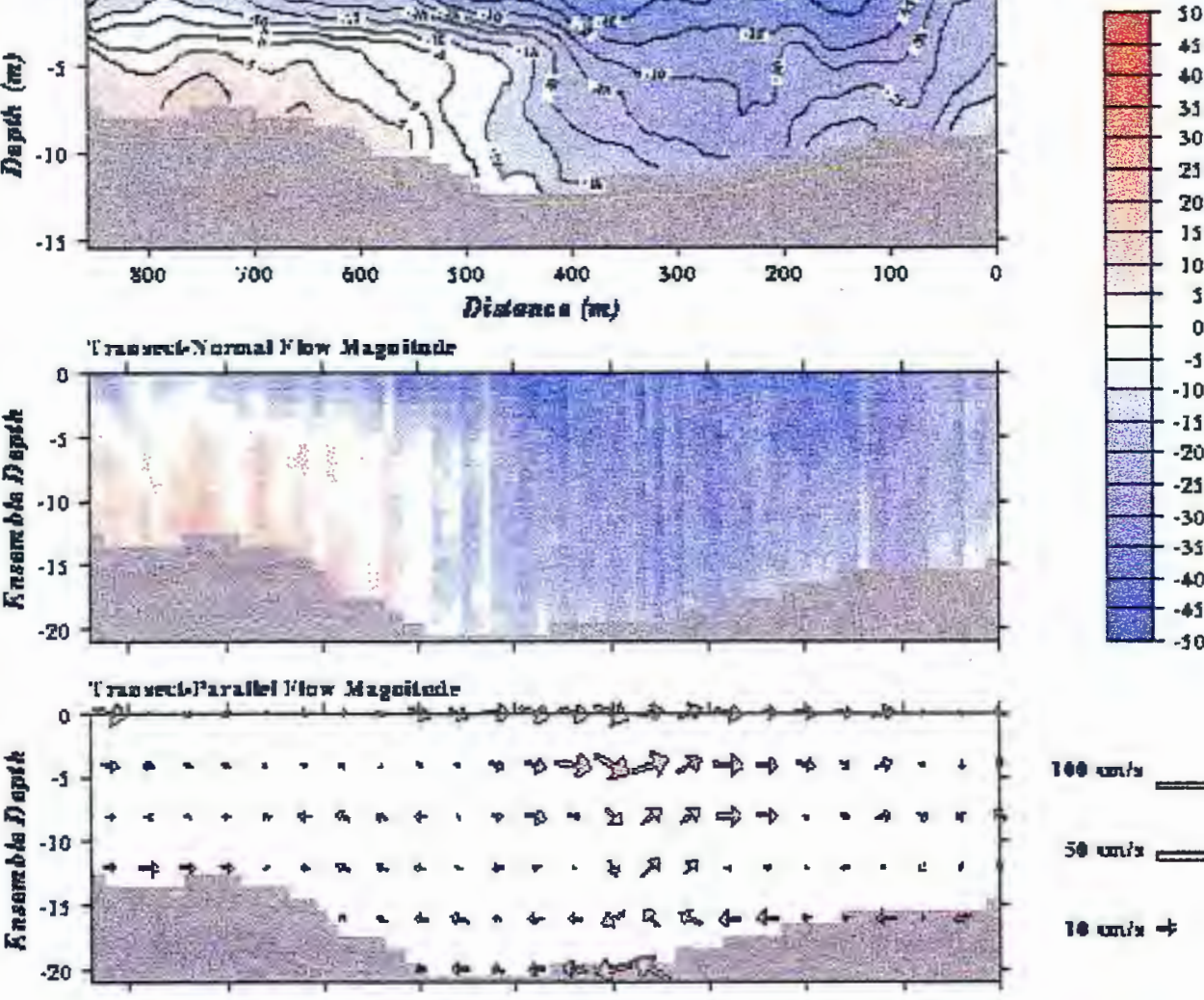

Into Rage

$\cos =$

14. exis

5. anix

$14 \operatorname{conin} t$
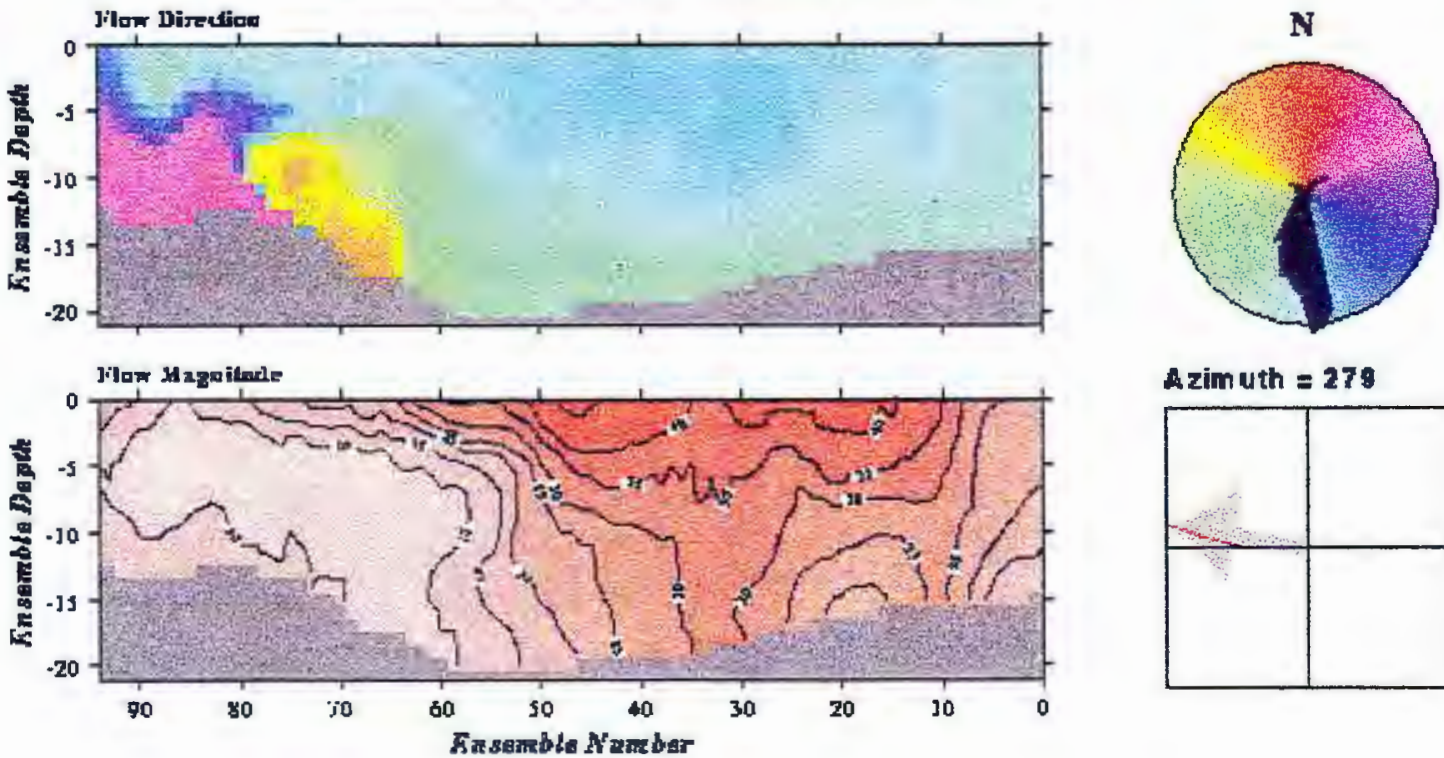

Azim uth $=278$

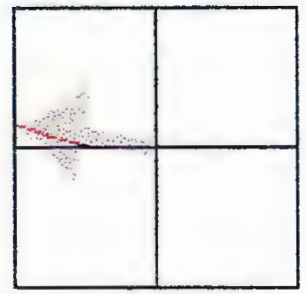



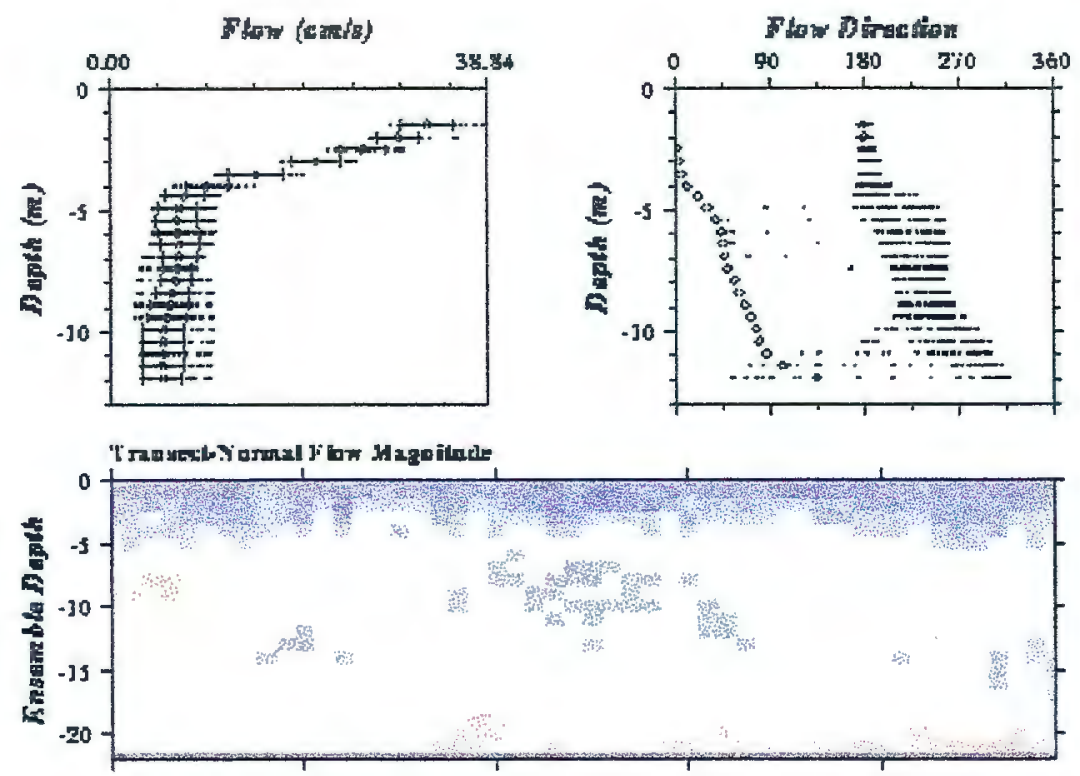

HOL2110A
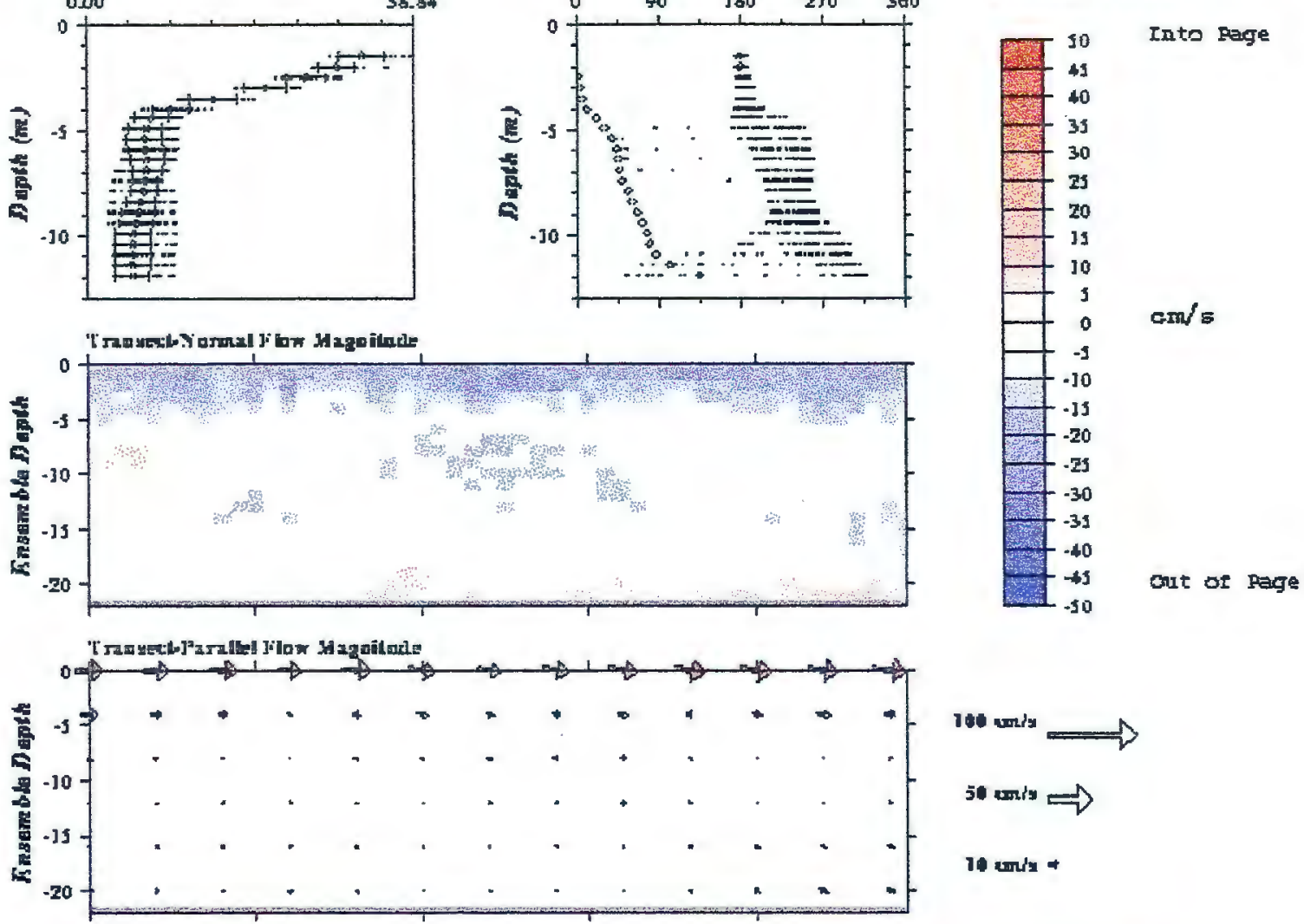

100 andy

50 anit

10 undr -
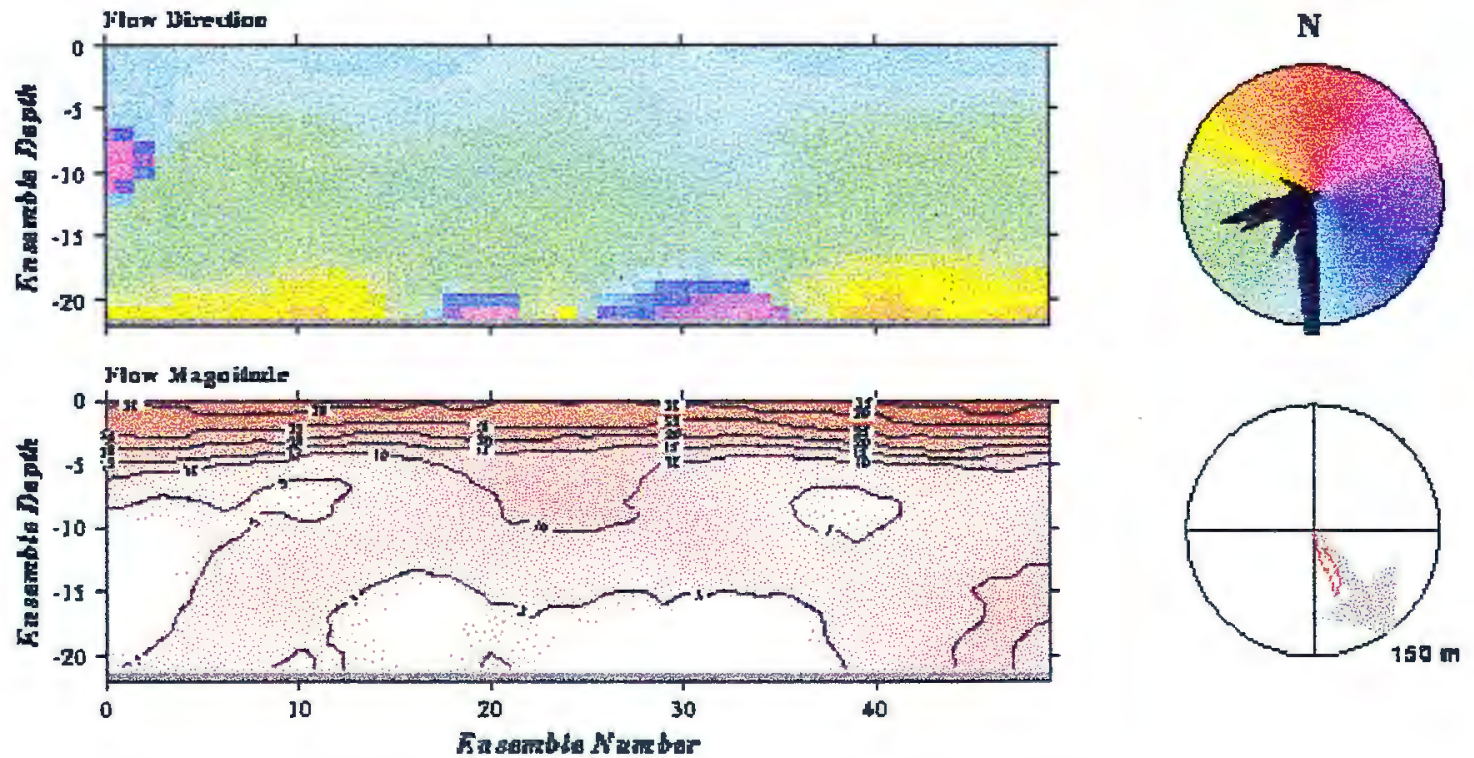


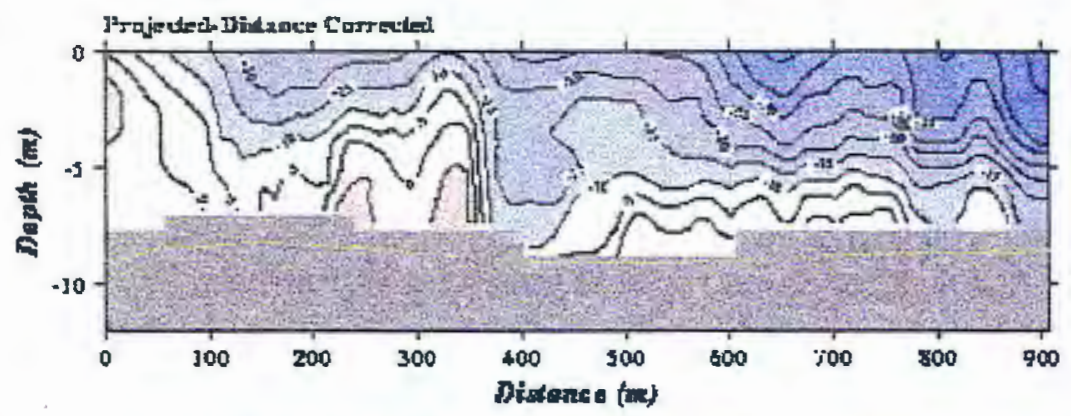

\section{HOL2111A}
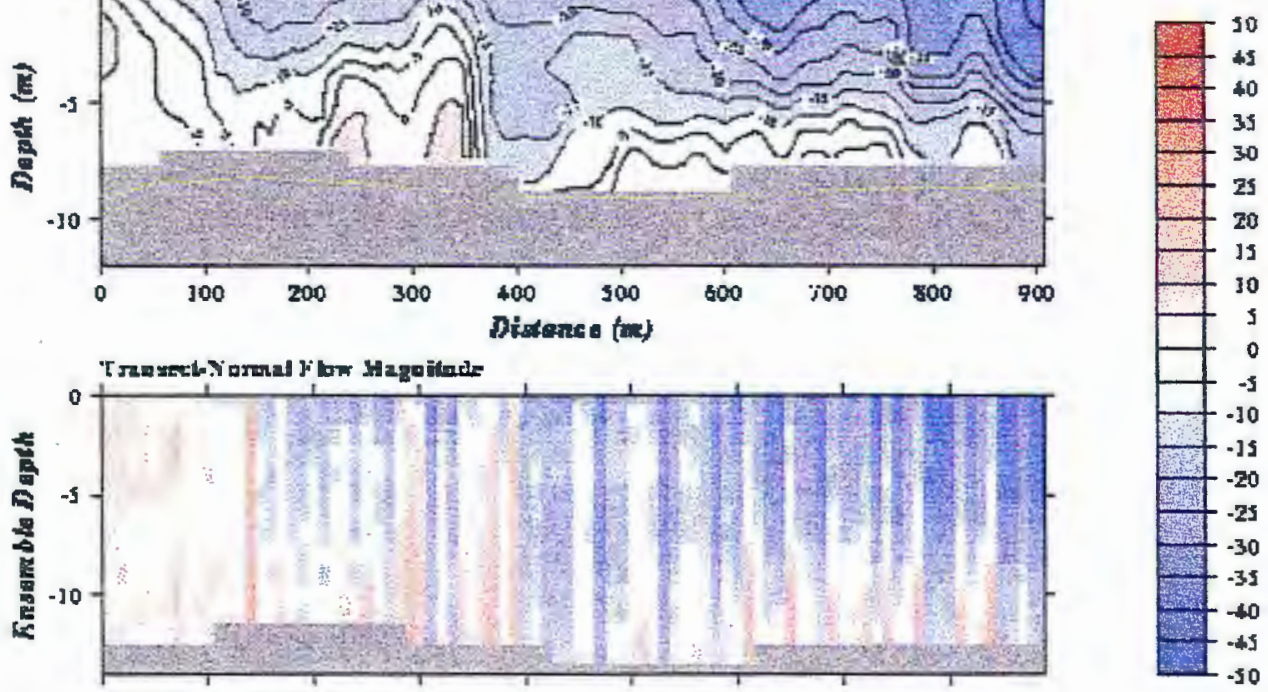

Into Page

$\mathrm{cm} / \mathrm{s}$

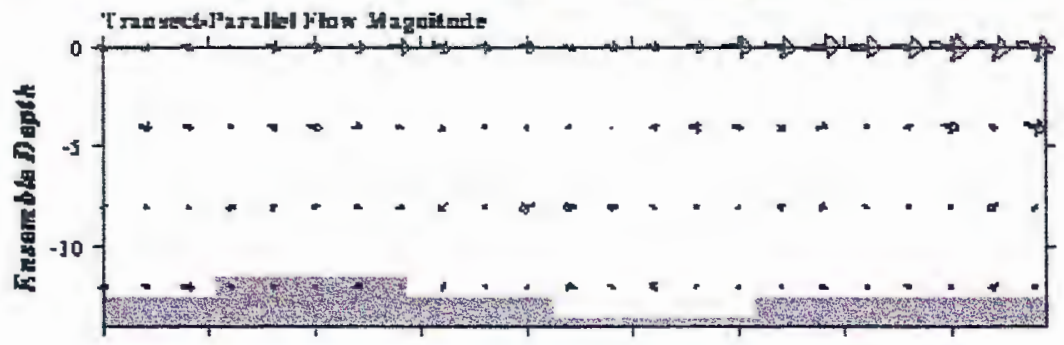

10u con's

$50 \cos x \Longrightarrow$

10 mis $\rightarrow$
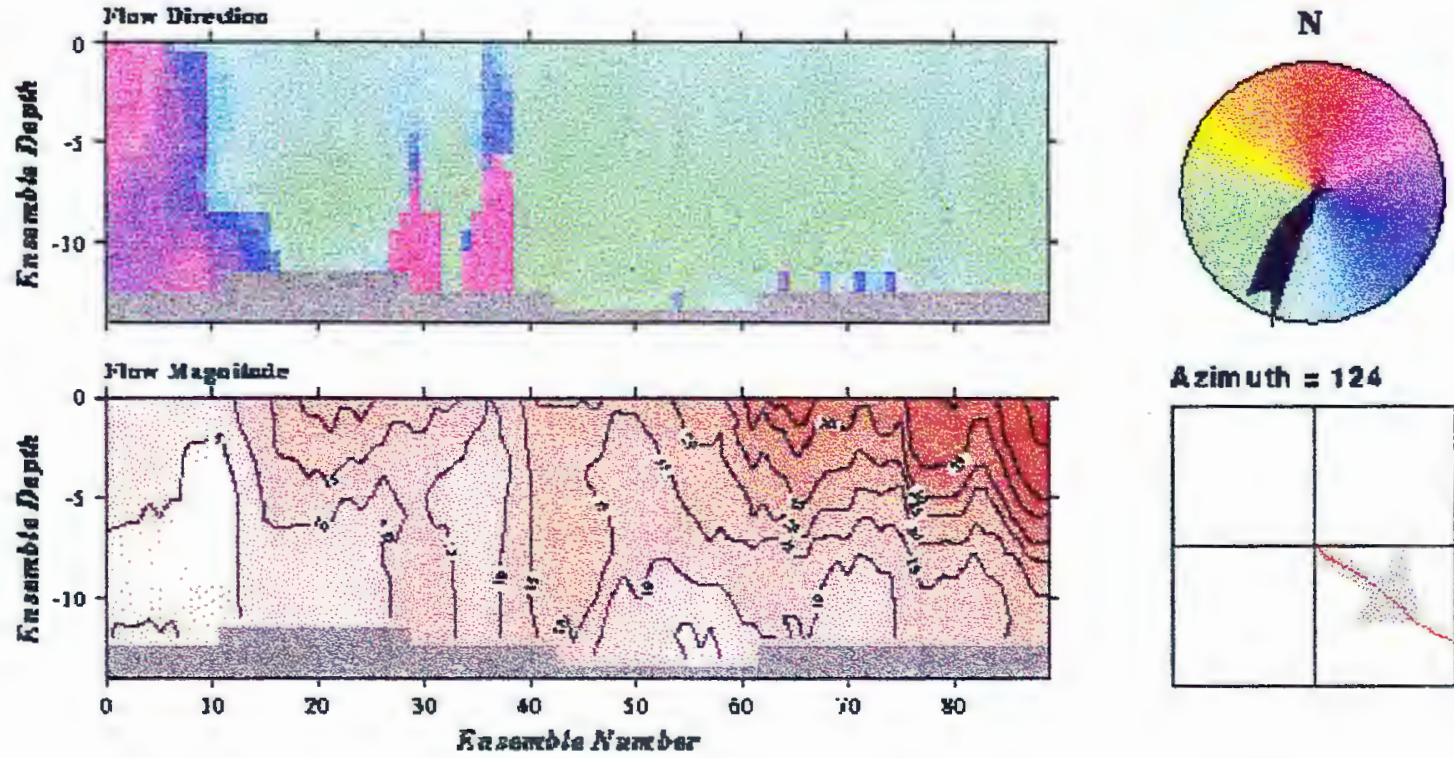

A simuth $=126$

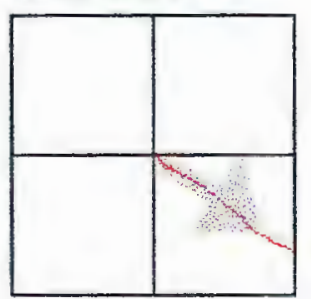




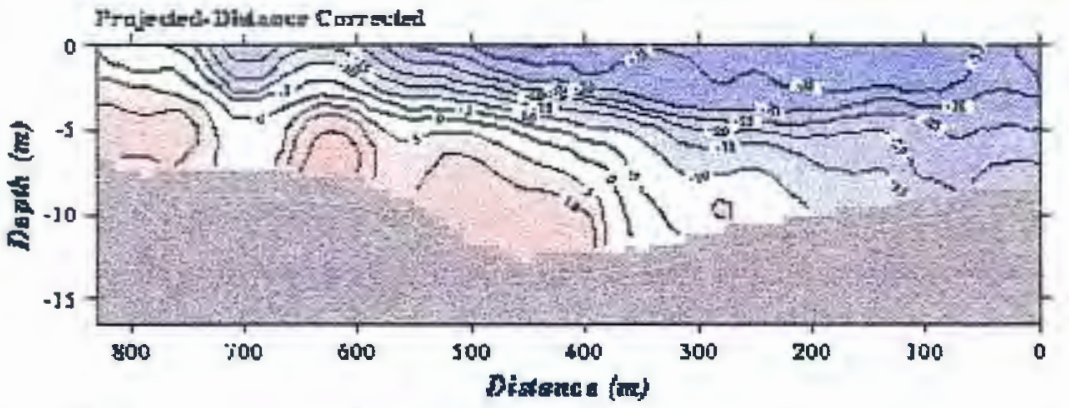

HOL2112A
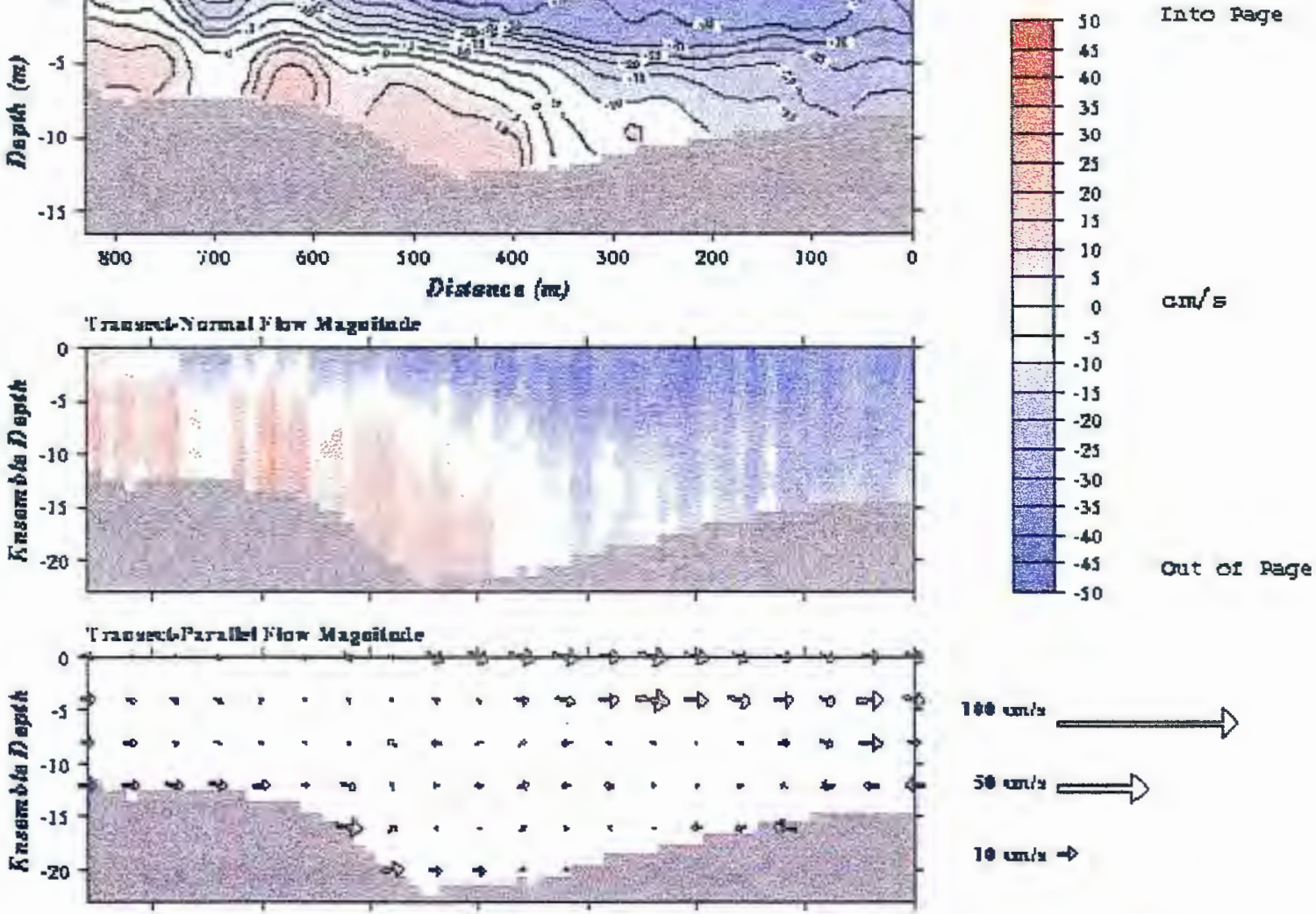

140 conis

S* undy

$10 \mathrm{cmix} \rightarrow$
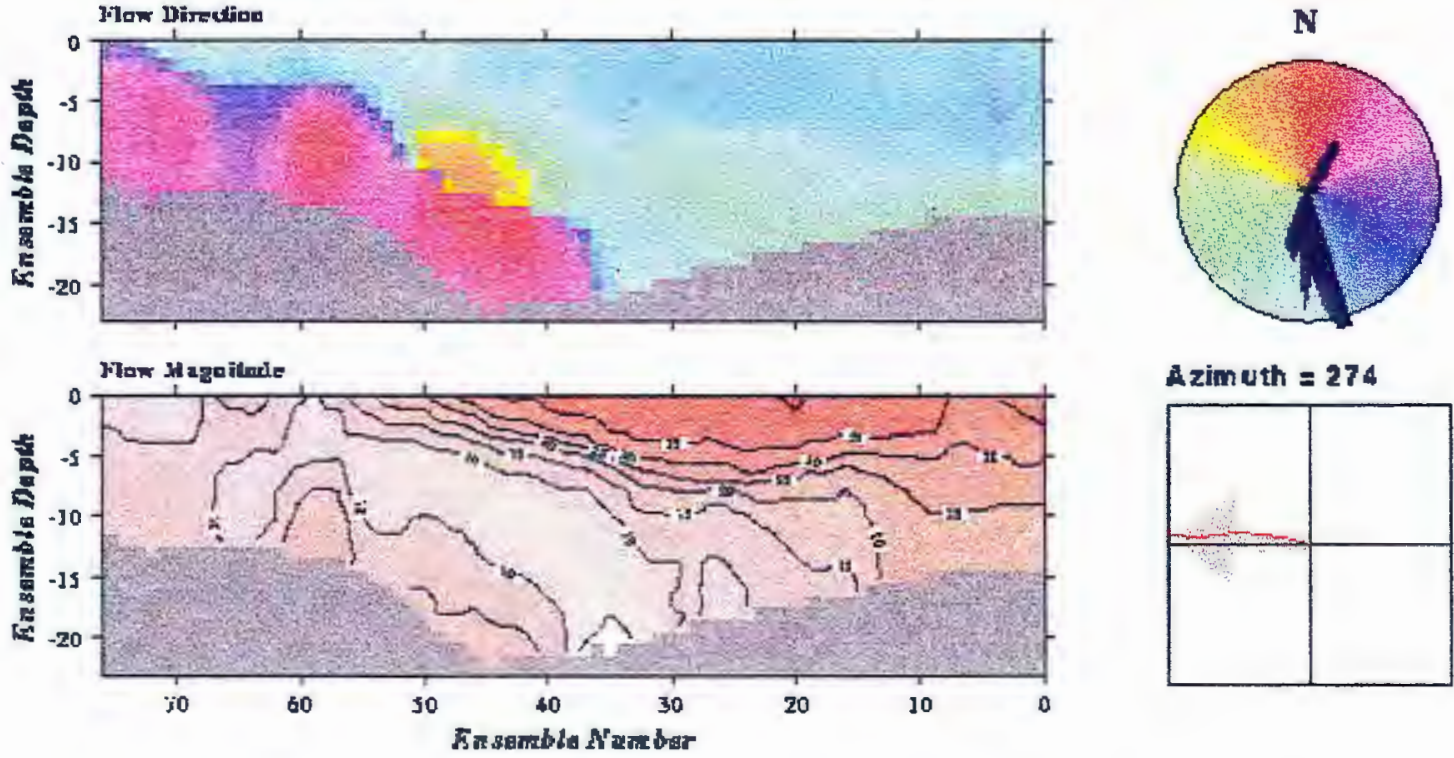

Azimuth $=274$

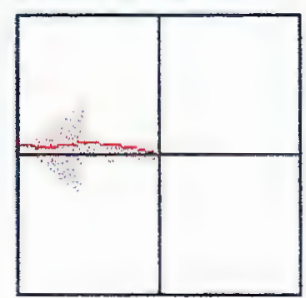




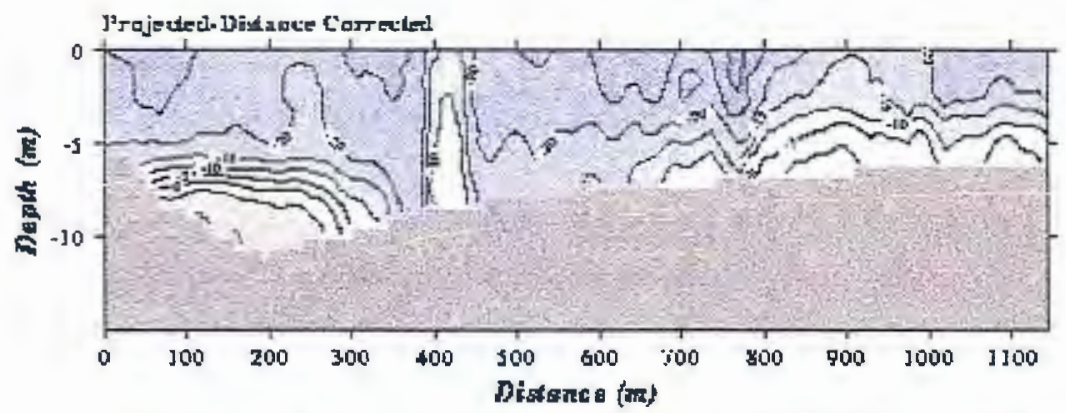

\section{HOL2113A}
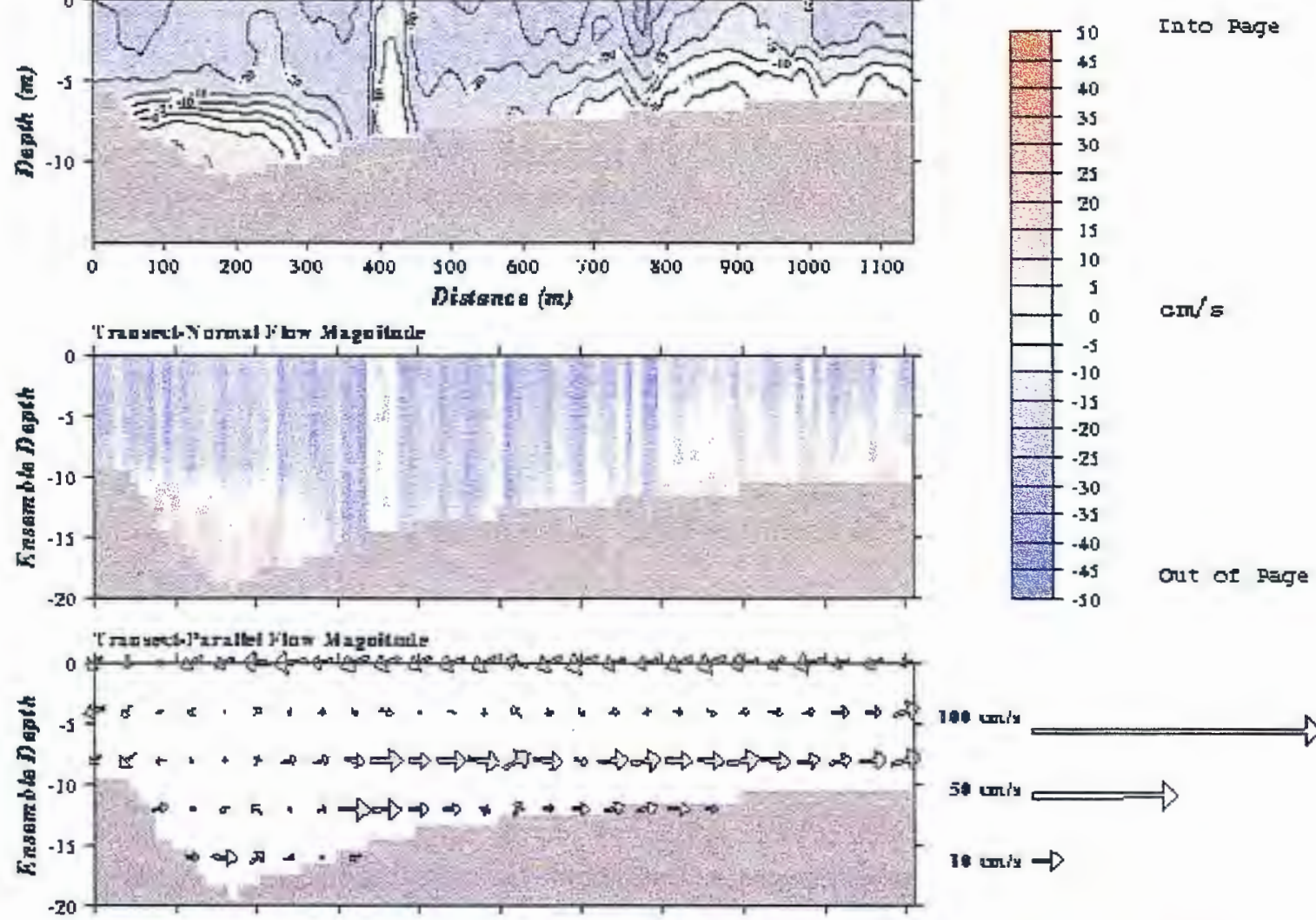

1 at corly

30 un'y

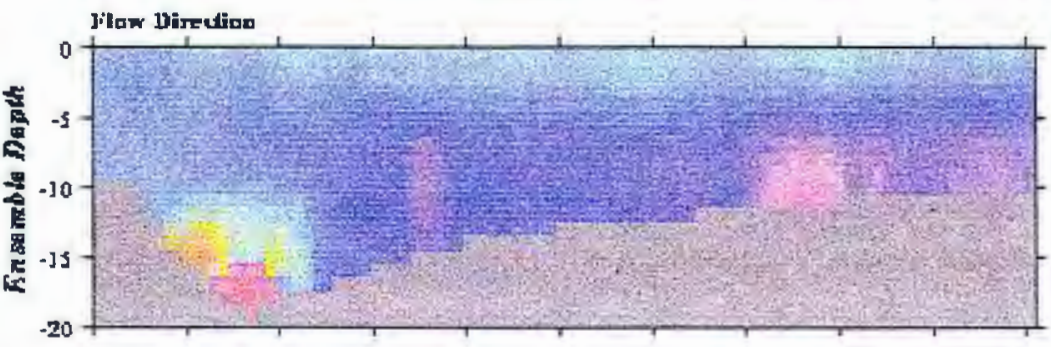

18 wriy $\rightarrow$

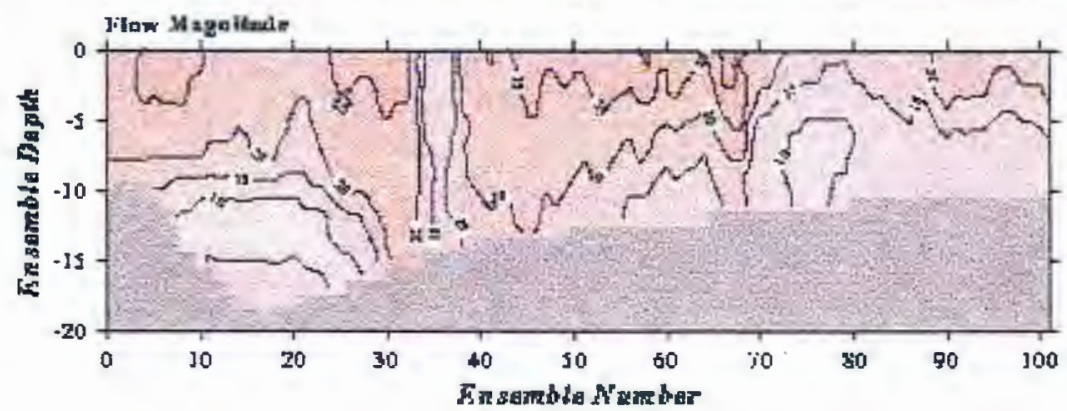

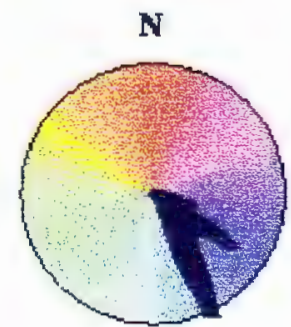

Azimuth $=54$

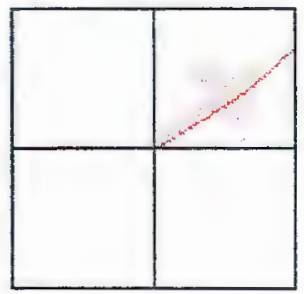



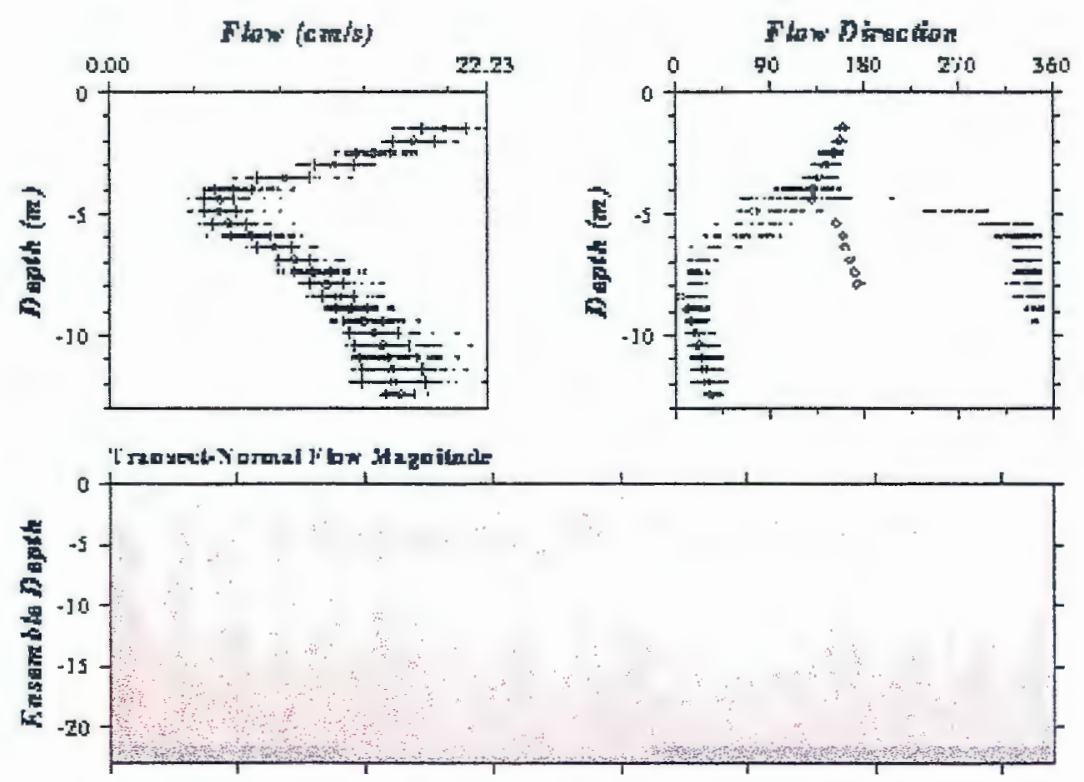

HOL2114A
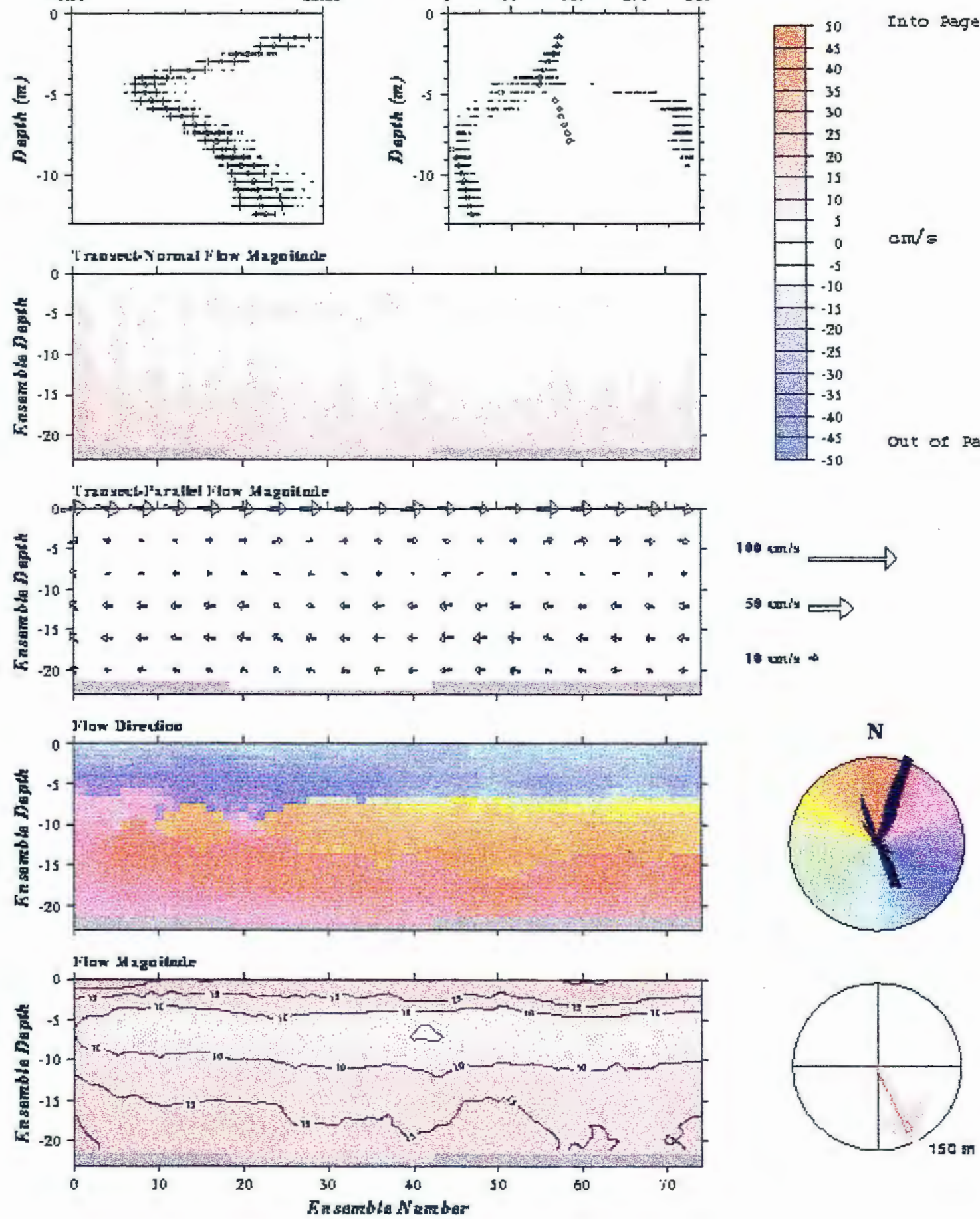


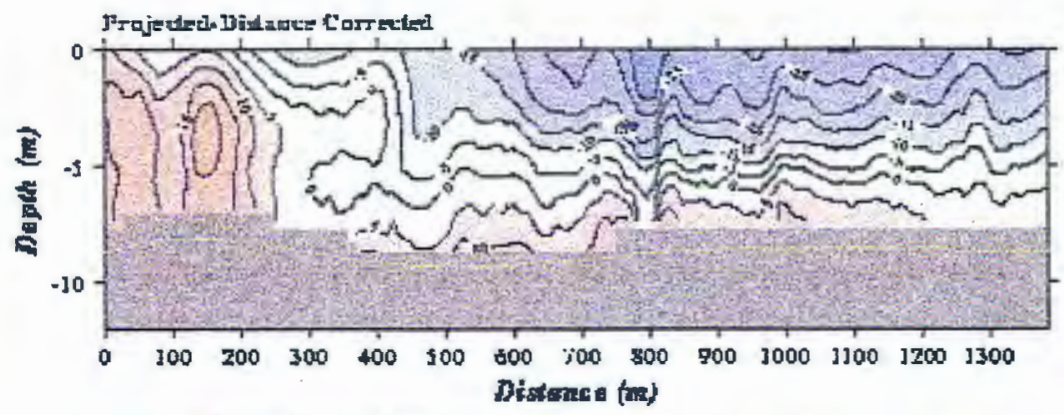

\section{HOL2115A}
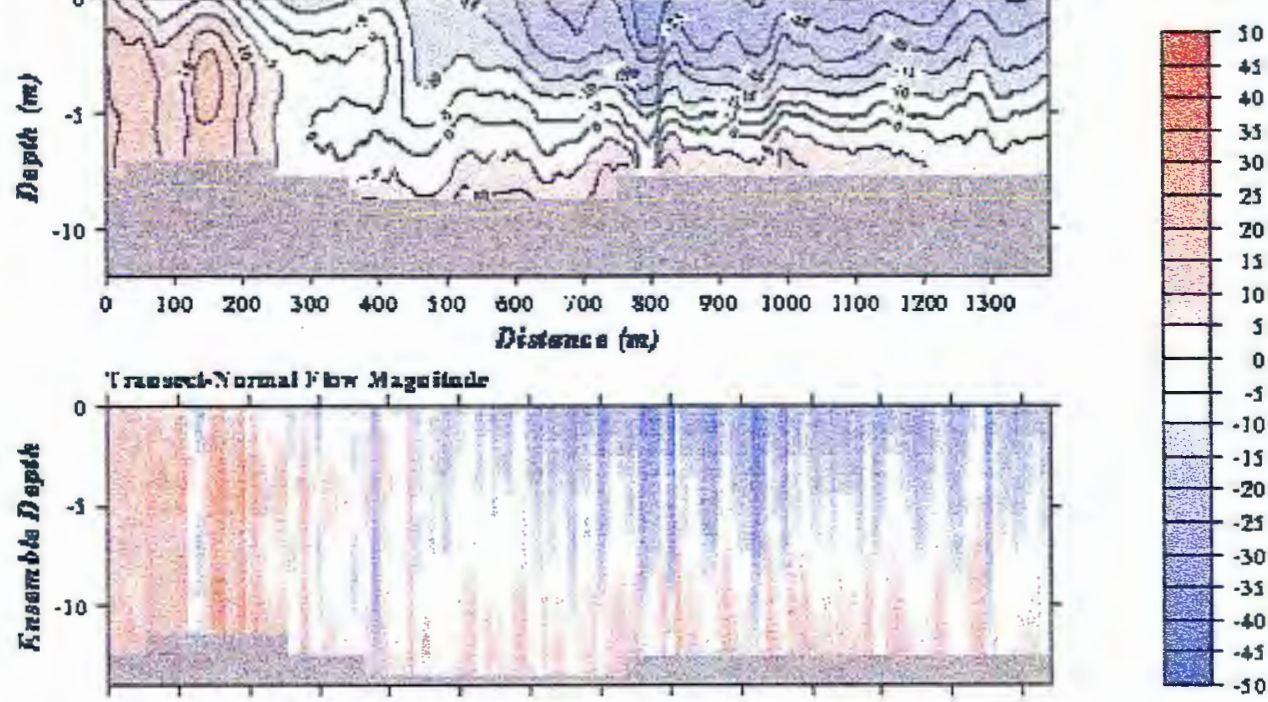

In to Page

$\mathrm{cm} / \mathrm{s}$

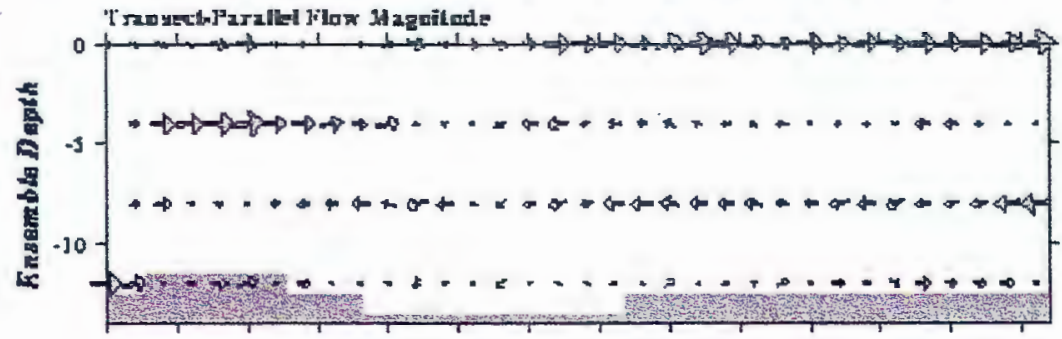

140 conis

jounis $\longrightarrow$

It) ands $\rightarrow$
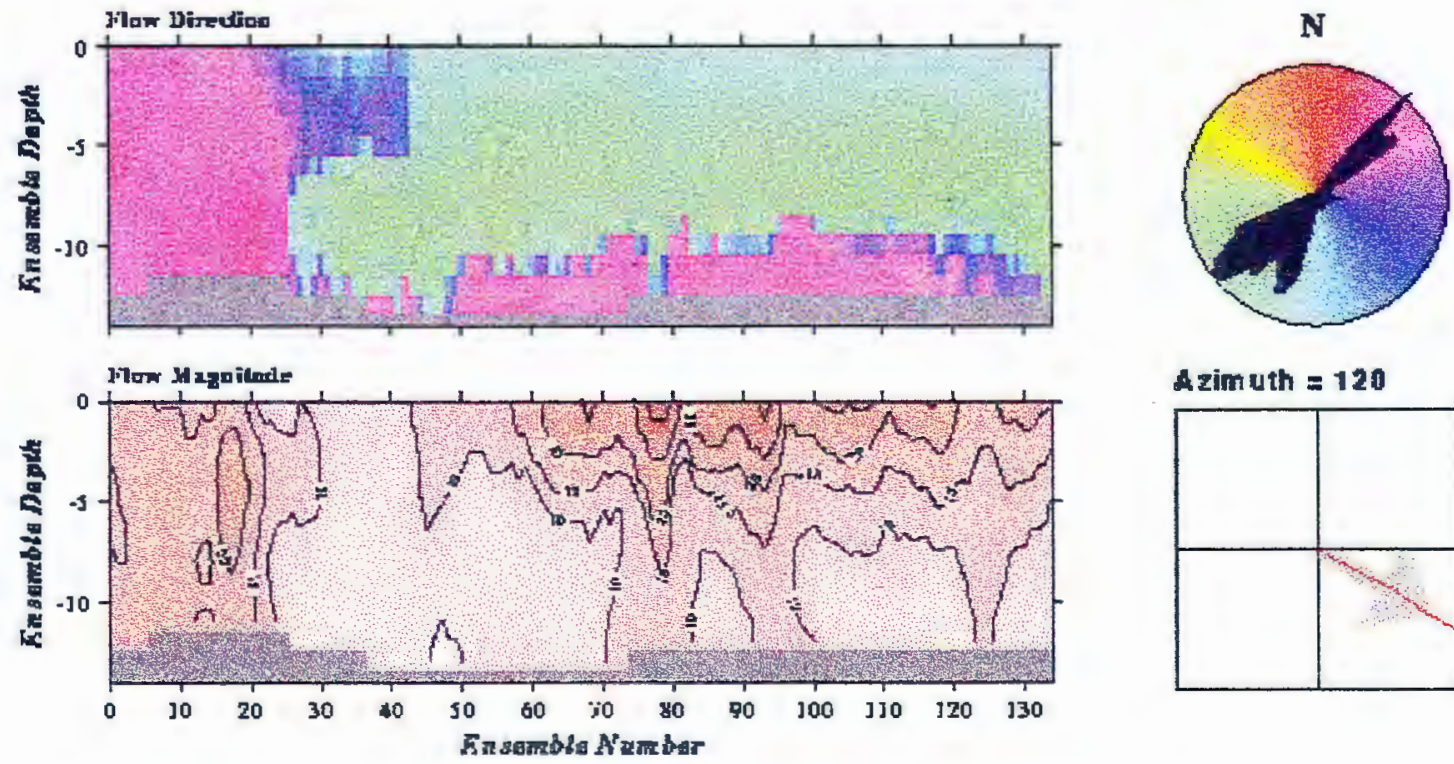

A zimuth $=120$

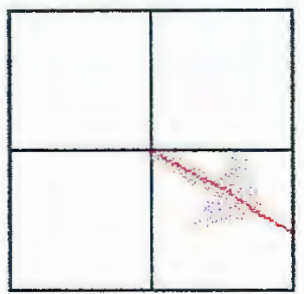



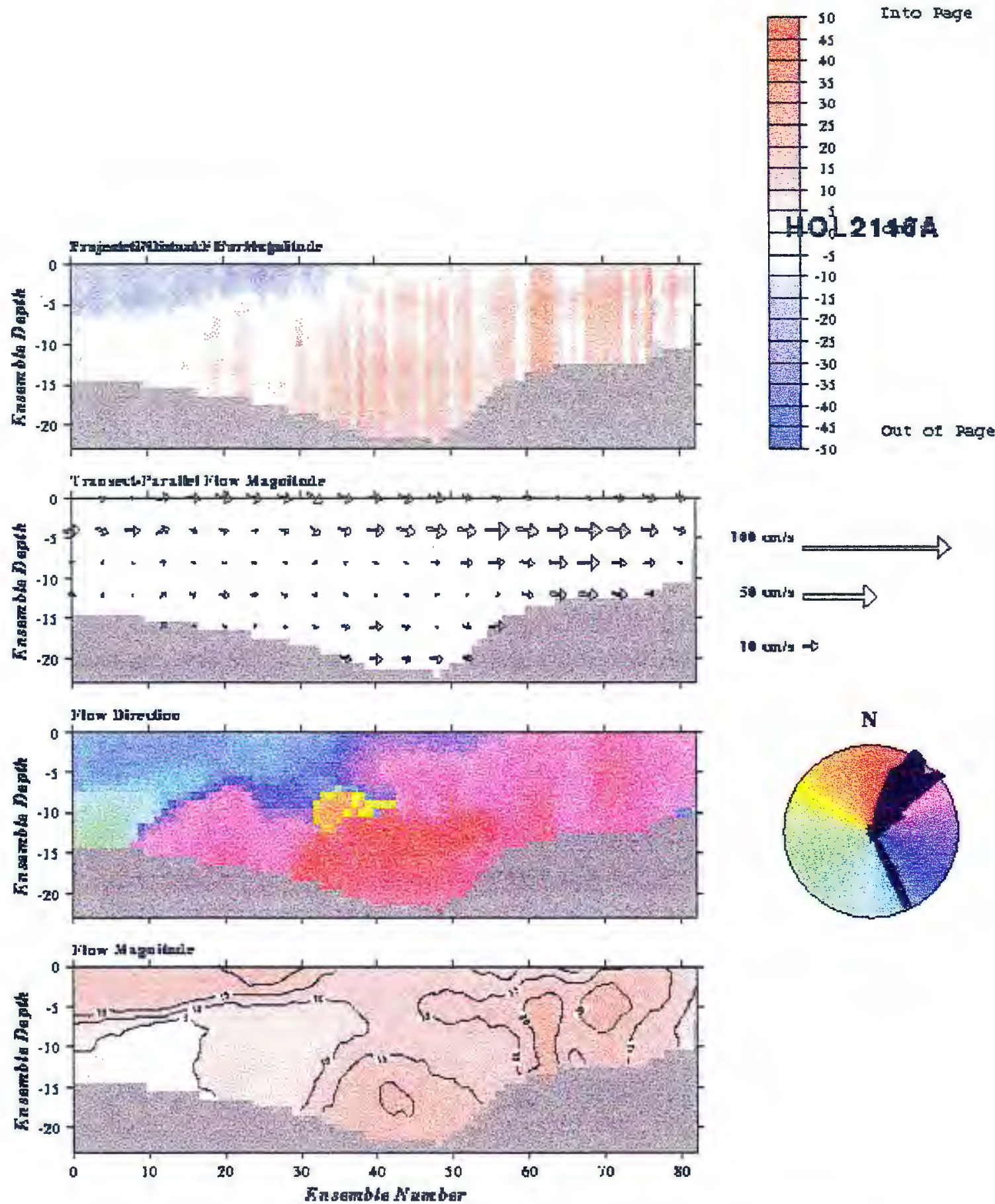

$A \sin u$ th $=90$ 

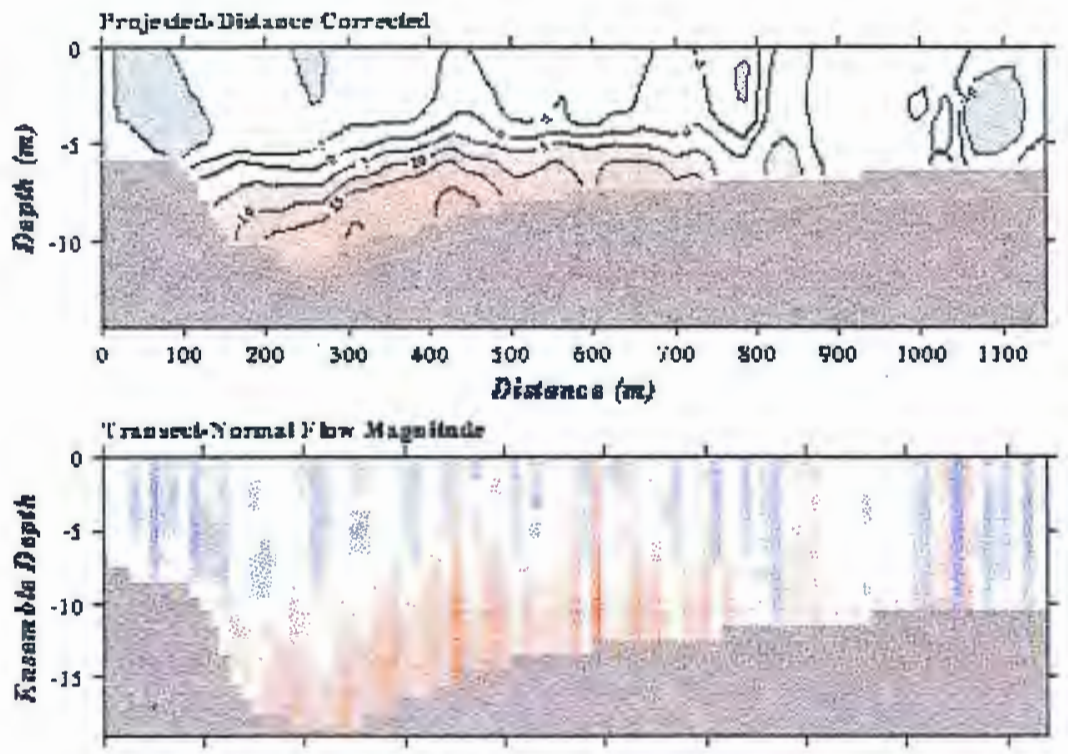

\section{HOL2117A}
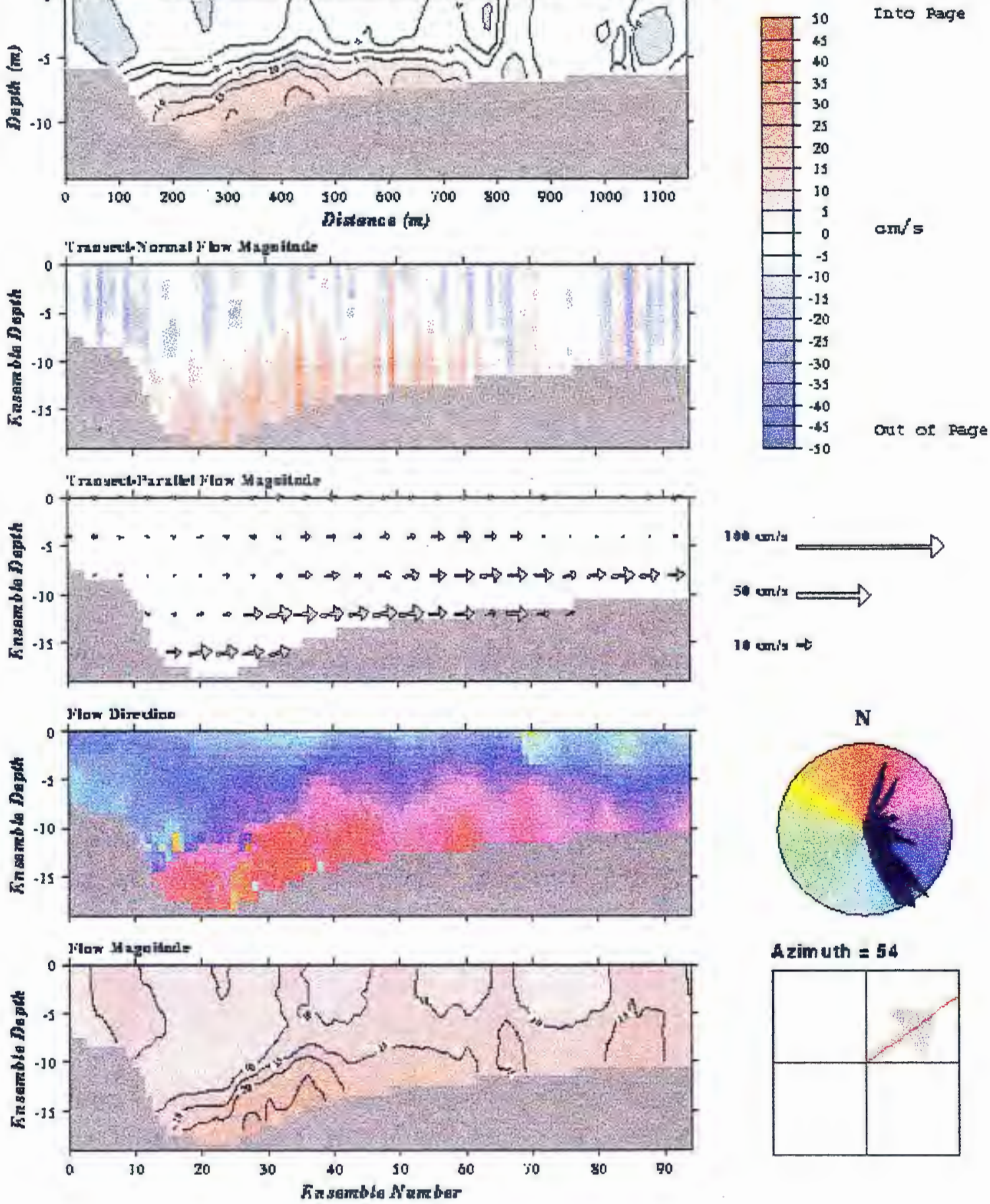

Azimuth $=54$

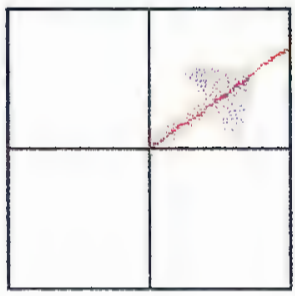



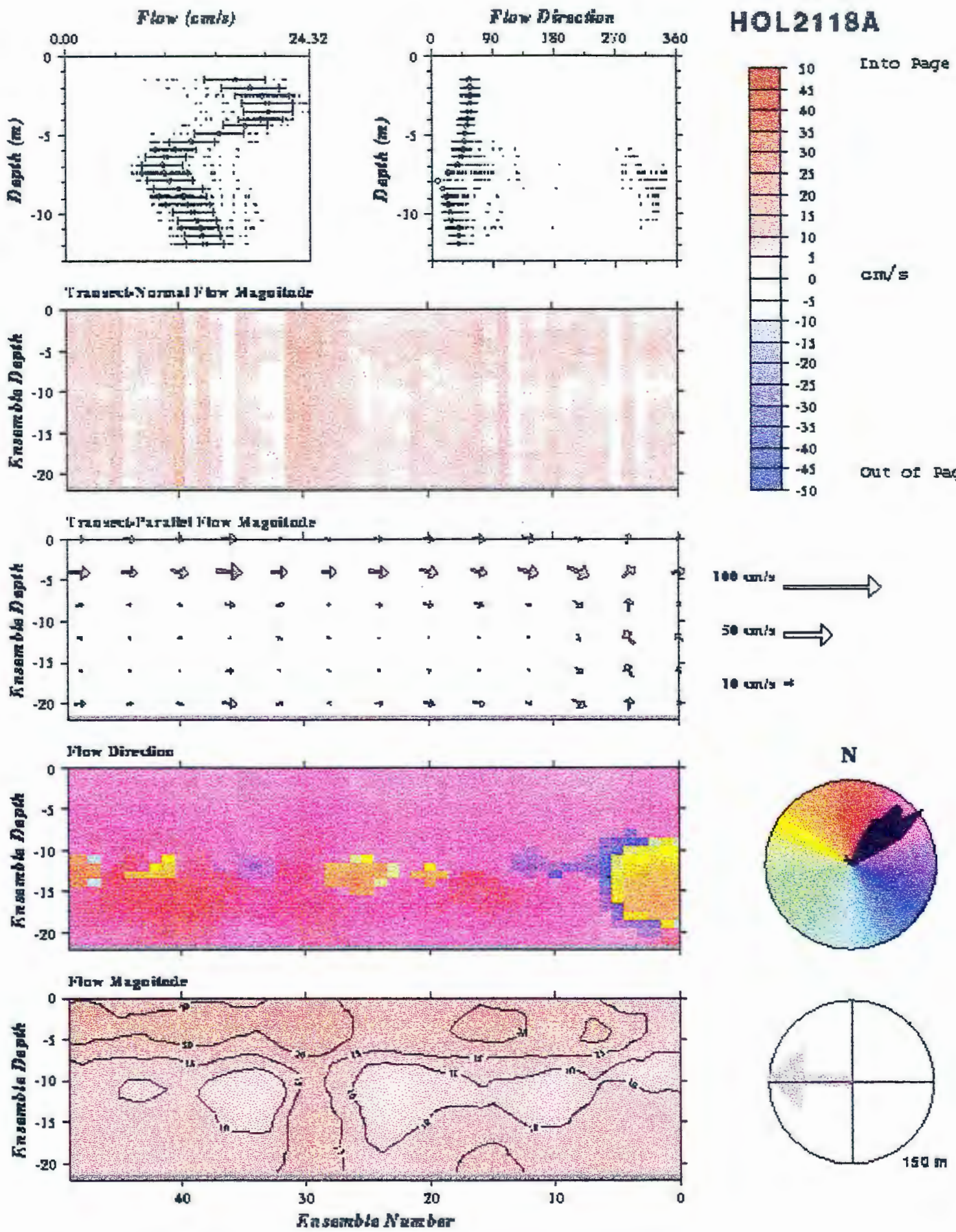


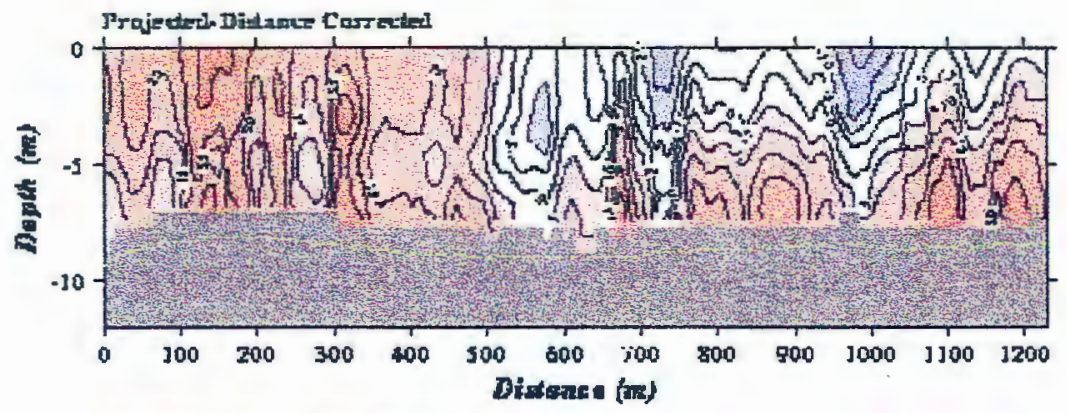

\section{HOL2119A}
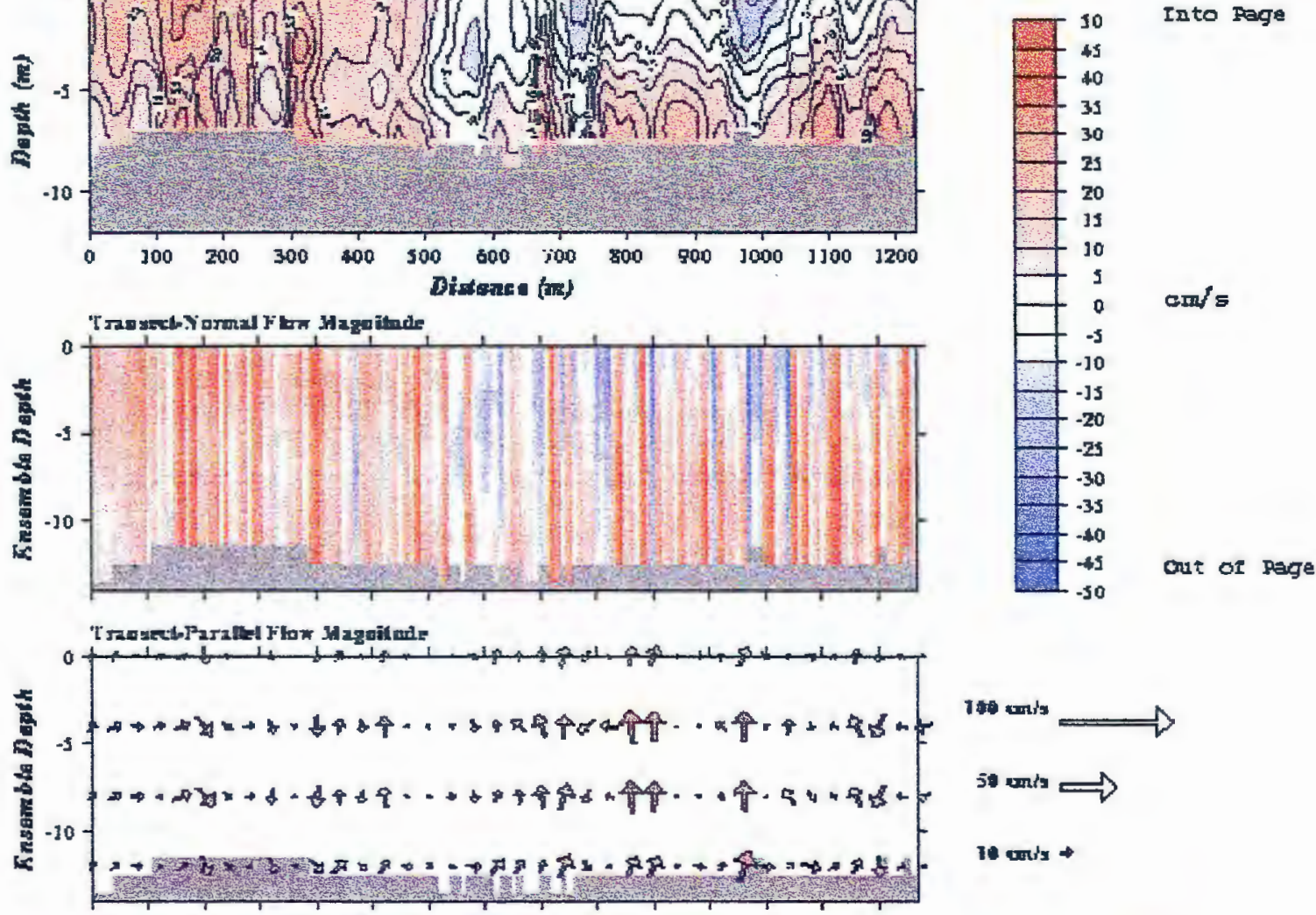

$100 \mathrm{~cm}$ '

5it ands

It) erry
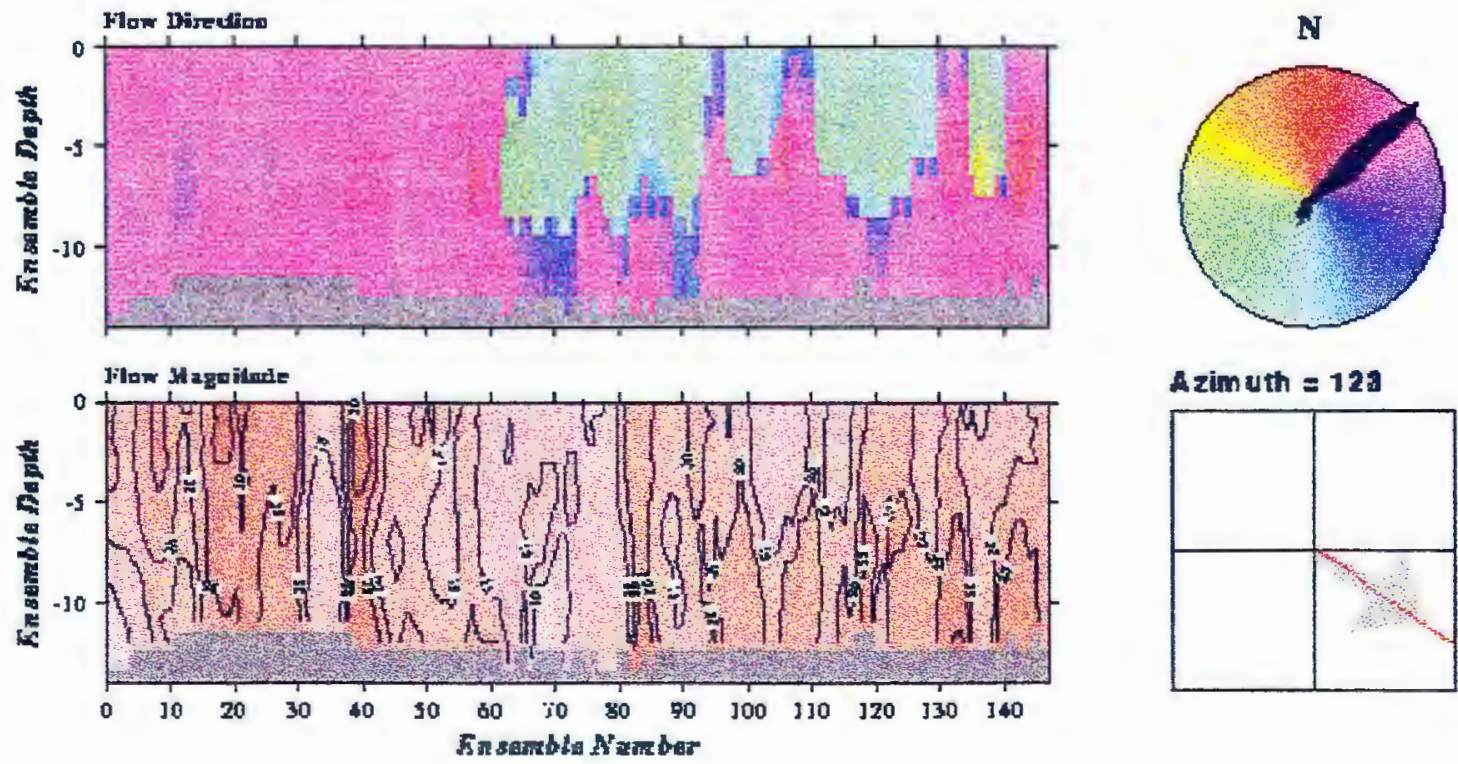

Azim uth $=123$

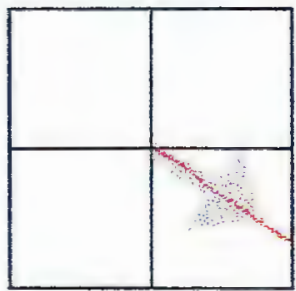



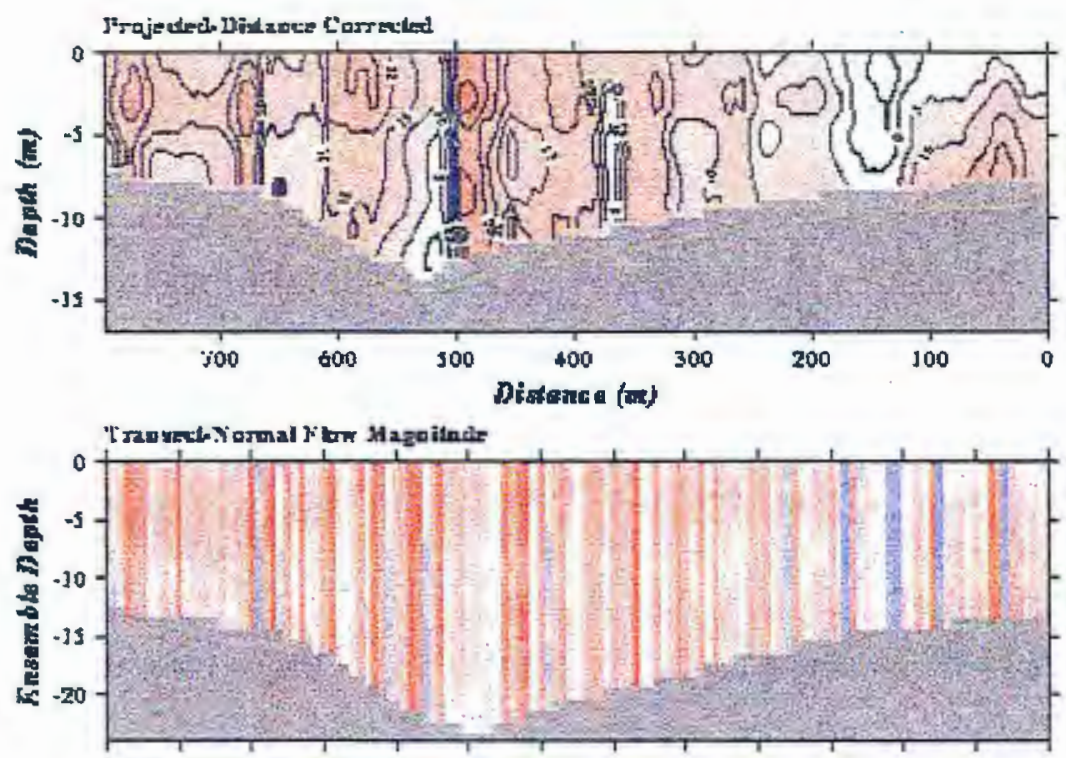

HOL2120A
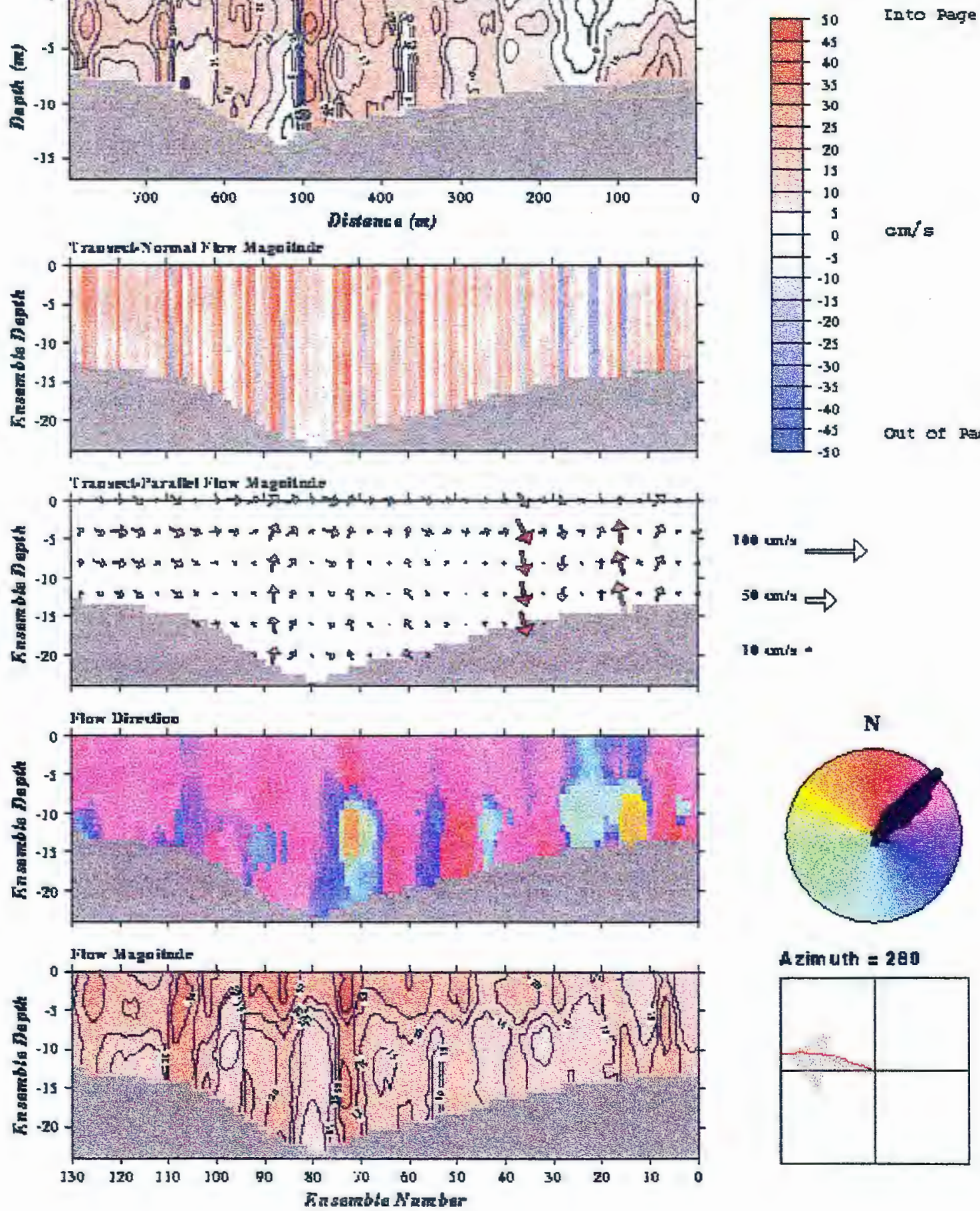

100 unis

50 mil

10 amia .

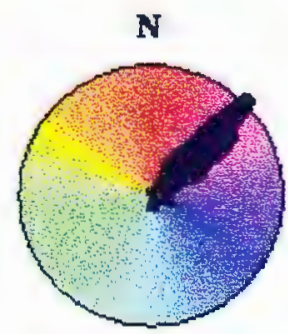

A $\operatorname{zim} u t h=280$

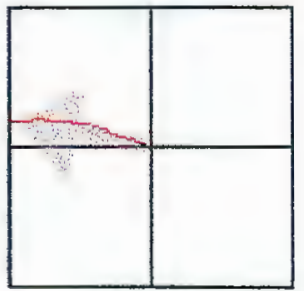



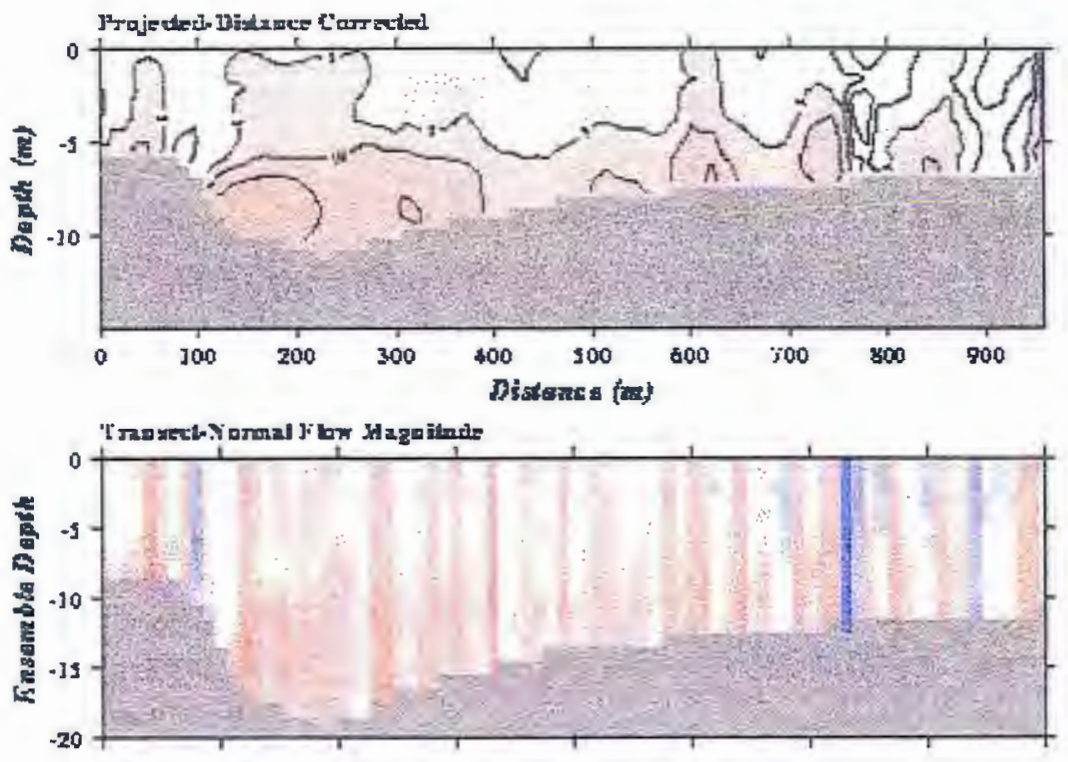

HOL2121A
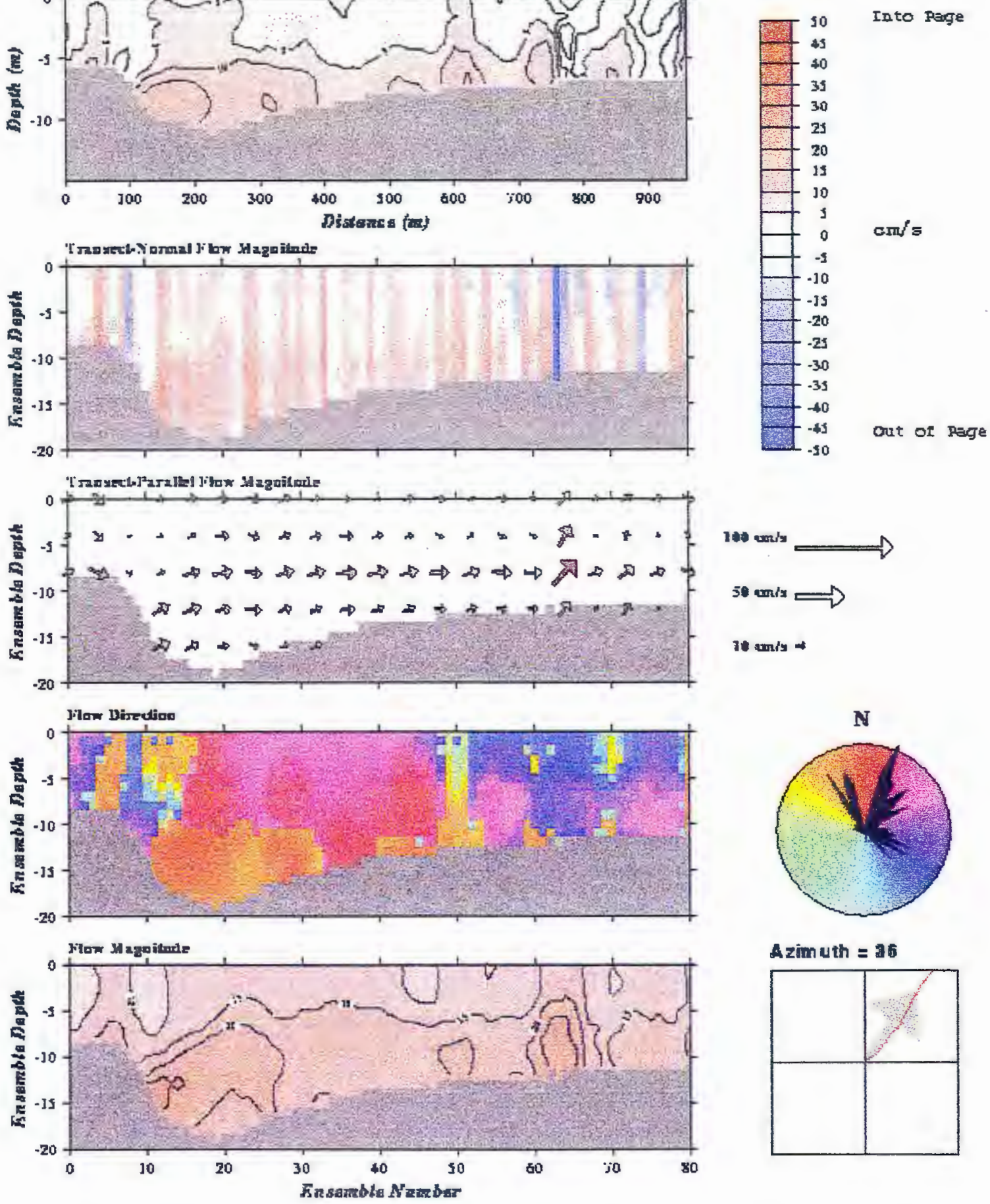

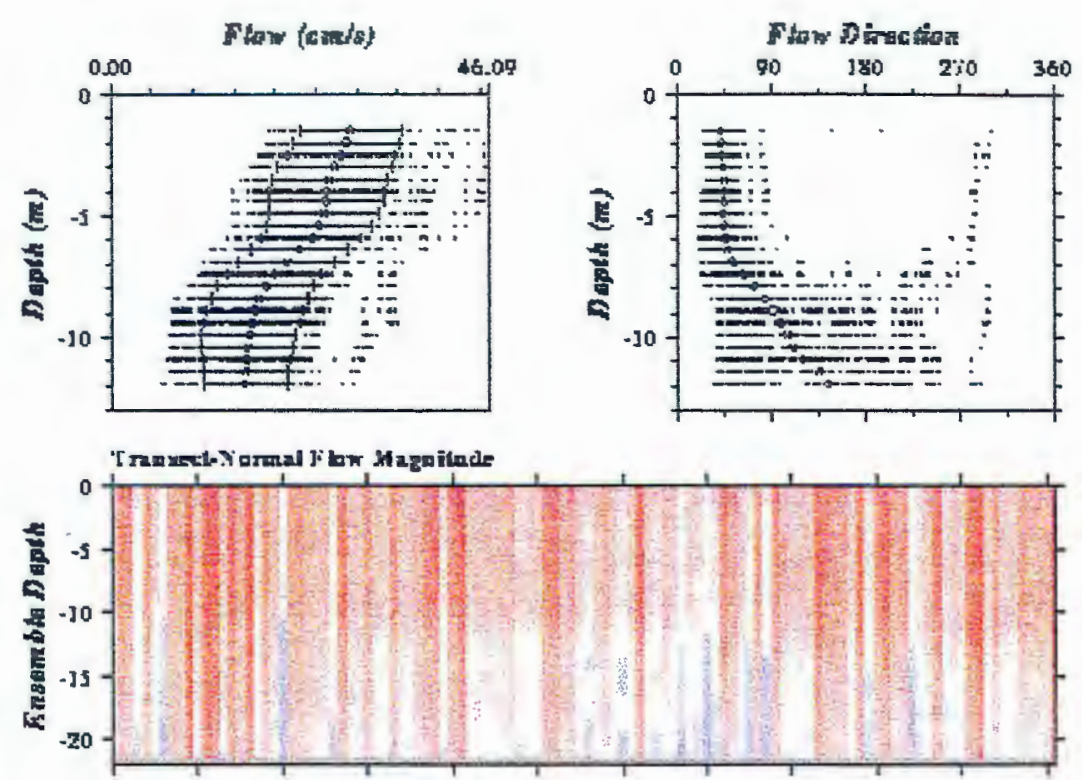

HOL2123A

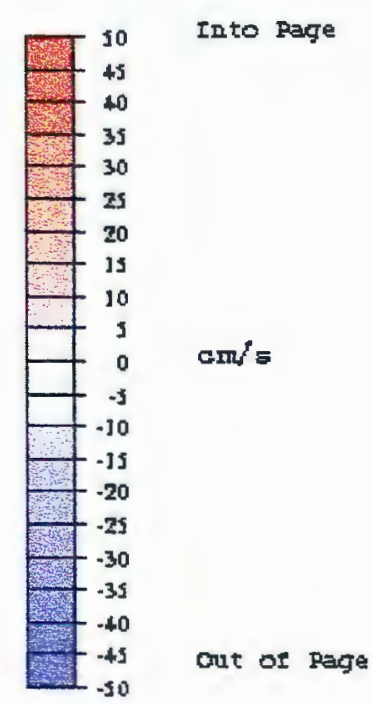

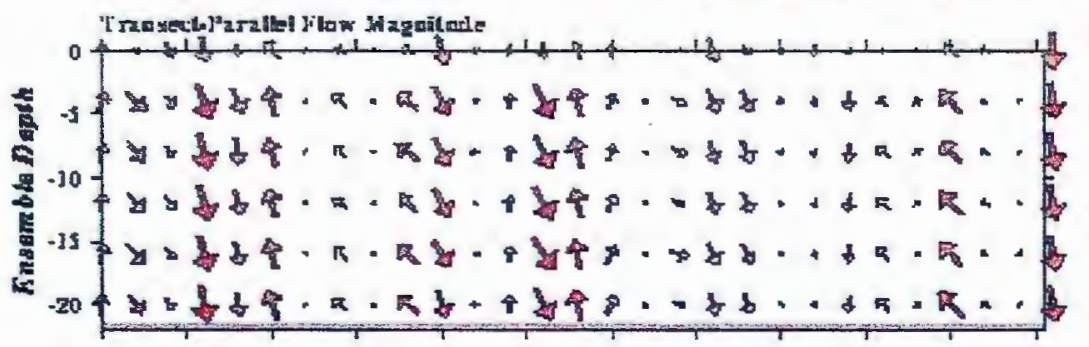

100 mil

5o and 1

14 endy -
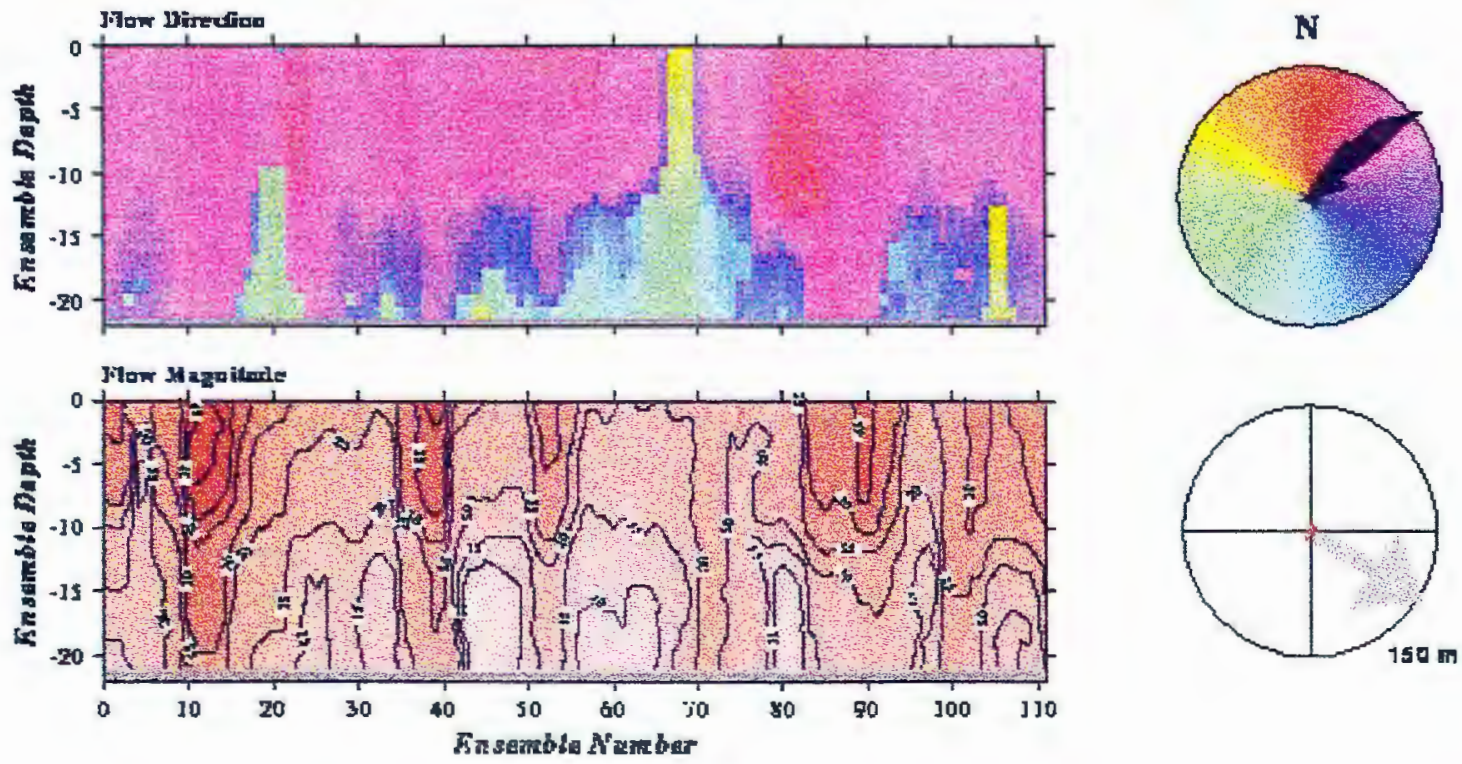

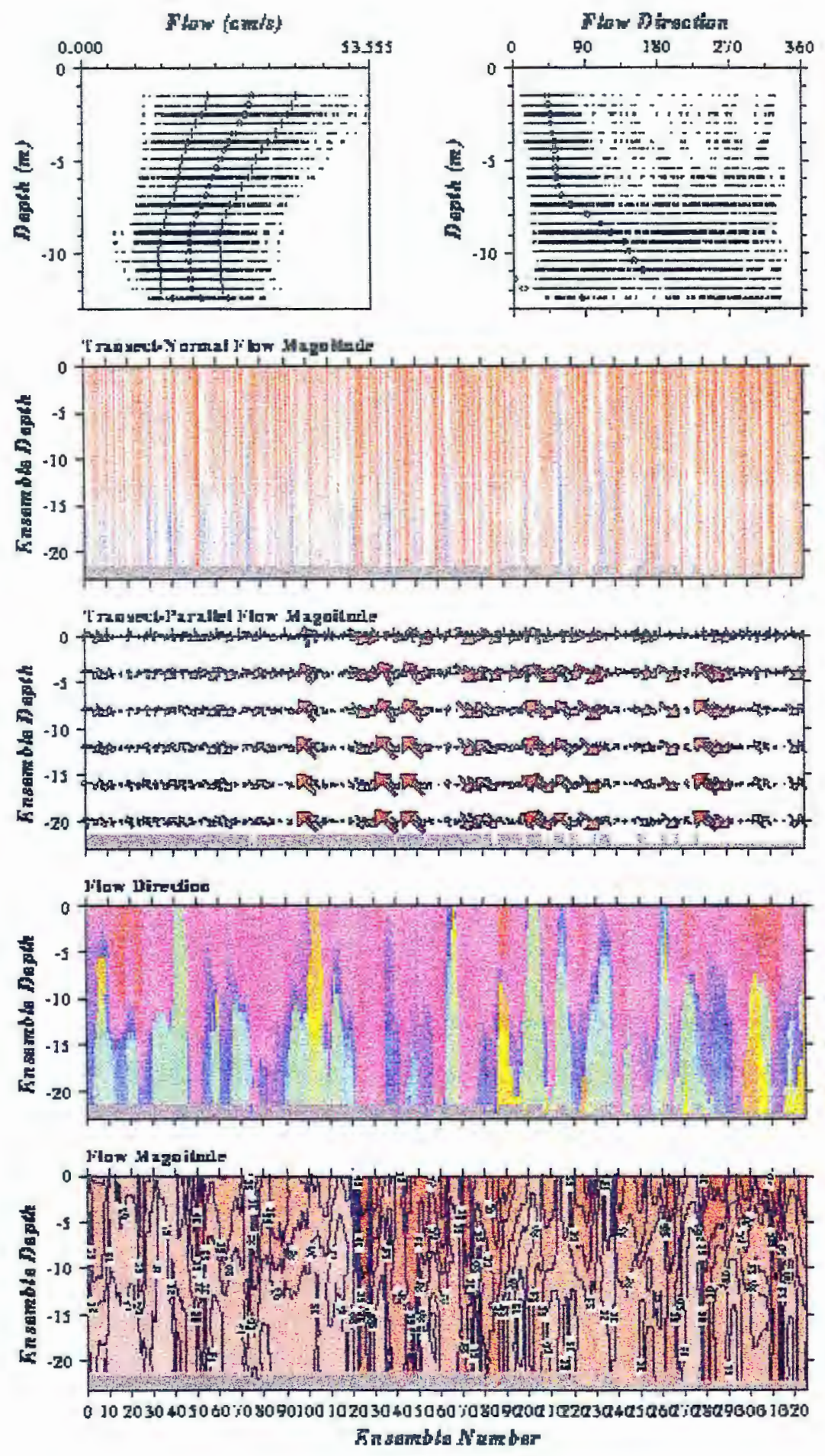

\section{HOL2125A}

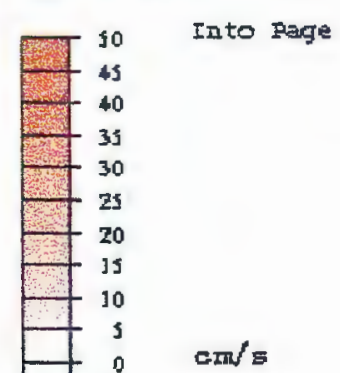

10 wris

5) amla $-p$

10 anix -
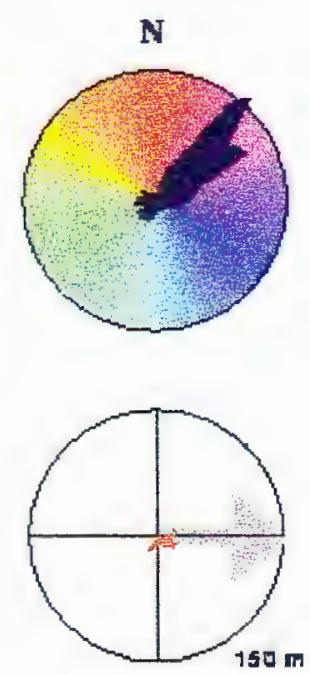

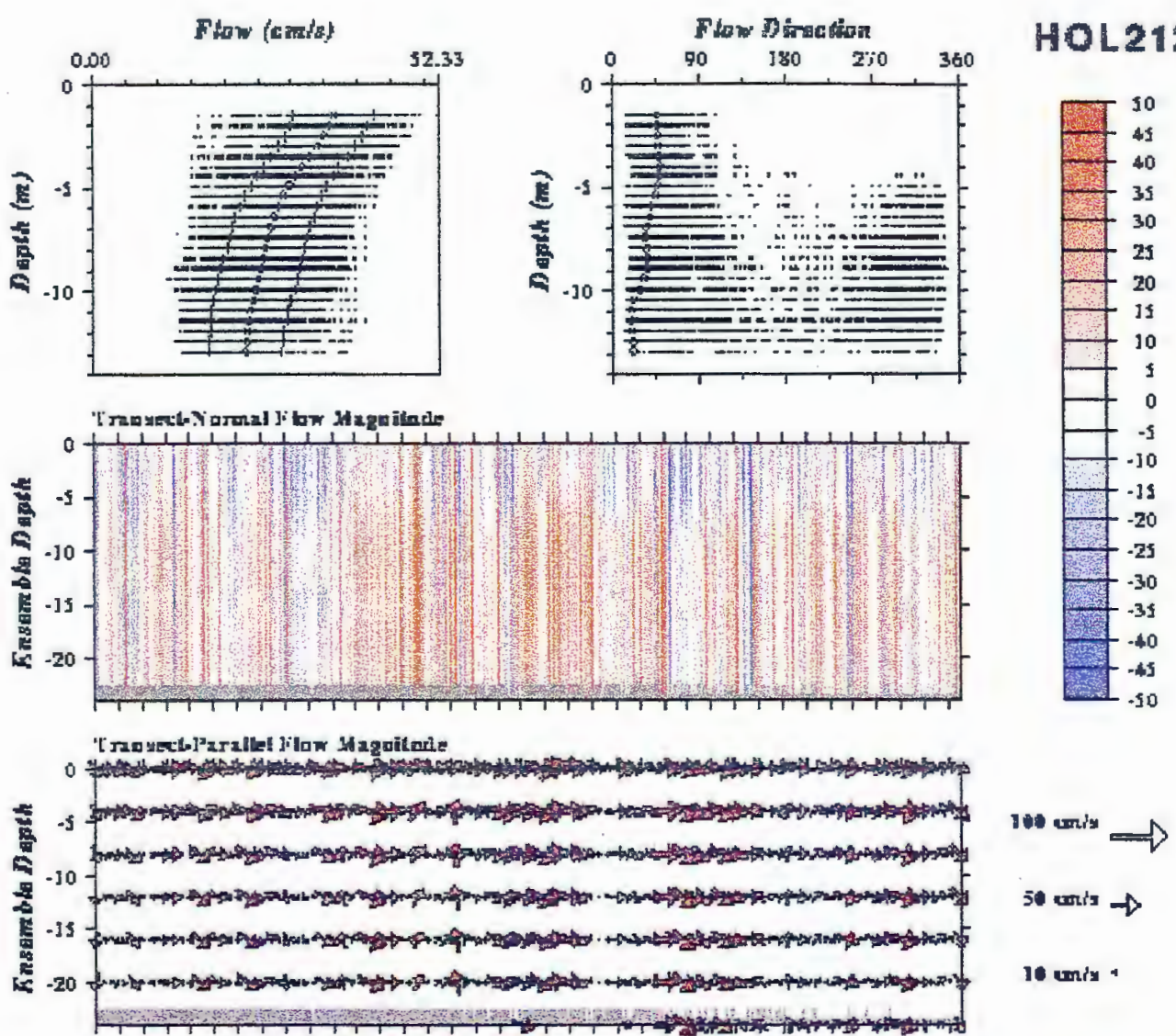

10 unis *
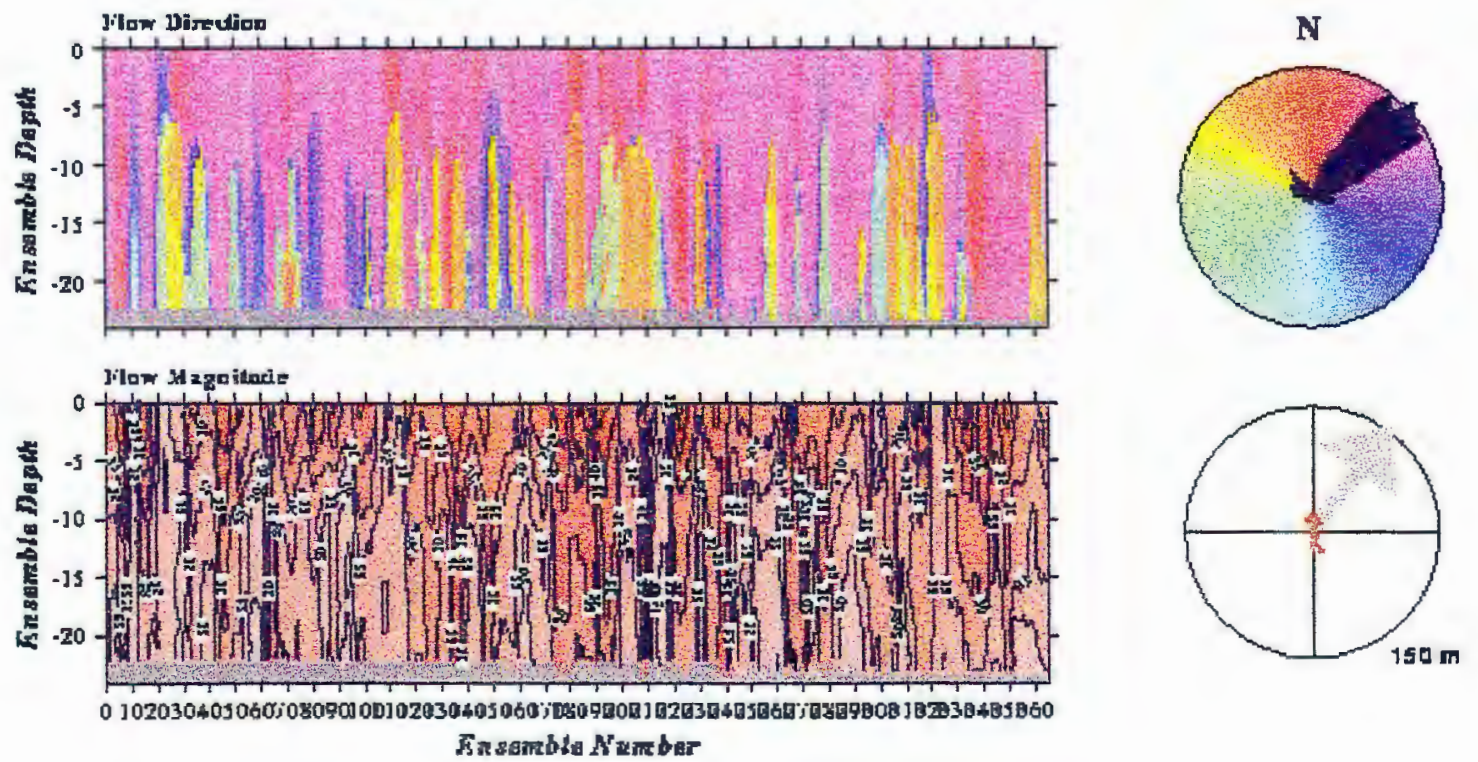

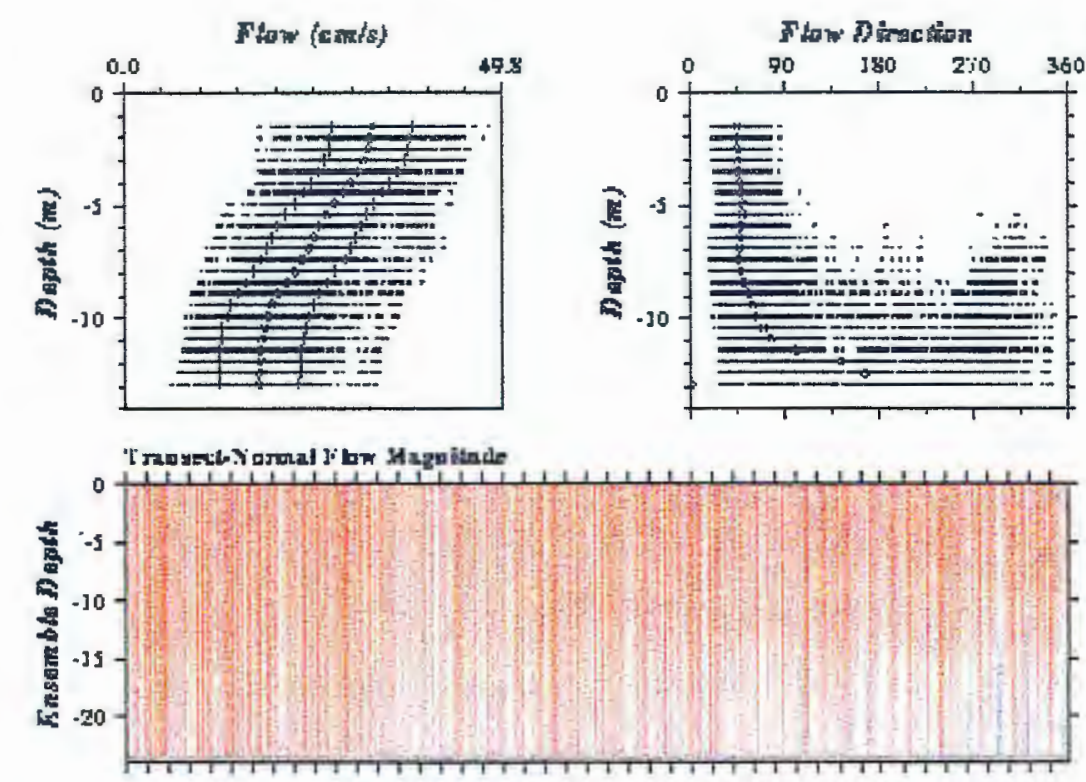

HOL2128_1A

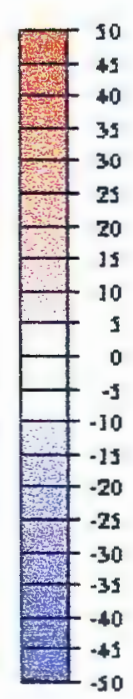

Into Fage

amp s

out of Rege

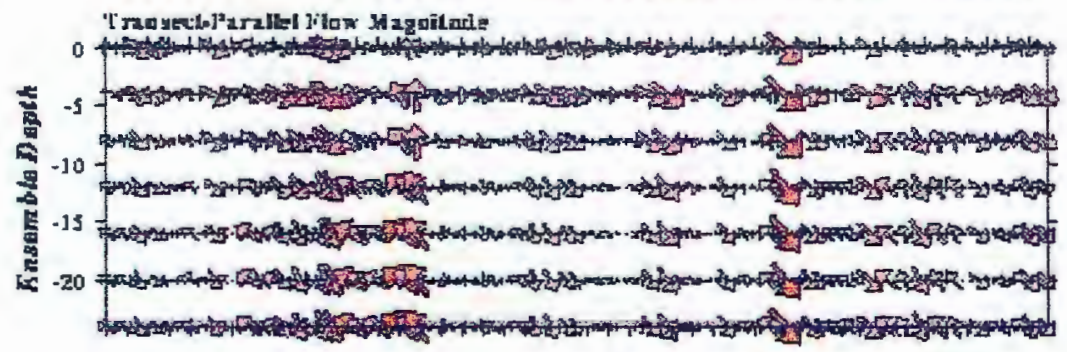

10 coriy

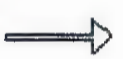

souris

10 4riy *
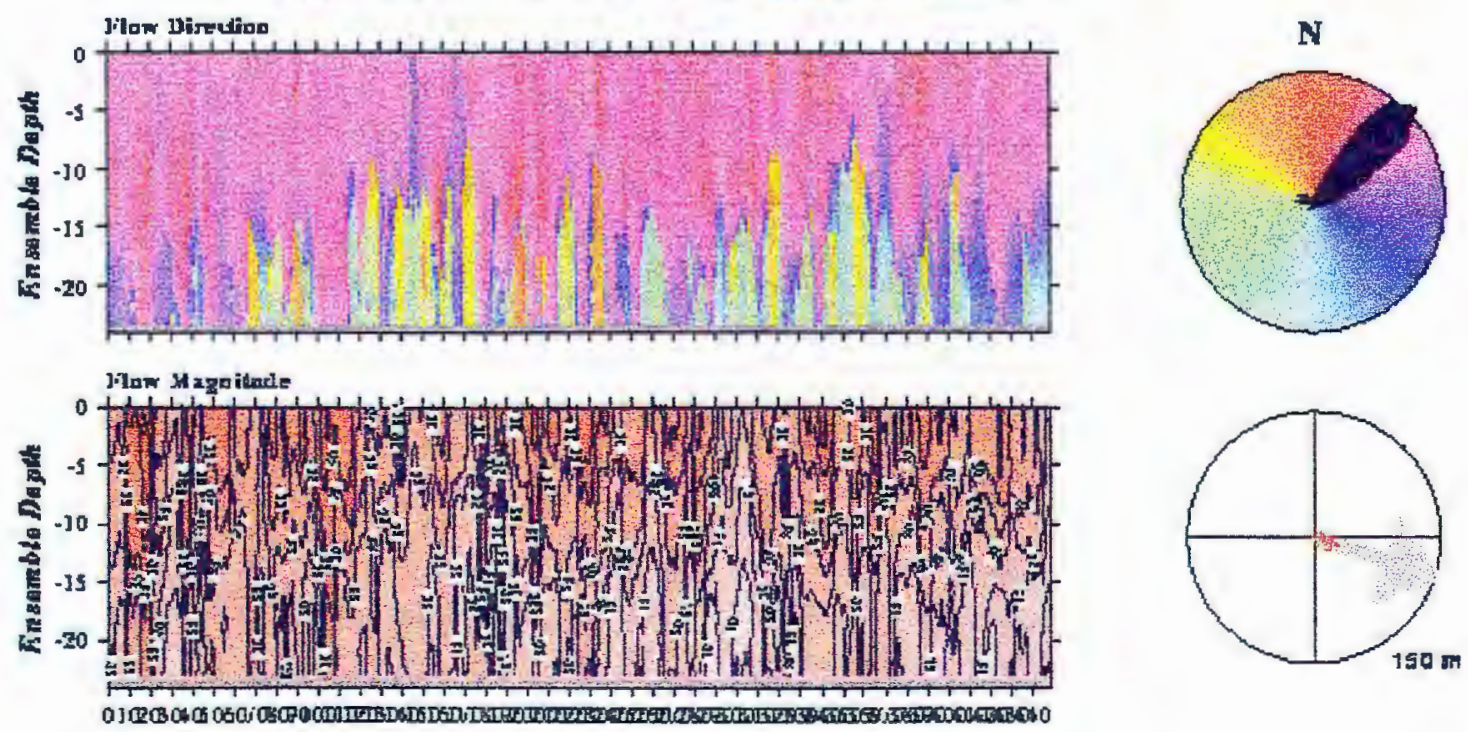

Finsambla Namber 

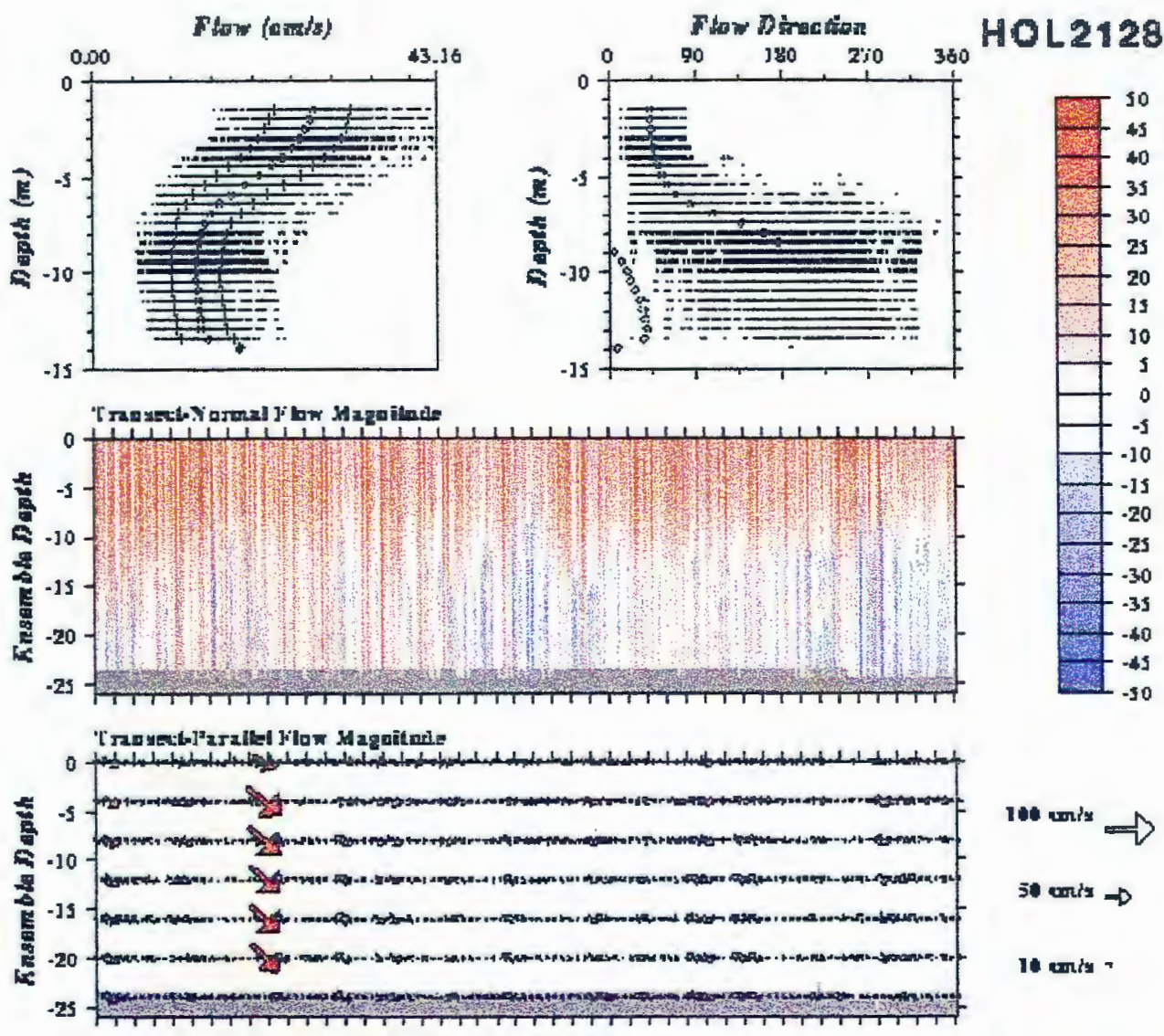

5. conis $\rightarrow$

14 antis?
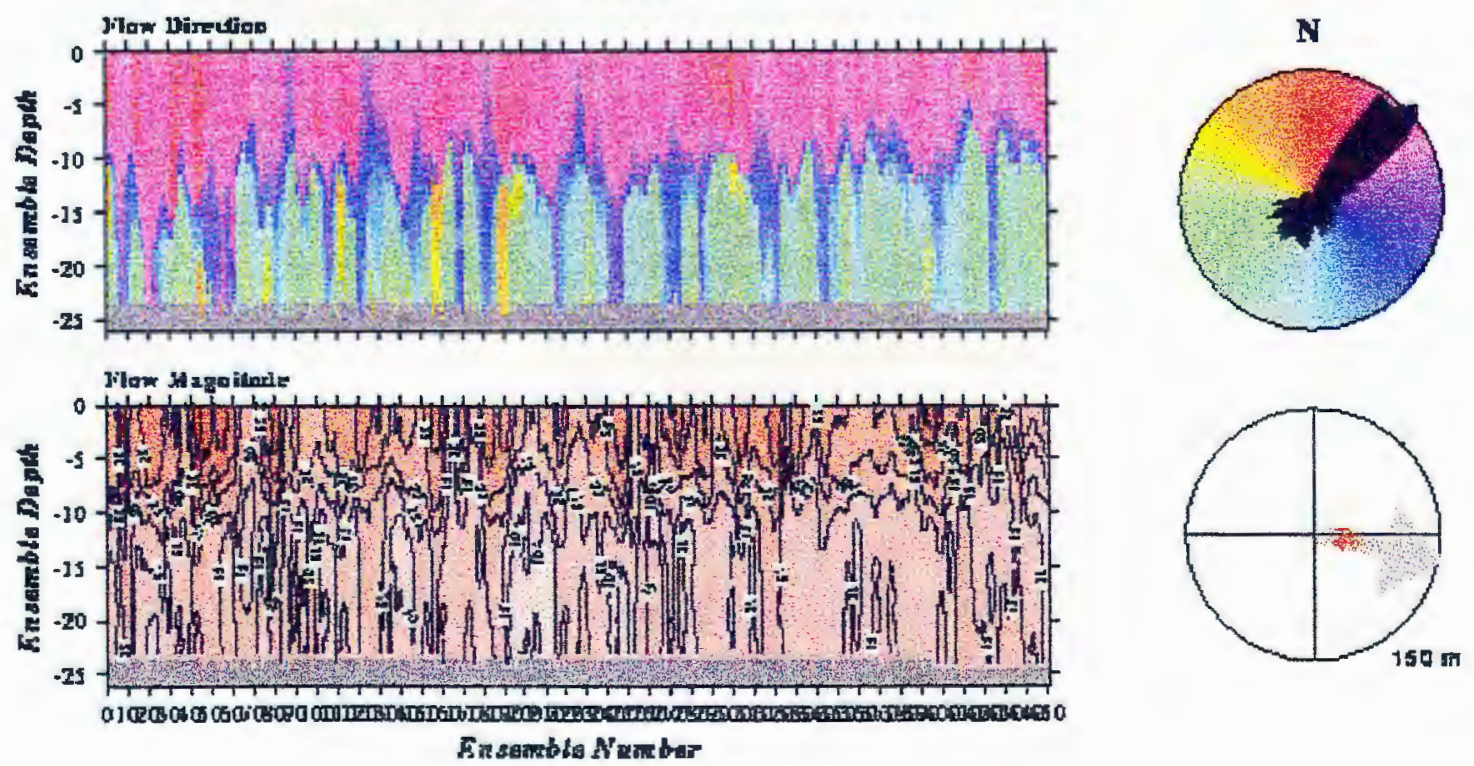


\section{References}

Anderson, J.J. and A.H. Devol (1973) Deep water renewal in Saanich Inlet, an intermittently anoxic basin. Estuarine and Coastal Marine Science 1: 1-10.

Blumberg, A.F. and D.M. Goodrich (1990) Modeling of wind-induced destratification in Chesapeake Bay. Estuaries 13: 236-249.

Brewer, P.G. and J.W. Murray (1973) Carbon, nitrogen and phosporus in the Black Sea. Deep-Sea Research 20: 803-818.

Brewer, P.G., D.W. Spencer and P.L. Sachs (1970) Trace metals in the Black Sea. Oceamus 15: 23-25.

Craig, H. (1971) The deep metabolism: oxygen consumption in abyssal ocean water. Journal of Geophysical Research 76: 5078-5086.

Doering, P.H, M.E.Q. Pilson, and C.A. Oviatt (1988) SPRAY Cruise dissolved oxygen and chlorophyll. Current Report of the Narragansett Bay Project; Report \#NBP89-24. $95 \mathrm{pp}$.

Downing, A.L. and G.A. Truesdale (1955) Some factors affecting the rate of solution of oxygen in water. Journal of Applied Chemistry 5: 570-581.

Endeco/YSI, Inc. (1995) 6000-UPG3 Multi-Parameter Water Quality Monitor: Instruction Mamual. Endeco-YSI Incorporated, Marion, MA, 1995

Falkowski, P.G., T.S. Hopkins, and J.J. Walsh (1980) An analysis of factors affecting oxygen depletion in the New York Bight. Journal of Marine Research 38: 479506 .

Fanning, K.A. and M.E.Q. Pilson (1972) A model for the anoxic zone of the Cariaco Trench. Deep-Sea Research 19: 847-863.

Frenette, J.J., S. Demers, L. Legendre, M. Boule, and J. Dodson (1994) Mixing, stratification and the fate of primary production in an oligotrophic multibasin lake system. Journal of Plankton Research. 16: 1095-1115.

Frithsen, J. B. (1989) The Benthic Communities Within Narragansett Bay. Current Report to the Narragansett Bay Project; Report \#NBP-90-28. 112 pp.

Goodrich, D.M, W.C. Boicourt, P. Hamilton, and D.W. Pritchard (1987) Wind-induced destratification in Chesapeake Bay. Journal of Physical Oceanography 17:22322240 . 
Grasshoff, K. (1975) Hydrochemistry of landlocked basins and fjords. In: Chemical Oceanography, 2nd ed. Riley and Skirrow, eds. Academic Press, New York, 2 , 455-597.

Haas, L.W. (1977) The effect of the spring-neap tidal cycle on the vertical salinity structure of the James, York and Rappahannock Rivers, Virginia, U.S.A. Estuarine and Coastal Marine Science 5: 485-496.

Haas, L.W., S.J. Hastings and K.L. Webb (1981) Phytoplankton Response to a Stratification-Mixing Cycle in the York River Estuary During Late Summer. In: Estuaries and Nutrients. Neilson and Cronin, eds. Humana Press, Clifton, NJ. pp. 619-636.

Hansen, D.V. and M. Rattray, Jr. (1966) New dimensions in estuary classification. Limnology and Oceanography 11: 319-326.

Hicks, S.D. (1959) The physical oceanography of Narragansett Bay. Limnology and Oceanography 4: 316-327.

Kester, D.R. and A. Magnuson (1994) Evaluation of the YSI rapid-pulse dissolved oxygen sensor. Technical Report No. 94-1, Graduate School of Oceanography, University of Rhode Island, Kingston, RI. 22 pp.

Kester, D.R., M.F. Fox and A. Magnuson. (1996) Modeling, measurements and satellite remote sensing of biologically active constituents in coastal waters. Marine Chemistry. 53: 131-145.

Klos, E. (1995) Personal Communication.

Kuo, A.Y. and K. Park (1992) Transport of hypoxic waters: an estuary-subestuary exchange. In: Coastal and Estuarine Studies. Prantle, D., ed. American Geophysical Union, Washington, D.C., 599-614.

Largier, J.L., J.H. Slinger and S. Taljaard (1992) The stratified hydrodynamics of the Palmiet- a prototypical bar-built estuary. In: Coastal and Estuarine Studies. Prantle, D., ed. American Geophysical Union, Washington, D.C., 135-153.

Liss, P. (1973) Process of gas exchange across an air-water interface. Deep-Sea Research 20: 221-238.

Lund-Hansen, L.C., P. Skyum and C. Christiansen (1996) Modes of stratification in a semi-enclosed bay at the North Sea-Baltic Sea transition. Estuarine, Coastal and Shelf Science 42: 45-54. 
Martin, J. H. (1965) Phytoplankton/Zooplankton Relationships in Narragansett Bay. Limnology and Oceanography 10: 185-191.

McMaster, R.L. (1984) Holocene stratigraphy and depositional history of the Narragansett Bay System, Rhode Island, U.S.A. Sedimentology 31:777-792.

Olsen, S.D., D.D. Robadue, Jr., and V. Lee (1981) An Interpretive Atlas of Narragansett Bay. Coastal Resources Center, University of Rhode Island Marine Bulletin 40.

Peeters, J.C.H., F.J. Los, R. Jansen, H.A. Haas, L. Peperzak, and I. de Vries (1995) The oxygen dynamics of the Oyster Ground, North Sea. Impact of eutrophication and environmental conditions. Ophelia 42: 257-288.

Pilson, M.E.Q. (1985) On the residence time of water in Narragansett Bay. Estuaries 8: 2-14.

Pockalny, R. C. (1997) Bathymetric Chart of Narragansett Bay. Unpublished data.

Prestidge, M.C. and A.H. Taylor (1995) A modelling investigation of the distribution of stratification and phytoplankton abundance in the Irish Sea. Journal of Plankton Research 17: 1397-1420.

RD Instruments (1995) Direct Reading and Self-Contained Broad Band Acoustic Doppler Current Profiler Technical Manual. San Diego, CA.

Rasmussen, B. (1995) Stratification and wind mixing in the southern Kattegat. Ophelia 42: 319-334.

Simpson, J.H. and D. G. Bowers (1984) The role of tidal stirring in controlling the seasonal heat cycle in shelf seas. Annales Geophysicae 2: 411-416.

Simpson, J.H. and T.P. Rippeth (1993) The Clyde Sea: a model of the seasonal cycle of stratification and mixing. Estuarine, Coastal and Shelf Science 37: 129-144.

Skirrow, G. (1975) Carbon Dioxide. In: Chemical Oceanography, 2nd ed., Riley and Skirrow, eds. Academic Press, 2, 611-645

Skyum, P., C. Christiansen, L.C. Lund-Hansen and J. Nielsen (1994) Advection-induced oxygen variability in the North Sea-Baltic Sea transition. Hydrobiologia 281: 6577.

Smayda, T.J. (1957) Phytoplankton Studies in Lower Narragansett Bay. Limnology and Oceanography 2: 342-359. 
Smayda, T.J. (1992) Survey of environmental conditions and plankton dynamics along a eutrophication gradient in Narragansett Bay during an annual cycle. Current Report to the Narragansett Bay Project; Report \#NBP-92-87 59 pp.

Spaulding, M. (1987) Circulation dynamics. In: Narragansett Bay: Issues, Resources, Status and Management. NOAA Estuarine Programs Office, NOAA, Washington, DC. pp. 71-146.

Spencer, D.W. and P.G. Brewer (1971) Vertical advection, diffusion and redox potentials as controls on the distribution of manganese and other trace metals dissolved in waters of the Black Sea. Journal of Geophysical Research. 76: 5877-5892.

Stanley, D.W. and S.W. Nixon (1992) Stratification and bottom-water hypoxia in the Pamlico River Estuary. Estuaries. 15: 270-281.

Swanson, J.C. and K. Jayko (1987) Preliminary results from a simplified numerical model of Narragansett Bay, Rhode Island. Oceans '87 Proceedings: The Ocean - An International Workplace, vol. 3: 843-846.

UNESCO (1981) Background papers and supporting data on the International Equation of State of Seawater 1980. UNESCO Technical Papers in Marine Science 38. Unesco, Paris. 192 pp.

Waldichuk, M. (1984) Laboratory observations on transfer of atmospheric oxygen into stratified seawater. In: Gas Transfer at Water Surfaces. W. Brutsaert and G.H. Jirka, eds. D. Reidel Publishing, Boston, 547-556.

Wehe, T.J. (1952) Inshore Survey Project, Preliminary report of existing data, Narragansett Bay and approaches. Part 1. Physical Data. Narragansett Marine Laboratory, URI, Kingston, RI. 41 pp.

Weisberg, R. (1974) The Non-tidal Flow in the Providence River of Narragansett Bay: A Stochastic Approach to Estuarine Circulation. Ph.D. Dissertation, University of Rhode Island. pp. 127. 